u…

\title{
Phase Change Thermal Energy Storage and the Model Building Codes
}

U.S. DEPARTMENT OF COMMERCE

National Burezu of Standards

National Engineering Laboratory

Center for Building Technology

Gaitnersburg, MD 20899

August 1984

Prepared for

U.S. Department of Energy

Office of Solar Heat Technologies

Active Heating and Cooling Division lington, DC 20585 



\title{
PHASE CHANGE THERMAL ENERGY \\ STORAGE AND THE MODEL BUILDING CODES
}

\author{
J. Greenberg \\ B.C. Reeder
}

U.S. DEPARTMENT OF COMMERCE

National Bureau of Standards

National Engineering Laboratory

Center for Building Technology

Gaithersburg, MD 20899

August 1984

\section{Prepared for}

U.S. Department of Energy

Office of Solar Heat Technologies

Active Heating and Cooling Division

Washington, DC 20585

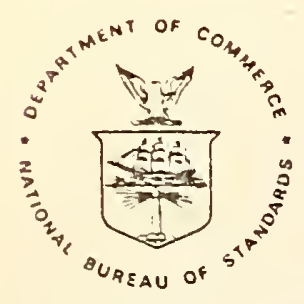

U.S. DEPARTMENT OF COMMERCE, Malcolm Baldrige, Secretary NATIONAL BUREAU OF STANDARDS, Emest Ambler, Director 

. 


\section{ABSTRACT}

Thermal energy systems using phase change materials are currently being developed and used for storing energy collected by solar and other means. This report is intended to bridge the gap between those who design and install phase change thermal storage devices and the building code official who evaluates these devices for code compliance. The first part of this report introduces the more commonly accepted phase change materials and systems, presents a taxonomy which is applicable to building construction, and describes the interface between the various model codes and the more advanced phase change system configurations. The report continues with an analysis of the model codes with a specific orlentation toward phase change thermal energy storage systems. The analysis is structured according to building, mechanical, and plumbing issues with topics relevant to phase change systems identified and specific code provisions applicable to each topic listed. In addition, an appendix is provided which cross references relevant topics according to individual model code requirements.

Key Words: solar energy; phase change materials; model building codes; salt hydrates; paraffin; thermal storage. 


\section{DISCLA IMER}

This report is intended to be informative and instructive and not an evaluation of any particular phase change material, system, or application. As such, certain commercial units are identified in order to provide a descriptive characterization of their features. Inclusion of a given unit in this report in no case implies a recommendation or endorsement by the National Bureau of Standards, and the presentation should not be construed as a certification that any unit would provide the indicated performance. Similarly, the omission of a unit does not imply that its capabilities are less than those of the included units. 
ABSTRACT . . . . . . . . . . . . . . . . . . . iii

1. INTRODUCTION ...................... . 1

1.1 BACKGROUND ........................ 1

1.2 APPROACH ................. . . . 2

2. PHASE CHANGE THERMAL ENERGY STORAGE MATERIALS - AN OVERVIEW. - 5

2.1 General . . . . . . . . . . . . . . . 5

2.2 CLASSIfICATION OF PHASE CHANGE MATERIALS . . . . . . 5

2.3 SAlT HYDRATES . . . . . . . . . . . . . 6

2.4 ORGANIC PHASE CHANGE MATERIALS . . . . . . . . . . 9

3. PhASE ChANGE THERMAL ENERgY STORAGE SYSTEMS. . . . . . . . 13

3. 1 PHASE CHANGE SYSTEMS CLASSIFICATION . . . . . . . . 13

3.2 THE PROPOSED CLASSIFICATION FRAMEWORK . . . . . . . 14

3.2.1 Air Systems . . . . . . . . . . . . 14

3.2.1.1 Building Components ......... 16

3.2.1.2 Individual Window Units........ 16

3.2.1.3 Interconnected Window Units....... 16

3.2 .2 Liquid Systems . . . . . . . . . . . 16

3.2.2.1 Separated Elements . . . . . . . 17

3.2.2.2 Immiscible Fluids (Direct Contact Liquid) 17

3.2.2.3 Direct Contact Solid . . . . . . 17

3.3 EXPANSION AND TESTING OF FRAMEWORK . . . . . . . . 17

3.3.1 Air Systems .. . . . . . . . . . 17

3.3.1.1 Building Components (Collector/Storage) . 17

3.3.1.2 Individual "Window" Units (Collector/ Storage .............. 18

3.3.1.3 Interconnected "Window" Units (Collector/ Storage .............. 23

3.3.1.4 Centrally Located (Connected To Building Ductwork) (Storage/Only) . . . . . 
3.3.2 Liquid Systems . . . . . . . . . . . . 31

3.3.2.1 Separated Elements (Storage Only). . . 31

3.3.2.2 Immiscible Fluids (Direct Contact Liquid) (Storage Only) . . . . . . . . 34

3.3.2.3 Direct Contact Solid (Storage Only)... 41

4. BUILDING CODES . . . . . . . . . . . . . . . . 47

4.1 OVERVIEW . . . . . . . . . . . . . . . . . 4 47

4.2 MODEL BUILDING CODE ORGANIZATIONS . . . . . . . . . . 47

4.3 BUILDING CODES AND PHASE CHANGE THERMAL ENERGY STORAGE SYSTEMS

4.4 THE MODEL BUILding CODES ................... 51

4.5 THE MODEL MECHANICAL CODES ................. 52

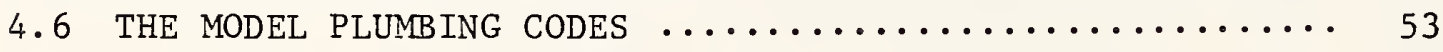

5. TOPICS AND PROVISIONS OF THE MODEL BUILDING CODES RELEVANT TO PHASE CHANGE SYSTEMS......................... 55

5.1 OVERVIEW . . . . . . . . . . . . . . . . . . 55

5.2 TOPICS AND PROVISIONS . . . . . . . . . . . 55

6. TOPICS AND PROVISIONS OF THE MODEL MECHANICAL CODES RELEVANT

TO PHASE CHANGE SYSTEMS....................... 113

6.1 OVERVIEW . . . . . . . . . . . . . . . . . . . . 113

6.2 TOPICS AND PROVISIONS . . . . . . . . . . . . . 114

7. TOPICS AND PROVISIONS OF THE MODEL PLUMBING CODES RELEVANT TO PHASE CHANGE SYSTEMS.......................... 191

7.1 OVERVIEW . . . . . . . . . . . . . . . . . . . 191

7.2 TOPICS AND PROVISIONS . . . . . . . . . . . . . 192

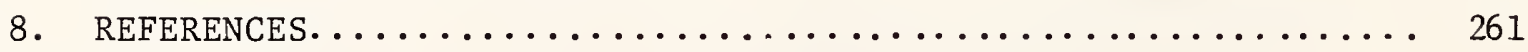

APPENDIX A -

THEIR CROSS REFERENCE TO TOPICS DISCUSSED IN THIS

REPORT . . . . . . . . . . . . . . . A-a

APPENDIX B -

THEIR CROSS REFERENCE TO TOPICS DISCUSSED IN THIS

REPORT . . . . . . . . . . . . . . . B B-a

APPENDIX C -

CROSS REFERENCE TO TOPICS DISCUSSED IN THIS REPORT . C C-a 


\section{LIST OF FIGURES}

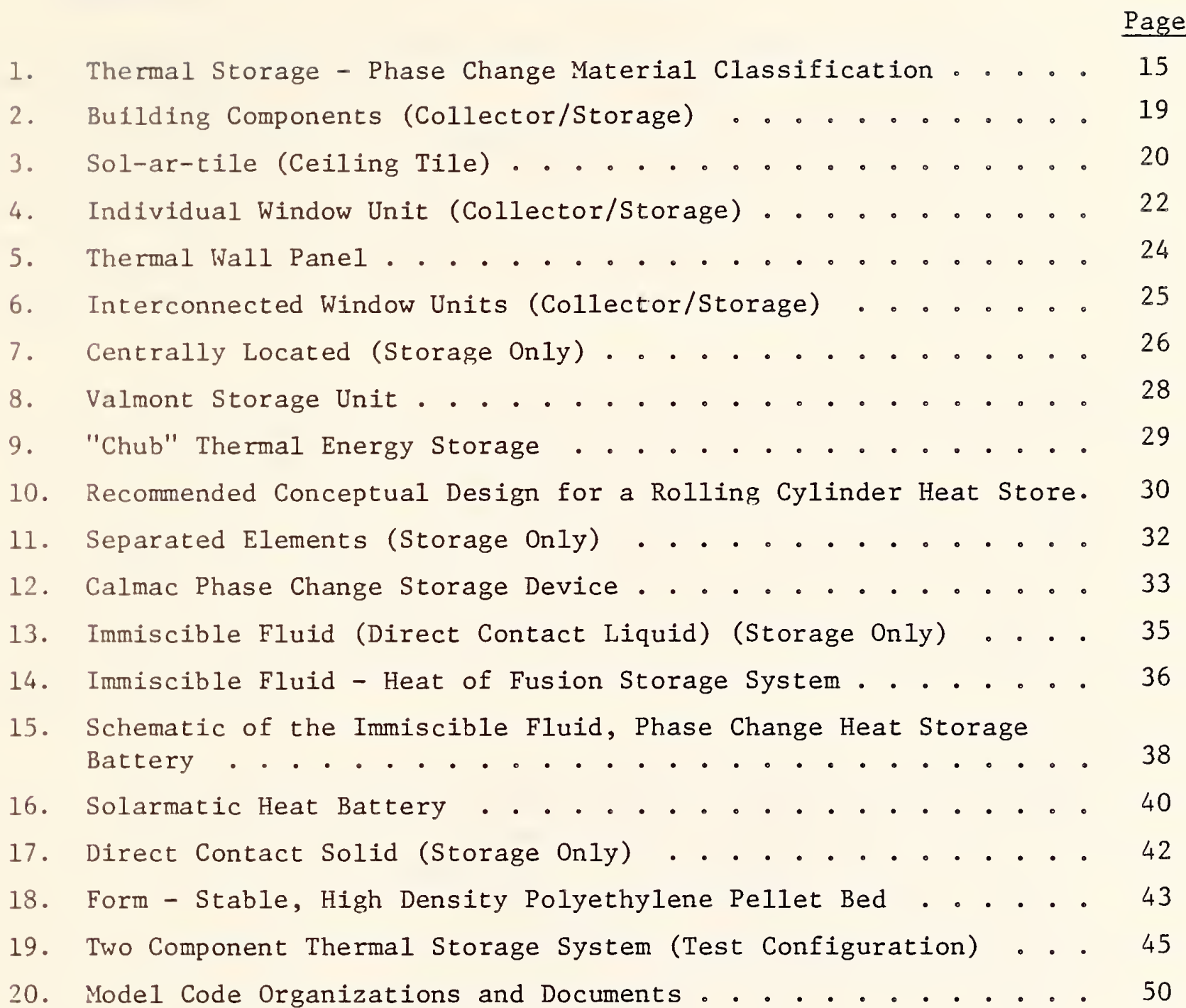




\subsection{BACKGROUND}

In response to growing concerns over energy shortages in the United States, a variety of measures have been undertaken to make the Nation energy self-sufficient. Of the many areas investigated, the promotion of energy conservation and the development and use of renewable energy sources rank high on the agenda of viable alternatives. The use of renewable energy sources, however, often involves the collection of energy at a time when the energy cannot be used directly. In order to take these developing systems more economically attractive or operationally tenable, a means of storing energy for later distribution is often required.

Many solar energy systems, therefore, are designed with a thermal storage capability, enabling the user to collect and use energy during the hours of maximum solar insolation while allowing for the storage of excess energy. A variety of successful storage systems are in operation using water tanks or rock bins. In this application, water storage tanks are normally associated with liquid solar systems - the excess energy being stored in water tanks directly or indirectly through the use of heat exchangers, while rock storage is normally associated with air systems which store energy when heated air passes over or through the rocks or gravel, later releasing their stored heat as cool air is passed over or through the material.

Other thermal storage systems use phase change materials as the storage media. These systems depend on latent heat for operation and have the inherent characteristics of being more compact than water or rock storage. They also provide an isothermal base for the collector system which generally results in a more efficient operating mode. However, these phase change systems generally have several undesirable characteristics which have impeded their design, development, and widespread acceptance. Despite these problems, phase change and other thermal storage systems are being used in an expanding range of building types. Accordingly, the market for products related to thermal energy stor ige systems is growing as these systems become an increasingly accepted factor in the building construction industry.

As phase change thermal storage systems become more commercially promising, the builder, manufacturer, architect, engineer, and code official need to understand how thermal energy storage systems should be designed, built, and evaluated in order to assure compliance with regulations protecting the health, safety, and welfare of building occupants. Thermal storage systems composed of materials and assemblies commonly used within the construction industry, such as water tanks or rock storage, should pose no difficulty in design, construction, or evaluation by the code official. However, phase change systems, could raise regulatory questions especially if they contained materials and assemblies new to the building industry. 


\subsection{APPROACH}

The purpose of this report is to assist in bridging the gap between those who design and install phase change thermal storage devices and the building code official who evaluates these devices for code compliance. The designer and installer are primarily concerned with making the technology work, integrating it into a successful system, and accomplishing it all within accepted economic constraints. The building code official bears the ultimate responsibility for ensuring that these devices present no hazard to the public.

Normally, these objectives converge through the establishment of standards. Through the standards mechanism, requirements are clearly stated for the designer and installer, and the building code official is given some reasonable assurance that the health, safety, and general welfare of the public is protected. The establishment of standards, however, especially for an evolving technology is a developmental process which normally occurs over a relatively long time interval. This does not necessarily have a negative impact on an emerging technology since standards tend to 'lock in place' specific practices and there is the widespread view that standards developed too early in a technology's evolution inhibit innovation.

Phase change materials and systems presently find themselves in a prestandards state. Those involved with this maturing technology must work together in an ad hoc manner to promote its successful and safe application. With this perspective, this document is intended to be used as a guide in applying the existing codes to phase change systems. By analyzing existing regulatory documents, issues relevant to the application of phase change thermal energy storage systems in building construction can be determined. As the technology matures, it is anticipated that this document will also be of use in establishing definitive standards.

Of immediate concern are those phase change systems which are currently gaining momentum within building industry markets. Phase change systems using thermo-chemical reactions are deliberately omitted from this study since the complexity of these systems and the dangerous chemicals used in at least one such system (sulphuric acid) requires an in depth study to be made of each specific system application. The scope of this report also excludes dessicant systems, as these systems have not presently found wide application for thermal storage in buildings. In addition, the newly developed solid state materials are not included since their potential has just recently been recognized.

In this context, the first segment of this study is devoted to the description of more commonly accepted phase change materials and their properties, as well as phase change systems and their applications. A classification framework of systems is included which is based on a breakdown of phase change thermal energy storage systems into generic types by building application. 
The second segment presents an overview of building codes; describes model code organizations and their documents including state level enactment and local enforcement; and general code issues with regard to phase change materials and systems.

The final segment of this report provides a detailed analysis of the model codes with regard to phase change thermal energy storage systems. The analysis is structured according to building, mechanical, and plumbing issues. Issues relevant to phase change systems are identified and code provisions applicable to each issue are described. An appendix is included which cross references relevant issue topics according to individual model code documents. 
This section is intended to provide an overview of phase change materials and to characterize their properties, uses, advantages, and limitations. Phase change materials are discussed here in general terms and not in connection with any specific system application since many of these materials have properties that allow them to be used in a variety of systems. Following this section, specific systems are addressed and categorfzed along with those properties which make the system potentially promising as a phase change storage device.

\subsection{GENERAL}

The use of phase change materials as a thermal storage concept is attractive for a number of reasons. The primary reason could be stated in terms of volumetric efficiency -- less material is needed to store a given amount of heat. Devices that depend on sensible heat storage require a relatively large bulk. This is demonstrated in solar applications by the two commonly used sensible storage media - water and crushed rock. As increments of heat are added, the temperature of these storage materials rise and this rise is a function of the specific heat of the material. Phase change materials, however, store a great deal of heat in a smaller volume by taking advantage of the latent heat of fusion (or vaporization) if operated in the solid/liquid, solid/solid, or liquid/gas phase change temperature range.

Another advantage of phase change operation is the constant temperature (isothermal) property inherent in phase change materials. When operated within the phase change mode, no change in temperature occurs while the material is storing or releasing heat until the media's capacity is fully exhausted. This results in automatic temperature regulation when the phase change material is incorporated in a system that directly interfaces with the habitable areas of the building. This isothermal property also has a positive effect on collectors, heat pumps, and other components interfacing with the storage device in that a constant temperature differential is maintained, resulting in an increased system efficiency.

It is generally agreed that only those systems which operate within the solid/liquid phase change transition range are of immediate practical use from an economic or operational consideration [1]. Although the liquid/gas phase change mode also has the potential for storing large amounts of thermal energy, the large volume and pressure changes associated with this operating mode make equipment design complex and costly. Some work is being done on the development of solid/solid systems, however, their potential as viable systems is still being explored [2].

\subsection{CLASSIFICATION OF PHASE CHANGE MATERIALS}

A great number of materials are possible candidates for phase change thermal storage applications. For convenience, phase change materials potentially appropriate for residential heat storage application can be broadly classified into two groupings - salt hydrates and organic materials.

A publication by the National Bureau of Standards (NBS) compiled a listing of approximately 6000 salts relevant to energy storage along with data compilations outlining their physical properties [3]. Only a very few salts have been studied in depth by researchers attempting to 
develop a practical system for residential heating or cooling use. However, materials initially eliminated for consideration by researchers because of cost, reliability, safety or other factors, could later become viable candidates if the factors that eliminated them in the first place can be accommodated or controlled.

\subsection{SALT HYDRATES}

of all the phase change materials studied, the salt hydrates presently appear to have the greatest potential for immediate application as solar thermal storage. These materials are bascially anhydrous (without water) materials that form crystalline solids when combined with water. Heat is released or stored when the "water of crystallization" is combined or removed from the anhydrous salt. These reactions are generally isothermal in nature.

The crystalline structures of the salt hydrates change phase or melt in three ways: congruent melting; incogruent melting; and semi-congruent melting. As described in Technical and Economic Feasibility of Thermal Storage [4], congruent melting occurs when the solubility of the salt is sufficiently high to completely dissolve in its water of crystallization when melted. Upon freezing, the dissolved material easily reforms into the original salt hydrate phase. If a material melts incongruently, the solubility of the resulting anhydrous material is not high enough to dissolve completely in its water of crystallization when melted, and some anhydrous material and water remain. Upon freezing, the dissolved anhydrous material in intimate contact with the water reforms into the crystalline state; however, the anhydrous material which was not originally dissolved cannot combine with the water to form the salt hydrate without stirring or agitating the solution in some manner. Still other hydrates melt semi-congruently; i.e., they are first transformed to a lower hydrate when heated and are congruent in that state. Upon further heating, this lower hydrate melts. The solubility of the anhydrous salt at this higher temperature is high enough to dissolve completely in its original water of cristallization.

Salt hydrates are also subject to supercooling which further degrades the full thermal potential of the material, although proper container design or nucleating additives can reduce or eliminate this problem. This is further discussed below.

Several studies have been completed which identified the most promising materials for advanced development. A 1973 study by the University of Pennsylvania [5] identified twenty-four salt hydrates with favorable characteristics for use as thermal energy storage materials. Criteria for selection were:

1. Melting point in desired temperature range

2. Large heat of fusion

3. Congruent melting

4. No supercooling

5. Stability

6. Inertness

7. Safety

8. Low Cost 
Ocher studies [4, 6, 7] have also identified potentially viable materials using criteria similar to those stated above. A brief description of two of the more promising materials follows:

2.3.1 Sodium Sulfate Decahydrate $\left(\mathrm{Na}_{2} \mathrm{SO}_{4} \cdot 10 \mathrm{H}_{2} \mathrm{O}\right)-$ Glauber's Salt

Sodfum Sulfate Decahydrate, commonly known as Glauber's Salt, is one material that seems to have a high potential for commercial application in residential thermal storage. The biggest attraction for the use of this material is its low cost and safety. Some of its properties are:

(a) Temperature Range $0^{\circ} \mathrm{C}$ to $40^{\circ} \mathrm{C}\left(32^{\circ} \mathrm{F}\right.$ to $\left.104^{\circ} \mathrm{F}\right)$ useful in heating or cooling applications.

(b) Heat of fusion (hydration) - $60 \mathrm{cal} / \mathrm{gm}$

(c) Thermal Conductivity - excellent

(d) Nontoxic

(e) Nonflammable

(f) Noncorrosive

(g) Use with air or liquid systems

(h) Melting behavior - incongruent

The practical use of this material for thermal storage, however, is not without its problems. When sodium sulfate decahydrate melts, it breaks down into two components anhydrous sodium sulfate and a solution of sodium sulfate and water. Because the melting of sodium sulfate decahydrate is incongruent, some anhydrous sodium sulfate remains undissolved in its water of crystallization, and the more dense anhydrous sodium sulfate sinks to the bottom of the container.

When the material refreezes, only the top portion of the anhydrous sodium sulfate, in contact with the sodium sulfate water solution, recombines to form a salt hydrate (the sodium sulfate decahydrate). This recrystallized sodium sulfate decahydrate, in effect, forms a barrier and prevents the anhydrous sodium sulfate from further combining with the water of crystallization which is part of the sodium sulfate water solution at the top of the container. The "frozen" state, instead of being a homogeneous mix of sodium sulfate decahydrate, is a stratified configuration in three layers - the bottom layer consisting of anhydrous sodium sulfate, the middle layer of sodium sulfate decahydrate crystals, and the top layer a saturated water and sodium sulfate solution.

This stratification reduces the heat storage efficiency of the material as the full heat of fusion potential of the sodium sulfate decahydrate is not utilized.

Many schemes have been proposed to solve this problem, including tumbling or stirring of the mix. In addition, certain additives such as silica gel will prevent the settling or stratification of the anhydrous sodium sulfate. However, repeated cycling results in disintegration of the silica gel.

In addition, as the temperature of the solution is lowered to its freezing point, some stimulus must be present to cause nucleation of the crystals to return the solution to the solid state. Without this nucleation, the liquid may be cooled below its freezing point and a condition known as supercooling occurs. This supercooling condition further reduces the heat storage efficiency of the material and destroys its isothermal properties. Supercooling can be controlled, however, through appropriate container design or the inclusion of additives such as borax which induces nucleation. 
The specific devices and/or additives used with the sodium sulfate decahydrate are described in a later section. It must be pointed out, however, that although the pure sodium sulfate decahydrate material is basically inert and safe, many of the additives to prevent settling or encourage nucleation are proprietary and could cause concern from a building inspector/local code perspective unless the composite material is demonstrated to be safe. Another concern could be the content of the preparatory additives which change the melting point of the sodium sulfate decahydrate. The "pure" sodium sulfate decahydrate has a melting point in the $90^{\circ} \mathrm{F}$ range, and other materials may be added, such as sodium chloride ( $\mathrm{NaCl}$ ) or ammonium chloride ( $\mathrm{NH}_{4} \mathrm{Cl}$ ) to lower its melting point to a range suitable for air conditioning applications $\left(40^{\circ} \mathrm{F}\right.$ to $\left.60^{\circ} \mathrm{F}\right)$. These additives, as well, must be shown to be safe.

\subsubsection{Sodium Thiosulfate Pentahydrate - $\left(\mathrm{Na}_{2} \mathrm{~S}_{2} \mathrm{O}_{3} \cdot 5 \mathrm{H}_{2} \mathrm{O}\right)$ - Hypo}

Sodium Thiosulfate Pentahydrate, commonly known as hypo (used widely for photographic developing) is another promising material for residential thermal storage applications. Because it melts in the $118^{\circ}$ to $126^{\circ} \mathrm{F}$ range, a higher temperature than sodium sulfate decahydrate, its use in an isothermal mode, gives a definite feeling of "warmth" when applied directly as an interface with the living environment. This material is also fairly low in cost and, because of its widespread photographic applications, relatively familiar to the general public. This familiarity could aid in gaining acceptance of the material for phase change applications.

Some of its properties are:

(a) Temperature Range $42^{\circ} \mathrm{C}$ to $52^{\circ} \mathrm{C}\left(118^{\circ}\right.$ to $\left.126^{\circ} \mathrm{F}\right)$ - useful in space heating applications.

(b) Heat of fusion (hydration) - $50 \mathrm{cal} / \mathrm{gm}$

(c) Nonhazardous

(d) Use with air or liqud systems

(e) Melting behavior-semicongruent

This material melts differently than sodium sulfate decahydrate previously discussed. Whereas the sodium sulfate decahydrate, when heated, changes directly into anhydrous sodium sulfate and a solution of sodium sulfate and water, sodium thiosulfate pentahydrate $\left(\mathrm{Na} \mathrm{S}_{2} \mathrm{O}_{3} \cdot 5 \mathrm{H}_{2} \mathrm{O}\right)$, when heated at $118^{\circ} \mathrm{F}$ changes first into a lower hydrate ( $\mathrm{Na} \mathrm{S}_{2} \mathrm{O}_{3} \cdot 2 \mathrm{H}_{2}^{2} \mathrm{O}^{2},{ }^{3}$ sodium thiosulfate dihydrate and water. Upon further heating $\left(122^{\circ} \mathrm{F}\right)$, the dihydrate melts into the anhydrous sodium thiosulfate. The anhydrous sodium thiosulf however, is not completely soluable in its water of crystallization until heated to $126^{\circ} \mathrm{F}$

Sodium thiosulfate pentahydrate also is characterized by its tendency toward supercooling In fact, this material is often used for demonstration purposes as a classroom example of supercooling. This supercooling tendency is at odds with the desirable isothermal model for thermal storage. The efficiency of the system is lowered since a considerable part of the heat of fusion must be used to bring the supercooled liquid to its melting point. Nucleating devices and techniques [8], however, have been studied to counteract this undesirable characteristic. 


\subsection{ORGANIC PHASE CHANGE MATERIALS}

Organic materials also have been identified for potential use as phase change materials. The spectrum of available material in this group is very broad. However, if the criteria for selection of the salt hydrates are applied, potential candidates are quickly limited to a very few. These are generally in the paraffin classification. In the document Technical and Economic Feasibility of Thermal Storage [4], approximately 25 paraffins are identified. These materials generally melt cungruently; therefore, they have no cycling problems as do many of the salt hydrates. These paraffins have fairly good latent heat capacities, and are commercially available. However, they shrink considerably upon solidifying, have low thermal conductivity, and in many cases are flammable. Other organic phase change materials are also candidates for thermal storage and these, along with the paraffins, are described below.

\subsubsection{Form Stable, High Density Polyethylene Pellets}

This material, developed by Monsanto Research Corporation [9], utilizes the crystalline-to-amorphous phase change properties in lightly crosslinked, form-stable, high crystallinity, high density, polyethylene pellets. These pellets, approximately an eighth of an inch in diameter, are suggested for use in direct contact with a working heat transfer fluid. These pellets may be placed in containers in a packed-bed configuration or may possibly be carried by the working fluid as a slurry. As the working fluid reaches the melting point of the pellets, they melt, storing latent energy in the heat-of-fusion mode, and later release this energy when the pellets solidify. The pellets have the unusual property of being form-stable; i.e., they do not deform or flow but retain their shape when melted. Because of their small and spherical shape and size, these thermal storage pellets present a large surface area contact with the working heat transfer fluid which encourages rapid heat exchange. The properties of this material are:

(a) Melting Point $255^{\circ} \mathrm{F}$ to $300^{\circ} \mathrm{F}$ - Most useful in absorption air conditioning applications

(b) Heat of fusion (50 cal/gm)

(c) Melts congruently

(d) Nontoxic, nonflammable, or corrosive

(e) Use with air or liquid systems

(f) Retention of capacity with time and use

(g) Unaffected by water or ethylene glycol

Because the melting point of these pellets is in the $255^{\circ} \mathrm{F}-300^{\circ} \mathrm{F}$ range, this material would be most useful in absorption air conditioning applications. Form-stable materials that melt at higher or lower temperatures than the high density polyethylene pellets described above are also being considered. The development of a form-stable polymer having a melting point nearer to room temperatures would be particularly advantageous for solar space heating applications. 


\subsubsection{Two-Component Thermal Storage Material - (Pellets of Encapsulated Wax)}

The feasibility of encapsulating commercial paraffin in a container which exhibits wall properties compatible with a solar environment is discussed in a study by Mehalick and Tweedie [10]. This approach takes advantage of the stable melting and solidifying characteristics of paraffin and minimizes its poor heat transfer characteristics by providing a high surface area to volume ratio. In addition, by directly interfacing with the heat transfer medium, no separating container is needed.

The material selected for encapsulation is commercial grade paraffin which has the following properties:

(a) Melting point $-116^{\circ} \mathrm{F}$

(b) Heat of fusion $42 \mathrm{cal} / \mathrm{gm}$

(c) Melts congruently

(d) Self nucleating - does not supercool

(e) Nontoxic, noncorrosive

(f) Flammable

(g) Low thermal conductivity

(h) Large volume reduction on solidification (5 to 13 percent)

The encapsulated paraffin is approximately $500-1000 \mu\left(1 / 50-1 / 25^{\prime \prime}\right)$ in size. A major problem with encapsulating paraffin is its comparatively high volume reduction on solidification. Because of this property, the encapsulating wall must have adequate strength and durability to repeatedly withstand the stresses associated with these volumetric changes. In addition, the material must tolerate the external physical forces acting on the material as a result of interaction with the heat transfer medium, and the effects of compression in a packed-bed configuration. The encapsulating wall material also must not react with the paraffin or heat transfer fluid and must be flexible enough to accommodate the expansion and contraction of the wax while having a thin shell to encourage heat transfer to the central core material. Successful formulations for encapsulating polymers have been developed. There are other commercially available paraffins which have a wide range of melting points and relatively high heat of fusion values, making this concept available for applications in other temperature ranges as well.

\subsubsection{Paraffin Wax}

The paraffins may be slightly less desirable as phase change materials than the salt hydrates in that they are generally more costly, are a petroleum based material, and generally do not have as high a latent heat of fusion. A typical paraffin under study is SUNOCO P-116 with a latent heat of 
approximately $40 \mathrm{cal} / \mathrm{gm}$ and a melting point of $116^{\circ} \mathrm{F}$.

The paraffins have the very desirable congruent melting property and do not supercool. Therefore, the melting/cooling/melting cycles are easily sustained over a great number of cycles with no apparent degradation in thermal performance. The major problem with the paraffins is the relatively high shrinkage rate during solidification and the very poor thermal conductivity.

The paraffins shrink approximately 5 to 15 percent upon solidifying, and when used in bulk, this shrinkage would result in a void inside any rigid container-thus affecting the heat transfer properties of the system. In addition, the poor thermal conductivity of the paraffin delays the heat transfer into the central core, further degrading the operation of such a system. Proper container design, however, can minimize these adverse properties but container costs may rise. In addition, the choice of containers requires some care because polyethylene and polypropylene are not compatible with paraffin. The wax causes environmental stress cracking of these plastics.

Because the generic name "paraffin" may refer to a plethora of substances, the use of this material in any heating and cooling operation could cause concern with most building officials unless the material and specific application are demonstrated to present no hazard to persons or property. 


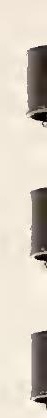




\section{PHASE CHANGE THERMAL ENERGY STORAGE SYSTEMS}

\subsection{PHASE CHANGE SYSTEMS CLASSIFICATION}

The technology of thermal energy storage has, to date, been in the domain of the sclentist, engineer, and manager, and efforts to classify the technology have, understandably, been oriented by these groups to their viewpoint and purposes. These classifications however, are not useful for code officials or others orfented toward building components and code document structure. In order to develop a framework of classification suitable for code application, several documents were studied.

One example of thermal energy storage classification is found in the reports and proceedings of the 1979 Solar Energy Options Workshop [11]. The basic breakdown is divided into four categories:
1. Liquid Storage
2. Solid Storage
3. Phase-change Storage
4. Thermochemical Storage

These categories are further divided to coincide with the "path schematics" established by the DOE program for planning and tracking projects related to solar heating and cooling of buildings (SHACOB) and the program for agricultural and industrial process heat (AIPH). The SHACOB "path schematics" are further refined and more oriented toward solar application. They are further subdivided by type of collector and working fluid (liquid heating collector, air heating collector, concentrating collector). There is also a category for direct or passive application. The storage descriptions within these SHACOB "path schematics" are described as:

\section{Low Temperature Storage \\ 2. High Temperature Storage \\ 3. Storage \\ 4. Passive Storage}

Other component classification schemes found in the proceedings are organized in matrix form and use the four (4) categories described above as one axis of the matrix. The other axis indicates Thermal Energy Storage Components Commercially Available by 1979 and is generally classified by contractor and/or component and includes such items as concrete tanks; salt gradient solar ponds; Solamatic heat battery; SCM thermal storage cells - glauber's salt; etc. Although useful for program management or technology monitoring, these classifications hardly interface with the building official's perspective or the codes which he is required to enforce.

Another document reviewed for organization and classification of thermal energy systems is the Solar Energy Research Institute's (SERI) Low Temperature Thermal Energy Storage: A State-of-the-Art Survey [12]. This document contains an 
analysis of activities in research, development, and demonstration of low temperature (below $250^{\circ} \mathrm{C}$ ) thermal energy storage (TES) technologies having application for renewable energy systems for heating and cooling of residential and commercial buildings and, to a limited extent, in agricultural and industrial processes. This report contains a chart entitled "Low Temperature Thermal Storage Technology Classification."

The classifications presented are divided into three groupings; Sensible Heat, Phase Change Materials, and Reversible Chemical Reactions. The Phase Change Material listing is further divided into (1) micro encapsulation, (2) bulk, and (3) building materials. These are further defined to indicate short term and annual storage. Short term storage is of immediate interest in building applications, while the long term or Annual Cycle Energy Storage (ACES), involving freezing water in the winter to later use the melting ice in the summer, is beyond the scope of this study. The short term classification of interest here is divided into salt-hydrates and organic materials.

The following documents were also studied: Project Summaries - Thermal Energy Storage Program [13] and Design and Installation Manual for Thermal Energy Storage [14]. These documents also were either oriented toward research or otherwise inappropriate in structure and/or format for interface with building codes and the realities of their enforcement.

\subsection{THE PROPOSED CLASSIFICATION FRAMEWORK}

Since no appropriate taxonomy has been identified to classify thermal storage systems from a code enforcement perspective, the following framework was established and used throughout this study. The framework integrates the attributes of the various systems and orients the groupings in a manner appropriate to analysis in a building code context. This classification is shown in Figure 1 .

The initial division is a natural cleavage that separates the systems by working fluid - air or liquid. Besides being a division that is easy to understand and identify, it also has the advantage of orienting systems by code document, as described later. In this regard, the air systems generally would be oriented toward the mechanical codes - with its scope covering ducts, plenums, blowers, etc.; the liquid systems allied to the plumbing codes - pipes, pumps, valves, etc. It must be noted, however, that this natural division is not all encompassing. Some systems do have liquid-to-air and air-to-liquid heat exchanges which, in effect, make these hybrid systems subject to evaluation by both the mechanical and plumbing codes.

\subsubsection{Air Systems}

Focusing on systems using air as the working fluid, a sub-classification has been established for those storage devices which could be integrated into a building and physically oriented to receive the rays of the sun during the daytime, storing energy in a latent mode for later release. Although these are primarily 


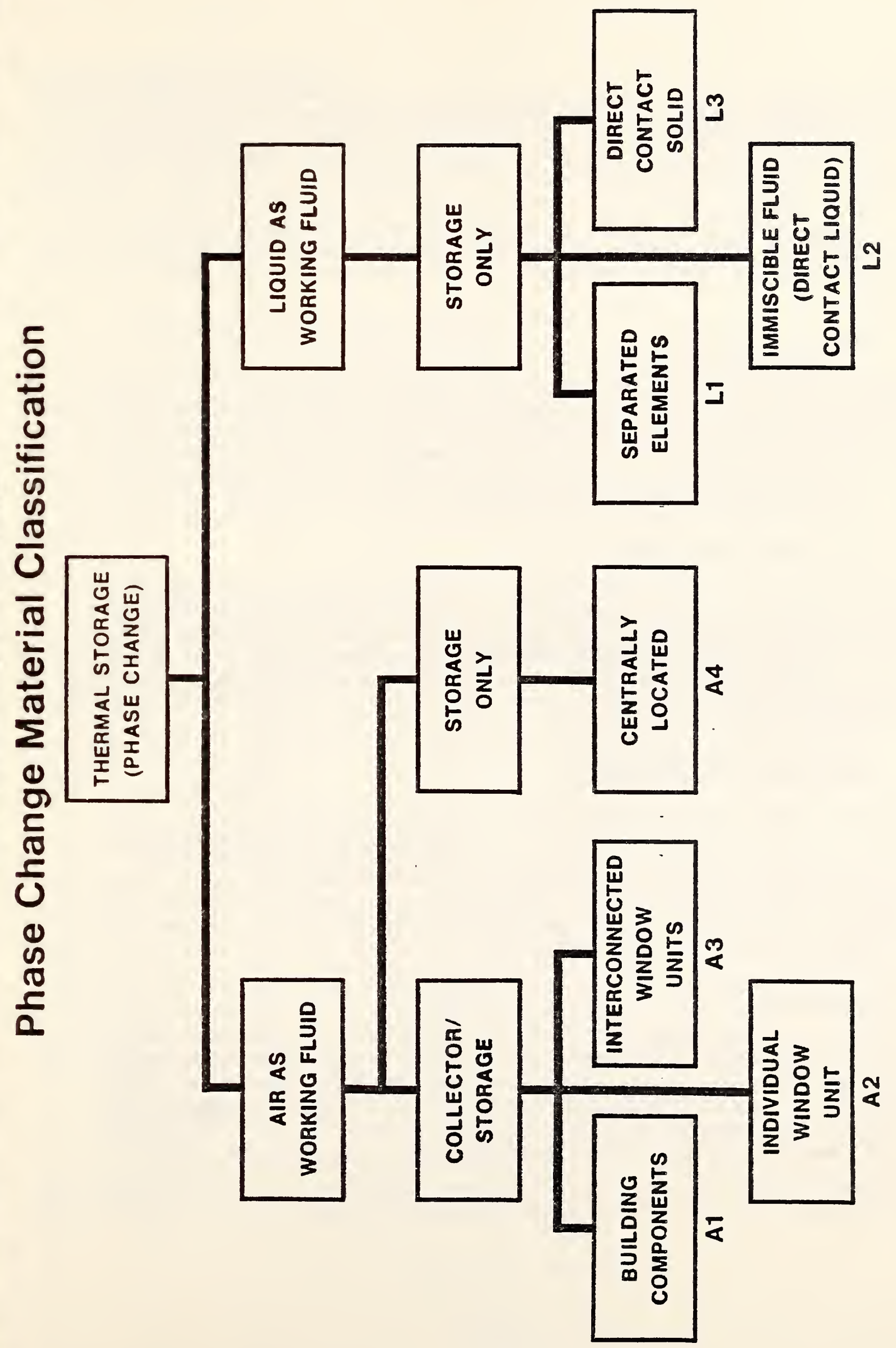


phase-change thermal storage devices, they also act as collectors and are categorized as collector/storage systems. Other storage devices more centrally located within the building and not having the capability of interfacing with the sun are classified as storage devices only and form an independent thermal storage classification.

Within the collector/storage scheme, a further sub-classification is possible when one views the thermal energy collector/storage device in terms of its function as a building element. This further sub-classification is described as follows:

\subsubsection{Building Components}

The phase-change thermal storage device could be a building element or component. It could be a structural wall containing salt hydrates; or a floor or ceiling element containing other phase-change materials. In effect, these devices would be intrinsic to the structure of the building and required to maintain structural integrity. These components could be viewed as passive elements with an added feature, the integrated phase-change capability.

\subsubsection{Individual Window Units}

Individual "window" units are another form of collector/storage devices. They basically are not part of the structure of the building but rather inserts into walls functioning to capture the sun's energy. They also are localized in application and not interconnected to the overall heating system of the building. They can be generally viewed as boxes which support and orient containers of phase-change materials and depend on small fans or natural convection to circulate air to a limited nearby area.

\subsubsection{Interconnected Window Units}

Interconnected window units may also serve as collector/storage devices. They are similar to the individual window units described above, but the air flow through these units is interconnected to the building heating system and is controlled centrally. Because these units are interconnected throughout ductwork, they present a different safety approach than the individual window units, and represent a discrete classification of thermal energy storage devices in their treatment relative to building codes.

\section{2 .2 iiquid Systems}

Thermal storage devices using liquid as the working fluid are generally not regarded as collector/storage elements. If the fluid is in contact with the sun (even indirectly) the device containing the liquid would be regarded as a solar collector and not part of the thermal storage scheme. Thermal storage devices using liquid as the working fluid can be divided further into classifications which lend themselves to code related studies. 


\subsubsection{Separated Elements}

The first grouping would revolve around systems using separated elements or some physical means to separate the working liquid from the phase-change materlals. These systems could be viewed, in effect, as conventional heat exchangers. They could be arranged as a coil-in-tank, shell and tube, or a varlety of other configurations. The phase-change materials could be stirred or circulated by mechanical or natural means but, because of the physical separation of the phase-change material and the heat transfer medium, the system would retain the separated elements classification.

\subsubsection{Immiscible Fluids (Direct Contact Liquid)}

Another grouping would be the direct contact liquid system or immiscible fluid classification. The heat transfer fluid in this case would be an immiscible liquid circulating in direct contact with the phase-change material. This classification is distinctive from the separated element storage devices and easily identified. These systems present unique problems, one of them being the possible hazardous properties of the immiscible fluid. This type of storage device would most likely be used in conjunction with an external or internal heat exchanger - to add or withdraw heat from the immiscible fluid.

\subsubsection{Direct Contact Solid}

The final classification for the liquid storage phase-change devices involves the direct contact solid systems. These systems consist of working fluids passing over encapsulated phase change or other materials such as form stable, crystalline polymer pellets. This classification is characterized by the working liquid being in intimate contact with the phase-change material (or packaged phase change material) and differs from the separated element category in that there are no physical walls separating the phase-change material from the working liquid.

\subsection{EXPANSION AND TESTING OF FRAMEWORK}

The proposed system framework for classification of phase-change storage systems is expanded and tested in the following sections. Each classification is defined in detail, the elements identified, a schematic diagram provided, and an operational description given to characterize the storage and heat release mode. A number of individual projects are identified and examined to test the proposed classification; the success of the classification system depending upon the ability of the established taxonomy to accommodate each of the projects. The code implications of the materials, configurations, and location of these devices relative to the building system will be analyzed later in this report.

\subsubsection{Air Systems}

\subsubsection{Building Components (Collector/Storage)}

This classification of phase-change thermal storage system is intended for those devices that are either free standing or building integrated. The free standing 
devices are, in effect, portable units that are usually semi-fixed in place or they may be truly portable devices designed for periodic relocation. These devices all use air as the heat transfer medium. An example of a semi-fixed device would be a container of phase-change material placed, like a large piece of furniture, somewhere in a room. The container may be located near a window to collect the sun's radiation during the day or may be located in the interior of a building to collect whatever ambient heat is available. These systems would differ from the truly portable devices which would be designed to be moved periodically. The portable device would be moved into the sunlight to collect heat during the day and perhaps wheeled into the interior of the building in the evening to release the latent heat that was earlier collected.

The building integrated devices, on the other hand, would be permanently fixed in place and would be a structural, spatial, or aesthetic element of the building. The device may be load bearing or non-load bearing and will usually be part of the wall, ceiling, or floor. The component would normally be expected to have a long life and be replaced no more frequently than a similar building element not specifically designed as a phase-change thermal storage device.

These free standing/building integrated devices would be considered passive elements even though the portable devices must be moved periodically to achieve their intended function. All the devices would use air as the heat transfer fluid and could also be considered collectors when they rely on the sun's direct interface to function in the heat collection/storage mode. The general schematic of this class of device is shown in Figure 2. In effect, the device is made up of two elements -- the container and the phase-change material. In a building integrated device, if it is load-bearing, the container would normally be the load bearing element but, conceivably, the phase-change material could also contribute to the load bearing requirements.

An example of this classification of phase-change device is shown in Figure 3 . This application is a ceiling tile(s) developed by Architectural Research Corporation called Sol-ar-tile [15]. It uses Glauber's salt as the phase-change. material. The tiles are $2 \times 2$ feet square, $11 / 2$ inches thick, and weigh 44 pounds. They are capable of storing $880 \mathrm{Btu}$ per tile over a range of 68 to $78^{\circ} \mathrm{F}$. The tile is a sandwich of 24 pounds of the eutectic mixture contained in two plastic bags surrounded by twenty pounds of polyester concrete. The system is said to be capable of cycling at least 2600 times with little loss in efficiency. When installed as a ceiling, the material absorbs heat from reflected sunlight or other available thermal energy. Another example would be a solid/solid material incorporated into a Trombe wall.

\subsubsection{Individua}

This grouping char. store heat for a The area and function independently of other heating or storage units. containers are infedirectly interface with the sun. They depend on air building. A fan may and are normally installed as an integral part of a on natural convectioided to circulate the air or circulation may depend 


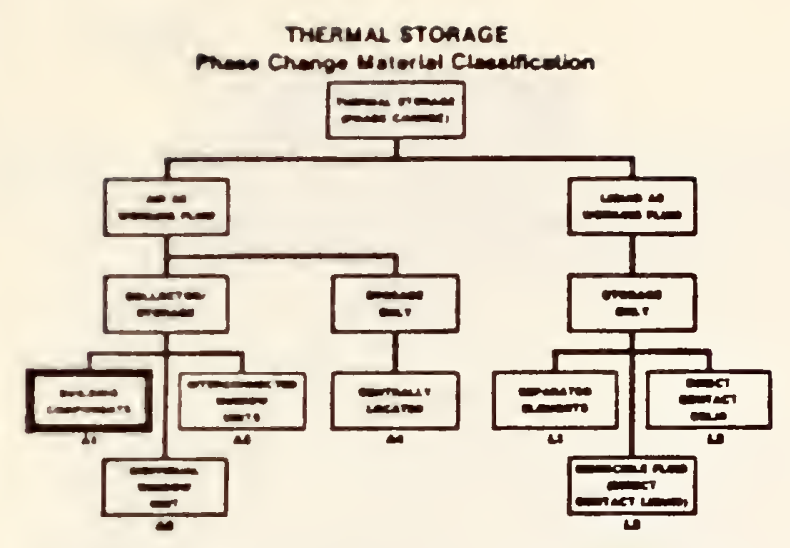

COLLECTOR / STORAGE

\section{BUILDING COMPONENTS}

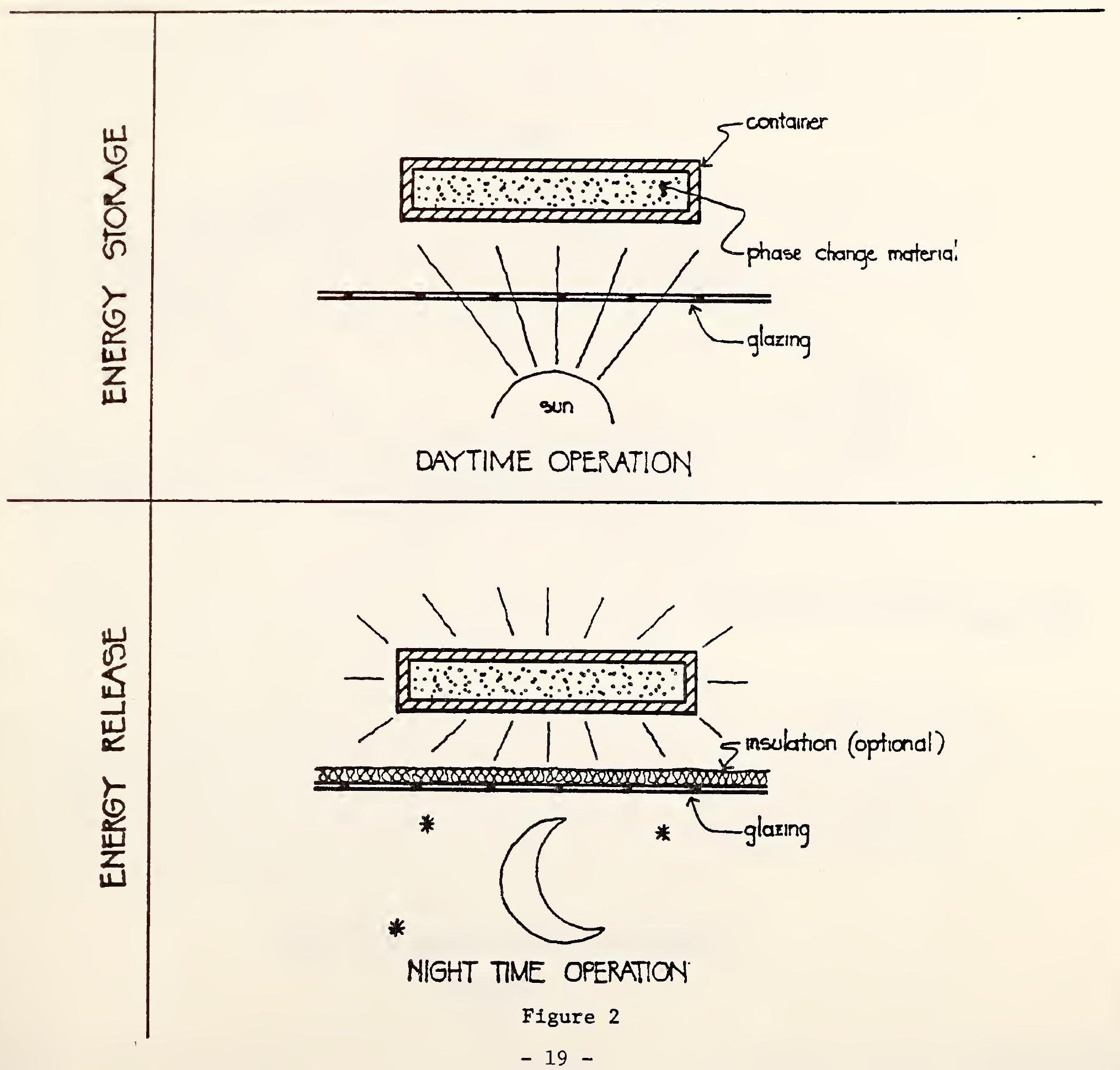




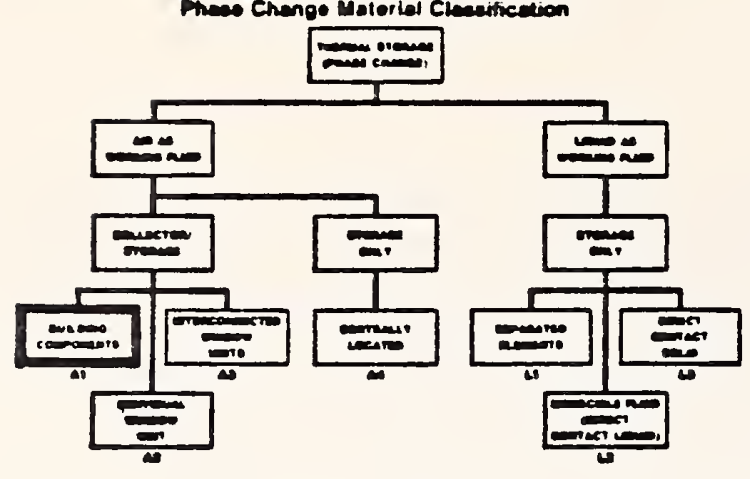

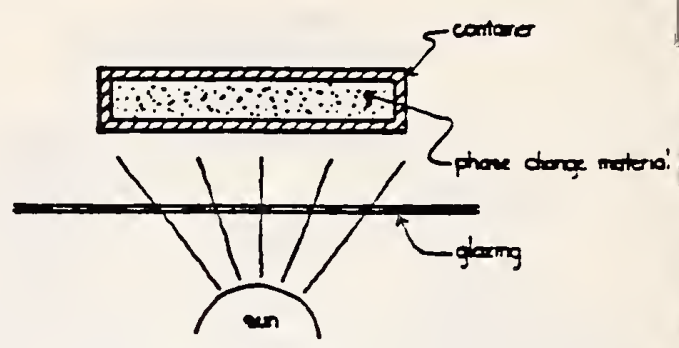

DAYTIME OREATION

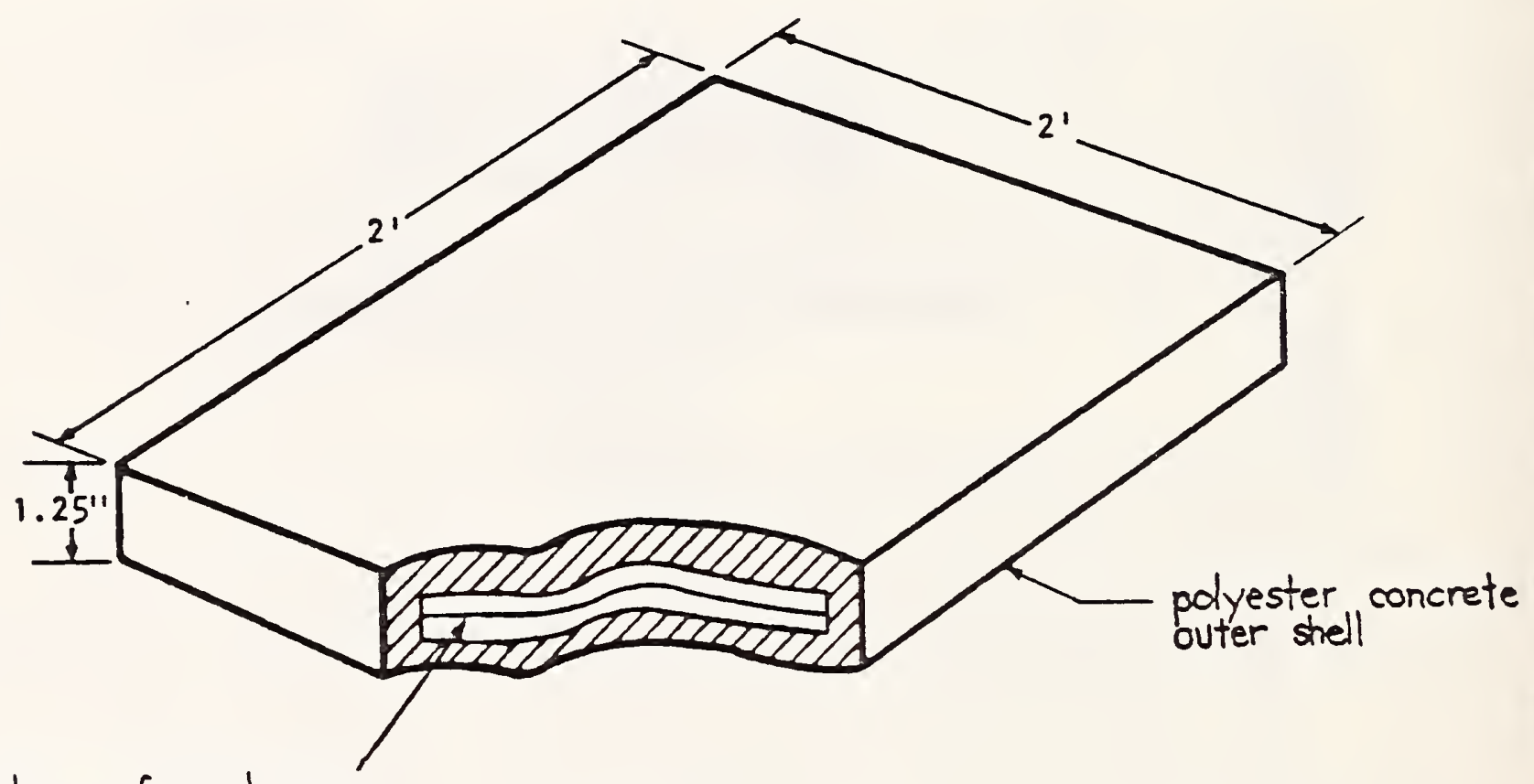

$\mathrm{pCm}$ in 2 waterproof membranes

$3 / 8^{4}$ each

SOL-AR-TILE (CEILING TILE)

Figure 3

$-20-$ 
The unit would normally have a glazing material to separate the storage elements from the outside environment and may have a movable thermal shield that covers the glazing to prevent heat loss at night. This category is analogous to a decentralized window air conditioner as compared to a central air conditioning system.

A schematic of the system is shown in Figure 4. As can be seen, the enclosure effectively establishes the bounds of the system. In this regard, it is basically a box or chase, incorporated into, or integral with, an exterior wall of the building. It may be constructed specifically for the thermal storage/collector system or may also be a structural component of the building. The enclosure would be open on one side to allow direct solar insolation impingement onto the phase-change thermal storage package. The open side, however, would be glazed to separate the outside environment from the collector system and could be transparent or translucent. Insulation may line the enclosure if the design of the system warrants its usage, and movable insulation may be provided to cover the glazing during the evening. This movable insulation may be placed and removed manually or by mechanical means. The enclosure would have an opening or openings to allow room air to enter the unit and another opening or openings for heated air to enter the room. An access panel may also be provided for inspection or maintenance of the interior of the enclosure.

The phase-change material assembly would consist of the phase-change material, the container, and any structural elements required to support the containerized phase-change material. The phase-change material would probably be selected to operate in the low temperature ranges $\left(90^{\circ} \mathrm{F}\right.$ to $\left.150^{\circ} \mathrm{F}\right)$ and could be any of a number of materials identified presently as viable candidates. The packaging of this material could take many forms and shapes and be constructed of a number of materials that would be compatible with the thermal requirements of the system and the properties of the phase-change substance.

Support structures will also vary to accommodate the packaging of the phase-change materials or conversely, the packaging of the phase-change material could be designed to facilitate the required orientation within a system. The support mechanisms may be built into the enclosure, allowing the phase-change package to be slipped in or out; may be platforms on which the phase-change packages are placed; or may contain wires or other devices to suspend the phasechange packages. In some applications, no support structure is used at all. For example, a design encapsulating the phase-change material in flat trays which has moulded legs would allow the phase-change packages to be stacked. The integrally moulded legs also provide separation for the trays, allowing a large heat exchange area through which the air can circulate.

Air movement may be provided by a fan within the enclosure. The fan may be thermostatically or manually controlled and would be sized to provide adequate velocities for heat exchange and circulation. In some designs, a fan need not be provided at all. The system could depend on natural convection to provide air movement. Natural convection would most likely provide low air velocities and would probably be oriented in a long, vertical configuration, perhaps spanning a height greater than a single story to make maximum advantage of 


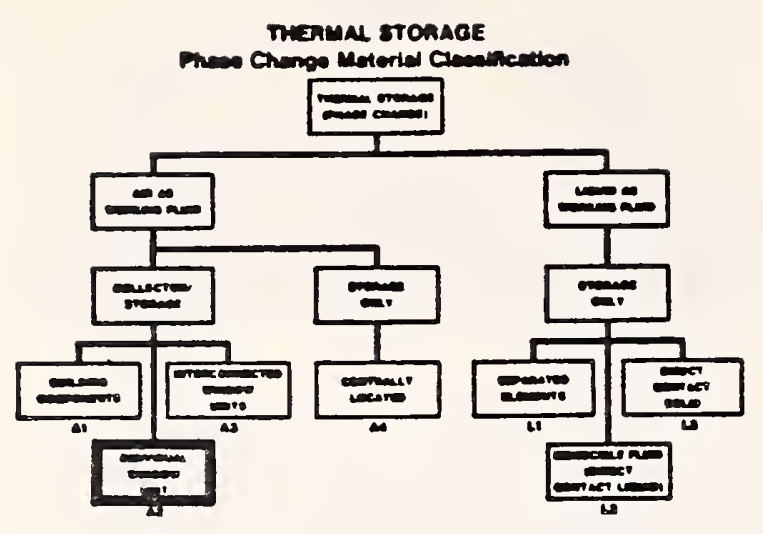

\section{COLLECTOR / STORAGE}

\section{INDIVIDUAL WINDOW UNIT}

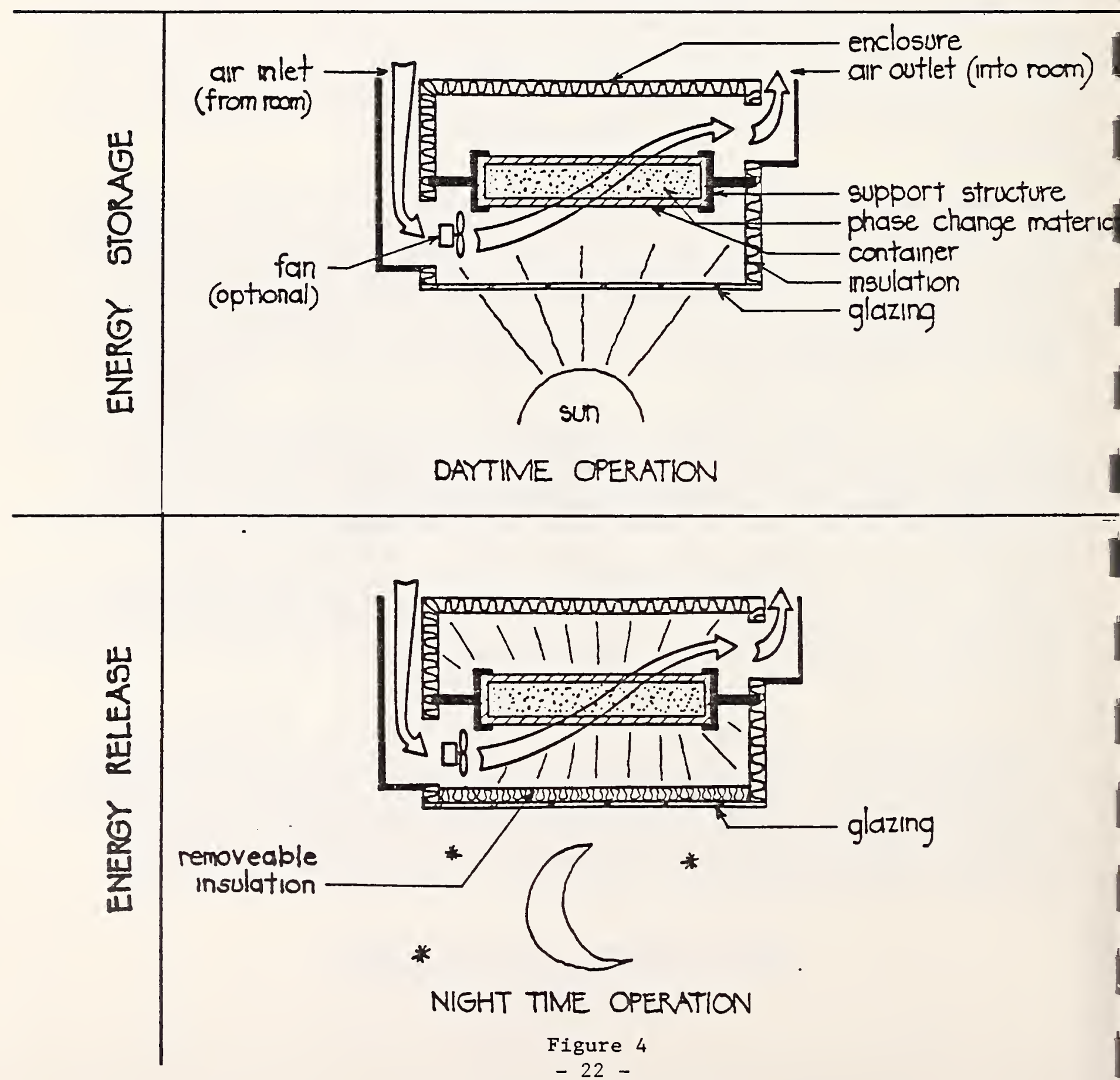


temperature gradients. A filter may be provided, but such a device would restrict the alr flow. especially in those systems depending on natural convection for air circulation.

An example of this type of collector/storage phase-change system follows in Figure 5. It is a Thermal Wall Panel System developed at the University of Delaware [16]. The system is described as a thermal wall panel containing sodium sulfate decahydrate $\left(\mathrm{Na}_{2} \mathrm{SO}_{4}-10 \mathrm{H}_{2} \mathrm{O}\right)$ in a patented mixture. The energy storage materials are deployed in a staggered array located in the structure's southfaclng wall. Forced air is thermostatically controlled to meet the heating demand. The panel is insulated to keep the room from being uncontrollably heated during the periods of high solar insolation. The system also keeps excessive nighttime heat from escaping by a variety of insulation methods. The phase-change material is packaged in a "CHUB" configuration - a multi-layer film package approximately 0.004 inch thick.

\subsubsection{Interconnected "Window" Units (Collector/Storage)}

This classification of phase-change thermal storage devices exhibit the same characteristics as the individual "window" units with one major exception. That exception is the air movement provisions. Whereas the individual window units move air by a localized fan or natural convection and operate independently of any centralized environmental conditioning system, this classification is characterized by the interconnection of the devices with the centralized building environment conditioning system. In effect, the units are serially connected to the building ductwork and generally depend on a centralized blower or fan for air circulation.

The implications of this configuration are significant in that hazards manifesting themselves anywhere in the system can be easily conveyed throughout the building through the extensive duct network that generally interfaces with all parts of the building. In this regard, this configuration may be subjected to a greater scrutiny by local code officials because of the higher inherent safety hazard potential.

The schematic for this configuration category is shown in Figure 6 . The explanation of the constituent elements as explained under 3.3.1.2 Individual "Window" Units (Collector/Storage), also apply to this classification. No example of the Interconnected Window Unit System has been identified for inclusion in this report.

\subsubsection{Centrally Located (Connected to Building Ductwork) (Storage Only)}

This classification of phase-change thermal storage devices includes those systems that depend on air as the working fluid while only functioning in the storage mode. There is no interplay with the sun and therefore no collector function. These phase-change thermal storage devices are similar in schematic configuration to the Interconnected Window Unit except for the glazing (see Figure 7). In this configuration, there is a solid enclosure surrounding the phase-change material assembly with provisions for the working fluid (air) to enter and leave. This classification is also characterized by the interconnection to the building's central air distribution system and its associated fan or blower that forces air distribution throughout the inhabited areas. The air, however, could be distributed by natural
convection. 

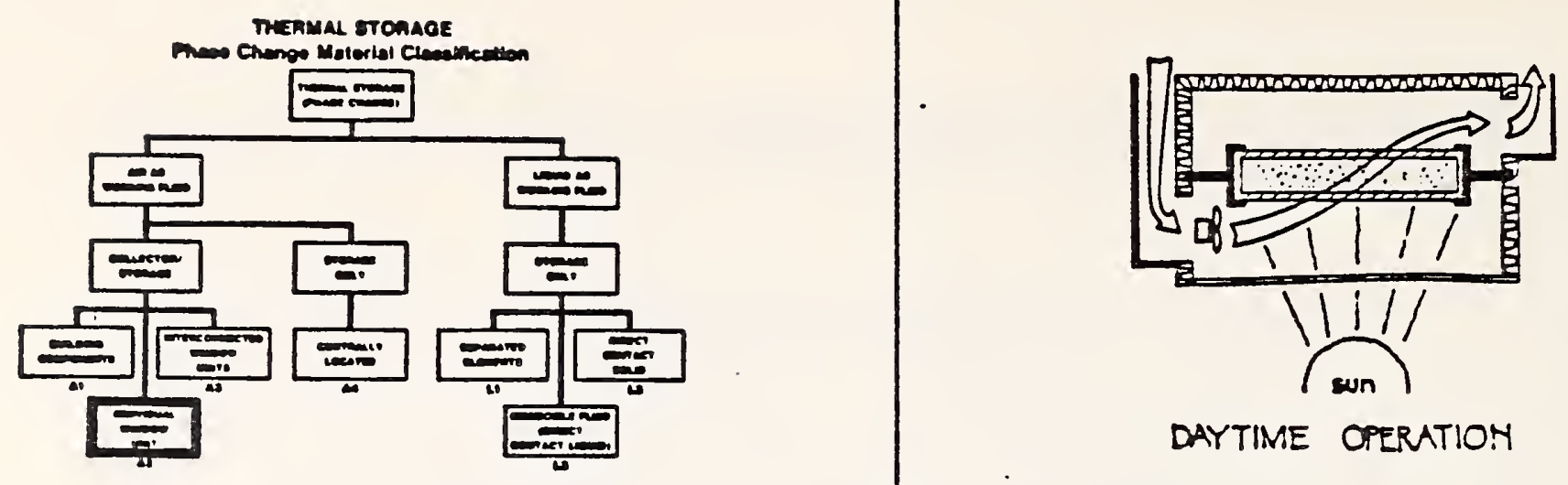

DAYTIME OPERATION

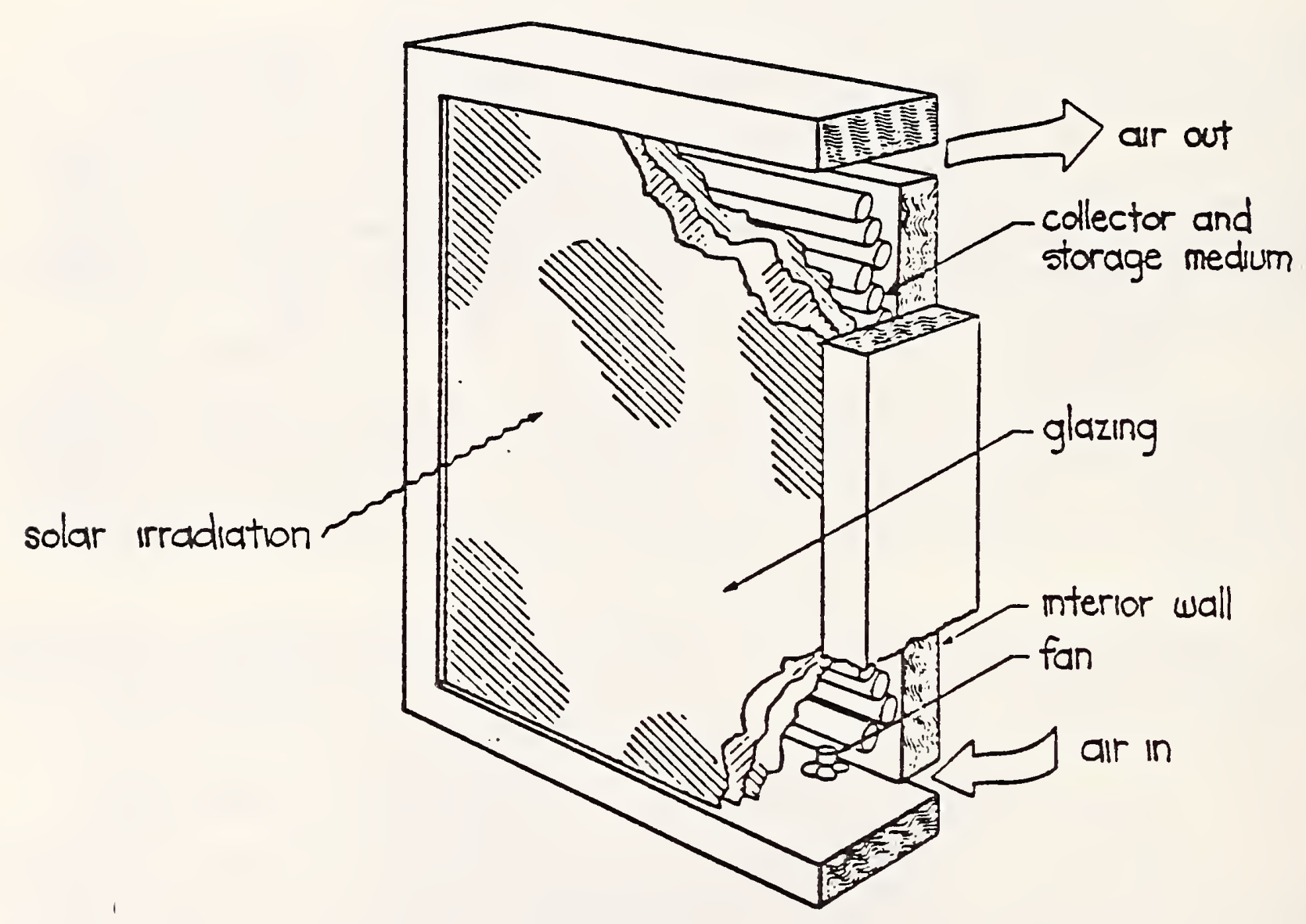

THERMAL WALL PANEL

Figure 5

- 24 - 


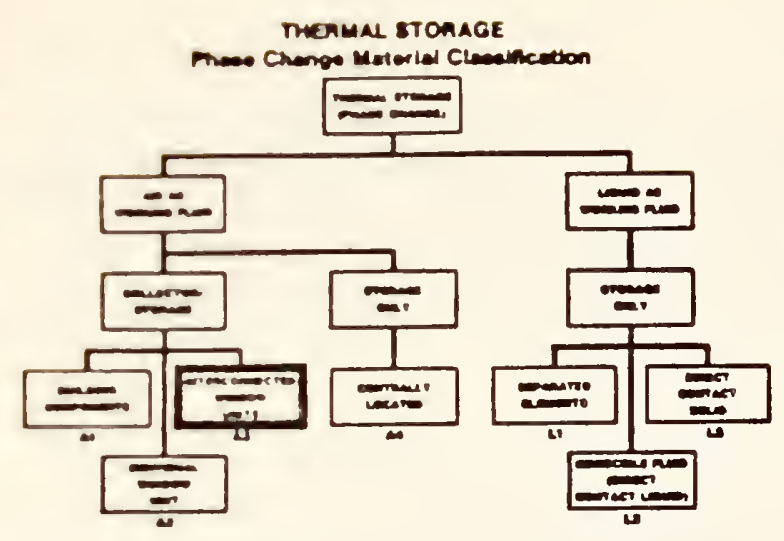

COLLECTOR / STORAGE

NTERCONNECTED WINDOW UNITS

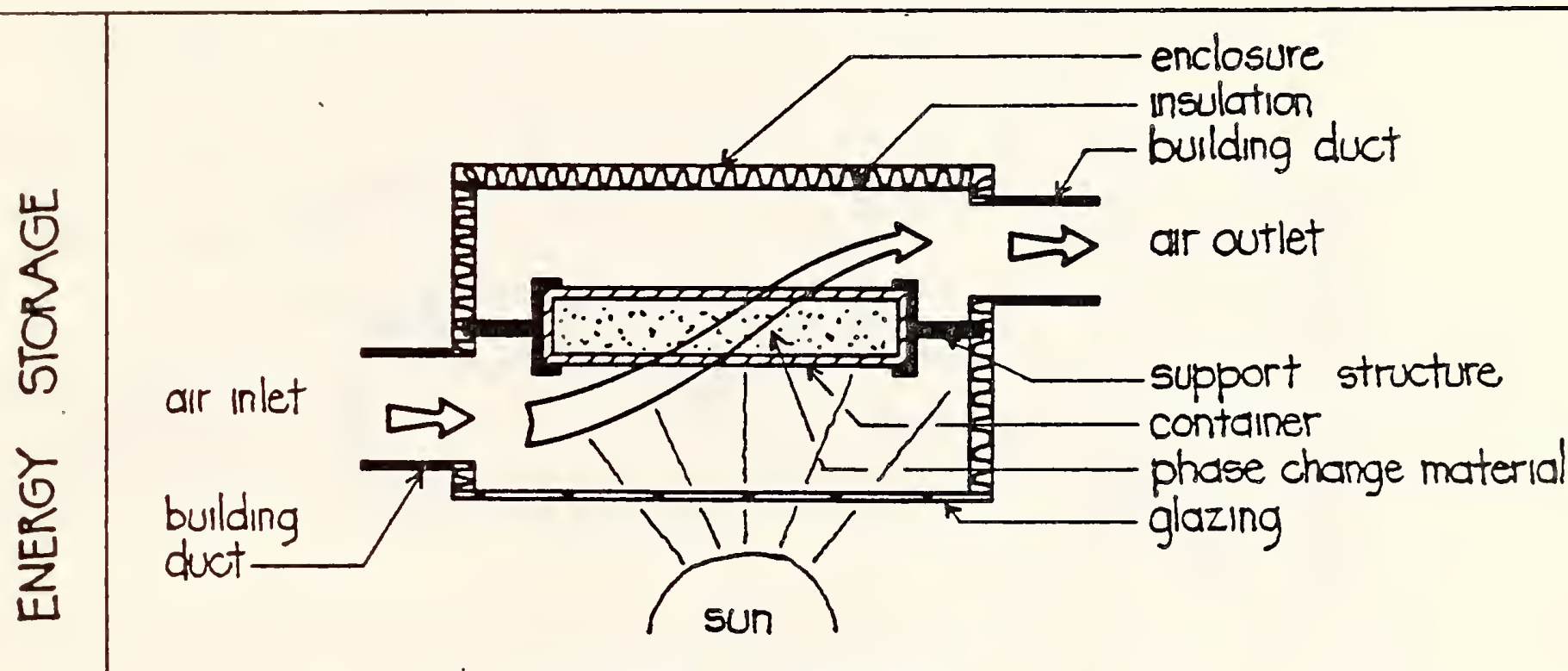

DAYTIME OPERATION

$\frac{n}{4}$

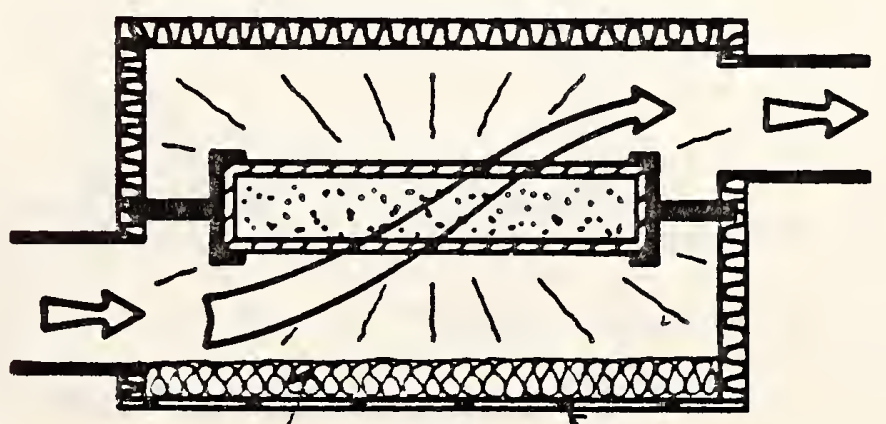

removeable insulation

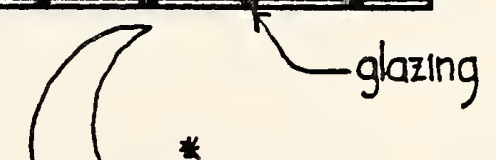

*

NIGHT TIME OPERATION

Figure 6

$-25-$ 


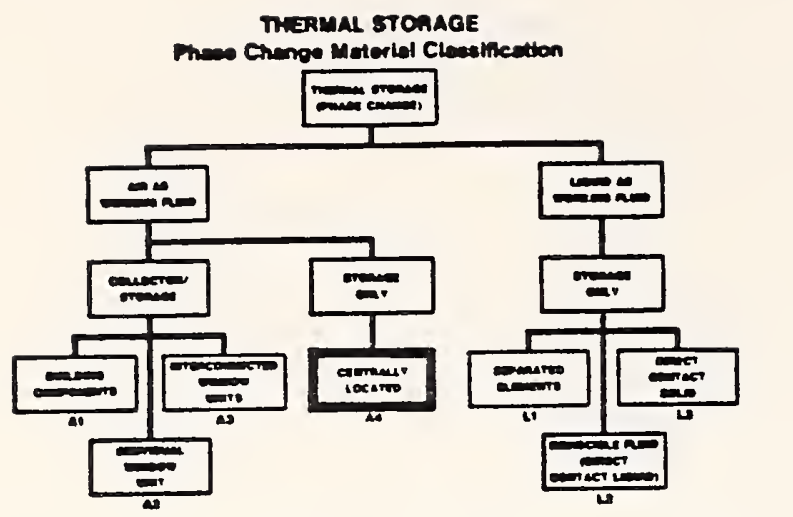

\section{STORAGE ONLY}

\section{CENTRALLY LOCATED}

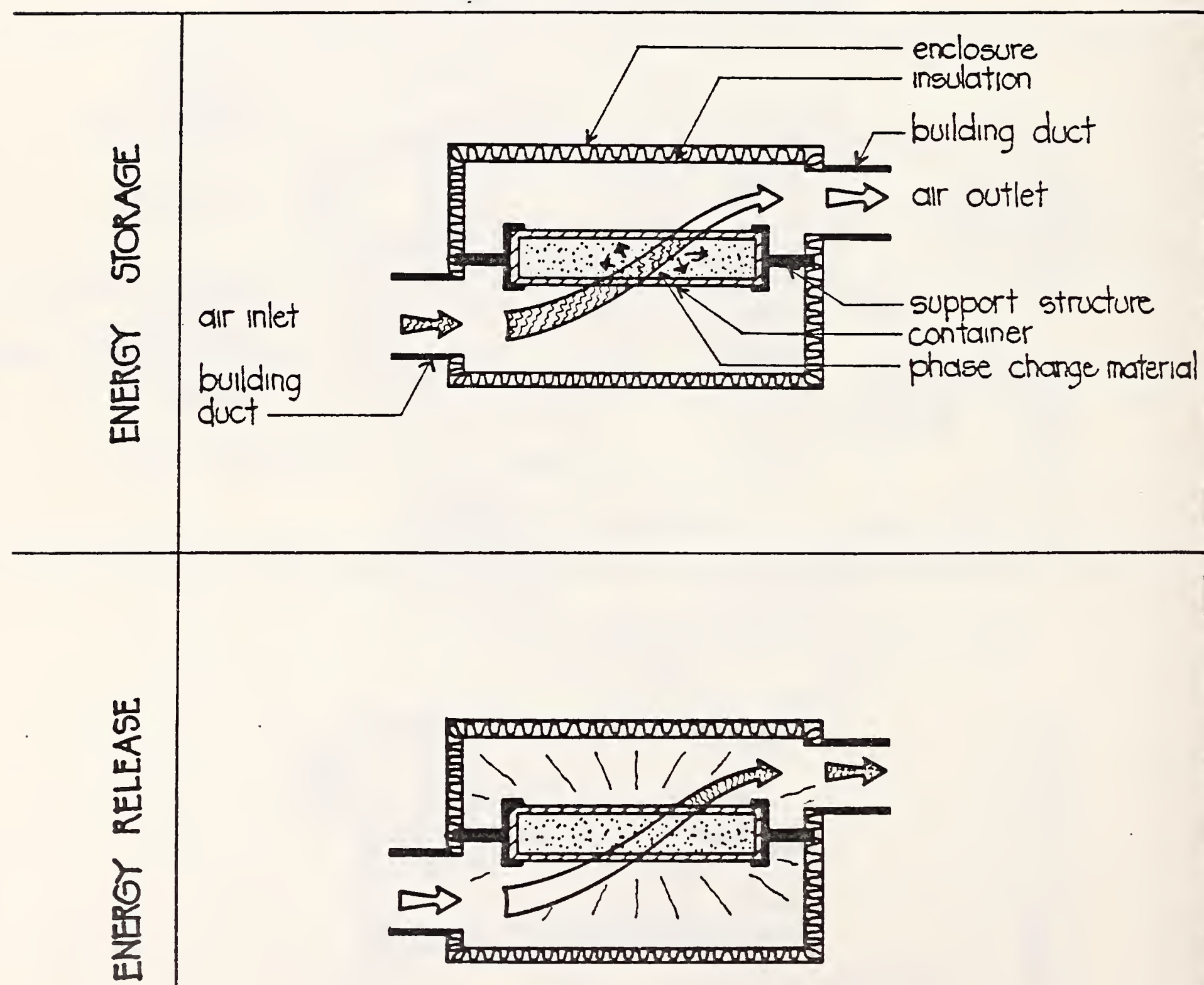


Because this phase-change storage system does not function as a collector, the enclosure need not be located adjacent to an outside wall, but could be placed in any convenient location within the building envelope. In addition, this phasechange system type can be operated within a wide temperature range -- the particular phase-change material being selected to accommodate a snecific temperature range. Cooling as well as heating storage can be provided.

The "storage only" feature of this class of device may generate a large number of possible configurations, since the storage assembly need not be oriented to take advantage of the sun's radiation. The less restrictive location requirements may also result in a larger aggregation of materials and allow for a variety of Innovative packaging techniques. In addition, these devices are not restricted to solar applications and may be used with heat pumps or conventional cooling devices in order to take advantage of off-peak operation to store heat in the evening for later use during the day.

Examples of design flexibility achievable in this classification are shown in Figures 8, 9, and 10. Figure 8 is a schematic of the Valmont Industries [17] concept using an encrusted conglomerate of Glauber's salt (sodium sulfate decahydrate) as the phase-change material. The encrusted conglomerate consists of 97 percent Glauber's salt and 3 percent additives packaged in high impact polyethelylene trays containing 20 pounds of the mixture. This mixture stores $100 \mathrm{Btu} / \mathrm{lb}$ at $89^{\circ} \mathrm{F}$ in a phase-change transformation. The additives create a honeycomb structure of closed cells locking the Glauber's salt crystal into a rigid lattice work which remains rigid as the Glauber's salt is alternately melted and solidified. It is claimed that this technqiue solves many of the problems associated with the gravity segregation of the mixture when in the liquid state. In an operating system, the Glauber's salt containers would be stacked inside an insulated enclosure and air from the centralized duct system passed through the enclosure to store or remove heat.

Another possible configuration is demonstrated by the University of Delaware's "CHUB" phase-change storage systems [18]. This is shown in Figure 9. The phasechange material is also sodium sulfate decahydrate in a patented mixture packaged in a multi-layer plastic film approximately 0.004 inch thick. This could be the same or similar material used in the individual "window" unit configuration. However, the "CHUBS" would be housed in an insulated enclosure, as described above for the Valmont system.

A third configuration, of the many possible under this classification, is shown in figure 10. This is the Rolling Cylinder Heat Storage System, developed by the General Electric Corporation [19]. This system also used Glauber's salt as the phase-change material. A cylindrical drum is 95 percent filled with Glauber's salt and slowly rotated along its axis. The heat transfer fluid (air) passes along the cylinder, gaining or releasing heat. During thermal energy extraction, this slow rotation provides enough agitation to keep the salt temperature uniform and prevents the salt from solidifying on the wall of the container. The phasechange material melts at $90.3^{\circ} \mathrm{F}$, exhibits satisfactory repeatable nucleation, and has demonstrated repeatable freeze-thaw cycling without degradation. The corrosion in the metal-walled vessel has been controlled by additives without affecting crystallization behavior and melt-thaw change has not been a problem. 

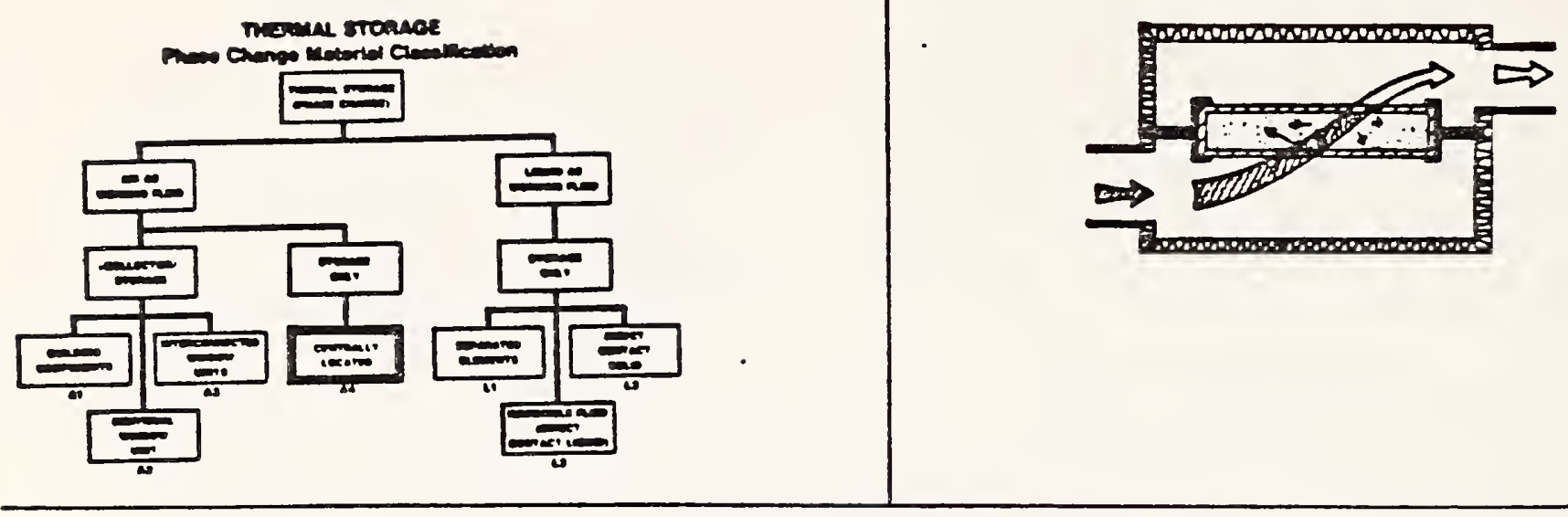

msulated storage
cabinet

eutectic salt storage containers
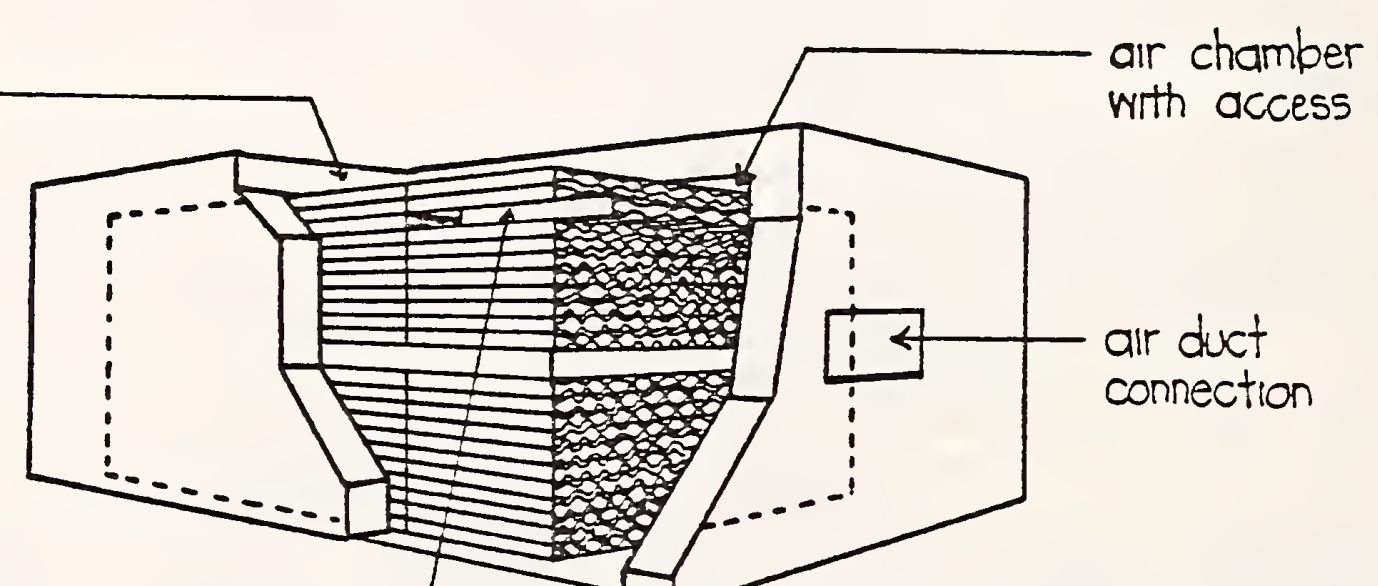

air duct connection

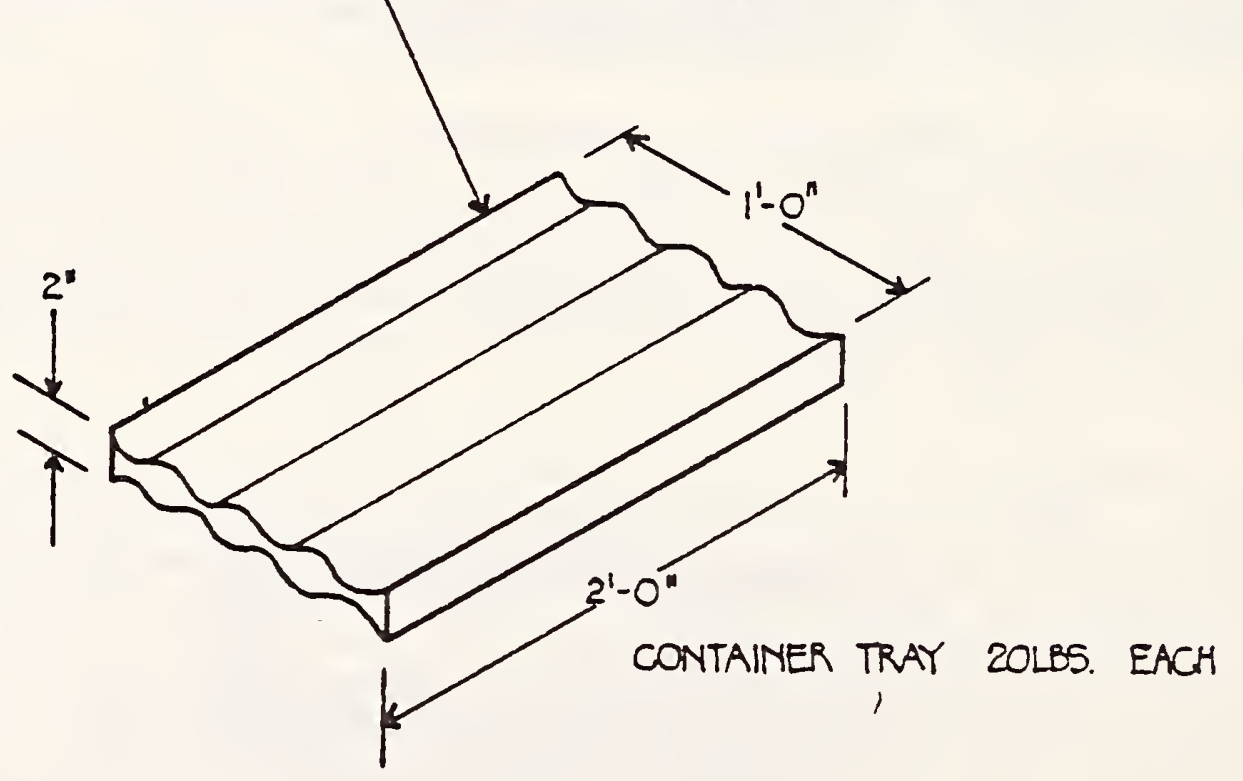

VALMONT STORAGE UNIT

Figure 8 

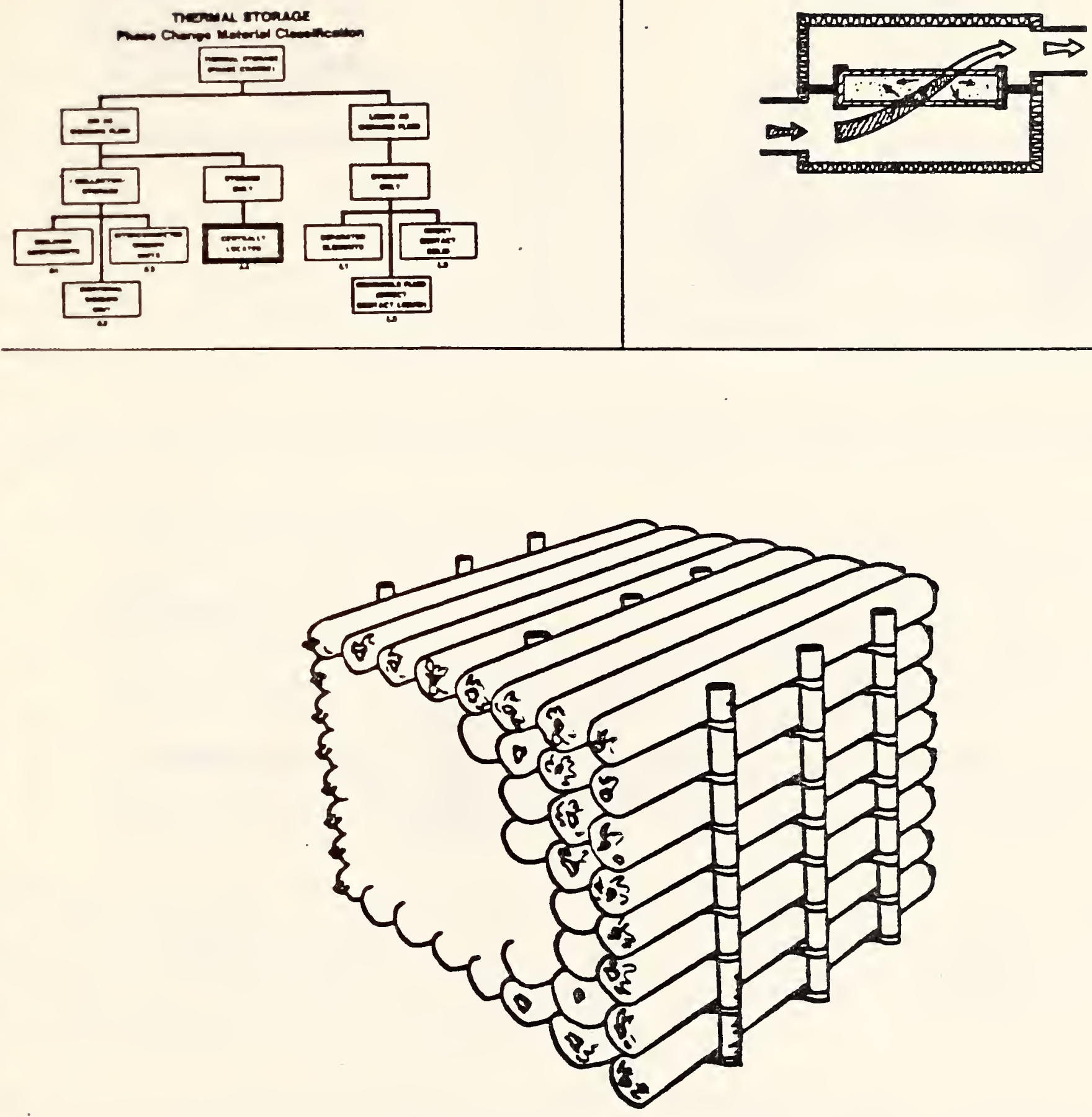

"chub" thermal energy storage Figure 9 

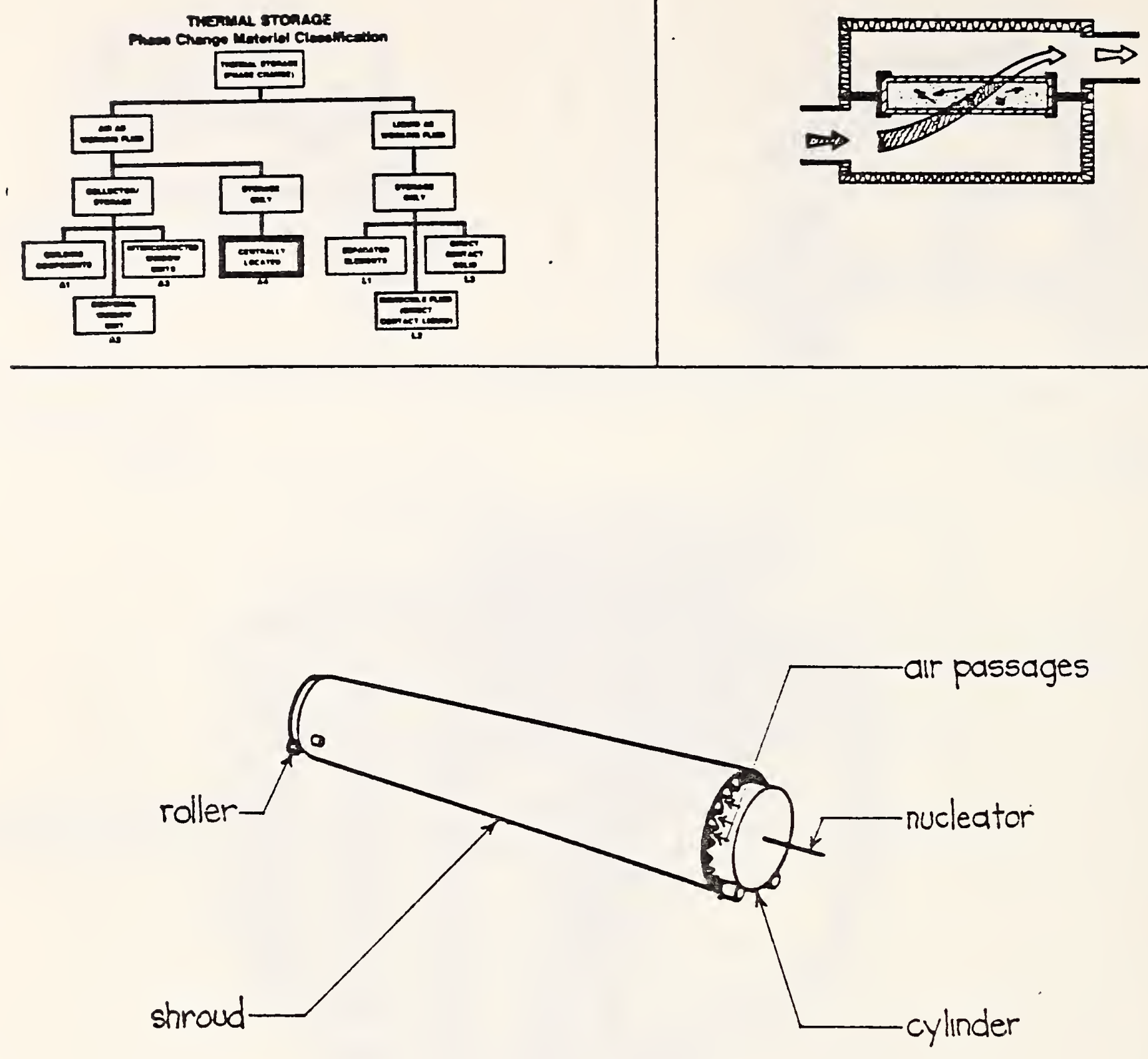

RECOMMENDED CONCEPTUAL DESIGN FOR A ROLLING CYLINDER HEAT STORE

Figure 10 


\subsubsection{Liquid Systems}

\subsubsection{Separated Elements (Storage Only)}

This classification of thermal storage devices uses a liquid as the working fluid. The liquid is generally water or water mixed with an antifreeze liquid such as ethylene glycol. The working liquid is contained in its own flow circuit and separated from direct contact with the phase change material by a physical barrier (See Figure 11). The entire system is normally housed in a closed vessel with openings to allow the separate circuit containing the working fluid to enter and leave the vessel. The walls and shape of the working fluid circuit are configured to allow the required heat to be transferred to and from the phase change material. The entire unit may be insulated to minimize heat loss.

The system described is basically a heat exchanger and although shown schematically in Figure 11 as a coil-in-tank type, other heat exchanger types are also included in this general classification. These other types include:

a) Heat exchanger wrapped around a tank -- the working liquid circuit or loop does not enter the tank but is wound in a helical or other configuration around the outside of the tank containing the storage (phase change) media.

b) Tank within a tank -- the working fluid is piped into an inner tank where heat is exchanged to the phase change material in the outer tank through the inner tank walls. An alternate configuration would use the inner tank for the phase change material and the outer tank for the working fluid.

c) Tank with cascade bath - the phase change material is contained in a tank and the working fluid cascades down the side of this tank to permit heat transfer to and from the phase change material. An outer tank would normally be used to contain the working fluid.

The common denominator of all these systems is the physical separation of the working fluid from the phase change material and that there never is a direct contact between the working fluid and the phase change material. Configurations may have mechanical or other means of agitating or stirring the phase change material. Assurance of the proper mixing alleviates the inherently undersirable properties associated with some phase change materials as described in Section 2.

An example of a separated element system using a mechanical agitation is shown in Figure 12. This is a phase change storage device developed by the Calmac Corporation [20]. This device consists of a tank containing a series of coiled plastic tubes. The phase change material, a salt hydrate $\left(\mathrm{Na}_{2} \mathrm{~S}_{2} \mathrm{O}_{3} \cdot 5 \mathrm{H}_{2} \mathrm{O}\right)$, is placed into the tank while the working liquid, water, circulates through the coiled plastic tubes. A stirring pump is also included at the top of the tank to operate intermittently when the salt is in a liquid state. This prevents stratification and the subsequent forming of a dehydrate salt in the bottom of the tank. 


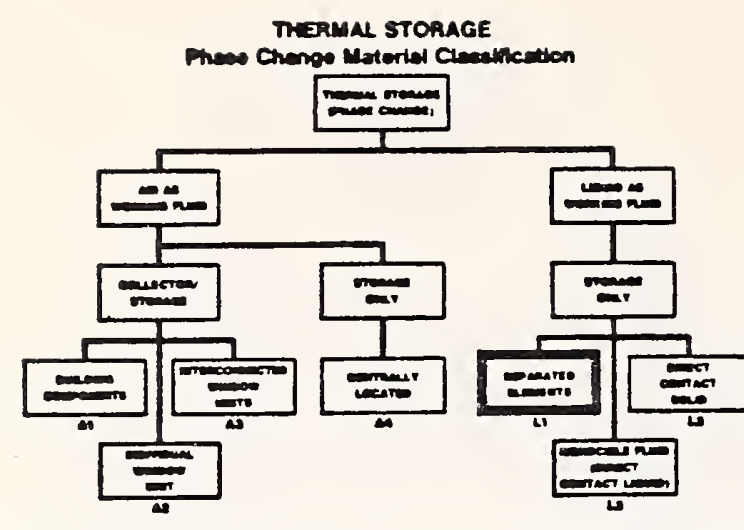

STORAGE ONLY

SEPARATED ELEMENTS

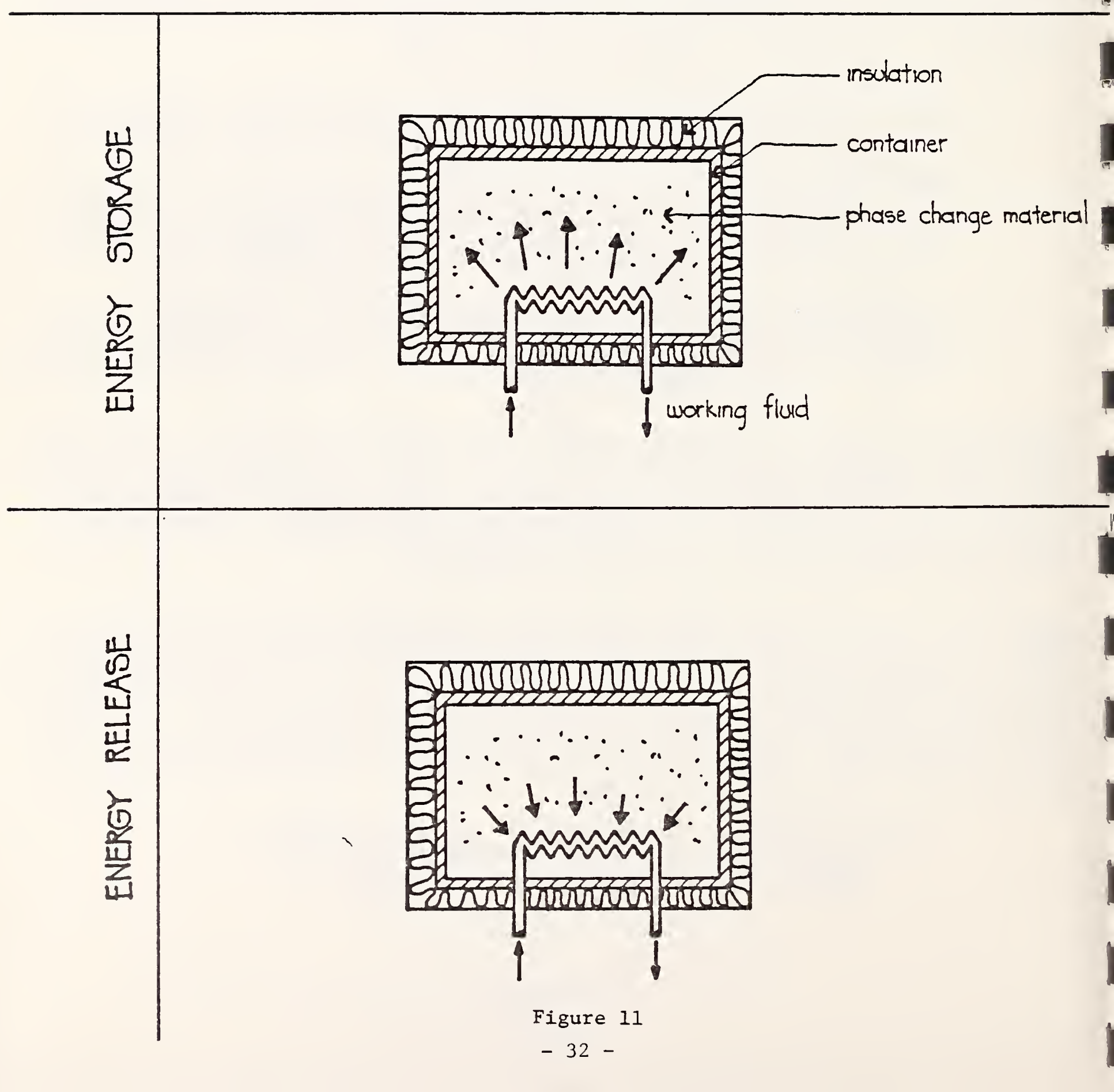



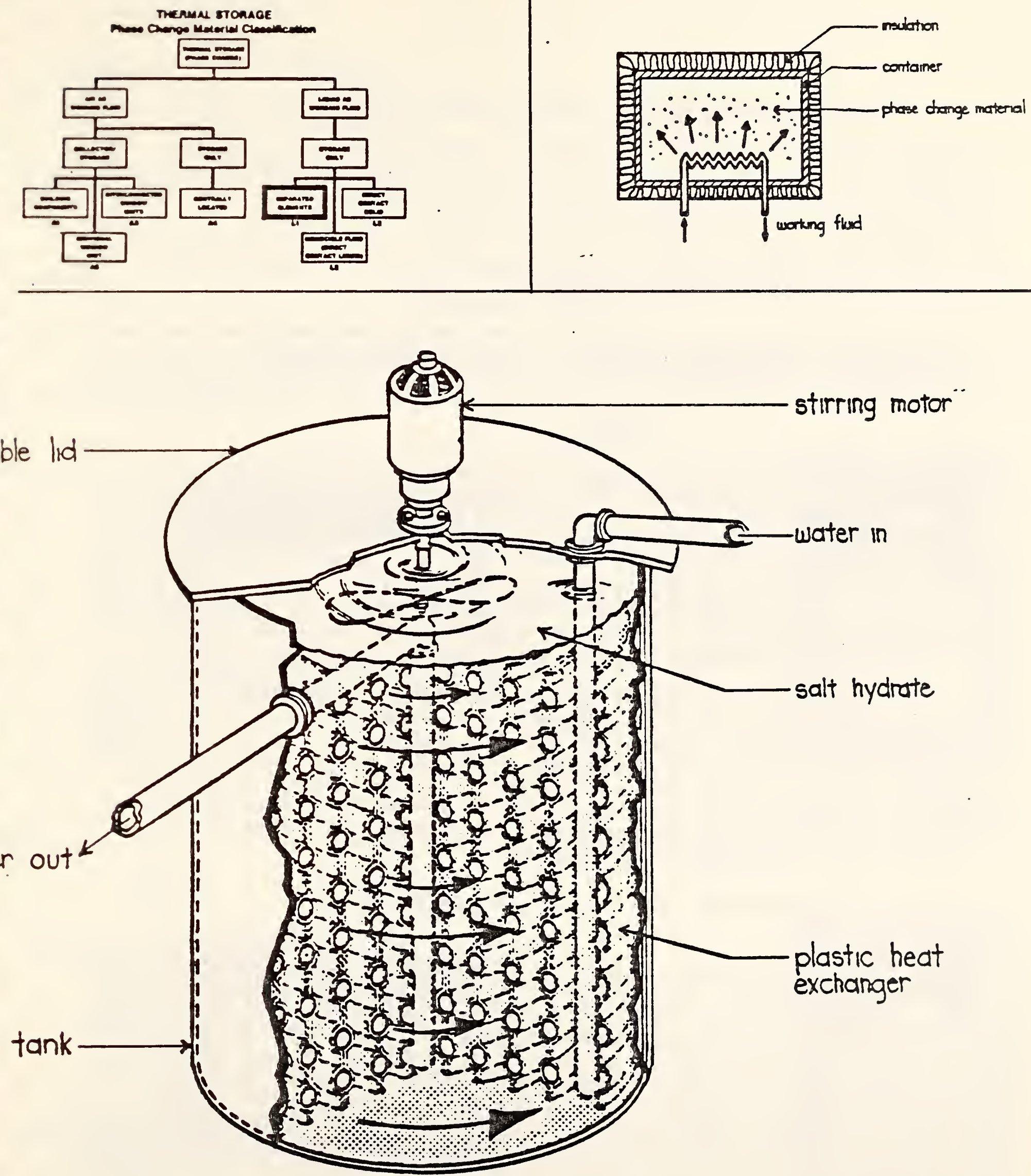

CALMAC PHASE CHANGE STORAGE DEVICE

Figure 12 


\subsubsection{Immiscible Fluid (Direct Contact Liquid) (Storage Only)}

Thermal storage devices that use immiscible fluids are categorized by this grouping. An immiscible fluid is a fluid that cannot be mixed or blended with another fluid. In this respect, the phase change material and the immiscible fluid are in direct and intimate contact with each other. This is true when the phase change material is in the liquid state as well as the solid state. When the phase change material is in the liquid state, the system could be looked upon as a liquid-to-liquid heat exchanger.

To function properly, the working fluid must be truly immiscible with the phase change material and be compatible in all other respects as well. The immiscible fluid should be chemically stable when in contact with the phase change material and, in itself, not change phase over the operating range of the storage system.

Water or aqueous solutions are precluded from being used as the immiscible fluid for this category as they are included in another category (see 3.3.2.3 - Direct Contact Solid). The immiscible fluids considered here are the hydrocarbon oils, the silicone fluids, or other materials of this nature. The phase change materials compatible with these fluids generally fall into the salt hydrate category. The immiscible fluid also should have a different density than the phase change material to allow it to rise and "bubble" through the phase change material, or settle and "fall" through the storage medium. In passing through the phase change material, a stirring or agitation may take place, promoting a more efficient heat exchange.

Since the immiscible fluid (except at the phase change interface) would normally have its own circulation circuit, it would not interface directly with the source of heat such as a solar collector or the thermal loop that supplies heat to the habitable spaces. This interface would normally be accomplished by another heat exchanger, which may be an integral part of the thermal storage assembly, or separate from it. If the immiscible fluid has any toxic or unsafe properties, any interface with the potable water supply will have to be protected to insure the integrity of the potable water supply.

The schematic representing this class of thermal storage device is shown in Figure 13.

Described below are three systems that use immiscible fluids and are representative of this type of system. They vary widely in configuration and operation. The first (see Figure 14) is a system developed by Clemson University [21]. This system utilizes a salt hydrate phase change material in conjunction. with a lower density immiscible fluid as the primary heat transfer agent. The lower density immiscible fluid is introduced at the bottom of the container, diffused outwardly toward the container walls, and allowed to rise through the salt solution. The rising immiscible fluid transfers heat to or from the heat storage material and, in the process, agitates the vessel contents. The immiscible fluid is pumped through its own loop and, when integrated into a heating system, works in conjunction with an external heat exchanger to transfer heat to or from other heat transfer elements of the system. 


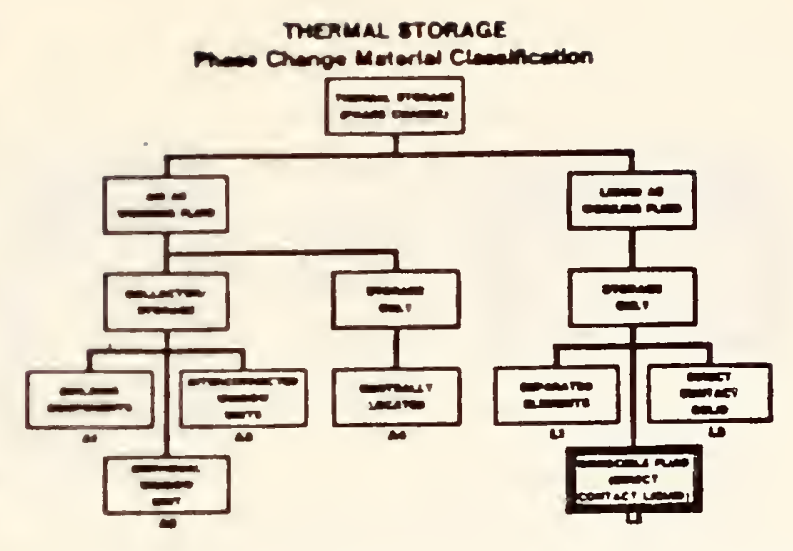

STORAGE ONLY

\section{IMMISCIBLE FLUID (DIRECT CONTACT LIQUID)}

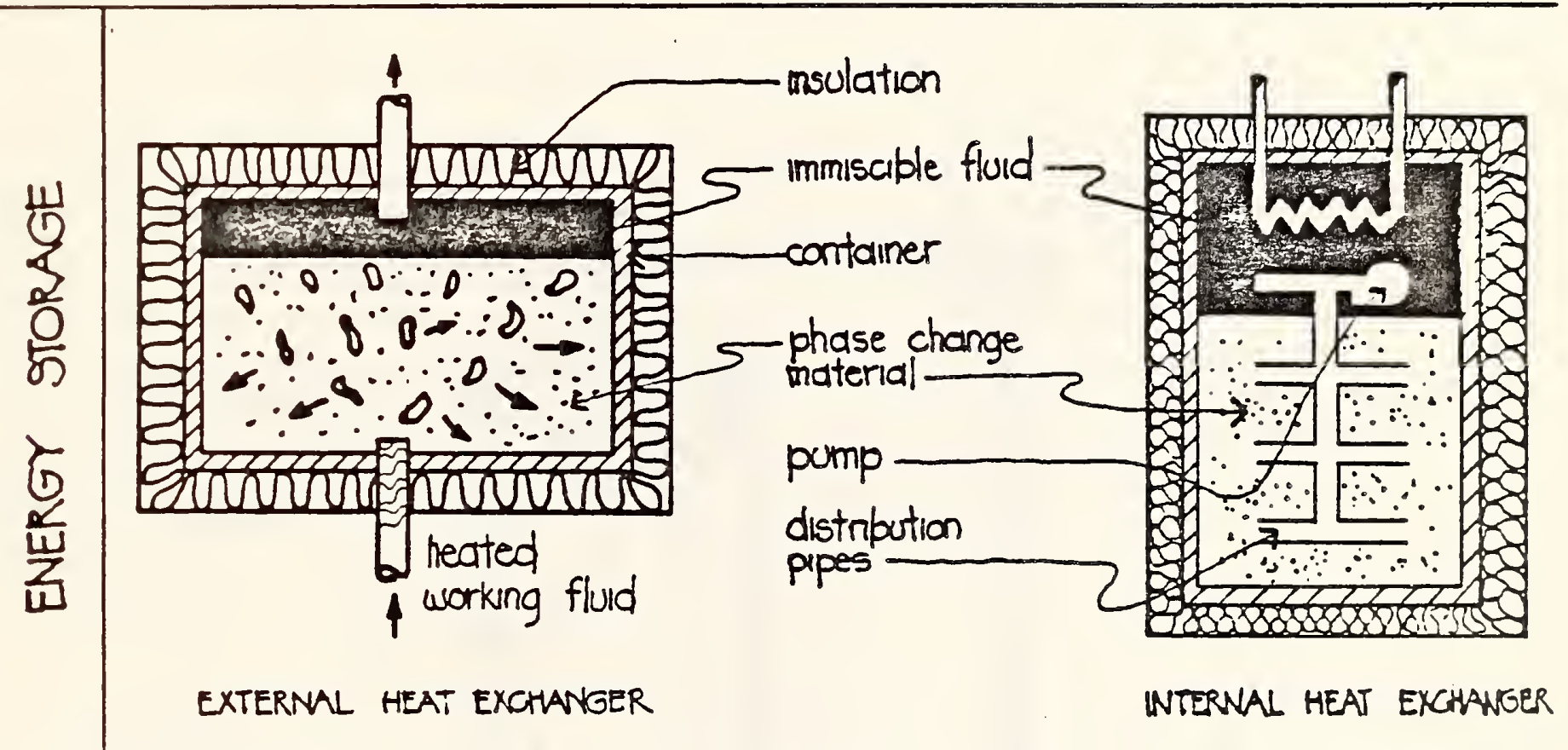

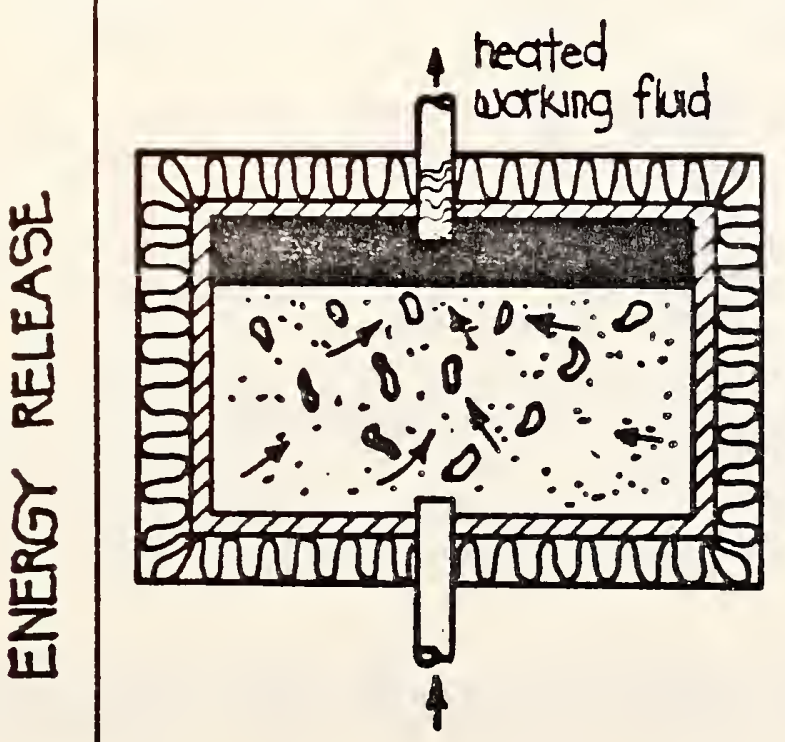

EXTERNAL HEAT EXCHANGER

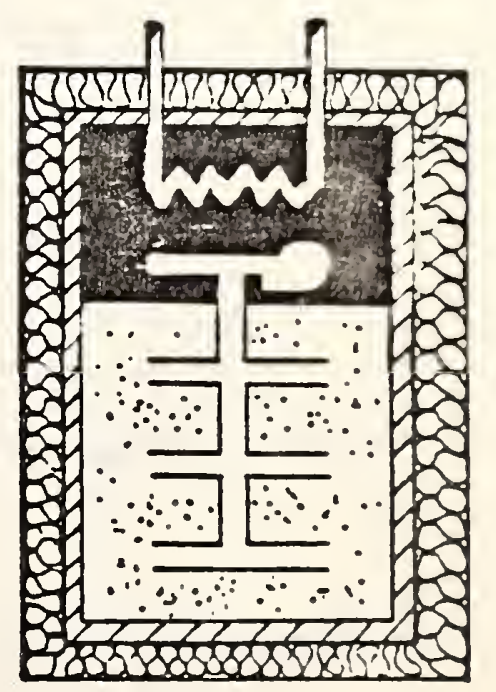

NTERNAL HEAT EXCHANGER 

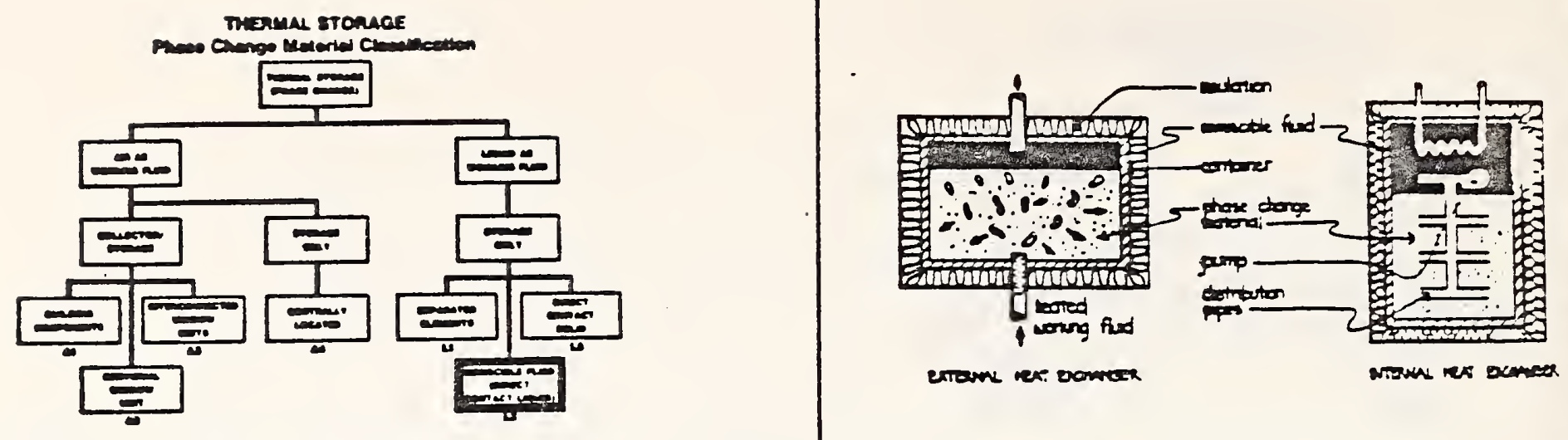

heat exchanger

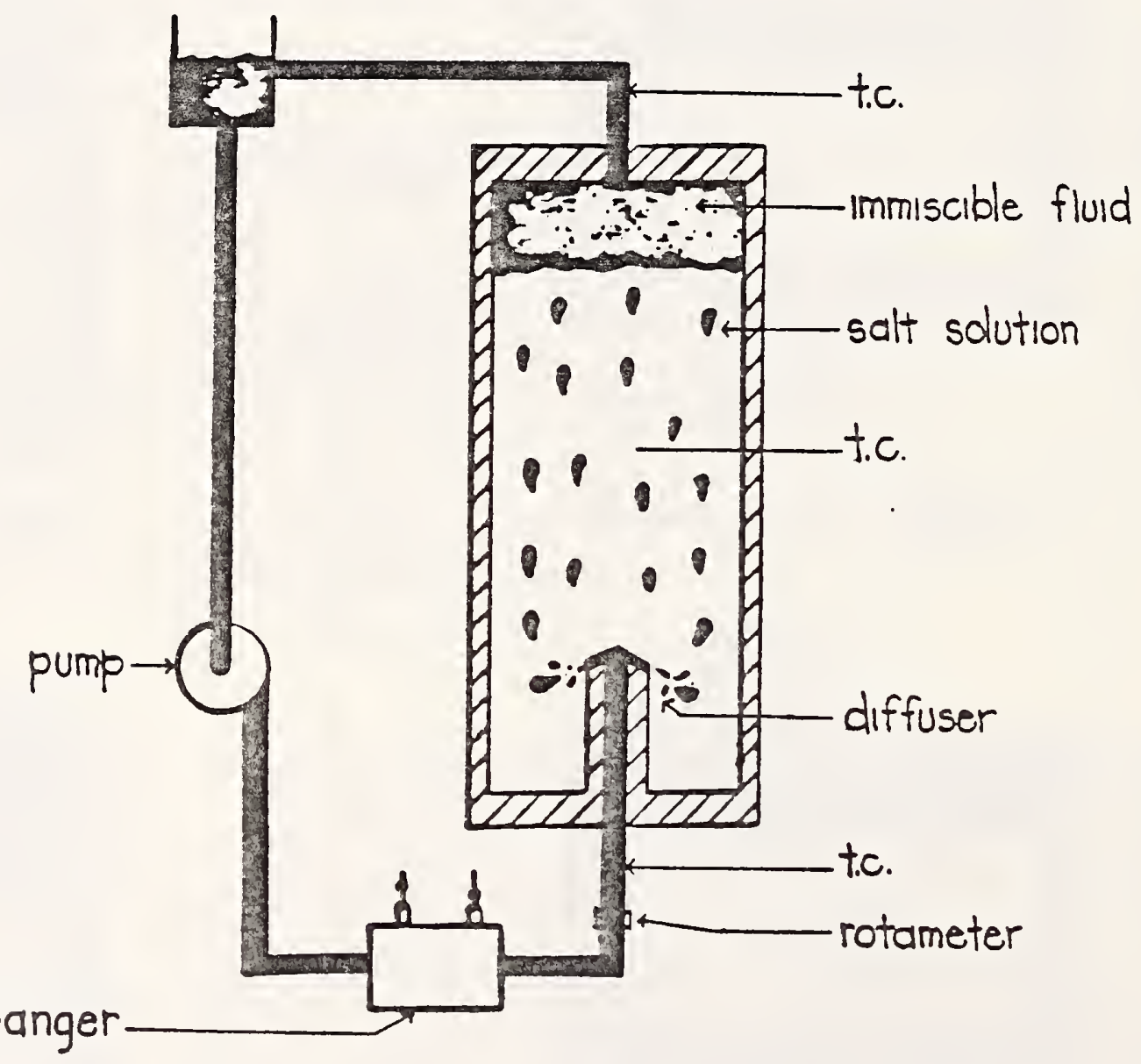

IMMISCIBLE FLUID-HEAT OF FUSION STORAGE SYSTEM

Figure 14 
The materials with the greatest potential for use with this system are tabulated below with some of their characteristics:

SALT

Disodium Hydrogen Phosphate $\left(\mathrm{Na}_{2} \mathrm{HPO}_{4} \cdot 12 \mathrm{H}_{2} \mathrm{O}\right)$ Dodecahydrate

Calcium Chloride Hexahydrate $\left(\mathrm{CaCl}_{2} \cdot 6 \mathrm{H}_{2} \mathrm{O}\right)$

Sodium Sulfate Decahydrate $\left(\mathrm{Na}_{2} \mathrm{SO}_{4} \cdot 10 \mathrm{H}_{2} \mathrm{O}\right)$

Sodium Thiosulfate Pentahydrate $\left(\mathrm{Na}_{2} \mathrm{~S}_{2} \mathrm{O}_{3} \cdot 5 \mathrm{H}_{2} \mathrm{O}\right)$
APPROXIMATE

APPROXIMATE MELTING POINT

$34^{\circ} \mathrm{C}\left(93^{\circ} \mathrm{F}\right)$

$27^{\circ} \mathrm{C}\left(80^{\circ} \mathrm{F}\right)$

$27^{\circ} \mathrm{C}\left(80^{\circ} \mathrm{F}\right)$

$47^{\circ} \mathrm{C} \quad\left(116^{\circ} \mathrm{F}\right)$
HEAT OF FUSION

(HYDRATION)

$66 \mathrm{cal} / \mathrm{gm}$

$32 \mathrm{cal} / \mathrm{gm}$

$60 \mathrm{cal} / \mathrm{gm}$

$50 \mathrm{cal} / \mathrm{gm}$

Each of the salt hydrates have good heats of fusion for use in latent storage applications. Because of the lower melting temperature ranges, calcium chloride hexahydrate $\left(\mathrm{CaCl}_{2} \cdot 6 \mathrm{H}_{2} \mathrm{O}\right)$ and sodium sulfate decahydrate $\left(\mathrm{Na}_{2} \mathrm{SO}_{4} \cdot 10 \mathrm{H}_{2} \mathrm{O}\right)$ would be useful in heat pump or solar assisted heat pump applications. The disodium hydrogen phosphate dodecahydrate $\left(\mathrm{Na}_{2} \mathrm{HPO}_{4} \cdot 12 \mathrm{H}_{2} \mathrm{O}\right)$ and sodium thiosulfate pentahydrate $\left(\mathrm{Na}_{2} \mathrm{~S}_{2} \mathrm{O}_{3} \cdot 5 \mathrm{H}_{2} \mathrm{O}\right)$, because of their higher melting point, could be directly applicable to direct solar heat storage. The immiscible fluids compatible with these phase change materials were selected based on cost, toxicity, density, viscosity, and flash point. The flash points of these materials are:

$\begin{array}{ll}\text { MATERIAL } & \text { FLASH POINT } \\ \text { Marcol } 72 & 185^{\circ} \mathrm{C}\left(365^{\circ} \mathrm{F}\right) \\ \text { Therminol } 44 & 207^{\circ} \mathrm{C}\left(405^{\circ} \mathrm{F}\right) \\ \text { Therminol } 60 & 154^{\circ} \mathrm{C}\left(309^{\circ} \mathrm{F}\right)\end{array}$

This property probably presents the highest safety risk inherent in the use of these materials.

Another property which may cause operational difficulties is related to the viscosity of immiscible fluids. These fluids seem to "carry-over" some of the salt hydrates into the immiscible fluid heat transfer circulation loop; the higher viscosity materials emulsifying and circulating more of the heat storage materials. These salt hydrates carried by the immiscible fluids crystalize on the cool heat exchanger surfaces, reducing the efficiency of the heat exchanger and otherwise clogging-up the immiscible fluid heat transfer loop. Filtering devices can reduce, but apparently not entirely eliminate, this carry-over.

Another representative system is shown in Figure 15. This immiscible fluid, phase change, "heat storage battery" was developed by the International Thermal Instrument Company [22]. The patented concept utilizes an immiscible fluid and a salt hydrate contained in a sealed vessel. The immiscible fluid does not leave the container and the heat is injected and extracted by means of a separate 

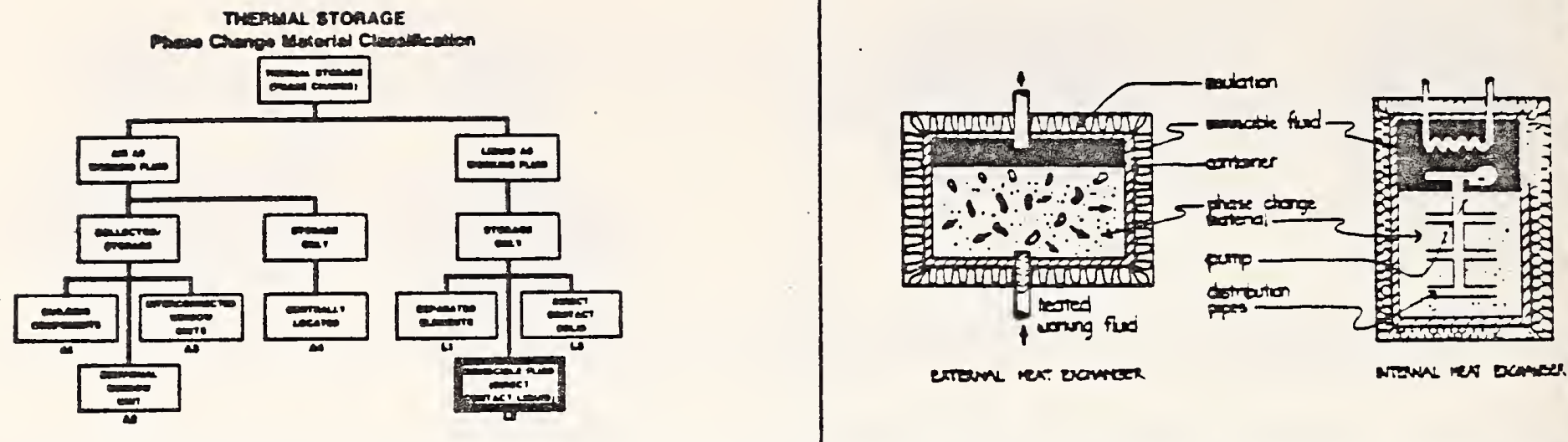

emulsion impeller

optional electrical heating elements emulsion/salt interface

salt hydrate
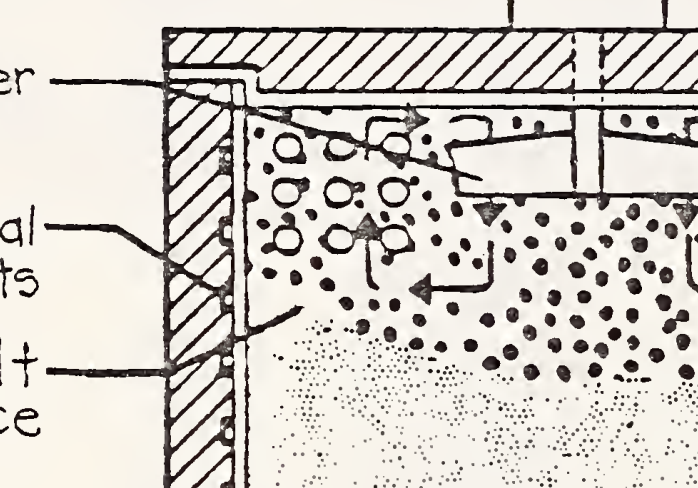

$130,0,0: C$

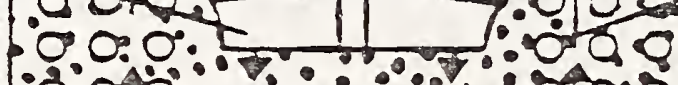
$\left.\int_{0}^{-}-0\right) 02$
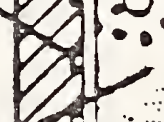

thermal charging/ extraction heat exchanger 
heat exchanger contained within the vessel. A propeller, driven by an external source, constantly stirs the salt hydrate/immiscible liquid emulsion, facilitating the heat transfer between the salt hydrate and the immiscible fluid and the Imiscible fluid and the internal heat exchanger. The working fluid entering and leaving the tank and flowing through the internal heat exchanger is water or a water/ ethylene glycol solution.

Because the immiscible liquid is of lower density than the salt hydrate, it remains at the top of the salt solution. Since the crystallization of the phase change material occurs basically at the emulsion/salt hydrate interface, no crystal deposit occurs at the heat exchange surfaces. Heat could also be supplied to the device through electrical heating elements wrapped around the circumference of the container, accommodating off-peak electrical power usage.

A third immiscible fluid (direct contact liquid) system is shown in Figure 16. This Solarmatic Heat Battery was developed by Solarmatic, Inc. [23]. This system may be characterized as a tank holding a salt hydrate in the lower two-thirds of the vessel and a less dense immiscible fluid in the top portion of the vessel. A central pipe is inserted into the salt hydrate material with a series of spiked, radial outlets provided at several levels. Included is an immersible pump near the top of the tank to pump the immiscible heat transfer fluid down through the spiked radial outlets. The heat transfer fluid interacts with the salt hydrate as it is discharged from the various outlets and bubbles to the top of the tank.

The outlets at the various levels have spring-loaded check valves with graduated pressure adjustments so that the salt hydrate melts in downward steps. With the salt hydrate in solid form, the pumped immiscible fluid only discharges through the highest series of outlets embedded in the solid. As the salts are melted around these outlets, the check valves allow the immiscible fluid to be discharged through the next row of outlets. This process continues downward until all the outlets are discharging the heat transfer fluid and all the salt hydrates melted. The immiscible fluid discharge mode is reversed during the cooling (heat discharge) process.

The system also contains a fluid separator several inches thick which "floats" on the salt hydrate/immiscible fluid interface. This device is a filter to keep the salt hydrate from the immiscible fluid reservoir at the top of the tank. A heat exchanger inside the vessel and immersed in the immiscible fluid reservoir transfers heat to and from the storage system.

The salt hydrate used is sodium sulfate decahydrate $\left(\mathrm{Na}_{2} \mathrm{SO}_{4} \cdot 10 \mathrm{H}_{2} \mathrm{O}\right)$ with a lowviscosity oil used as the immiscible fluid. The operating range of this device in the phase change mode is approximately $90^{\circ} \mathrm{F}$. Other salt hydrates may be used in this system, provided the two fluidic materials are immiscible and otherwise compatible. 

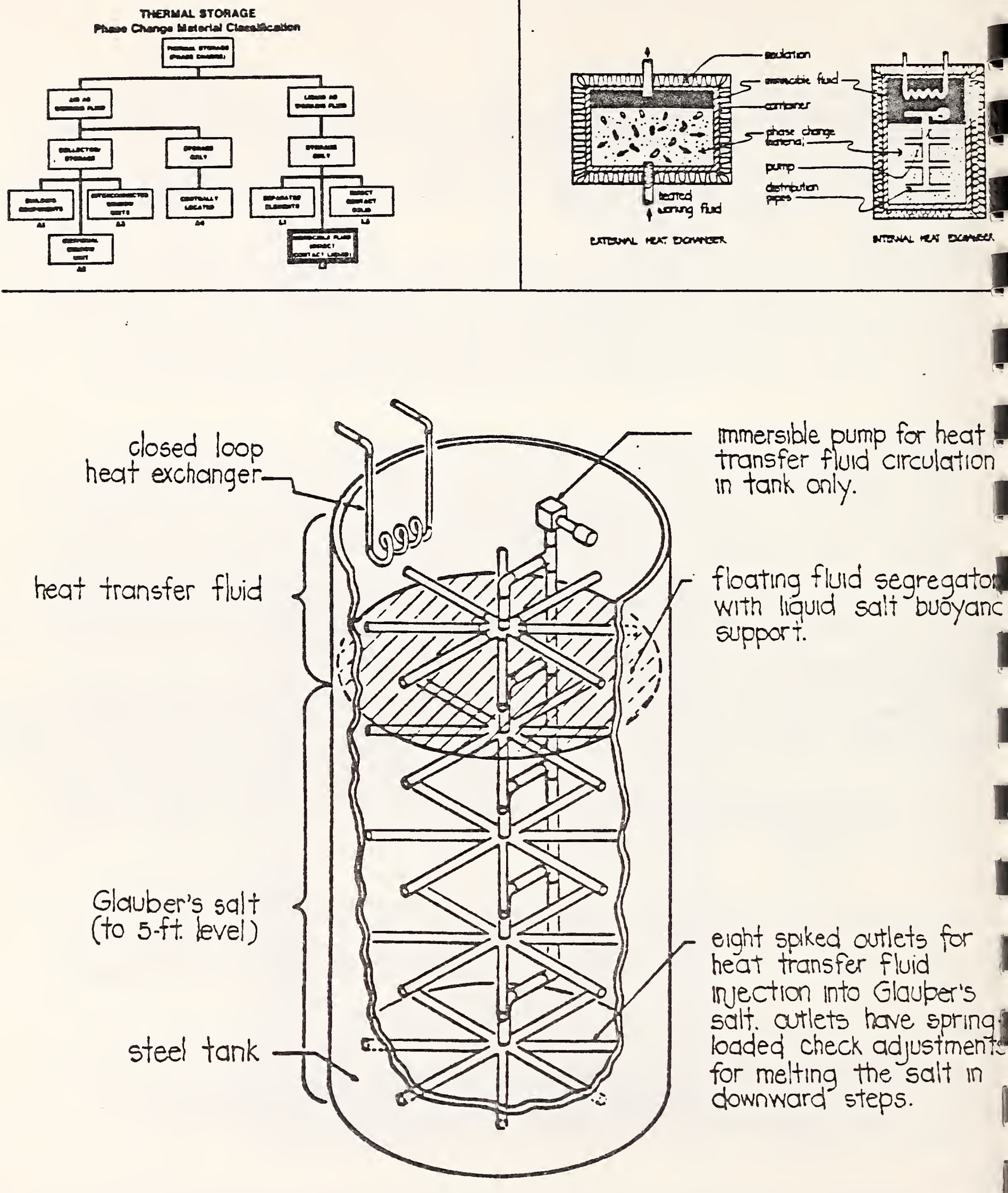

SOLARMATIC HEAT BATTERY

Figure 16 


\subsubsection{Direct Contact Solid (Storage On1y)}

This category is another grouping of direct contact phase change thermal storage systems. The working fluid in this type of system is not channelled through its own circuit and is therefore not separated from the phase change material by a physical barrier. The system is a direct contact solid system, characterized as such because the phase change material is packaged into small solids which are deposited within the working fluid. These phase change particles are often viewed as a phase change slurry, carried by the working fluid, even though the phase change particles may be physically constrained within defined bounds. These phase change solids are in direct contact with the working fluid and present a large surface area to facilitate efficient heat transfer. Although in some applications the phase change solids have an outer surface which, in effect, encapsulates the material and separates it from the working fluid, the encapsulating shell will not be defined here as a physical barrier. Encapsulated paraffin wax is one example of this type of material.

The working fluid would normally be water or an ethylene glycol/water solution, although other working fluids could be used as long as they were compatible with both the phase change material and the requirements of the system. Consideration must also be given to any interface between the working fluid and the potable water supply in order to prevent the possibility of contamination of the water supply in the event of system failure. Precaution must be taken even if the working fluid is itself water and considered potable in quality. A hazard could develop if the encapsulating shell or phase change material were to degrade and be carried as contaminating particles by the working fluid through its circulating loop.

The schematic configuration of this system category is shown in Figure 17. The solid phase change materials are shown contained in an insulated vessel with openings provided to allow the working fluid to enter and exit. Filters or screens may be installed to contain the phase change pellets within the insulated vessel, and diffusers may be included in the design to establish a more uniform distribution of the working fluid through the container. Configurations and systems are also possible which move the encapsulated phase change material as a "slurry" through its own circulating 1oop. Systems such as these may require special pumps to prevent damage to the encapsulated material and perhaps special heat exchanges in order to facilitate practical operation of the system.

Figures 18 and 19 provide two examples of direct contact solid phase change systems. Figure 18 is a schematic of a form - stable, high density polyethylene pellet bed system developed by Monsanto Research Corporation [24]. A description of the phase change material is contained in Section 2.4.1. The material, in the form of small pellets, has the unusual property of being form stable; i.e., it does not deform or flow but rather retains its pellet shape even when melted. When applied to an operating system, these pellets would be housed in a container and the working liquid pumped through the container so that it directly contacts the solid pellets as it passes through. 


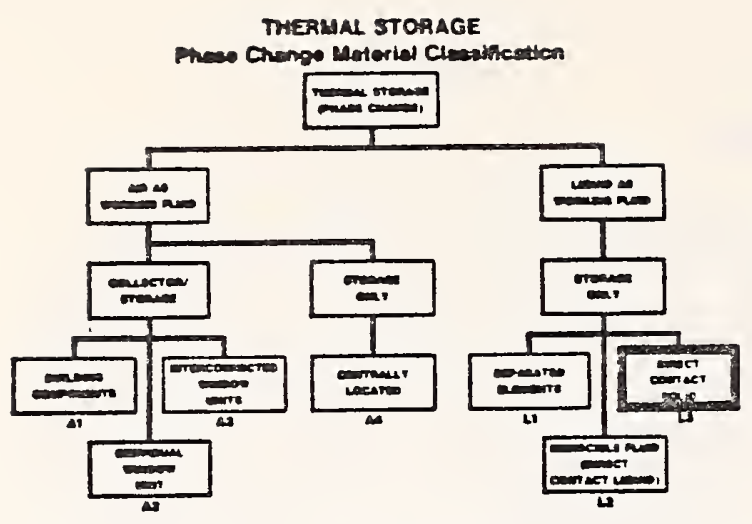

STORAGE ONLY

DIRECT CONTACT SOLID

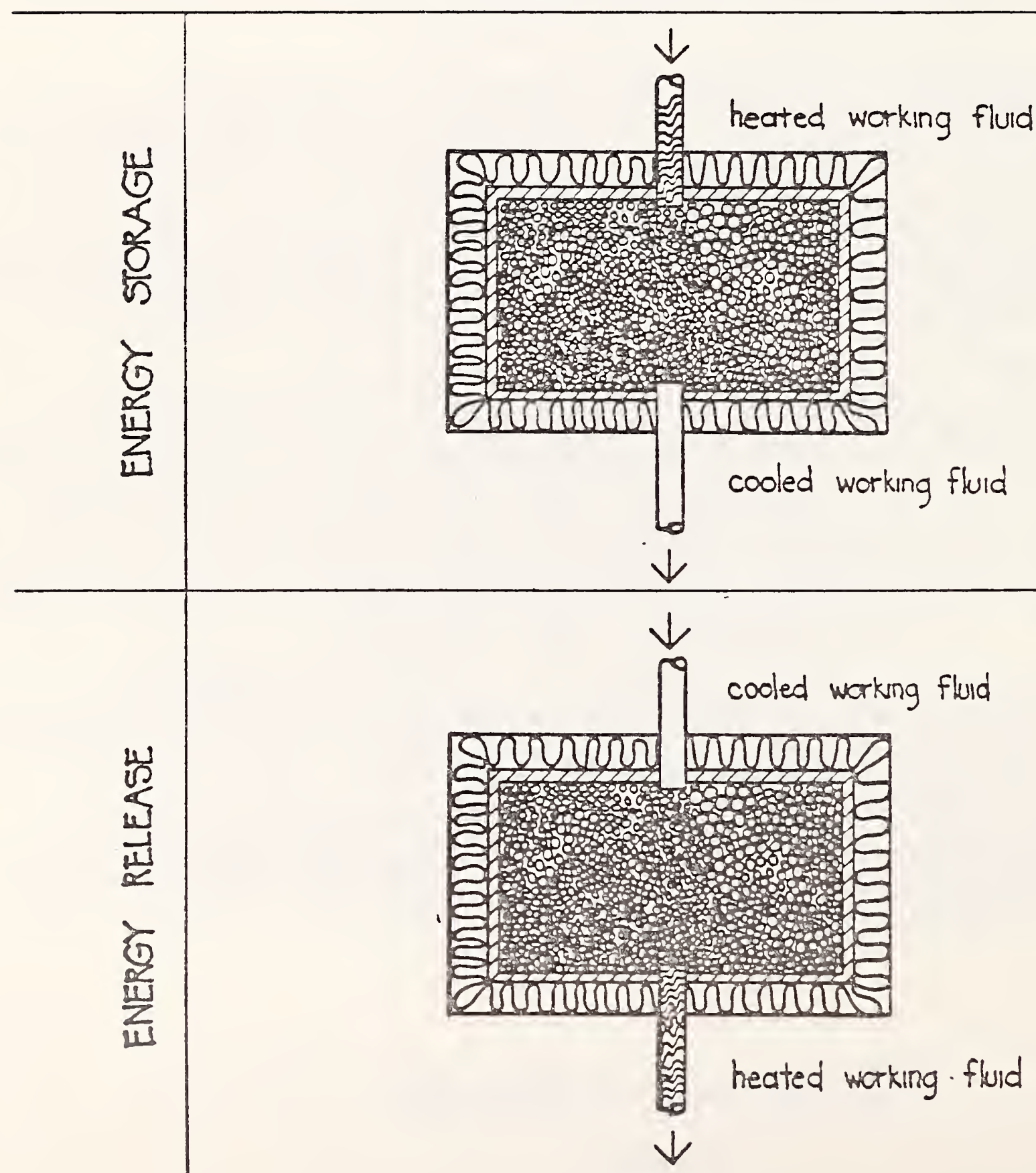

Figure 17

$-42-$ 

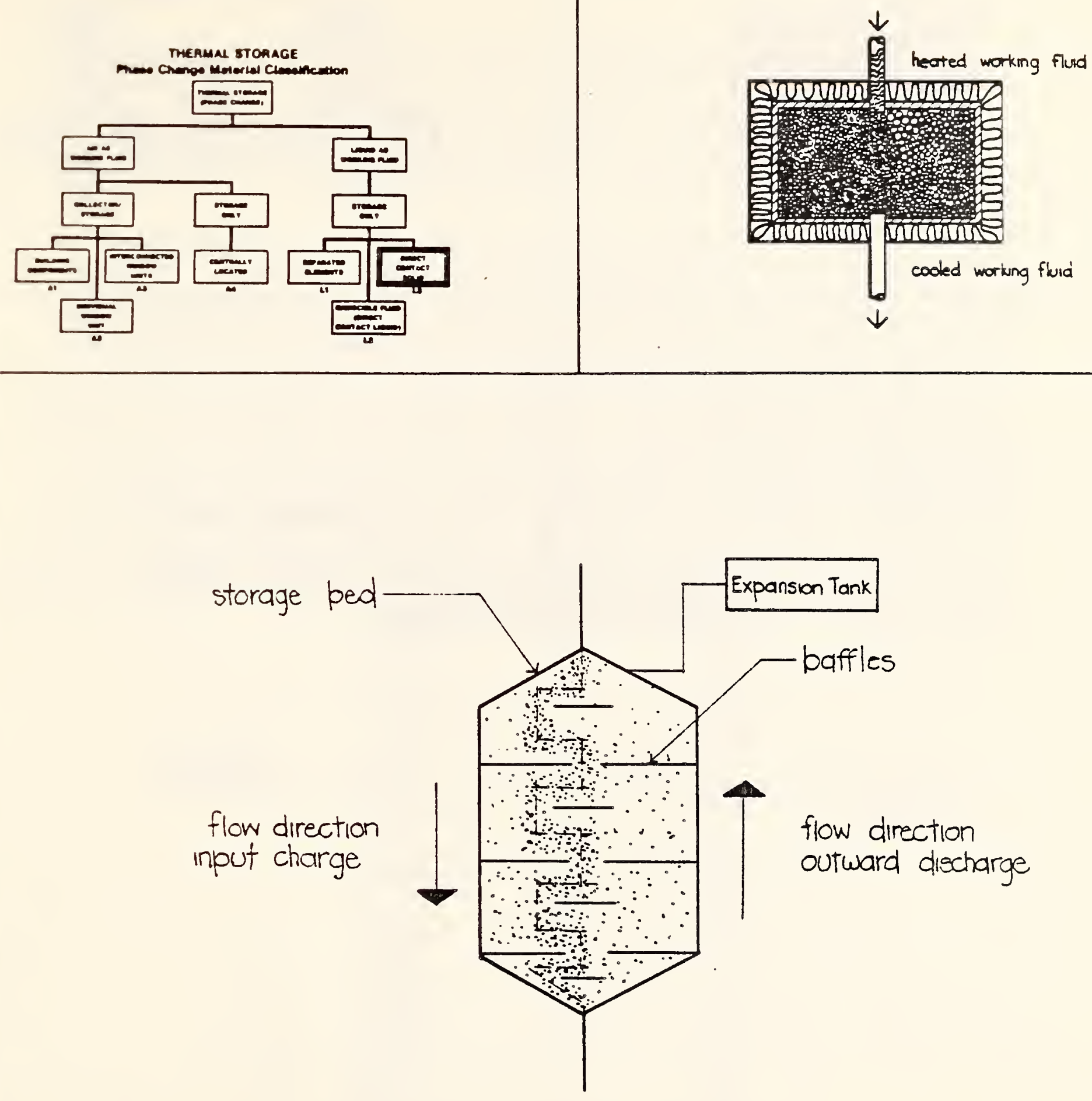

\section{FORM-STABLE, HIGH DENSITY POLYETHYLENE PELLET BED}


When operating in the storage mode, the hot working fluid would transfer some of its heat to the pellets as it passes through the container; the container baffles would encourage the hot fluid to contact all of the phase change pellets, regardless of location within the tank. To recover the stored heat, cooler fluid would be pumped through the vessel, causing the pellets to "give-up" their heat to the working fluid.

Another example of a direct contact solid phase change system is shown in Figure 19. This configuration is intended for use with the Two Component Thermal Storage Material described in 2.4.2, [25]. This system basically uses small pellets of incapsulated paraffin. Although the configuration shown was solely developed for testing purposes, some of its features might be incorporated into operational systems. The configuration consists of a container to house the encapsulated phase change material and an inlet and exit port for the working fluid. Because the working fluid must pass through the material, the pellets must be sized so that they are not too small to unreasonably raise the pumping requirements of the system, nor must the pellets be too large to prevent a sufficient volume of material to be packaged in a given space. This test configuration provides injector holes to distribute the working fluid and a fine screen to prevent broken pellet pieces from traveling through the working fluid loop. The system, however, regardless of final configuration or refinements, clearly falls into the direct contact solid phase change category. 

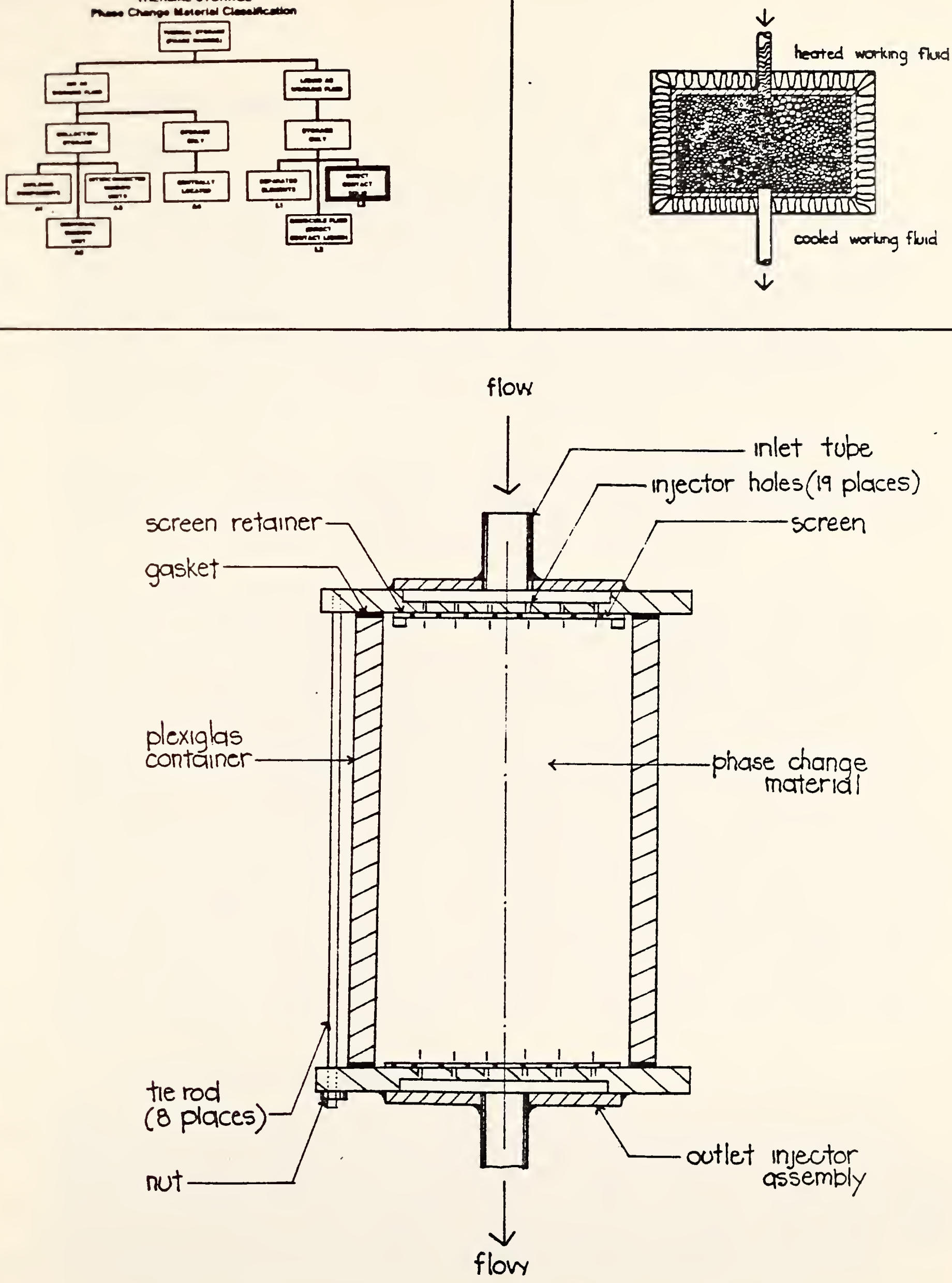

TWO COMPONENT THERMAL STORAGE SYSTEM (TEST CONFIGURATION) 


\subsection{OVERVIEW}

A building code is a legal document which sets forth requirements for the construction of buildings and structures in order to protect the public health, safety, and general welfare of building occupants. Historically, the United States has elected not to legislate a national, federally mandated, building code, the enactment of building codes being reserved as a function of state government. The states, in turn, may choose to enact overall mandatory state codes, may enact no codes at all, or may delegate their enforcement powers with regard to building codes to the various local jurisdictions within the state. In addition, major cities may establish their own codes tailored to their particular needs and circumstances.

Because of this freedom, the building code development process in the United States is quite complex and has resulted in a considerable diversity of substantive provisions among the thousands of locally enacted codes. This is true even though three-quarters of these locally enacted codes are based on model codes developed by model building code organizations.

The delegation by states of their code enactment authority to local governments has never been complete. Within the past several years, many states have assumed more active roles in writing, promulgating, and enforcing building codes. A growing minority of states have withdrawn virtually all authority to enact building codes from their municipalities. Presently, about half of the states have enacted some type of statewide building code authority which affects approximately half of the nation's population. Most of these codes are mandatory statewide, but in several states their adoption by localities is voluntary. The nature of the codes also varies. Codes may be written to only include minimum requirements or, on the other hand, they may include both maximum and minimum requirements. When a statewide minimum code is provided, the locality is generally free to adopt stricter requirements. However, if the statewide code is of the minimum/maximum type, the locality must secure state approval for its proposed change on the basis of some unusual condition or special need in the locality. Statewide code enforcement is usually delegated to the local authority with some supervision, training, and assistance from the state. Within single municipalities, the authority to enforce codes may be fragmented among different departments without coordinated supervision. These conditions cause considerable variation among localities in the interpretation of similar code requirements.

\subsection{MODEL BUILDING CODE ORGANIZATIONS}

Except for some of the largest cities, drafting of building codes in the United States is generally accomplished by model building code associations and allied groups. These model building code organizations are private entities whose membership include code officials and others interested in building codes and their provisions. The building codes developed by these organizations generally focus on health and safety. The provisions contained in the model codes are updated periodically through a complex process involving a vote of the membership. 
The nodel codes developed by these organizations have no weight of law. They are rightfully "models" and serve as a guide to the various code-adopting jurisdictions in enacting their own legislation. These jurisdictions may enact all or part of a model code, or elect to change some of the provisions. Even after adoption, subsequent changes to the model code may not even be considered for enactment by the code-adopting jurisdiction, while other changes may be adopted in whole, in part, or revised.

It also should be noted, that topical provisions of various model codes are not always uniform. They may vary in format and organization and, although they generally cover the same subjects, comparable provisions do not always specify the same quantitative measures. In some cases, different subjects are given greater emphasis and, in other cases, certain topics contained in one code are completely absent from the others. Even with this diversity, the model codes, on an overall basis, are more alike in content than not. Their differences, nevertheless, are reflected in the diverse range of provisions actually enacted into law by the code regulating jurisdictions.

There are three major model code organizations in the United States. They are regionally located and have membership controlled by code enforcement officials from local government. These model code organizations are:

BOCA - Building Officials and Code Administrators International, Inc. ICBO - International Conference of Building Officials; and

SBCC - Southern Building Code Congress International, Inc.

The Basic Building Code is published by the Building Officials and Code Administrators International, Inc. (BOCA) and is extensively used in the Midwest, New England, and the Middle Atlantic States. The Uniform Building Code, developed by the International Conference of Building Officials, (ICBO) is currently used extensively on the West Coast and in the Central Midwest. The Standard Building Code, prepared by the Southern Building Code Congress International, Inc. (SBCC), is the dominant building code in the Southern States.

BOCA, ICBO, and SBCC revise their codes annually and publish new code editions every three years. Generally, this allows the model codes to be updated to permit the use of new materials and techniques in building construction. Two other impor tant functions provided by these model code associations are those of plan review and product approvals. Product approval allows a manufacturer to get a single appro which can generally apply at all locations where the model code is used.

Another model code not listed above is the National Building Code, developed by the American Insurance Association (AInA). This code is not as inclusive as the previously mentioned model codes since it emphasises only building and mechanic. aspects. In addition, the AInA does not offer the supporting auxiliary services provided by the three model code groups. The National Building Code has not been updated since 1976; however, provisions included in this code are found in codes adopted by many jurisdictions. In 1984, an agreement between BOCA and AInA transferred title rights of the National Building Code to BOCA.

In addition to the above, two specialized model codes must be included. One is the Uniform Plumbing Code developed by the International Association of Plumbing and Mechanical Ufticials (IAPMO) in conjunction with the ICBO organization, and the second is the National Standard Plumbing Code developed by the National Association of Plumbing, Heating, Cooling Contractors (NAPHCC). 
The model code organizations and the various codes that they publish are summarized in Figure 20. The Building Codes, Mechanical Codes, and Plumbing Codes are emphasized in this chart because they form the basis of the code analysis in this document. It should be noted that the inclusive family of codes which regulate design, construction, and use of buildings and equipment contained therein is generally referred to as the Building Codes. of that family, those codes which specifically address structural and other related building components are also called Building Codes. These specific 'structural' Building Codes, together with the Mechanical Codes, Plumbing Codes, and other special codes, comprise the total Building Code. As can be seen from Figure 20, there are four model building codes, three model mechanical codes (with mechanical provisions incorporated into the National Building Code), and five model plumbing codes. The other codes are included to show the overall scope and range covered by each model code organization.

\subsection{BUILDING CODES AND PHASE CHANGE THERMAL ENERGY STORAGE SYSTEMS}

In reviewing the model building codes, the absence of any reference to thermal energy storage devices incorporating phase change systems becomes apparent. This absence is a result of the complex and time consuming nature of the code change process and its tendency to incorporate only those technologies which are used typically within the building industry. Since phase change thermal energy storage systems technology and its application in building construction are still developing, wide acceptance within the building industry and direct code reference to phase change thermal energy storage systems could be expected to lag behind the already achieved knowledge and experience in their useful application. This has been true for other innovative materials systems within the building industry.

Wide acceptance of a developing technology within the building industry and direct code reference to that technology are very closely linked. Although direct code reference to a new technology is normally a result of its wide acceptance, it has been often shown that code reference to a developing technology will facilitate and therefore stimulate its use. The development and acceptance of solar energy technologies are a case in point. As solar energy systems became more attractive as a source of renewable energy, building officials were faced with the problem of evaluating the safety of solar installations through their existing codes. This effort was difficult, at best, since the existing codes gave no guidance regarding the proper design, installation, and operation of solar systems. This difficulty in determining code compliance inhibited many from approving the use of these systems.

Efforts to stimulate the development of solar energy were directed toward solving this dilemma. After several years of effort, and with the encouragement of the U.S. Department of Energy, the document "Recommended Requirements to Code Officials for Solar Heating, Cooling and Hot Water Systems" was developed by the Council of American Building Officials (CABO). This document was adopted in whole or in part by at least one model building code organization and several local jurisdictions.

The "Recommended Requirements to Code Officials for Solar Heating, Cooling and Hot Water Systems" is intended to supplement and be an integral part of the three major model codes. Although this document does address thermal storage, emphasis is placed on the use of water and rocks as the storage media. The building official is still left on his own to address and evaluate the new technology of phase change thermal storage systems. 


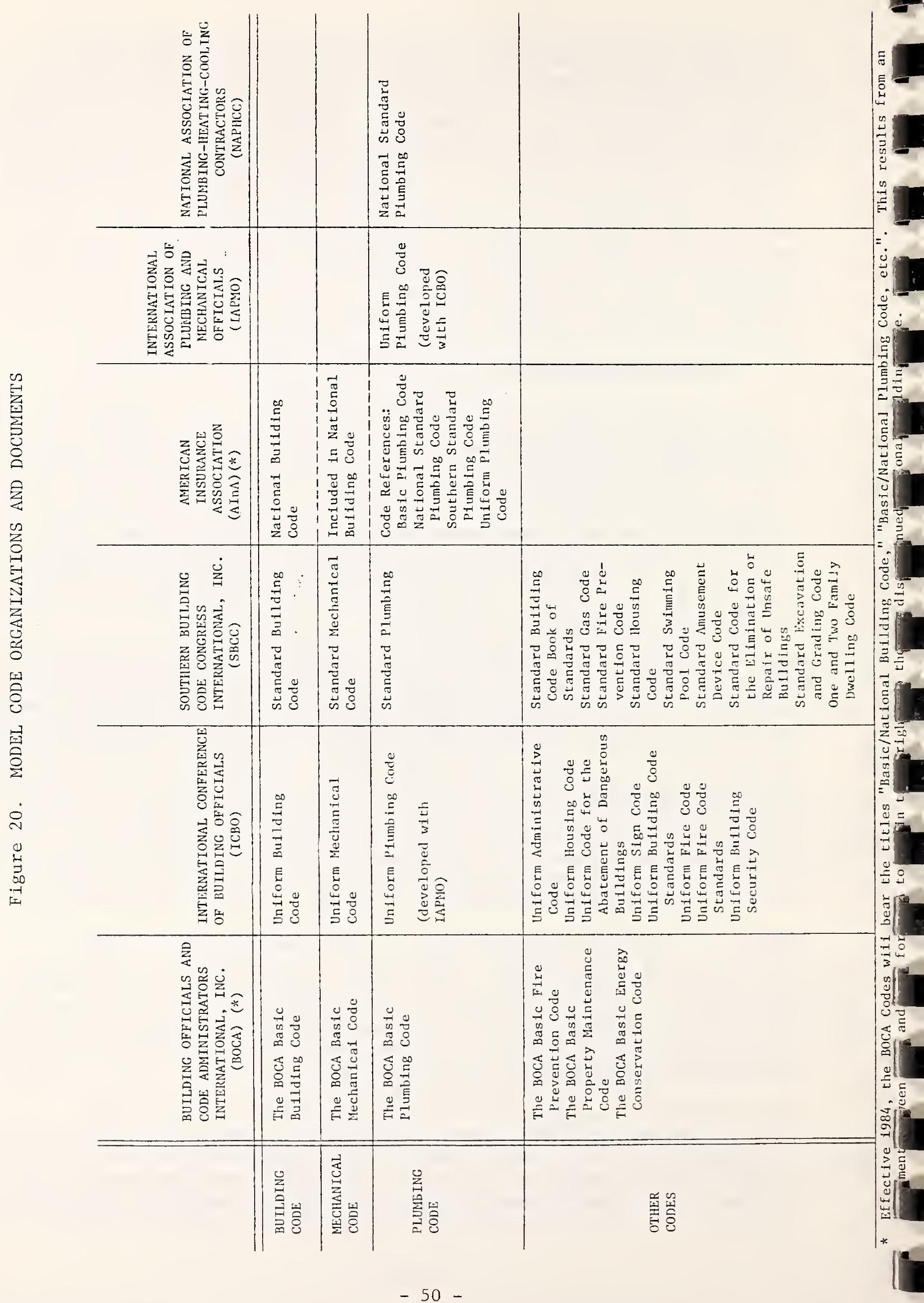


The purpose of this report, and in particular, the following chapters, is to assist the code official in identifying those provisions in existing codes which might be pertinent to evaluating phase change materials and systems for code compliance. It is also intended to aid designers and manufacturers in their development of phase change thermal energy storage systems that display health and safety characteristics compatible with the intent and spirit of present code requirements. As experience is gained with the design and application of phase change systems by interpreting existing code provisions for evaluation purposes, it is contemplated that future efforts will develop code provisions which directly address phase change materials and systems.

The following chapters are oriented to the three types of codes that effect phase change thermal storage devices and to those specific code documents which would be used by building officials to evaluate the phase change devices. The types of codes addressed are the Building Codes, the Mechanical Codes, and the Plumbing Codes. Each chapter of the code documents addressed is defined according to its provision topics. Only those code provisions which are relevant to phase change thermal storage systems have been included. Each provision topic is summarized as to intent; the specific requirement described and the possible interpretation and problems anticipated in evaluating a particular phase change thermal energy storage system are described. Actual interpretations, of course, will depend on the complexity of the phase change system and the background and experience of each particular building official in evaluating the merits of the provision topic addressed.

It also should be noted that the code provisions are identified by their sponsoring organization rather than by code title. This is to avoid the confusion that arises when the code titles do not always reflect the codes association with the sponsoring organization. For example, the model codes developed by ICBO generally carry the title "Uniform" as part of the code nomenclature, i.e., Uniform Building Code, Uniform Mechanical Code, Uniform Fire Code, etc. However, the "Uniform Plumbing Code" was developed jointly by ICBO and IAPMO (see Fig. 20). Also the "National Standard Plumbing Code" developed by NAPHCC has no affilitation with the "National Building Code" developed by AInA.

\subsection{THE MODEL BUILDING CODES}

The Model Building Codes referred to here are those codes which specifically address structural and other related building components.

In the taxonomy proposed for phase change thermal energy storage systems (see Section 3.2 and Figure 1), these Model Building Codes, in their local application, would be used by the code official to evaluate phase change systems that are classified as Building Components (Al). Other classifications of phase change thermal energy storage systems which relate directly to the building's structure may also be regulated by these Codes.

Section 5 of this report describes those topics and provisions contained in the Model Building Codes that would impact phase change thermal storage systems classified as Building Components. This would include components such as structural walls and ceiling configurations that contain phase change materials. Any phase change devices which would be intrinsic to the structure 
of the building and required to maintain structural integrity would be subject to evaluation by the topics and provisions contained in Section 5 along with structural requirements for the components of liquid phase change systems.

Topics in Section 5 include the purpose and scope of the Model Building Codes, definitions, and a variety of technical topics which could relate to phase change thermal energy storage systems and their application in buildings. Generally, only health and safety topics are included, as this is the thrust of the Model Building Codes and the mandate for enforcement by building code officials. Performance and durability, however, are also addressed indirectly through the required or prohibited use of certain materials or practices.

The Model Building Codes addressed in Section 5 are:

The BOCA Basic Building Code (BOCA) - 1981

The Uniform Building Code (ICBO) - 1982

Standard Building Code (SBCC) - 1982

National Building Code (AInA) - 1976

Each of the Model Building Codes above is an independent, self-contained code document that only addresses structural or other related building component issues. Provisions for mechanical and plumbing systems are contained in other separate documents that are produced by the sponsoring organization.

The National Building Code, however, is unique in that the scope of that single AInA code also includes provisions for heating, ventilating, and air conditioning systems. Although the National Building Code also contains a plumbing section, it consists of references to other codes, and no provisions per se are included.

The appendix (see Appendix A) includes a table of contents for each of the Model Building Codes, indicating those provisions which are applicable to phase change thermal energy storage systems, with references to the provision topic in this report which discusses that particular issue.

\subsection{THE MODEL MECHANICAL CODES}

The Model Mechanical Codes generally address those components of equipment installed in a building that relate to the building's heating, cooling, and ventilation systems. These codes would generally be applicable to those phase change systems which use air as the working fluid.

In the taxonomy proposed for phase change thermal energy storage systems (see Section 3.2 and Figure 1), this type of phase change system could be classified as:

Individual Window Unit (A2)

Interconnected Window Units (A3)

Centrally Located Units (A4) 
Note that although the Building Components classification (Al) is also dependent upon air as the working fluid, this system type is more appropriately covered by the Model Building Codes, as described in Section 4.4 above.

Section 6 of this report describes those topics and provisions contained in the Model Mechanical Codes which impact phase change thermal energy storage systems classified as Individual Window Units, Interconnected Window Units, and Centrally Located Units. Some of these units may serve as collectors, as described in Section 3. Some may also have structural characteristics in order to practically integrate them within the building configuration. In this case, provisions from the Model Building Codes may also be applicable.

Topics covered in Section 6 include the purpose and scope of the Model Mechanical Codes, definitions, and a variety of technical topics related, in some reasonable manner, to phase change thermal storage systems. Generally, only health and safety topics are included, as this is the thrust of the Model Mechanical Codes and the mandate for enforcement by the mechanical code officials. Performance and durability, however, are addressed indirectly through the required or prohibited use of certain materials or practices.

The Model Mechanical Codes that are addressed in Section 6 are:

The BOCA Basic Mechanical Code (BOCA) - 1981

Uniform Mechanical Code (ICBO) - 1982

Standard Mechanical Code (SBCC) - 1982

National Building Code (AInA) - 1976

Each of the Model Mechanical Codes shown above is an independent, selfcontained code that generally addresses mechanical systems and other related items. The National Building Code, developed by AInA, although basically a building code, nevertheless includes mechanical provisions. It is therefore included with the other Model Mechanical Codes.

The appendix (see Appendix B) includes a table of contents for each of the Mode? Mechanical Codes addressed. This table indicates which provisions are applicable to phase change thermal energy storage systems, and references the provision topic in this report which discusses that particular issue.

\subsection{THE MODEL PLUMBING CODES}

The Model Plumbing Codes address those components of equipment installed in a building that relate to plumbing systems. The code, however, also includes hot water systems along with provisions applicable to hydronic (hot water) heating systems.

Those phase change thermal energy storage systems using a liquid as the working fluid would fall under the aegis of the Model Plumbing Codes. In the taxonomy proposed for phase change systems (see Section 3.2 and Figure 1), this kind of phase change system would be classified as:

Separated Elements (L1)

Direct Contact Liquid (Immiscible Fluid) (L2)

Direct Contact Solid (L3) 
These systems also fall under the purview of the Plumbing Codes because of their direct or indirect interface with the buildings potable water supply. The responsible plumbing official would find it essential to protect the water supply through the enforcement of the established safeguards.

Section 7 of this report describes those topics and provisions contained in the Model Plumbing Codes which impact phase change thermal storage devices that use a liquid as the heat-conveying medium: the Separated Element system, the Direct Contact Liquid system, and the Direct Contact Solid system.

Topics covered in Section 7 include the purpose and scope of the Plumbing Code, basic principle of plumbing systems, definitions, and a variety of technical topics related to phase change thermal storage systems. As in the other codes, generally only health and safety topics are included. Performance and durability, however, are addressed indirectly through the required or prohibited use of certain materials or practices.

The Model Plumbing Codes that are addressed in Section 7 are:

The BOCA Basic Plumbing Code (BOCA) - 1981

Uniform Plumbing Code (ICBO/IAPMO) - 1982

Standard Plumbing Code (SBCC) - 1982

National Standard Plumbing Code (NAPHCC) - 1983

Each of the Model Plumbing Codes shown above is an independent, selfcontained code. The BOCA Basic Plumbing Code and the Standard Plumbing Code are a part of a family of building, mechanical, plumbing, and special codes prepared by BOCA, and SBCC respectively. The Uniform Plumbing Code, developed jointly by the International Association of Plumbing and Mechanical Officials (IAPMO), and the International Conference of Building Officials (ICBO), is also part of a family of building, mechanical, and special codes developed by ICBO. The National Plumbing Code, developed by the National Association of Plumbing-Heating-Cooling Contractors (NAPHCC) is a single topic code. The AInA's National Building Code, although containing no plumbing code provisions, references the Basic Plumbing Code, the National Standard Plumbing Code, the Standard Plumbing Code, and the Uniform Plumbing Code.

The appendix (see Appendix $C$ ) includes a table of contents for each of the Model Plumbing Codes which are addressed in this Section. This table indicates which provisions are applicable to phase change thermal energy storage systems, and references the provision topic in this report which discusses that particular issue. 
5. TOPICS AND PROVISIONS OF THE MODEL BUILDING CODES RELEVANT TO PHASE CHANGE SYSTEMS

\subsection{OVERVIEW}

This section addresses those provisions contained in the Model Building Codes that would impact phase change thermal storage systems when they are integrated into the temperature comfort conditioning systems in buildings. Each of the issues presented is organized into a "provision topic" which aggregates the code information related to that topic. Provisions common to more then one code are quickly recognized and the degree of commonality or divergence between codes is easily distinguished. Each provision topic is discussed from a code perspective and the impact of these issues upon system design and installation is provided.

A "reference" designator is also included in the heading of each provision topic which keys to the Appendix. In the Appendix, each of the model codes are shown. The topics discussed in this report are cross-referenced to the table of contents of each of the model building codes. In this format, the user of the Appendix is directed by the code reference to the applicable provision topic found in the report. In addition, the "applicability" boxes shown in the heading of each provision topic refer to the appropriate phase change material classification, as shown in Figure 1, and as defined in the text.

The material presented on the following pages, although paraphrased, is based on the model codes referenced under each provision topic. These model codes are copywritten material published periodically by each of the model code organizations (see page 50 for a complete listing of these codes and the names of the parent organizations). The user should refer directly to the source document(s) applicable to the jurisdiction in question if specific provisions are required for design, installation, maintenance, or other needs. 


\subsection{TOPICS AND PROVISIONS}

B-A Purpose and Scope

$B-B$ Definitions

$B-C$ Maintenance

B-D Alternate Measures

B-E Approved Materials and Equipment

B-F Review of Plans and Specifications

$B-G$ Light Transmitting Plastics

B-H Foam Plastics

B-I Thermal Insulating Materials

$\mathrm{B}-\mathrm{J}$ Glass

$\mathrm{B}-\mathrm{K}$ Testing

B-L Emergency Egress

$B-M$ Light and Ventilation

$\mathrm{B}-\mathrm{N}$ Design Loads and Tests

B-0 Fire Resistive Ratings

B-P High Hazard Buildings

B-Q Miscellaneous 


\section{$\mathrm{B}-\mathrm{A}$}

PURPOSE AND SCOPE

Al

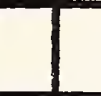

(SEE FIG. 1)

Each of the building codes includes a statement regarding the purpose and/or scope of the code. Although only the ICBO and AInA Codes include statements that the purpose of the code is to provide for safety, health, and public welfare, this is the usual function of a code and this can be construed as applying to the BOCA and SBCC Codes as well. Also, as is true of most codes, efficiency, economy, effectiveness, or durability are generally not issues; however, the above attributes are usually influenced in a positive manner through the control of design, material, and installation.

Although not readily distinguishable by the specific code provisions, the AInA Building Code is unique as compared to the other building codes in that the scope of that single AInA code includes provisions for heating, ventilating, and air-conditioning. These are covered by separate Mechanical Codes by the other model code organizations. Plumbing provisions, also contained in separate plumbing codes by the other model code organizations, are covered in the AInA by reference.

With regard to phase-change materials, the building codes directly affect those phase-change storage devices that are free-standing or building integrated. The remaining phase-change thermal storage devices which are operated in a more active mode and which use air or water for the heat transfer medium are generally covered by either the mechanical or plumbing codes. There is some interface, however, with the building codes even if no direct reference is made. This interface would generally be in the area of structural adequacy or integrity and perhaps fire protection to assure adequate building strength to support the added load of a heavy liquid filled phase-change thermal storage vessel and provisions for the installed ductwork to not contribute to the spread of fire or smoke.

\section{REFERENCES}

Organization

Code

Section

BOCA

ICBO

$\mathrm{SBCC}$

AInA
The BOCA Basic Building Code

The Uniform Building Code

Standard Building Code

National Building Code
100.2

$102 ; 103$

101.3

100.3 


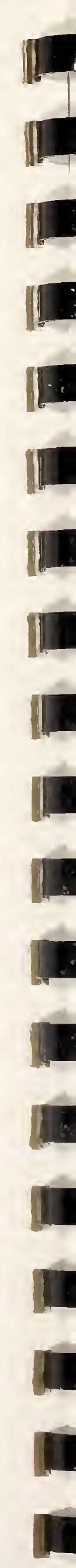




\begin{tabular}{l|l|l|l|l|l|l|l|l}
\hline B-B & DEFINITIONS & A1 & A1 & A3 & A4 & L1 & L2 & L3 \\
\hline
\end{tabular}

(SEE FIG. 1)

Each of the building codes contains a section on definitions to aid the user in understanding the code. When applying the information in this report the reader should refer to the specific code of interest, and if there is any doubt about the technical meaning of a word, the definition section of the code should be consulted. It should be noted, that many of the definitions in each of the building codes are identical while other definitions, although worded differently, are similar in intent. Some definitions for the same word in the different codes, however, contain subtle differences and nuances and should be read carefully for their full meaning and implication.

\section{REFERENCES}

Organization

Code

Section

BOCA

ICBO

SBCC

AInA
The BOCA Basic Building Code

The Uniform Building Code

Standard Building Code

National Building Code
201.0

402 through 427

201

200 


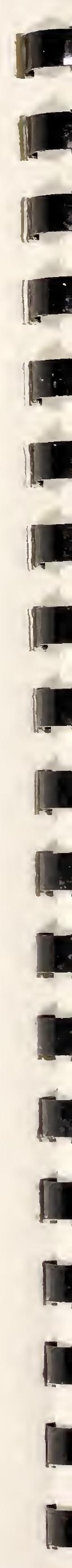




\begin{tabular}{l|l}
\hline $\mathrm{B}-\mathrm{C}$ \\
\hline
\end{tabular}

The building codes each contain provisions regarding building maintenance. These provisions require that the buildings and structures, both existing and new, be maintained in a safe and sanitary condition. In addition, all devices and safeguards required when the building was erected, altered, or repaired, are required to be maintained in good working order. The companion plumbing and mechanical codes also contain similar provisions and address repair and maintenance of heating, plumbing, and mechanical equipment with special restrictions oriented toward those devices.

The effect of the maintenance provisions on building integrated phase-change devices is unclear. One can expect phase-change thermal storage devices integrated with conventional heating components to be maintained in a manner consistent with good maintenance practice for conventional equipment. Phase-change thermal storage devices which are integrated into the building, however, may be considered in a different view. What maintenance provisions apply to a masonry wall or ceiling tile containing phase-change materials? Certainly, if a structural problem develops with these elements, the deficiency must be corrected to protect life; however, the codes also require that they remain in good working order. If one principally defines good working order as "structurally sound," then any decrease in working efficiency of the building integrated element is irrelevant with respect to the code. If, however, the building official interprets the meaning of these provisions to include efficient or effective working order, the phase-change element may have to be replaced.

\section{REFERENCES}

Organization

Code

Section

BOCA

ICBO

SBCC

AInA
The BOCA Basic Building Code

The Uniform Building Code

Standard Building Code

National Building Code
104.2

104 (d)

101.6

100.6 


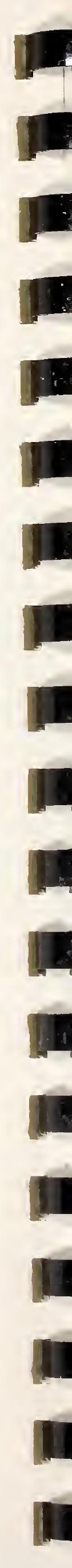




\begin{tabular}{l|l|l|l|l|l|l|l|}
\hline $\mathrm{B}-\mathrm{D}$ & ALTERNATE MEASURES & AI & & & \\
\hline
\end{tabular}

(SEE FIG. 1)

In each building code, there is an acknowledgment that there may be times when it is impractical for a designer or installer to follow the letter of each provision. In recognition of this, each code contains an alternate materials and methods provision which, in summary, states that the provisions of the code are not intended to prevent the use of any material, device, methods, etc., provided any such alternate has been approved and its use authorized by the building official. Further, the building official may approve such alternate materials and methods if he finds them to be in compliance with and at least the equivalent of the materials and methods prescribed in the code. In order to substantiate the proposed use of any material or method, the building official may require technical data to be submitted or tests to be made to demonstrate compliance. The tests may be required to be performed in accordance with generally recognized standards or a test procedure specified by the building official.

Because of their innovative character relative to commonly used and accepted building materials, innovative phase-change devices used as structural members or in other building integrated applications may have to qualify under the alternate measure provisions to be accepted by the building official. There is little guidance in the building codes to allow acceptance under an "approved" or "listed" clause of the code. With time, precedent setting approvals will make the building official's task easier. Until then, the building official may have little alternative than to insist that the designer or manufacturer of innovative building integrated phase change thermal devices prove, through test or otherwise, that the intent of the code is met. This could be a costly and time-consuming procedure and, in itself, may be impossible without some accepted test method. Although the codes allow tests to be made in the absence of generally recognized standards, the burden is generally on the building official to specify the test procedure to be used a rather formidable task for the individual building official since even simple test procedures developed by a committee of experts is an often complex undertaking.

\section{REFERENCES}

Organization

Code

Section

BOCA

ICBO

SBCC

AInA
The BOCA Basic Building Code

The Uniform Building Code

Standard Building Code

National Building Code
$101.3 ; 107.2 ; 107.4$;

$107.4 .1 ; 107.4 .2$

$105 ; 106$

$103.5 ; 103.6$

100.7 
The BOCA and AInA building codes contain specific provisions addressing the requirements for materials, equipment, and devices to be approved by the building official. The other building codes also contain these requirements although the provisions are not explicitly detailed as specific general provisions. To validate the use of innovative materials, testing may be generally required and all approved materials deemed necessary for structural safety are required to be identified by a distinctive brand mark or label.

With regard to building integrated innovative phase-change storage devices, it could be assumed that specific approval for use must be given by the building official. This would certainly be a requirement if the phase-change material also served as a loadbearing component of the building and its structural characteristics not well documented.

This requirement may also be critical in storage systems which also serve as collectors - both the individual "window" unit as well as the duct integrated devices. Since these systems must contain a glazing to allow solar radiation to impinge upon the phase-change container, approval of this glazing, from a fire viewpoint, may also be required for these phase-change storage systems. Most glazing materials, however, are plastics or glass, and experience with these materials may make approval for these applications relatively easy to obtain.

In any case, if approval cannot be obtained directly because of the proposed use of an innovative material or a unique application of a commonly used material, the phase-change storage designer or installer could have his system approved under the alternate material provisions; however, extensive testing may be required. Once these innovative systems mature, they may be listed by a recognized testing laboratory facilitating their approval for subsequent use.

\section{REFERENCES}

Organization Code Section

$\begin{array}{lll}\text { B The BOCA Basic Building Code } & 107.1 ; 1104.1 ; 1104.2 ; \\ & 1104.3 ; 1104.4\end{array}$




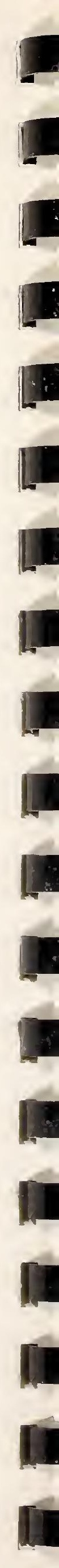




\begin{tabular}{l|ll|l|l|l|l|l|l|l|l|l|}
\hline B-F & REVIEW OF PLANS AND SPECIFICATIONS & A1 & A2 & A33 & & & \\
\hline
\end{tabular}

(SEE FIG. 1)

The building codes generally require that plans and specifications accompany applications for a permit. These plans normally are required to be drawn in sufficient detail to indicate the location, nature, and extent of the work proposed along with supporting engineering calculations, diagrams, and other data required to substantiate that the intent of the codes is met. The BOCA, ICBO and SBCC building codes also require that plans indicate how the required structural and fire-resistive integrity will be maintained when service systems penetrate critical structural or fire-resistive members. The BOCA code requires this only of buildings more than two (2) stories in height.

Several of the building codes also require the submitted material to be approved or signed by a licensed engineer or architect. BOCA requires that all engineering plans and computations bear the signature of the engineer or architect responsible for the design. SBCC requires all buildings or structures three (3) stories or more in height or five thousand square feet in area, except one and two family dwellings, and all buildings in use Group E-Educational, Group IInstitutional, and Group A-Assembly to be signed by an architect or engineer legally registered under the laws of the governing state.

All of the above may be waived by the building official if he finds the nature of the work is such that he can determine code compliance without these documents.

The satisfaction of these requirements is a necessary task for the designers of phase-change storage devices which interface strongly with the building structure or envelope. Phase-change devices which are building integrated may need evidence that the material, in both the quiescent and active state, is adequate to handle the structural loads imposed. Glazing usually forms a portion of the building envelope when used in thermal storage devices that also serve as collectors. The building official may require the necessary documentation to be submitted to assure that any fire integrity provisions are not violated. One can anticipate that designs that are innovative or unique to the building official would also have to be supported by testing if the supporting documentation is weak or speculative.

\section{REFERENCES}

Organization

Code

Section

BOCA

ICBO

SBCC

AInA
The BOCA Basic Building Code

The Uniform Building Code

Standard Building Code

National Building Code
$111.5,111.7$

$302(b), 302(c)$

$105.3(\mathrm{a}), 105.3(\mathrm{~b})$

$105.3(\mathrm{c}), 105.3(\mathrm{~d})$

102.6 


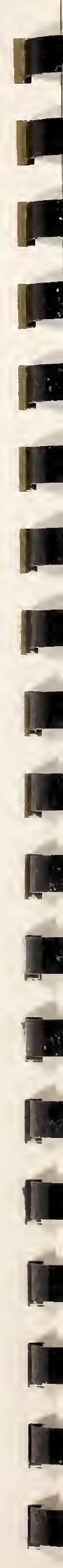




\begin{tabular}{l|l|l|l|l|l|l|}
\hline B-G & Light transmitting Plastics & A2 & A3 & & & \\
\hline
\end{tabular}

(SEE FIG. 1)

Light transmitting plastics are addressed in great detail in the BOCA, ICBO, and SBCC building codes. This material, along with glass (see Reference B-J), could be used as the glazing for phase-change storage devices which also function as collectors and include both the individual "window" units and those storage/ collector devices connected to the building.ductwork. The provisions addressed in this section have been grouped by subtopic for ease of discussion. Covered are such topics as (a) general information; (b) definitions; (c) design and installation; (d) glazing of unprotected openings; (e) exterior wall panels; (f) roof panels; (g) skylights; and (h) miscellaneous information.

\section{A. GENERAL}

The general provisions lay the framework for the specific requirements and subtopics that follow. They govern the quality and method of application for plastics used as light-transmitting materials in buildings and structures. The BOCA and SBCC codes require plastic materials used as interior finish to meet all the provisions concerning fire resistance of interior trim and finishes of a building. Regarding this issue, BOCA states that the use of a surface finish of paper or material of not a greater fire hazard than paper, is not prohibited provided such finish does not exceed $1 / 28$ of an inch in thickness, and is applied directly to a noncombustible base or substrate meeting BOCA requirements. The SBCC and BOCA requirements for interior finish are flame spread classifications which are based upon use or occupancy as set forth in each code. The SBCC and ICBO codes also state that light-transmitting plastic materials which meet the code requirements for walls and roofs can be used in accordance with other applicable requirements of the code.

The BOCA general provisions allow the use of plastics which meet the strength, durabilicy, sanitary, and fire resistive requirements of the code including flammability, thickness and ignition properties, smoke emission, and surface burning characteristics, when tested in accordance with ASTM D635, Standard Method of Test for Flammability of Self-Supporting P1astics; ASTM D374, Method of Test for Thickness; ASTM D1929, Method of Test for the Ignition Properties of Plastics; ASTM D2843, Standard Method of Test for Measuring the Density of Smoke from the Burning or Decomposition of Plastics; and ASTM E84, Method of Test for Surface Burning Characteristics of Building Materials. These standards are contained in Appendix A of the BOCA code. BOCA, ICBO, and SBCC codes require that application for approval of plastic materials must include technical data. BOCA states that this data should be all that is necessary as required by the building official, and may include chemical composition; pertinent physical, mechanical, and thermal properties such as fire resistance, flammability and flamespread; weather resistance; electrical properties; products of combustion and coefficients of expansion. ICBO requires that the submitted technical data substantiate the proposed use of the material. SBCC states that the plastic materials may be of any class as defined by the code, and that the technical data required to be submitted must relate to the proposed use of the material and shall include the pertinent physical, mechanical and thermal properties such as weather resistance, expansion coefficient and combustibility characteristics. The building official will determine the adequacy of the data. The BOCA, ICBO, and SBCC codes all require that the plastic materials approved for use be identified and marked accordingly. 
As applied to phase-change thermal storage devices which also serve as collectors, the general provisions need present no problem if an approved material is used. The collector/storage designer would generally be treated as if he designed a conventional "window" that was glazed with plastic. If a special plastic were required to focus, diffuse, or otherwise process the incoming sunlight, approval would be required along with all of the data, testing, and marking requirements.

\section{B. DEFINITIONS}

Although the building codes contain their own definition sections, the light transmitting plastics sections also contain definitions which specifically address this topic. The BOCA and SBCC sections contain identical definitions, both of which generally differ slightly from the ICBO code. Both BOCA and SBCC codes define an approved plastic as a thermoplastic, thermosetting or reinforced thermosetting plastic material which has a self-ignition temperature of $650^{\circ} \mathrm{F}$ or greater when it is tested in accordance with ASTM D1929, "Standard Method of Test for Ignition Properties of Plastics," a smoke density rating which is no greater than 450 when the material is tested in the way it is intended for use in accordance with ASTM E84, "Standard Method of Test for Surface Burning Characteristics of Building Materials," or a smoke density rating no greater than 75 when the material is tested in the thickness intended for use by ASTM D2843, "Standard Method for Measuring the Density of Smoke From the Burning or Decomposition of Plastics." Approved plastics are also defined by the BOCA and SBCC codes as those products of combustion which are no more toxic than those of untreated wood when burned under similar conditions and which meet one of the following combustibility classifications. Class $\mathrm{C}-1$, or CCI is a classification of plastic materials which have a burning extent of one inch or less when they are tested in a nominal .060 inch thickness by ASTM D635, "Test for Flammability of Self-Supporting Plastics." Class C-2, or CC2 is a classification of plastic materials which have a burning rate of two and one-half (2.5) inches per minute or less when tested in nominal .060 inch thickness by ASTM D635 or in the thickness intended for use. The ICBO code differs from these definitions and classifications only to the extent of the standard by which materials are tested. The self-ignition temperature must be determined by the U.B.C. Standard No. 52-3. The smoke-density rating must be derived from the U.B.C. Standard No. 42-1, or the U.B.C. Standard 52-2. Classification of approved plastics must be in accordance with U.B.C. Standard No. 52-4.

Most of the other definitions concerning light transmitting plastics are identical in the BOCA, SBCC, and ICBO codes. Plastic glazing is defined as plastic materials which are glazed or set in frame or sash and not held by mechanical fasteners which pass through the material. Glass fiber reinforced plastic is defined as plastic reinforced with glass fiber having not less than twenty (20) percent of glass fibers by weight. 


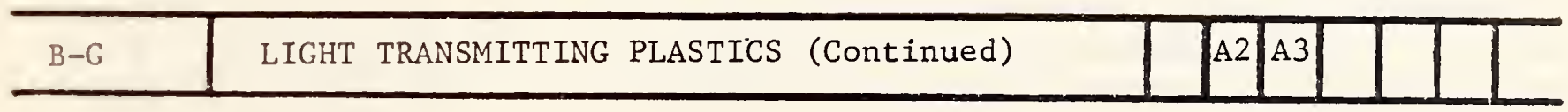

(SEE FIG. 1)

Thermosetting materials are defined as plastic materials capable of being changed into a substantially non-reformable product when cured. Thermoplastic materials are defined as those which are capable of being repeatedly softened by increase of temperature and hardened by decrease of temperature. Other definitions vary slightly between that which is stated identically in the BOCA and SBCC codes and definitions found in the ICBO code. The BOCA and SBCC codes define a light diffusing system as a suspended construction consisting in whole or in part of lenses, panels, grids, or baffles which is suspended below independently mounted electrical lighting sources. In addition to this definition, the ICBO code also states that lenses, panels, grids, and baffles which are part of an electrical fixture cannot be considered as a light diffusing system. The BOCA and SBCC codes define plastic roof panels as materials which are fastened to structural members or panels or to sheathing and which are used as light-transmitting media in the plane of the roof. The ICBo code differs only to the extent that it defines the material as structural panels other than skylights which are fastened to structural members, panels, or to sheathing. The BOCA and SBCC codes define plastic wall panels as plastic materials which are fastened to structural members or panels or to sheathing and which are used as light-transmitting media in exterior walls. The ICBO code calls this component exterior wall panels and differs from the other codes only to the extent that the panels are defined as materials which are not classified as plastic glazing.

\section{DESIGN AND INSTALLATION}

These provisions in the BOCA, SBCC, and ICBO codes are intended to assure that the light-transmitting plastics and their assemblies are adequate in strength and durability to withstand the applied loads and forces. The ICBO code also requires that technical data be submitted to establish stresses, maximum unsupported spans and other such information for the various thicknesses and forms used as required by the building official.

In addition, fastenings are required to be adequate to withstand design loads and differential expansion and contraction. The BOCA code requires that all fastenings, connections, and supports be proportioned to safely transmit two and one-half times the design live load. The ICBO code states that the proper allowance for expansion and contraction of plastic materials must be in accordance with accepted data on coefficient of expansion of the material and other materials with which it is used.

These provisions would directly apply to glazing used in phase-change thermal systems. 


\begin{tabular}{l|l|l|l|l|l|l|l|l}
\hline B-G & LIGHT TRANSMITtING PLAStics (Continued) & & A2 & A3 & & & & \\
\hline
\end{tabular}

(SEE FIG. 1)

\section{GLAZING OF UNPROTECTED OPENINGS}

The building codes allow approved plastic glazing to be used for doors, sash, and framed openings which are not required to be fire-protected openings. In the BOCA code, this refers to buildings of Type 4B (unprotected, frame) construction, and those buildings in use group $F$ (factory and industrial). In the SBCC code this is applicable to Group R-Residential buildings, and Group E-Educational buildings. The ICBO code allows this in buildings of type $\mathrm{V}-\mathrm{N}$ construction. In types other than those prescribed, these three codes all allow plastic glazing to be used providing certain requirements are met. In other types of construction the codes specify that the area of such glazing shall not exceed twenty-five percent of the wall face; the area of a single pare of glazing installed above the first story shall not exceed sixteen square feet and the vertical dimension of a single pane shall not exceed four feet. The BOCA and SBCC codes also require that there must be a minimum of three feet in vertical spandrel wall between stories and the ICBO code require that this dimension be four feet, or that there be approved flame barriers that extend 30 inches beyond the exterior wall in the plane of the floor, when glazed units are located in adjacent stories. The ICBO code also requires that plastics not be installed more than 65 feet above grade level. The BOCA and SBCC codes limit this dimension to 75 feet. The BOCA code allows approved thermoplastic materials to be installed in areas up to $50 \%$ of the wall area of each story in structures less than 150 feet in height which are provided on each floor above the first floor with continuous architectural projections constituting an effective fire canopy extending at least three feet from the surface of the wall in which the glazing is installed. In this type of installation, BOCA does not limit the size or dimension of individual units except as required to meet structural loading requirements. The SBCC code has an identical requirement, except that the limiting height of applicable structures is 75 feet. Both the BOCA and SBCC codes also require no vertical separation between panels at those floors on which such a fire canopy exists, except that provided by the projection itself. The ICBO and SBCC codes allow the area of glazing to be a maximum of $50 \%$ of the wall face of the story in which it is installed with no limit on the maximum dimension or area of a single pane of glazing when an approved automatic sprinkler system is provided throughout. When this condition exists, the SBCC code does not require continuous fire canopy projections. The BOCA code allows the maximum dimension to be increased 100\% when such a sprinkler system is installed.

\section{E. EXTERIOR WALL PANELS}

The BOCA, ICBO and SBCC building codes cover the use of approved plastic materials used as wall. panels. Types of construction, area limitations, separation requirements, etc. are specified for different classes of approved plastics.

The BOCA and SBCC codes have identical tables which list area limitations, horizontal/vertical separation, and percentage of exterior wall allowed to be plastic panels according to various dimensions of fire separation for both $\mathrm{C}-1$ and C-2 classifications of plastic. Both the BOCA and SBCC codes further state 


\begin{tabular}{l|l|l|l|l|l|l|l}
\hline$B-G$ & LIGHT TRANSMITTING PLAStics (Continued) & A2 & A3 & & & & \\
\hline
\end{tabular}

(SEE FIG. 1)

that in such cases as those in which an automatic sprinkler system is provided in the building, the maximum areas of plastic panel allowed in the above described table can be increased $100 \%$, but in no case can the resulting area of plastic panel be over $50 \%$ of the exterior wall area.

The BOCA code requires that combinations of plastic glazing and plastic wall panels comply with all requirements applicable to the class of plastics as prescribed for wall panel installations.

The 1 CBO code allows approved plastics to be used in exterior walls of type $V-\mathbb{N}$ construction provided the walls are not required to have a fire-resistive rating. ICBO also allows this in construction other than type V-N, subject, though, to special requirements. These requirements state that approved exterior wall panels cannot be installed more than 40 feet above grade level. Also, approved exterior wall panels cannot be installed in exterior walls located less than 10 feet from the property line. Area and size of panels used are subject to area limitation and separation requirements for exterior wall plastic panels which are listed for each class of plastic. ICBO allows exception to these requirements for construction other than type $\mathrm{V}-\mathrm{N}$ when structures are provided with approved flame barriers extending 30 inches beyond the exterior wall in the plane of the floor. In this case, no vertical separation between panels is necessary, except that provided by the vertical distance of the flame barrier projection. Also ICBO allows exception when an automatic sprinkler system has been provided throughout the building. Then the maximum percentage area of plastic panels in the exterior wall and the maximum area of any individual panel can be increased $50 \%$ above the set limitations. Also in this case, the separation requirements, both vertical and horizontal, can be reduced by $50 \%$.

The application of placing phase-change storage devices behind a plastic exterior wall panel may be viewed as equivalent to placing the phase-change material in an unprotected opening. In some instances, the distinction may be unclear and the governing provisions difficult to determine. The provisions, however, for unprotected openings and exterior wall panels are generally similar and complementary and the design and installation of phase-change systems using approved plastic glazing should perhaps be tested against both sets of provisions.

\section{F. ROOF PANELS}

The use of approved plastic roof panels is covered by the BOCA, ICBO, and SBCC building codes. These panels may generally be installed in roofs that are not required to have a fire-resistive rating. Further, individual roof panels are required to be separated from each other by at least four feet measured in a horizontal plane.

Specifically, the BOCA and SBCC does also allow plastic roof panels to be installed (except in use groups $\mathrm{A}-1, \mathrm{~A}-2, \mathrm{~A}-3, \mathrm{H}$ and $\mathrm{I}$ ) in roofs of buildings protected by a complete approved automatic fire suppression system. Also, such panels may be used when they meet the requirements for roof coverings of the particular occupancy group. 
In addition, limitations are placed by the BOCA, SBCC and ICBO codes on the use of plastics within certain distances from fire-resistive rated exterior wall openings. BOCA requires this distance to be within 6 feet. For the SBCC and ICBO codes, this maximum is 8 feet.

These three codes also limit the area of each roof panel and the aggregate area of panels as a percentage of the floor area of the space sheltered. For Class. 1 (CC1) plastics, BOCA and SBCC codes limit the individual unit panel area to 300 square feet with a maximum aggregate area of $30 \%$ of the floor area. The ICBO code limits the unit area of this class plastic to 150 square feet and the maximum aggregate area as $331 / 3 \%$ of the floor area. For Class-2 (CC2) plastics, all three codes limit the maximum area of individual panel to 100 square feet and the maximum aggregate area to $25 \%$ of the floor area.

The BOCA and SBCC codes allow exception to these limitations in one story buildings which are not more than sixteen feet in height, not exceeding 1200 square feet, and not closer than 11 feet to another building. The BOCA and SBCC codes also allow approved plastics as roof coverings over terraces and patios of one- and two-family dwellings. These codes also exempt low hazard buildings, such as swimming pool shelters, greenhouses, etc. from the area limitations providing the buildings do not exceed 5,000 square feet and are not closer than 11 feet to the property line or adjacent building. The ICBO code also exempts swimming pool shelters under the same square footage maximum and if located not closer than 10 feet to the property line or adjacent building.

Plastic roof panels may also have an application in phase-change storage systems which function as a collector. In effect, the "individual" window unit, the unit connected to the building ductwork, and the free-standing unit is configured in a horizontal rather than vertical application. Of course, natural convection applications are probably limited because of the roof location of the phasechange device which would, perhaps, limit the system to one containing a fan or blower to circulate the heated air. This could eliminate the free standing devices entirely unless they are designed to operate primarily in a radiating mode. In addition, the area and separation requirements could impose unfavorable design restrictions on the phase-change system.

\section{G. SKYLIGHTS}

The provisions which apply to roof panels also generally apply to skylights. These include area limitations which control the aggregate area and maximum size of panel for different classes of plastic. 
The BOCA, SBCC, and ICBO codes state that skylights can be glazed with approved plastic materials except in use group $\mathrm{H}$, if all other applicable provisions are met. The BOCA code allows exception to this in cases where a skylight is on a building which is not more than one story in height, has as fire separation of at least $30 \mathrm{feet}$, and the space sheltered by the skylight is not classified as use group $\mathrm{H}$ or $\mathrm{I}$, or a means of egress. Also, the BOCA code states that exception shall be made for skylights in which the plastic material used meet the fire-resistive requirements of the roof.

Additional skylight provisions in the BOCA, SBCC, ICBO, and AInA codes include the requirements for the skylight to be mounted on a curb, with construction requirements consistent for the type of construction classification. Further, these curbs must be at least 4 inches above the adjoining roof surface. The SBCC code states that this curb may be omitted on dwellings with a minimum roof pitch of 3 1/2:12 for one- and two-family dwellings or buildings with an unclassified roof covering. The ICBO code allows the curbs to be omitted on roofs of Group R, Division 3 occupancies which have a minimum roof slope of 3:12 when self-flashing skylights are used. The AInA code states that curbs of combustible material must be covered, on the sides adjacent to the roof covering, with metal. The BOCA code requires that the edges of plastic skylights be protected with metal or a noncombustible material.

In addition, there are specific requirements for the use of dome-shaped skylights and the use of wire screening in certain applications. The SBCC and ICBO codes require that the edges of plastic domes and other skylights be protected by metal or noncombustible materials. The ICBO code waives this requirement if ordinary roof coverings are permitted. The BOCA, SBCC, and ICBO codes state that dome-shaped skylights can rise above the mounting flange a minimum distance equal to 10 percent of the maximum span of the domes but not less than 5 inches. The ICBO code allows exception to this requirement for those skylights which pass the Class "B" burning-brand test specified in the U.B.C. Standard No. 327.

The ICBO code also requires that flat or corrugated plastic skylights must slope at least $4: 12$. The AInA requires that this slope be not less than 20 degrees from the horizontal or that the glazing be covered with substantial wire screen. The AInA code goes on to require that dome-shaped plastic skylights must also be covered with this wire screen or have a shape such that flying brands are unlikely to lodge there. The wire screens cannot be lighter than 12 gage and must have a mesh neither less than $3 / 4$ inch nor larger than one inch. The wire mesh must be placed neither less than 4 inches nor more than 8 inches above the plastic, and must extend beyond the glazing or the dome, on all sides, a distance of not less than the height of the screen above the plastic. 


\begin{tabular}{l|l|l|l|l|l|l|l|l}
\hline B-G & LIGHT TRANSMItTING PLASTICS (Continued) & A2 & A3 & & & & \\
\hline
\end{tabular}

(SEE FIG. 1)

The four codes also limit the unit and aggregate areas of skylights as well as their spacing. The BOCA and AInA codes require that each skylight unit have a maximum area within the curb of 100 square feet. In the SBCC code, this maximum is 300 square feet for CC1 material and 100 square feet for CC2 material. The ICBO code allows a maximum of 200 square feet for CC1 material and 100 square feet for CC2 material, with the following exception: if the building on which the skylights are located is not more than one story in height, the building has an exterior separation from other buildings of at least 30 feet, and the room or space sheltered by the roof is not classified in a Group I, Division 1 or 3 occupancy or as a required means of egress, the maximum area within the curb for the skylights need not be limited. Also, the maximum area within the curb need not be limited if the skylights are serving as a fire venting system complying with the ICBO code or are used in a building completely equipped with an approved automatic sprinkler system. These two exceptions do not apply to Groups A, Divisions 1 and 2 , I and $\mathrm{H}$, Division 1 Occupancies.

The aggregate areas of skylights are also limited by the codes. The BOCA code limits the aggregate areas of skylights using Class $\mathrm{C}-1$ (CC1) materials to $33 \%$ of the floor area that is sheltered. The SBCC and ICBO .codes limit this to $331 / 3 \%$. When Class $\mathrm{C}-2$ (CC2) materials are used, all three codes limit the aggregate area to $25 \%$ of the floor area sheltered. The AInA code limits the aggregate area of the skylights to $20 \%$ of the floor area sheltered for all classes of materials. The BOCA code makes an exception to its area limitation for buildings of Use Group $\mathrm{H}$ and $\mathrm{I}$. Here the aggregate area of approved plastic skylights can increase $100 \%$ beyond the limitations required if the skylights are used as a fire venting system or if the building is equipped with an approved automatic fire suppression system.

The BOCA, SBCC, and ICBO codes require that skylights be separated from each other by a distance of not less than 4 feet measured on a horizontal plane. The ICBO code makes exception to this requirement for Groups A, Division 1 and 2, $H$ and I, Division 1 occupancies. In these cases, the separation is not required if the skylights are serving as an approved fire venting system or if the building is completely equipped with an approved automatic sprinkler system.

The BOCA and SBCC codes require that skylights cannot be installed within 6 feet of an exterior wall which is required to be fire resistance rated. The ICBO code limits this distance to 8 feet. 


\begin{tabular}{l|l|l|l|l|l|l|l|l}
\hline$B-G$ & LIGHT TRANSMITTING PLASTics (Continued) & A2 & A3 & & & & \\
\hline
\end{tabular}

(SEE FIG. 1)

The SBCC code states that the provisions regarding skylights need not be applied if the building on which the skylights are located are not more than one story in height, the building has an exterior separation from other buildings of at least 30 feet and the space sheltered by the roof is not classified in a group of high hazard or institutional occupancy, or as a means of egress, or if the plastic material to be used meets the fire-retardant requirements of the roof. Also, the SBCC code allows approved plastic materials to be used beyond the area limitations specified (except for Group I-Institutional, Group A-I-Assembly and Group H-Hazardous occupancies) if they are serving as an approved fire venting system or if they are used in a building equipped with an approved automatic fire extinguishing system.

The statements regarding the interface requirements for phase-change material and plastic roof panels also apply to skylights.

\section{H. MISCELLANEOUS}

Provisions in this category address combustion of plastic roof panels and skylights, plastic glazing and plastic exterior wall panels, and provisions for venting over stairways and shafts.

The BOCA, SBCC, and ICBO codes require that combinations of plastic roof panels and plastic skylights are subject to the area, percentage limitations, and separation requirements applicable to roof panel installations. The ICBO code also states that combinations of plastic glazing and plastic exterior wall panels are subject to the area, height, percentage and separation requirements applicable to the class of plastics as prescribed for wall panel installation. This code also allows approved plastic materials which will not automatically vent, but which are able to be vented, to be used over stairways or shafts, providing the installation conforms to all applicable requirements.

Since the provisions for plastic roof panels, skylights, glazing, exterior wall panels, etc., complement one another and seem consistent, the comments made in each individual subsection apply here as well.

\section{REFERENCES}

Organization

Code

Section

A. GENERAL

BOCA

ICBO

SBCC
The BOCA Basic Building Code

The Uniform Building Code

Standard Building Code
$2400.1,2400.2,2400.2 .2$ 2400.3

$5201(\mathrm{a}), 5201(\mathrm{~b}) ; 5201(\mathrm{c})$

2601.1(a), 2601.1(b), 2601.1(c) 
B. DEFINITIONS

BOCA

ICBO

SBCC
The BOCA Basic Building Code The Uniform Building Code

Standard Building Code

C. DESIGN AND INSTALLATION

BOCA. The BOCA Basic Building Code

ICBO

SBCC

Standard Building Code

D. GLAZING OF UNPROTECTED OPENINGS

BOCA

The BOCA Basic Building Code

ICBO

SBCC

The Uniform Building Code

Standard Building Code

E. EXTERIOR WALL PANELS

BOCA

SBCC

ICBO

The BOCA Basic Building Code

Standard Building Code

The Uniform Building Code

F. ROOF PANELS

BOCA

ICBO

SBCC
The Uniform Building Code

The BOCA Basic Building Code

Standard Building Code
(SEE FIG. 1)

2400.2 .1

5202

2601.2

$2401.1,2401.2$

$5203(\mathrm{a}), 5203(\mathrm{~b})$

2601.3(a), 2601.3(b)

$2402.1,2402.2,2402.3$, $2402.4,2403.1 .3$, Table 2403, $2403.2,2403.3$

5204,5205 , Table 52-A

$2602.1,2602.2(a), 2602.2(b)$

2603.1(a), Table 2603.1,

$2603.2(a), 2603.2(b)$

2403.1, 2403.1.1, 2403.1.2, 2403.1.4, 2403.1.a, 2403.1.5, $2403.2,2403.3$

2603.1, 2603.1(3), 2603.1(2), 2603.1(1), 2603.2(a), 2603.2(b)

5205

$2404.1,2404.2,2404.3$, $2404.4,2404.5 .1,2404.5 .2$, 2404.5 .3

5206

2604.1, 2604.2(a), 2604.2(b), 2604.2(c), 2604.3(a), 2604.3(b), $2604.3(\mathrm{c})$ 


\begin{tabular}{l|l}
\hline$B-G$ & LIGHT TRANSMITTING PLASTICS (Continued) \\
\hline
\end{tabular}

G. SKYLIGHTS

BUCA

ICBO

SBCC

A InA

H. MISCELLANEOUS

BOCA

ICBO

SBCC
The BOCA Basic Building Code

The Uniform Building Code

Standard Building Code

National Building Code

The BOCA Basic Building Code

The Uniform Building Code

Standard Building Code
$2405.1,2405.2,2405.2 .1$, $2405.3,2405.4,2405.5,2405.6$

5207 (a), 5207 (a)1, 5207 (a)2, 5207 (a) 3, 5207 (a) 4, 5207 (a) 5, 5207 (a) 6, 5207 (a) 7

2605.1(a), 2605.1(a)1, 2605.1 (a)2, 2605.1(a)3, 2605.1(a)4, 2605.1(a)5, 2605.1(a)6, 2605.1(a)7, $2605.2(a), 2605.2(b)$

$807.7(f), 807.7(h), 807.7(g)$
2405.7

5201 (e), 5201 (d), 5207 (b)

2605.3 


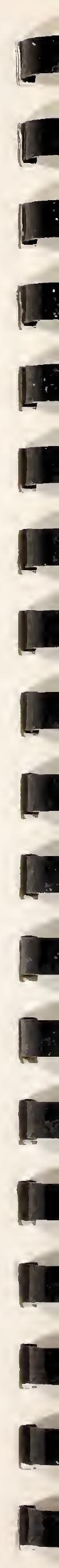




\begin{tabular}{l|l|l|l|l|l|l|l|l}
\hline $\mathrm{B}-\mathrm{H}$ & FOAM PLASTICS & & A2 & A3 & A4 & & & \\
\hline
\end{tabular}

(SEE FIG. 1)

The BOCA, ICBO, and SBCC codes contain provisions relative to the use of foam plastics. Each code generally requires that foam plastics have a flame-spread rating of not more than seventy-five (75) and a smoke-developed rating of not more.than four hundred fifty (450) when tested in the maximum thickness intended for use in accordance with ASTM E-84.

The codes also specify the conditions under which foam plastics may be used. Generally, this material must be isolated from the interior of the building and one method of achieving this isolation is to cover the foam plastic with onehalf inch gypsum board. An equivalent thermal barrier material is permitted if it meets the performance standards required of each code. Also, foam plastic insulation having a flame-spread rating of twenty-five or less may be used in or on walls in a thickness not to exceed four inches when the foam plastic is covered by aluminum or galvanized sheet steel in thicknesses specified in the provisions and the insulated area is protected with automatic sprinklers.

Other requirements relate to specific applications. For masonry or concrete construction, for instance, all three codes, BOCA, ICBO, and SBCC, allow the use of foam plastics without the use of a thermal barrier when the foam plastic is protected by a minimum of one inch thickness of masonry or concrete. These codes also have the same requirements for use of foam plastics in attic or crawl spaces where entry is made only for service of utilities. In these spaces, foam plastic may be used without the thermal barrier, but must be protected against ignition by 1 1/2 inch thick mineral fiber insulation, $1 / 4$ inch thick plywood, particle board, hardboard, gypsum wallboard, corrosionresistant sheet metal, or other approved material installed in such a manner that the foam plastic is not exposed.

For roofing applications, the BOCA, ICBO, and SBCC codes also have the same requirements for use of foam plastics. Here foam plastics may be used in a roof covering assembly without the thermal barrier when the foam is separated from the interior of the building by plywood sheathing not less than $1 / 2$ inch in thickness, bonded with exterior glue, with edges supported by blocking, tongue and groove joints, or other approved type of edge support or an equivalent material. The foam plastic roof insulation used must comply with the standards applicable to each individual code. For all roof applications, the smoke developed rating shall not be limited.

All three of the above-mentioned codes also allow foam plastic to be used as siding backer board with a maximum thickness of $1 / 2$ inch without the thermal barrier provided if is separated from the interior of the building by 2 inches of mineral fiber insulation or equivalent, or when applied as residing over existing wall construction. The SBCC code also limits this use to foam plastic of not more than 2000 Btu per square foot. 


\begin{tabular}{l|l|l|l|l|l|l|l}
\hline $\mathrm{B}-\mathrm{H}$ & FOAM PLASTICS (Continued) & & A2 & A3 & A4 & & \\
\hline
\end{tabular}

(SEE FIG. 1)

Regarding the use of foam plastics in exterior walls of buildings, the BOCA code allows the foam plastic insulation having a flame spread of 25 or less to be used in a thickness of not more than 4 inches without a thermal barrier when the foam plastic is covered by a metal facing of specified gage in aluminum or steel, and the building is provided with automatic sprinklers. This application is limited to buildings of Types $2 \mathrm{C}, 3$, or 4 construction where an automatic fire suppression system is not required. Where this sprinkler system is required, the thermal barrier is also required. The SBCC code also addresses use of foam plastics in exterior walls in buildings of fire-resistive or noncombustible construction. For one story buildings, this code allows foam plastic insulation having a flame spread of 25 or less to be used without thermal barriers in or on walls in thickness of not more than 4 inches when the foam plastic is covered by a thickness of not less than 0.016 inch and the insulation area is protected with automatic sprinklers. For multi-story buildings, where walls face a street or permanent open space of 30 feet or more, foam plastic may be used in a non-fire rated wall assembly. Where a separation of less than 30 feet exists, foam plastic may be used within exterior walls, provided the wall assembly affords the required fire-resistance. In multi-story buildings, the SBCC code also requires that any foam plastic insulation shall be separated from the building interior by a thermal barrier meeting the provisions for general use, unless specific approval is obtained. The SBCC code also requires that, in multi-story buildings, the potential heat of foam plastic, in any portion of the wall or panel, shall not exceed 6000 Btu/square foot of projected area as determined by approved tests. The foam plastic core, coatings, and facings shall have a flame spread rating of 25 or less and a smoke-developed rating of 450 or less as determined in accordance with approved tests. Results of diversified or full scale fire tests reflecting an end-use configuration are required by the SBCC code to be submitted to the building official demonstrating the assembly in its final form does not propagate flame over the surface or through the core when exposed on the exterior face to a fire source.

With regard to phase-change thermal storage devices, the most probable application for the use of foam plastics would be in the systems using air as the working fluid. These plastics, if used, would form the enclosure in which the phasechange material would be housed and, in effect, be a part of the ductwork through which the air passes in delivering or removing heat from the phasechange material. Certainly, if the enclosure were to use a foam plastic as an insulation, the provisions addressing the use of this material would apply.

\section{REFERENCES}

Organization

Code

Section

BOCA

The BOCA Basic Building Code

ICBO

SBCC
The Uniform Building Code

Standard Building Code
$1319.1,1319.2,1319.3,1319.3 .1$, $1319.3 .4,1319.3 .5,1319.3 .7$, $1319.3 .8,1319.4$

$1712(\mathrm{a}), 1712(\mathrm{~b}), 1712(\mathrm{c})$

$717.1,717.2,717.3$ 


\begin{tabular}{l|l|l|l|l|l|l|}
\hline B-I & THERMAL INSULATING MATERIALS & A2 & A3 & A4 & & \\
\hline
\end{tabular}

(SEE FIG. 1)

The BOCA, SBCC, AInA, and ICBO building codes contain explicit provisions covering the use of thermal insulating materials. Thermal insulation materials are also covered in the mechanical code and complement the building code provisions. The BOCA building code, in effect, requires that insulation be used in a manner that will not increase the fire hazard characteristics of the building. This code further requires that the insulation material shall meet specific requirements for fire resistance depending upon the type of construction in which the material is installed, and the location of the installation (exposed and/or located in attic spaces). BOCA also states that vapor barriers, breather papers, or other coverings of insulating materials, installed adjacent to or not more than one and one-half inches from the exposed surface of ceiling or sidewall interior finish, or when installed in completely enclosed wall spaces and firestopped as required by BOCA, are not required to have a flame resistance rating. Also, a flame spread rating of 25 or less is required of vapor barriers, breather papers, and similar coverings of insulation materials which are left exposed when installed between ceiling joists or rafter spaces. In addition, BOCA requires that cellulosic insulation meet specific requirements.

The SBCC building code requires concealed insulation to have a flame-spread rating not higher than seventy-five; a smoke developed rating no higher than four hundred fifty, and lists the characteristics of cellulose fiber thermal insulation. These characteristics include requirements for density, thermal resistance, surface burning characteristics, flame resistance permanency, moisture absorption, odor emission, corrosiveness, and starch pressure. Also, any insulation material which is subject to an increase in flame spread rating or smoke developed rating beyond the established limits through the effects of age, moisture, or other atmosphere conditions shall not be permitted. SBCC does not require its limitations for flame spread and smoke developed ratings to apply to facings used in certain type constructions where insulation materials are installed in concealed spaces of a building, provided that the facing is installed in contact with the unexposed surface of the ceiling, wall or floor finish.

The AInA code requires the potential heat value of insulation to be no greater than 3,500 Btu per pound in Fire Resistive Construction and Protected and Unprotected Limited-Combustion Construction, and no greater than 9,000 Btu per pound for Heavy Timber Construction, Ordinary Construction, and Wood-Frame Construction. Exceptions to the above are permitted if certain other conditions are met. For instance, the 3,500 Btu per pound limitation for fire resistive, protected and unprotected limited-combustion construction and the 9,000 Btu per pound limitation for heavy timber, ordinary, and wood-frame construction can both be exceeded if: 


\begin{tabular}{l|l|l|l|l|l|l|l|l}
\hline B-I & THERMAL INSULATING MATERIÁLS (Continued) & A2 & A3 & A4 & & & \\
\hline
\end{tabular}

(SEE FIG. 1)

(1) The insulation material is installed within the cavity of a hollow wall of masonry and has a flame spread rating of not greater than 75 . In this kind of installation, the drainage function of the wall cannot be impaired.

(2) The insulation material is covered by a protective material having a finish rating of not less than 25 minutes, based upon tests conducted by a nationally recognized testing laboratory, and has a flame spread rating not greater than 25; the method of attachment of the protective material must be in accordance with the method of attachment used in the test which establishes the finish rating.

The ICBO code requires that insulation and covering on pipe and tubing have a flame-spread rating not exceeding 25, and a smoke density not greater than 450 , when tested according to UBC Standards. Insulation materials subject to this requirement include facings, such as vapor barriers or breather papers installed within floor-ceiling assemblies, roof-ceiling assemblies, walls, crawl spaces or attics. Exceptions to this requirement occur when such materials are installed in concealed spaces of Types III, IV and V construction and the facing is installed in substantial contact with the unexposed surface of the ceiling, floor, or wall finish. Also, foam plastic insulation is expected as this material must comply with other requirements within the ICBO code.

Thermal insulating materials would be expected as an element of the enclosure in which the phase-change material is housed. This enclosure would be insulated to prevent heat loss and could be considered a part of the ductwork through which air passes in delivering or removing heat from the phase-change material. Phase-change designs using thermal insulation would have to comply with the requirements for the types of construction indicated and be integrated into the building design.

\section{REFERENCES}

Organization

Code

Section

BOCA The BOCA Basic Building Code

SBCC

Standard Building Code

AInA

Nationa1 Building Code

ICBO

The Uniform Building Code

$1318.1,1318.2,1318.3$, $1318.4,1318.5$

$719.1,719.2(\mathrm{a}), 7.9 .2(\mathrm{~b})$, $719.7,719.7(\mathrm{a}), 719.7(\mathrm{~b})$, $719.7(\mathrm{c}), 719.7(\mathrm{~d}), 719.7(\mathrm{e})$, 719.7 (f), $719.7(\mathrm{~g}), 719.7(\mathrm{~h})$

$702.9,703.9,704.9,705.8$, $706.9,707.10,708.9$

$1713(\mathrm{a}), 1713(\mathrm{~b}), 1713(\mathrm{c})$ 


\begin{tabular}{l|l|l|l|l|l|l|l}
\hline B-J & GLASS & & A2 & A3 & & & \\
\hline
\end{tabular}

(SEE FIG. 1)

The use of glass as a building element is addressed in the model building codes. This material, along with light transmitting plastics could be used as glazing for phase-change storage devices which also function as collectors and include both the individual "window" units and those storage/collector devices connected to the building ductwork. The provisions addressed in this section have been grouped by subtopic for ease of discussion. The subtopics concerned with the use of glass include: (a) labeling and identification; (b) glass supports; (c) windloads and area limitations; (d) skylights; (e) human impact; and (f) dimensional tolerances. These subtopics are discussed indivdually below:

\section{A. LABELING AND IDENTIFICATION}

The BOCA, ICBO, and SBCC codes all require that each light shall bear the manufacturer's label designating the type and thickness of glass. With the approval of the building official, labels may be omitted, provided that an affidavit is furnished by the glazing contractor certifying that each light is glazed in accordance with approved plans and specifications.

To qualify as glass with special performance characteristics both BOCA and SBCC require that each unit of laminated, heat strengthened, fully tempered, and insulating glass be permanently identified by the manufacturer. The identification shall be etched or ceramic fired on the glass and be visible when the unit is glazed. Heat strengthened and tempered spandrel glass are exempted from permanent labeling and shall be labeled by the manufacturer with a removable paper label.

\section{B. GLASS SUPPORTS}

The building codes contain provisions detailing the support requirements for glass. These requirements specify the need for detailed shop drawings, specifications, analysis or test data for glass not firmly supported on all four edges. Consideration is given to such items as design wind pressures, glass supports, minimum frame lap, minimum glass edge clearance, and maximum deflection requirements.

Specifically, BOCA, ICBO, and SBCC require the building official to approve glass installations where one (1) or more sides is not firmly supported or is subject to unusual load conditions. Also, BOCA and SBCC require detailed shop drawings, specifications, and analysis or test data to be prepared by engineers experienced in this work assuring safe performance for the specific installation. ICBO requires glass that is firmly supported on all four edges to be glazed with minimum laps and edge clearance as provided in a table contained in the code while AInA requires a minimum frame lap of not less than $1 / 4$ of an inch and a minimum glass edge clearance of not less than $1 / 8$ of an inch. 


\begin{tabular}{l|l|l|l|l|l|l|l|l}
\hline B-J & GLASS (Continued) & A2 & A3 & & & & \\
\hline
\end{tabular}

(SEE FIG. 1)

The ICBO and SBCC codes both provide that glass supports such as sash members, glazing stops or glazing clips shall be considered firm when deflection of the support at design loads does not exceed $1 / 175$ of the span. In addition, BOCA and AInA address wind loads and refer to other sections of the respective codes. BOCA also provides that the elevation of the glazed opening shall be computed by adding the distance from grade to the head and sill respectively, and dividing the sum by two (2). AInA does not permit glass floor lights including glass block panels, between stories of buildings and structures.

The glass support requirements detailed in the building codes apply directly to the glazing of phase-change thermal storage devices also functioning as collectors. of particular concern could be systems which are designed to be maintained from the outside of the unit. This could be the case in systems that are inaccessible from the inside of the building due to design peculiarities or unique configurations. Unconventional fastenings, attachments, or other devices which permit removal of the glass may have to demonstrate that they meet the requirements of the provisions.

\section{WIND LOADS AND AREA LIMITATIONS}

The BOCA, ICBO, and SBCC building codes provide for glazing to withstand wind pressure loadings by limiting the maximum allowable glass area for specified thicknesses and wind loads. Specifically, the BOCA code specifies minimum glass thickness and required nominal thickness of regular plate or sheet glass while the ICBO code provides a table indicating minimum allowable area of glass. BOCA, ICBO, and SBCC all include a table indicating the relative resistance to wind load of various types of glass and provide a methodology for determining safe glazing practices. SBCC also requires the design factor to be not less than the two and one-half $(2$ 1/2) for regular plate, float, or sheet glass supported on four sides and includes a thickness guide for regular plate, float, or sheet glass.

The wind loads and area limitations contained in the model building codes apply directly to glazing associated with phase change storage/collector devices. Generally, the restrictions on these devices should not be any different than any other glass applications in buildings.

\section{SKYLIGHTS}

The AInA code defines a skylight to mean the glazing, sash, and frames for openings in roofs, floors, roof monitors, and sawtooth roofs. The provisions for skylights are covered in each of the building codes and are rather involved. Sashes and frames of certain construction are required to be of noncombustible materials and, in some cases, designed and constructed to support the same maximum live loads as required for roofs. Also, inclined skylights are required to meet certain provisions regarding type mounting, thickness, and wire reinforcements. Skylights placed over shafts or exits are generally required to be glazed with plain glass and have installed a substantial wire screen above and below the glass. There are other provisions limiting glass areas, distances, etc., as well as provisions specifying how skylights are to be guarded in other applications. 


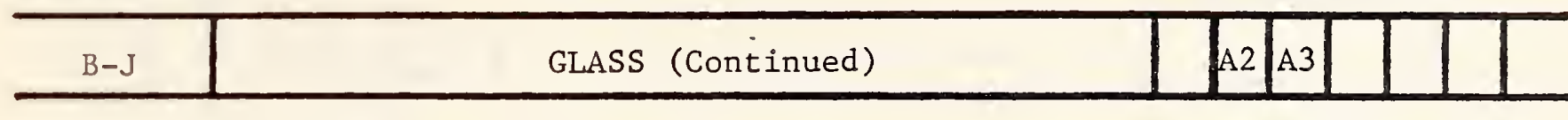

(SEE FIG. 1)

Specifically, BOCA, ICBO, and SBCC require all skylights, the glazing of which is set at an angle of less than 45 degrees from the horizontal, to be mounted at least 4 inches above the plane of the roof on a curb constructed as required for the frame. AInA, however, requires skylights in roofs other than over shafts and exits which are inclined less than 60 degrees from the horizontal to have their sashes and frames constructed of noncombustible material and be glazed with wire glass not less than $1 / 4$ inch thick, glass block, or plastic which does not present a fragmentation hazard. Skylights placed over shafts and exits shall be glazed with plain glass, not more than $1 / 8$ inch thick, or other noncombustible material which is easily pierced by firefighters. SBCC requires glazing at an angle greater than 15 degrees measured from the vertical, over lobbies, reception areas, office areas, walkways, and other areas accessible to the public, to be laminated glass, wire glass, rigid plastic, or have protective wire screens immediately beneath the glass.

Both ICBO and SBCC specify that spacing between supports in one direction for flat wired glass in skylights shall not exceed 25 inches. Corrugated wired glass may have supports 5 feet apart in the direction of the corrugation. All glass in skylights shall be wired glass laminated glass or tempered glass, minimum thickness $7 / 32$ inch, except that skylights over vertical shafts extending through two or more stories shall be glazed with plain glass as specified in this section, provided that wired glass may be used if ventilation equal to not less than one-eighth the cross-sectional area of the shaft but never less than 4 square feet is provided at the top of such shaft. Further, ICBO and SBCC require glass used for the transmission of light, if placed in floors or sidewalks, be supported by metal or reinforced concrete frames, and such glass shall be not less than $1 / 2$ inch in thickness. Any such glass over 16 square inches in area shall have wire mesh embedded in the same or shall be provided with a wire screen underneath, as specified for skylights in this section. All portions of the floor lights or sidewalk lights shall be of the same strength as is required by this code for floor or sidewalk construction, except in cases where the floor is surrounded by a railing not less than 3 feet 6 inches in height, in which case the construction shall be calculated for not less than roof loads.

BOCA allows skylights to be glazed with any of the following materials, subject to certain limitations: laminated glass, wired glass, annealed glass, heat strengthened glass, tempered glass, glass block and light transmitting plastic. Annealed, heat strengthened and tempered glass are required to be protected by screens. The ICBO code states that any glass not wired glass, laminated glass or fully tempered glass be protected above and below with a screen constructed of wire not smaller than No. 12 U.S. gauge with a mesh not larger than 1 inch. The screen shall be substantially supported below the glass. BOCA requires annealed glass skylights to be protected from falling objects by screens above the skylight. Annealed, heat strengthened and tempered glass skylights shall be equipped with screens below the skylight to protect building occupants from falling glazing should breakage occur. Screens shall be of noncombustible materials and shall have a mesh not larger than 1 inch by 1 inch. The screen 


\begin{tabular}{l|l|l|l|l|l|l|l|l}
\hline B-J & GLASS (Continued) & & A2 & A3 & & & \\
\hline
\end{tabular}

(SEE FIG. 1)

shall be constructed of not lighter than No. 12 material. When utilized in a corrosive atmosphere, structurally equivalent noncorrosive materials shall be used. Screens above the skylight shall be at least 4 inches (102 mm) above the skylight and shall project on all sides for a distance of not less than the height of the screen above the glass. When multiple layer glazing systems are used and the layer facing the interior is laminated glass, the protective screen below the skylight is not required.

The ICBO and SBCC codes allow ordinary glass to be used in the roofs and skylights for greenhouses, provided the height of the greenhouse at the ridge does not exceed 20 feet above the grade. The use of wood in the frames of skylights are permitted in greenhouses if the height of the skylight does not exceed 20 feet above the grade, but in other cases noncombustible frames are designated.

All of the following requirements are from the AInA code: skylights, placed over shafts, having plain glass glazing, shall be provided with substantial wire screen installed above or below the skylights. Skylights, placed over exits, having plain glass glazing, shall be provided with substantial wire screen below the skylights. The wire screen shall be as required for flat or corrugated plastic glazing. The wire screen for plain glass glazing over shafts shall be placed neither less than 4 inches nor more than 8 inches above the glass, or shall be placed not more than 18 inches below the glass, and shall extend beyond the glazing, on all sides, a distance of not less than the distance between the screen and the glass, but need not extend beyond the enclosing walls of the shaft. The wire screen for glass glazing over exits shall be placed not more than 18 inches below the glass and shall extend beyond the glazing, on all sides, a distance of not less than the distance between the screen and the glass, but need not extend beyond the enclosing walls of the exit.

Skylights, except skylights over exits, in which plain glass not more than $1 / 8$ inch in thickness or plastic is used for glazing, shall comply with the following provisions (1) through (5).

(1) The distance between skylights shall be not less than 5 feet.

(2) The distance between skylights and any exterior wall of an adjacent building in which exterior wall openings are required to be protected and shall be not less than 30 feet.

(3) The distance between skylights and the edges of roofs of buildings of fire-resistive construction and required parapets shall be not less than 10 feet.

(4) The distance between skylights and doors in bulkheads for stairways, scuttles, or trap doors, required for access to roofs, shall be not less than 10 feet. 


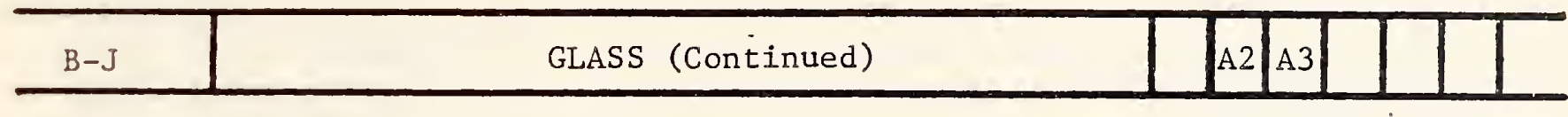

(SEE FIG. 1)

(5) The distance between skylights and openings in walls of penthouses, roof structures, or machinery compartments shall be not less than 15 feet and the distance between skylights and walls of penthouses, roof structures, or machinery compartments shall be not less than 10 feet.

The AInA code continues that skylights larger than 5 square feet in area or having a horizontal dimension greater than 30 inches, glazed with flat or corrugated sheets of plastic or glass, other than $1 / 4$ inch wired glass or glass blocks, that are installed on terminuses of shafts which are less than 3 feet above the roof, shall have substantial guards not less than 3 feet in height on all sides or shall have screens or grids located neither more than 6 inches above nor more than 18 inches below the glazing. Guards, including attachment of vertical members to roofs and structural members for roofs, shall be of noncombustible materials and shall be designed and constructed to withstand a concentrated load of not less than 200 pounds, applied in any direction, at any point on the top rail. Screens or grids and their attachments to roofs shall be of noncombustible materials and be capable of supporting a load of 300 pounds per square foot at midspan or near attachments; the spacing of wire or bars for screens or grids shall not exceed 4 inches.

As can be seen from the above, the codes covering the skylighting provisions are varied and complex. Although the application of skylights to phase-change systems may appear remote, it is possible to view a skylight as a horizontal or tilted window which will allow solar radiation to impinge upon phase-change storage material assembled below. If used in this configuration, the detailed glazing provisions enforced for ordinary skylights would apply to this solar configuration as well. Skylights, however, intended as escape exits, or for emergency venting, would perhaps preclude the installation of containers holding phase-change materials directly beneath the skylight.

\section{E. HUMAN IMPACT}

The BOCA and ICBO building codes address the problem of human impact on glazing materials. The ICBO code requires the glazing material to pass the test requirements of Part I of U.B.C. Standard No. 52-2, or equivalent, while BOCA specifies the test requirements of CPSC 16-CFR, Part 1201. ICBO prohibits the use of annealed glass while both codes provide exceptions to polished wire glass. In consideration of the above, phase-change systems containing glass apertures would generally have to meet these requirements if the aperture could be impacted by persons.

\section{F. DIMENSIONAL TOLERANCES}

The BOCA and SBCC building codes specify dimensional tolerances for glass. BOCA provides a table showing the nominal glass thickness and the corresponding plate glass and sheet glass minimum thickness. The SBCC code, on the other 


\begin{tabular}{l|l}
\hline $\mathrm{B}-\mathrm{J}$ & GLASS (Continued) \\
\hline
\end{tabular}

hand, references Federal Specification DD-G-45ld. Phase-change thermal storage systems using glass as part of their design should incorporate glass with thicknesses specified in the building codes.

\section{REFERENCES}

Organization

Code

Section

A. LABELING AND IDENTIFICATION

BOCA The BOCA Basic Building Code

ICBO

$\mathrm{SBCC}$

1301.5 .1

5402

2701

B. GLASS SUPPORTS

BOCA

The BOCA Basic Building Code

ICBO

The Uniform Building Code

SBCC

Standard Building Code

A InA

National Building Code

C. WIND LOADS AND AREA LIMITATIONS

BOCA

The BOCA Basic Building Code

ICBO

SBCC

The Uniform Building Code

Standard Building Code

D. SKYLIGHTS

BOCA

The BOCA Basic Building Code

ICBO

The Uniform Building Code

SBCC

Standard Building Code

AInA

National Building Code

1301.5 .2

5404; Table 54-C

2704 (a); 2704 (b)

$930.1(\mathrm{a}) ; 930.1(\mathrm{~b}) ; 930.1(\mathrm{c})$

1301.5.4; Table 1301.5.4.1;

Table 1301.5.4.2

5403; Table 54.A; Table 54-B

$2703.2(\mathrm{a}) ; 2703.2(\mathrm{~b})$;

Table 2707

$1426.3 .1 ; 1426.3 .2 ; 1426.3 .3$; $1426.3 .4 ; 1426.3 .5$

3401

707 (a); $707(\mathrm{~b}) ; 707(\mathrm{c})$;

707 (d); 707 (e)

807.7 (a); $807.7(\mathrm{~b}) ; 807.7(\mathrm{c})$; 807.7 (d); 807.7 (e); $807.7(\mathrm{i})$; $807.7(\mathrm{j}) ; 807.7(\mathrm{k})$

1301.5 .6

$5406(c)$

F. DIMENSIONAL TOLERANCES

BOCA

The BOCA Basic Building Code

$1301 \cdot 5 \cdot 3$

SBCC

Standard Building Code 


\begin{tabular}{l|l|l|l|l|l|l|l|l}
\hline $\mathrm{B}-\mathrm{K}$ & TESTING & A1 & A2 & A3 & & & & \\
\hline
\end{tabular}

(SEE FIG. 1)

The building codes require that testing be conducted if there is any reason to doubt the quality of the material or its suitability for the proposed use in the structure. The test methods are generally to be approved by the building official and the tests made by an approved agency or laboratory. Test reports are required to be submitted and, in some cases, kept on file by the building official.

Specifically, the testing provisions apply to all new building materials, equipment, appliances or methods of construction not provided for by the code as well as any material of questioned suitability proposed for use in the construction of a building or structure. Several of the codes specify that, as proof of compliance, tests or test reports may be requested especially if there is reason to doubt the quality of a material or method of construction to be used.

The codes generally require that the tests or other investigations be conducted by an approved testing laboratory or other approved agency and the expense borne by the applicant with no cost to the jurisdiction. The ICBO and AInA codes state that if there are no recognized and accepted test methods, the building official shall determine the test procedures. In addition, the ICBO and the SBCC codes specify that the reports of such tests be retained by the building official.

The requirements for testing new and innovative materials, equipment, appliances, systems, or methods are probably the most restrictive and perhaps necessary provisions within the building codes for the acceptance of innovative phasechange systems. Masonry units filled with phase-change materials, phase-change materials encapsulated in ceiling tile or wall panels, or other innovative applications of building integrated storage devices would normally be difficult to evaluate by the building official. Since these may be structural elements or components that are also required to have fire resistive characteristics, testing of the materials would probably be necessary to assure that they will perform as intended when integrated into a structural system. Once successfully tested, these materials could be formally approved by a recognized approval authority and become generally accepted for use.

\section{REFERENCES}

Organization

Code

Section

BOCA

ICBO

SBCC

AInA
The BOCA Basic Building Code

The Uniform Building Code

Standard Building Code

National Building Code
$1100.2 ; 1100.4$

107

104

$101.1 ; 101.2 ; 101.3$ 


\begin{tabular}{l|l|l|l|l|l|l|l|l}
\hline B-L & EMERGENCY EGRESS & & A2 & A3 & & & & \\
\hline
\end{tabular}

(SEE FIG. 1)

The building codes contain provisions for emergency egress. Generally, an operable window or exterior door approved for emergency egress or rescue is required for every sleeping room. The codes specify a minimum net clear opening of 5.7 square feet, a minimum net clear opening height of 24 inches, a net clear opening width of 20 inches, and a specified sill height above the floor. Windows are to be openable from the inside without the use of separate tools. Exceptions are made for grade floor windows or the substitution of two interior doors providing separate escape paths of travel, or, for some use groups, direct access to a corridor which links to two remote exits in opposite directions. Bars, grills or screens may be placed on emergency escape or rescue windows or doors, according to some codes, if these devices are releasable or removable from the inside without the use of a key, tool, excessive force, or special knowledge. ICBO also allows these devices over emergency escape openings if the building is equipped with smoke detectors installed according to ICBO provisions.

The provisions requiring operable windows or exterior doors for every sleeping room may inhibit the use of phase-change systems which also function as collectors. Because the individual "window" unit system and the system connected to the building ductwork lend themselves architecturally and functionally in a configuration that substitutes these units for windows, the emergency egress requirements could cause serious design constraints. One could conceive of a design in which the device could be removed for emergency egress; however, the design may be costly or unacceptable to the occupants. Another solution might be to use these devices only in rooms which are not used for sleeping or are equipped with smoke detectors; however, the requirements for light and ventilation may also inhibit such use.

\section{REFERENCES}

Organization

Code

Section

BOCA

ICBO

SBCC

AInA
The BOCA Basic Building Code

The Uniform Building Code

Standard Building Code

National Building Code
809.4

1204

1104.4

$382.3(b) ; 382.3(c)$ 


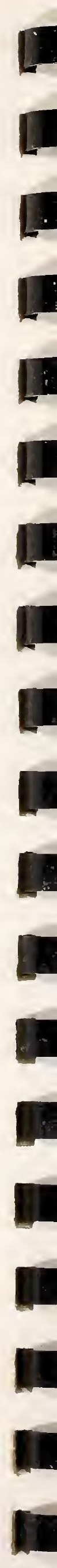




\begin{tabular}{l|l|l|l|l|l|l|l|l|}
\hline B-M & LIGHT AND VENTILATION & & A2 & A3 & & & & \\
\hline
\end{tabular}

(SEE FIG. 1)

Each of the model building codes makes provision for light and ventilation for habitable and occupiable rooms. Generally, habitable rooms; i.e., rooms used for sleeping or living purposes, are required to have at least one or more windows, skylights, monitors, glazed doors, transoms, glass block panels or other light transmitting media to provide natural light and ventilation. The required window opening shall face an approved open space such as a street, alley, yard, or court, although under certain conditions exceptions may be made. The required glass area is sometimes specified as well as requirements for opening and type of glazing. The BOCA code specifies the natural light levels in foot-candles of illumination and natural ventilation in cubic feet of air per occupant.

Where the natural light and ventilation do not meet the minimum requirements, artificial light and mechanical means of ventilation, under certain conditions, may be used. For artificial ventilating systems, the number of air changes per hour is sometimes specified as well as the percentage of supply air to be taken from the outside, recirculation provisions, and certain requirements for bathrooms, kitchens, and other special rooms.

Specifically, the BOCA lighting requirements are based on two hundred and fifty (250) foot candles of illumination on the vertical plane adjacent to the exterior of the light transmitting device in the enclosure wall and shall be adequate to provide an average illumination of six (6) foot-candles over the area of the room at a height of thirty (30) inches above the floor level. In addition, BOCA and SBCC generally require windows to have a glazed area not less than eight (8) percent of the floor area of the room with one-half (1/2) of the area available for unobstructed ventilation. The ICBO and the AInA codes, however, specify a minimum of one-tenth $(1 / 10)$ the floor area and this area to be at least ten (10) square feet. AInA requires bathrooms to have a glazed area of not less than three (3) square feet while ICBO precribes a minimum of one and one-half $(1 / 12)$ square feet for bathrooms, water closet compartments, laundry and similar rooms.

The mechanical ventilation provisions of ICBO specify that the system shall be capable of providing two air changes per hour in all guest rooms, dormitories, habitable rooms and in public corridors. One-fifth of the air supply shall be taken from the outside. In bathrooms, water closet compartments, laundry rooms and similar rooms a mechanical ventilation system connected directly to the outside, capable of providing five air changes per hour, shall be provided. The BOCA code provides the standard of natural ventilation for all habitable and occupied rooms to be based on a volume of four hundred (400) cubic air per occupant. ICBO requires that all guest rooms, dormitories and habitable rooms within a dwelling unit shall be provided with natural ventilation by means of openable exterior openings with an area of not less than one-twentieth of the floor area of such rooms with a minimum of five (5) square feet.

Finally, both BOCA and SBCC address the need for adequate additional ventilation to ensure safe and healthful conditions in rooms where by reason of use or occupancy, dust fumes, gases, vapors, odors or other hazardous, obnoxious, or injurious impurities exist. 


\begin{tabular}{l|l|l|l|l|l|l|l|l|}
\hline B-M & LIGHT AND VENTILATION (CONTINUED) & & A2 & A3 & & & & \\
\hline
\end{tabular}

(SEE FIG. 1)

With regard to the installation of phase-change materials, these provisions directly affect those air systems which also function as collectors and are classified as individual "window" units and systems directly connected to the building ductwork. In addition, these requirements may also affect the installation of free-standing phase-change packages when placed in front of a window. However, since they are not physically integrated into the building, the building official may not be aware of their potential installation unless, perhaps, shown on a drawing.

Since the phase-change devices would be installed in a configuration which will obstruct natural light and ventilation, difficulty may be encountered by the builder or designer in receiving acceptance for such installation. These restrictions may be overcome through the use of skylights, transparent translucent roof panels, or light from other sources along with artificial ventilation. Alternatively, these units could be installed in conjunction with conventional windows so that the assemblies are, in effect, placed in a wall rather than in a window.

\section{REFERENCES}

Organization

Code

Section

BOCA

ICBO

SBCC

AInA
The BOCA Basic Building Code

The Uniform Building Code

Standard Building Code

National Building Code
$702.1 ; 703.1 ; 704.1$; $704.2 ; 704.3 ; 706.1$; $706.2 ; 706.3 ; 706.4$

1205 (a)

2001.1(a); 2001.1(b); 2001.1(d); 2001.1(e); 2001.1(f)

$382.3(\mathrm{a}) ; 601.2(\mathrm{a})$; $603.2(\mathrm{a}) ; 603.2(\mathrm{~b})$; $603.2(\mathrm{c}) ; 603.2(\mathrm{~d})$; $603.3(\mathrm{a}) ; 603.3(\mathrm{~b})$; $603.3(c) ; 603.3(d)$. 


\begin{tabular}{l|l} 
B-N & DESIGN LOADS AND TESTS \\
\hline
\end{tabular}

The building codes contain a number of provisions to assure the structural adequacy of a building. This includes the ability to safely support all loads without exceeding the allowable stress for the materials used. This includes live loads, dead loads, and all other loads specified by the particular code, such as impact loads, which are identified in the ICBO code. Provisions are made to consider wind and earthquake loads and the hazards associated with progressive collapse, such as that due to local failure caused by severe overloads or abnormal loads not specifically called out by the code. In all cases, consistency with good engineering practices is required. Where there is reason to question the safety of a structural element, all codes state that the building official may require the material or configuration to be tested to determine its structural adequacy.

Regarding the requirements for testing, the SBCC and BOCA codes require that, if a load test is necessary to determine the stability of a construction, the structure in question must sustain a superimposed load equal to twice the design live load and must recover at least $75 \%$ of its maximum deflection within 24 hours after the load is removed. If the structure shows evidence of failure, the building official may order modifications, or he may reduce the working load. Also, when the structural assembly or unit has been approved through the required testing, BOCA states that it must sustain two and one-half times the required live load and, under working load, not exceed the deflection limits prescribed. The AInA code will consider the member or assembly safe if the deflection, after the design load has been applied for 6 hours, does not exceed the deflection computed by engineering formulas for the material used. Where this deflection is exceeded, the member or assembly is permitted to be considered safe, if, after the member or assembly is loaded for a duration of 18 hours to two times the design live load in increments not exceeding $20 \%$ of the design live load and at a rate which allows time intervals of not less than 10 minutes for each increment, recovery of the member or assembly 24 hours after removal of the test load is not less than $75 \%$ of the maximum deflection.

The BOCA code requires that the design strengths and permissible stresses of all controlled materials in the structure conform to the specifications and methods of design of accepted engineering practice. Ordinary materials used without selection and without controlled design and supervision, or when the material is not identified as to strength and stress grade, are limited by BOCA to the average working stress that the code approves. Tests are provided to be used to establish the working stresses of materials not specifically addressed in the BOCA code. 


\begin{tabular}{l|l|l|l|l|l|l|l}
\hline $\mathrm{B}-\mathrm{N}$ & DESIGN LOADS AND TESTS (Continued) & Al & & & & & \\
\hline
\end{tabular}

(SEE FIG. 1)

The ICBO code states that every building component must have adequate strength to resist the most critical effect resulting from the following combination of loads: (the live load is not to be included where its inclusion will result in lower stresses in the member under investigation) 1. - Dead plus floor live plus roof live (or snow). 2. Dead plus floor live plus wind (or seismic). 3. Dead plus floor live plus wind plus snow/2. 4. Dead plus floor live plus snow plus wind/2. 5. Dead plus floor live plus snow plus seismic. In these combinations, crane hook loads need not be combined with roof live load nor with more than threefourths of the snow load or one-half wind load. Also, snow loads over 30 psf can be reduced $75 \%$ upon approval of the building official, and snow loads 30 psf or less need not be combined with seismic. The ICBO code also requires that a rational analysis in accordance with wellestablished principles of mechanics be used as the basis for any system or method of construction to be used. This code then defines a rational analysis as one which results in a system that provides a complete load path capable of transferring all loads and forces from their point of origin to the load-resisting elements. The code requires that this analysis include but not be limited to the following: distribution of horizontal shear, horizontal torsional moments, stability against overturning, and anchorage.

When structural members are arranged so as to create continuity, the ICBO code also requires that the loading conditions which would cause maximum shear and bending moments along the member be investigated. All allowable stresses and soil-bearing values specified in the ICBO code for working stress design may be increased by $1 / 3$ according to this code, when considering wind or earthquake forces either acting alone or when combined with vertical loads. No increase is allowed by the ICBO code for vertical loads acting alone. Load factors for ultimate strength design of concrete and plastic design of steel are indicated in the applicable materials chapters of the ICBO code.

When structural testing is required by the building official, the code, or the approved rules, the BOCA code also requires that the material or construction shall be subjected to sustained and repetitive loading to determine its resistance to fatigue, and to tests for durability and weather resistance. Also, BOCA requires that all materials be tested to assure the maintenance of the standards of approved materials when reasonable doubt exists as to quality and when required by the building official.

The AInA code states that all workmanship in fabrication, preparation, and installation of materials must conform to accepted good practice and be safe to persons and property. 


\begin{tabular}{l|l|l|l|l|l|l|l}
\hline B-N & DESIGN LOADS AND TESTS (Continued) & AI & & & & & \\
\hline
\end{tabular}

(SEE FIG. 1)

The BOCA code references tests and standards which should be followed in determining flash points, combustibility, flame resistance, and fire resistance ratings of construction materials and methods. The BOCA code also addresses test procedures and methods. It states that the selection and construction of all test specimens and the details of test procedures required by this code must conform to the recognized test procedures listed therein. All constructions to be tested must be truly representative of the materials workmanship and details which are normally applied in practice. When structural or fire-resistant properties are dependent on adequate curing, the BOCA code requires that the age of the specimen be not less than seven nor more than 28 days, unless otherwise approved by the building official.

The BOCA code also states criteria upon which structural requirements should be based. Deflection of roof and floor assemblies, under approved working loads, cannot be greater than 1/360 of the span for plastered construction, $1 / 240$ of the span for unplastered floor construction, and 1/180 of the span for unplastered roof construction. Bearing walls and partition assemblies must sustain the load test both with and without window framing. The BOCA code further states that the building official may require comparative tests of assemblies of standard traditional forms of construction used for similar purposes if test data is not available to assist him in determining the adequacy of a new construction. When not capable of design analysis, all floor constructions to be evaluated under the BOCA code must be subjected to concentrated loads of the use group specified when such loading exceeds in stress effect the uniformly distributed load specified for such uses. The BOCA code also requires that all finish floor construction using light gage metal or other thin materials as a structural floor must withstand the application of a $200 \mathrm{1b}$. concentrated load applied to the top surface of an area of one square inch at any point or points of the construction designated bv the building official.

The AInA code requires that any temporary supports placed in or under a building or portion thereof should be of a sufficient strength to carry the load to be supported without exceeding allowable stresses. This code also permits higher stresses than specified only if it is established by test or other approved evidence that a higher grade material or superior workmanship is to be employed. The AInA code also requires that in buildings used for business, high hazard, industrial, mercantile, or storage occupancies, the approved floor loads apply. This code also prohibits any person placing or permiting to be placed on any floor or roof of the building, a load greater than the unit load for which it has been designed. 


\begin{tabular}{l|l|l|l|l|l|l|l|l}
\hline $\mathrm{B}-\mathrm{N}$ & DESIGN LOADS AND TESTS (Continued) & Al & & & & & \\
\hline
\end{tabular}

(SEE FIG. 1)

These provisions would directly apply to building elements and components that are structurally integrated and configured to contain phase-change materials. Since the properties of these materials may be uncertain, extensive testing may be required to demonstrate their ability to adequately function under their intended use. Acceptance of these products will become common after testing and use prove them to be reliable products.

\section{REFERENCES}

901.1, 901.2, 901.3, 902.1, $902.2,919.1,919.2,919.3$, $1102.1,1102.2,1102.3,1102.4$ $1102.5,1102.6,1102.7,1102.9$, $1103.1,1103.2,1103.3,1103.4$, $1103.5,1103.6,1103.7$

IBCO

SBCC

AInA
The Uniform Building Code

Standard Building Code

National Building Code $2303(\mathrm{a}), 2303(\mathrm{f}), 2303(\mathrm{~b})$, $2303(\mathrm{c}), 2303(\mathrm{~d}), 2303(\mathrm{e})$

$1201,1203.10$

900 (a) $, 900(d), 901(b), 901(c)$, $901(\mathrm{a}), 900(\mathrm{~b}), 900(\mathrm{c}), 900(\mathrm{e})$ 900 (f) 


\begin{tabular}{l|l|l|l|l|l|l|l|}
\hline B-0 & FIRE RESISTIVE RATINGS & AI & & & & & \\
\hline
\end{tabular}

(SEE FIG. 1)

The building codes all contain provisions regulating the fire resistive requirements for building structural elements for different types of construction and use. The acceptance of commonly used materials in different thicknesses, assemblies, and configuration is based on demonstrated performance over many years or through fire testing successfully performed by an approved laboratory using standardized fire testing methods. The standard fire test method specified by the building codes is the "Standard Methods of Fire Tests of Building Construction and Materials, ASTM E119." Since the fire-resistive ratings are articulated differently in each code, the appropriate code should be studied carefully to understand the specific requirements.

The BOCA code requires built up masonry units and composite assemblies of structural materials including walls, partitions, columns, girders, beams, slabs and assemblies of slabs and beams or other combinations of structural units for use in floor and roof construction to be regulated by the fire resistance ratings as indicated in Table 401 of the code. In addition, floor assemblies which are required to be fire resistance rated must extend to and be tight against exterior walls or other provisions be made for maintaining the fire resistance rating of the assembly at such locations.

ICBO requires that materials and systems used for fire resistive purposes be limited to those specified in the code unless conforming to the UBC standards specifically regulating such materials. For the purpose of determining the degree of fire resistance afforded, the materials of construction are assumed to have the fire resistance rating indicated. Any material or assembly of materials of construction tested in accordance with the requirements in U.B.C. Standard No. 43-1 are to be rated for fire resistance in accordance with the results and conditions of such tests. As an alternate, fire resistive construction may be approved by the building official on the basis of evidence submitted by the person responsible for the structural design showing that the construction meets the required fire resistive classification. The code further states that fire resistive assemblies tested under U.B.C. Standard No. 43-1 are not considered restrained unless evidence satisfactory to the building official is furnished by the person responsible for the structural design showing that the construction qualifies for a restrained classification in accordance with U.B.C. Standard No. 43-1. Restrained construction is required to be identified on the plans.

The SBCC fire protection requirements are based on fire resistance ratings, materials, thicknesses, and assemblies which have successfully performed under tests made by a recognized laboratory in accordance with the requirements of the "Standard Methods of Fire Tests of Building Construction and Materials, ASTM E119." Other methods are acceptable if they are based on calculations, testing and accepted engineering practices as set forth in Appendix $B$ of the code. 


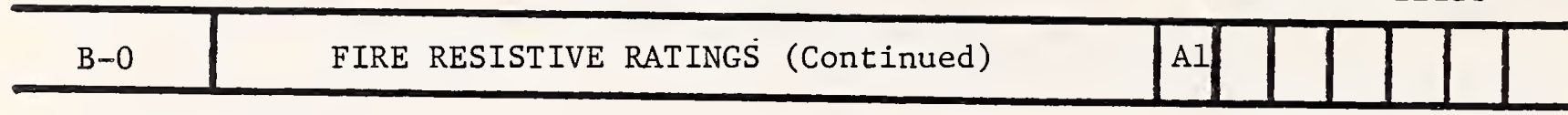

(SEE FIG. 1)

Thicknesses as established by said tests are construed as establishing minimum requirements for fire resistance only, and shall not preclude the application of other requirements of the SBCC code where consideration of strength, durability or stability require greater thicknesses. Fire doors, curtains, shutters, windows, or other protection required for openings in fire resistive walls, shall also be in accordance with the requirements of the SBCC code. The penetration of fire resistant walls or partitions, floors, or floor ceiling assemblies for electrical, telephone, plumbing air conditioning, intercommunication systems or similar facilities are not permitted unless such openings are installed in such a manner that the required fire resistance is not decreased. When walls, floors and partitions are required to have a minimum one (1) hour or greater fire resistance rating, cabinets, bathroom components, lighting and other fixtures are to be so installed such that the required resistance will not be reduced. Excepted are fixtures which are listed for such installation.

The AInA requirements are set forth in Appendix B of the code. It states that the AINA publishes a loose-leaf book entitled "Fire Resistance Ratings" which should be utilized in combination with the "Fire Resistance Index" published by Underwriters Laboratories Inc. or the "List of Equipment and Materials, Volume II" published by Underwriters Laboratories of Canada to determine the acceptability of construction assemblies (beam, girder and truss protections and assemblies; wall and partition assemblies; floor-ceiling and roof-ceiling assemblies; and column protections and assemblies) considered "approved" as defined in the National Building Code. In addition, "Fire Resistance Ratings" is intended to provide guidance as to the construction of assemblies which are required by provisions of codes or regulations to have fire resistance ratings of $1,1-1 / 2$, $2,2-1 / 2,3$ and 4 hours. Its use by building inspectors and other public officials, architects, engineers, and others interested in fire safety in buildings is encouraged.

Descriptions of assemblies are given in terms of minimum requirements necessary to obtain the assigned fire resistance ratings. Ratings are given in terms of hours and half-hours (where applicable) to fit the requirements for fire resistance given in building codes. Unless otherwise noted, ratings for beams and floor-ceiling or roof-ceiling assemblies are given for assemblies considered to be restrained against thermal expansion.

In addition to ratings based on standard fire tests conducted substantially in accordance with "Standard Methods of Fire Tests of Building Construction and Materials," ASTM E119, or UL 263 or NFPA 251, the publication contains estimated ratings of certain forms of construction which have been commonly recognized and used for many years, but for which standard test data have not been available. In judging and interpreting test results it is necessary to carefully analyze the test data, if ratings therefrom are to be on a comparable basis. With many of the older fire tests, the fire exposure, and, with many of the early tests on floor assemblies, unexposed surface temperatures were not observed. Many of the tests on columns, conducted prior to 1925 , were made with column loads somewhat lower than permitted today. In certain cases this necessitates 


\begin{tabular}{l|l|l|l|l|l|l|l}
\hline B-0 & FIRE RESISTIVE RATINGS (Continued) & Al & & & & & \\
\hline
\end{tabular}

(SEE FIG. I)

consideration of the effect of greater loads on the fire resistance rating. Many tests have been conducted on samples smaller than the minimum size specified in the standard fire test method. Such tests cannot be considered the equivalent of tests made on samples of standard size. In some cases they may be satisfactory in determining heat transmission characteristics, from which fairly reliable estimates of the fire resistance rating may be made, provided other characteristics affecting performance in the standard fire test have been established, but such estimates are made with considerable caution. These factors have been taken into account in arriving at the ratings assigned to the assemblies described in "Fire Resistance Ratings" and all ratings are based on use of materials and forms of construction in full conformity with the requirements of the National Building Code.

Although some degree of duplication between "Fire Resistance Ratings" and the "Fire Resistance Index" or "List of Equipment and Materials, Volume II" may exist it should be noted that, for various reasons, not all assemblies described in the publications by Underwriters Laboratories Inc. or Underwriters Laboratories of Canada are described in "Fire Resistance Ratings." In addition, "Fire Resistance Ratings" contains many descriptions of, and assigns ratings to, many assemblies of a nonproprietary nature which are not described in either of the other two publications.

Descriptions of assemblies have been broken down in a way to enable easy reference to types of materials of interest to users of the publication.

To summarize, phase-change thermal storage devices that are integrated into the building structure would generally have to be fire rated depending on the circumstances of use. The fire rating would have to be established through the construction of a fabricated assembly that reasonably represents the in-use configuration of that assembly and tests performed in accordance with the approved test procedure. If the material is to be used in difference configurations or thicknesses, tests would be required for each variation unless a clear interpolation can be made from the data. Final approval for use of the system may be based on other considerations such as structural strength or durability.

\section{REFERENCES}

Organization

Code

Section

$\begin{array}{ll}\text { BOCA } & \text { The BOCA Basic Building Code } \\ \text { ICBO } & \text { The Uniform Building Code } \\ \text { SBCC } & \text { Standard Building Code }\end{array}$

AInA
National Building Code
1403.1
$4302(a) ; 4302(b)$
1001 (a); 1001(b); 1001 (c); $1001(\mathrm{~d}) ; 1001(\mathrm{e}) ; 1001(\mathrm{f})$; 1703.3
Appendix B 


\begin{tabular}{l|l|l|l|l|l|l|l|l|l|}
\hline B-P & HIGH HAZARD BUILDINGS & AI & & & & \\
\hline
\end{tabular}

(SEE FIG. 1)

The building codes classify buildings by use group and provide for fire safety and other levels of protection appropriate to that use group. Use groups are classified similarly in each of the codes and some of the common groups are:

\section{ASSEMBLY \\ BUSINESS \\ EDUCATIONAL \\ HAZARDOUS \\ FACTORY-INDUSTRIAL}

\section{INSTITUTIONAL MERCANTILE \\ RESIDENTIAL STORAGE}

This section addresses high hazard buildings which derive their classification by virtue of the highly combustible or explosive products or materials used in the building for storage purposes, manufacturing, or processing. For mixed occupancies within the same building, the provisions applying to each class of occupancy shall apply except if the provision conflicts, then the requirements providing the greater safety shall prevail. The codes generally require the building official to determine the classification of a building whenever there is uncertainty regarding its use.

The BOCA Code also describes high hazard buildings as those which store, manufacture, or process highly corrosive, toxic, or noxious alkalies, acids or other liquids or chemicals producing flame, fume, poisonous, irritant or corrosive gases; and those buildings used for storage or processing of materials producing explosive mixtures of dust, or which result in the division of matter into fine particles subject to spontaneous ignition. The BOCA code also lists the processes, materials and manufacturers which are indicative of and should be included among high hazard uses.

The ICBO code defines divisions of high hazard occupancies. Division 1 concerns the storage, handling, use or sale of hazardous and highly flammable or explosive materials other than flammable liquids, except if the quantity of hazardous materials are below those maximums listed in this code, and the activities concerning these materials are in compliance with the Fire Codes. In these cases, hazardous materials are permitted in other occupancies. Division 2 involves the storage, handling, sale or use of Classes I, II and III-A liquids; dry cleaning plants using Class I, II, or III-A liquids; paint stores with bulk handling; paint shops and spray-painting rooms or shops. These materials, however, are permitted in other occupancies if the quantities do not exceed the maximums listed in this code, and the activities concerning these materials are in compliance with the Fire Code. Division 3 involves woodworking establishments, planing mills, box factories, buffing rooms for tire-rebuilding plants and picking rooms; shops, factories, or warehouses where loose combustible fibers or dust are manufactured, processed, generated, or stored, and pin-refinishing rooms. Division 4 are repair garages not classified as a Group B, Division 1. Division 5 concerns aircraft repair hangers. Special provisions involve buildings used for educational purposes, vocational shops, laboratories, and similar areas. These buildings need not be classified as Group H Occupancies if:hazardous areas are separated from classrooms other than the classroom directly related to the use by not less than a one-hour fire-resistive occupancy separation; such areas are separated from each other by not less than a one-hour fire resistive occupancy separation unless the uses are determined to be compatible; 


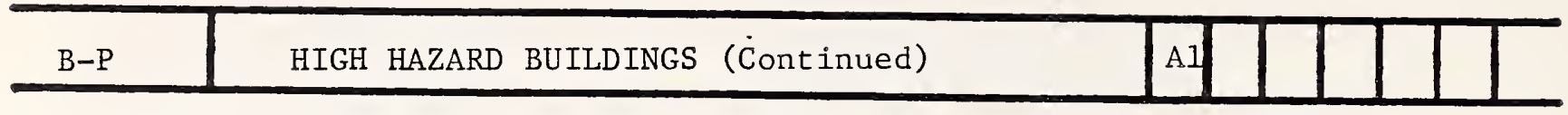

(SEE FIG. 1)

all applicable requirements on this code and the Fire code are met. This code also states that where an approved spray booth is constructed as specified in the Fire Code, it need not be separated from other Group H or B occupancies.

Table No. 9-A of the ICBO code lists exempt amounts of hazardous materials, liquids and chemicals.

The SBCC.code, in addition to defining hazardous occupancy in a manner similar to the BOCA code, also lists materials or products which are considered hazardous and the quantities of these materials above which constitute special hazardous materials.

The AInA code also lists specific materials and their characteristics which constitute a safety hazard.

The effect of the introduction of phase-change materials into a building for thermal storage, from a building use classification perspective, is unclear. Certainly, the commonly used materials in the salt hydrate category are relatively inert with regard to fire or explosive hazards. Other materials in the paraffin category are more hazardous, and the risks must be evaluated in terms of the properties of the specific material and the quantities involved. Systems using sulfuric acid, although classified as thermochemical systems, rather than phase-change systems, also present a hazard.

The provisions described in this section represent the worst case with regard to building classifications, and if a building were classified hazardous because of the introduction of large quantities of phase-change material, the increased requirements for fire protection and other safety requirements would certainly affect the economics of the system in an adverse manner. The introduction of smaller quantities of materials of unknown combustible or explosive properties could cause concern with the building official and, although the building which is to contain the phase-change material would not be placed in the hazardous classification, some additional fire protection requirements could be imposed.

Finally, there is the danger that large quantities of combustible phase-change material may be packaged as free standing devices that are meant to be placed next to a window or some other location to take advantage of excess heat by storing this heat for later release. This type of material would normally not be indicated on building drawings and not brought to the attention of the building official. The inherent danger of packaging and using this material should be reviewed carefully so that unsuspecting individuals are not exposed to any unnecessary danger in the interest of energy conservation. 


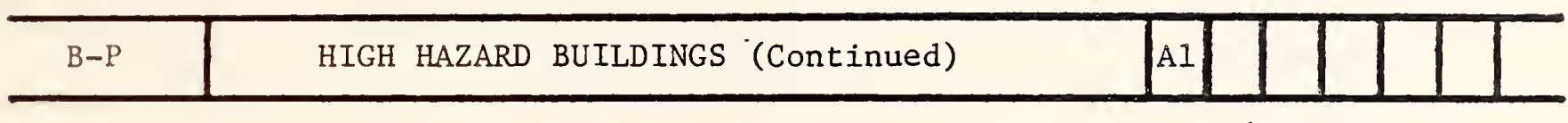

(SEE FIG. 1)

\section{REFERENCES}

\begin{tabular}{cll} 
Organization & \multicolumn{1}{c}{ Code } & \multicolumn{1}{c}{ Section } \\
\hline BOCA & The BOCA Basic Building Code & $305.1,305.2$, Table 305.2 \\
ICBO & The Uniform Mechanical Code & 901, Table No.9-A \\
SBCC & Standard Mechanical Code & $407.5(\mathrm{a}), 407.5(\mathrm{~b}), 407.5(\mathrm{c})$ \\
AInA & National Building Code & $300.2(\mathrm{e}), 300.3,300.4$,
\end{tabular}




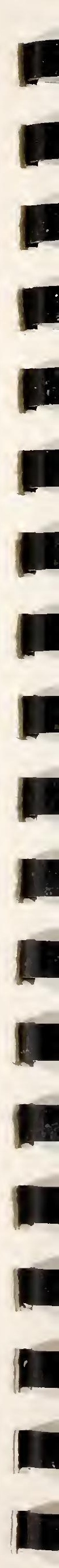




\begin{tabular}{l|l|l|l|l|l|l|l|l}
\hline $\mathrm{B}-\mathrm{Q}$ & MISCELLANEOÚS & $\mathrm{A} 1$ & $\mathrm{~A} 2$ & $\mathrm{~A} 3$ & $\mathrm{~A} 4$ & & & \\
\hline
\end{tabular}

(SEE FIG. 1)

There are additional provisions in the building codes that could have an effect on the installation of phase-change thermal storage devices that cannot be easily combined into the topics already covered by this building code study. These miscellaneous items cover (a) plenums; (b) tanks; and (c) acoustical ceiling systems.

\section{A. PLENUMS}

The BOCA building code contains a provision addressing plenums. The wording is essentially the same as contained in Section M-301.1 of the BOCA mechanical code. The provision states that the use of uninhabited basements, cellars, cavity walls, areas above ceilings or attic spaces as supply, make up, exhaust air or return air plenums or ducts is prohibited. Excepted from this rule are air ceiling plenums installed as supply or return air plenums in all occupancies except buildings of Use Group R-3, provided such air plenums meet the requirements of other applicable articles of the building code and provided fuel fired equipment or exposed combustible materials are not located therein. The use of air ceiling plenums are required to be confined to one fire area. The floor or roof assembly above an unlisted air ceiling plenum is not to depend upon the air ceiling for a portion of its fire resistance rating. Insulated cold water, hot water, steam and fire protection piping, building sanitary and storm drains, and vent systems may be installed in air ceiling plenums. Electrical wiring and equipment in air ceiling plenums are to conform to the requirements of the National Fire Protection Agency (NFiPA70) and the use of air ceiling plenums in evaporative cooling systems is prohibited. Panning of the joist or stud space tor return air is permitted in buildings of Use Group $\mathrm{R}-3$ only.

The impact of these provisions on phase-change storage devices is included in provision topic M-I. (See Section 6.)

\section{B. TANKS}

The SBCC building code contains several provisions regarding tanks. These provisions cover the structural support of these tanks, detail some construction requirements, discuss provisions for emptying the contents in an emergency, and specify certain placement requirements. The code specifically requires tanks of more than five hundred (500) gallons capacity placed in or on a building to be supported on masonry, reinforced concrete or steel construction, except that portion of the supporting structure which is above the roof of the building may be of heavy timbers; provided that when such construction is within the building it conforms to the requirements for Type I Construction. Such tanks shall have in the bottom or on the side near the bottom, a pipe or outlet, fitted with a suitable quick opening valve for discharging the contents in an emergency through an adequate drain. Such tanks are not to be placed over nor near a line of stairs or an elevator shaft, unless there is a solid roof or floor underneath the tank. All unenclosed roof tanks are required to have covers sloping toward the outer edges and when hoops are used in the construction of tanks, they should be of metal, and provision shall be made to guard against corrosion. 


\begin{tabular}{l|l|l|l|l|l|l|l|l}
\hline $\mathrm{B}-\mathrm{Q}$ & MISCELLANEOUS (Continued) & A1 & A2 & A3 & A4 & & & \\
\hline
\end{tabular}

(SEE FIG. 1)

These provisions generally would not seem applicable since phase-change devices using a liquid as the working fluid would normally have a capacity of less than 500 gallons. If, however, a large system were constructed, the above provisions may apply. The requirement for a suitable quick opening valve for discharging the contents, however, may be an undesirable feature unless the system and the characteristics of its contents are analyzed for any undesired consequences of draining such a system as stated in the provision.

\section{ACOUSTICAL CEILING SYSTEMS}

The SBCC building code addresses acoustical ceiling systems. The code covers installation requirements as well as the quality, design, fabrication, and erection of the metal suspension system. In addition, interior finish and fire-resistive construction are detailed.

The code requires the quality, design, fabrication and erection of metal suspension systems for acoustical tile and lay-in panel ceilings in buildings or structures to conform to good engineering practice. Acoustical materials complying with the interior finish requirements shall be installed in accordance with the manufacturer's recommendations and applicable provisions for applying interior finish. Suspended acoustical ceiling systems are to be installed in accordance with the provisions of "Standard Specification for Metal Suspension Systems for Acoustical Tile and Lay-In Panel Ceilings" ASTM C635 and "Recommended Practice for Installation of Metal Ceiling Suspension Systems for Acoustical Tile and Lay-In Panels" ASTM C636. Acoustical ceiling systems which are part of a fire-resistive construction shall be installed in the same manner used in the assembly tested. If the weight of lay-in ceiling panels, used as a part of fire-resistive floor-ceiling or roofceiling assemblies, is not adequate to resist an upward force of one (1) pound per square foot, wire or other approved devices shall be installed above the panels to prevent upward displacement under such upward force.

The ICBO code also addresses the installation of acoustical ceiling systems and suspended tiles and such installation is guided by the provisions contained in UBC Standard No. 47-18. In addition, horizontal force factors are included for suspended ceiling framing systems for application in active seismic zones. 


\begin{tabular}{l|l|l|l|l|l|l|l|l}
\hline B-Q & MISCELlANEOUS (Continued) & Al & A2 & A3 & A4 & & & \\
\hline
\end{tabular}

(SEE FIG. 1)

The use of a phase-change material sandwiched in a ceiling tile configuration has been demonstrated as a workable storage system. The code requirements regarding suspension requirements, finish, fire-resistive construction, etc. for ordinary accoustical ceiling systems and suspended tiles should generally be applicable to phase-change configurations as well.

\section{REFERENCES}

A. PLENUMS

BOCA

The BOCA Basic Building Code

1405.10 .1

B. TANKS

SBCC

Standard Building Code

$713(\mathrm{a}) ; 713(\mathrm{~b}) ; 713(\mathrm{c})$;

$713(d) ; 713(e)$

C. ACOUSTICAL CEILING SYSTEMS

ICBO The Uniform Building Code

Table 23-Ji 4701 (e)

SBCC Standard Building Code 


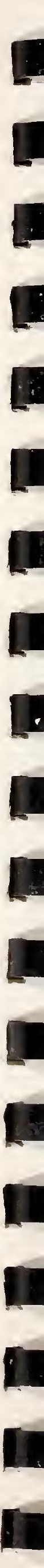


6. TOPICS AND PROVISIONS OF THE MODEL MECHANICAL CODES RELEVANT TO

PHASE CHANGE SYSTEMS

\subsection{OVERVIEW}

This section addresses those provisions contained in the Model Mechanical Codes that would impact phase change thermal storage systems when they are integrated into the temperature comfort conditioning systems in buildings. Each of the issues presented is organized into a "provision topic" which aggregates the code information related to that topic by identifying the code and section and then detailing the specific provision language found in that section. Provisions common to more than one code are quickly recognized and the degree of commonality or divergence between codes is easily distinguished. Each provision topic is discussed from a code perspective and the impact of these issues upon system design and installation is provided.

A "reference" designator is also included in the heading of each provision topic which keys to the Appendix. In the Appendix, each of the model mechanical codes are shown. The topics discussed in this report are cross-referenced to the table of contents, or provisional outline, of each of the model mechanical codes. In this format, the user of the Appendix is directed by the code reference to the applicable provision topic and change issue found in the report. In addition, the "applicability" boxes shown in the heading of each provision topic found in the report refer to the appropriate phase change material classification, as shown in Figure 1, and as defined in the text.

The material presented on the following pages, although paraphrased, is based on the model codes referenced under each provision topic. These model codes are copywritten material published periodically by each of the model code organizations (see page 50 for complete listing of these codes and the names of the parent organizations). The user should refer directly to the source document(s) applicable to the jurisdiction in question if specific provisions are required for design, installation, maintenance, or other needs. 


\subsection{TOPICS AND PROVISIONS}

M-A Purpose and Scope

$M-B$ Definitions

$M-C \quad$ Repair and Maintenance

$M-D$ Alternate Measures

M-E Unsafe Conditions

M-F Review of Plans and Specifications

$M-G$ Inspections

M-H Use of Approved Materials and Equipment

$\mathrm{M}-\mathrm{I}$ Plenums

$\mathrm{M}-\mathrm{J}$ Heating Equipment in Crawl Spaces

$\mathrm{M}-\mathrm{K}$ Air Filters

$\mathrm{M}-\mathrm{L}$ Insulation

M-M Manufacturer's Instructions

$\mathrm{M}-\mathrm{N}$ Motors, Fans, and Blowers (Electrical Requirements)

M-0 Access

M-P Attic Installation

$\mathrm{M}-\mathrm{Q}$ Clearances

M-R Non-Combustible Construction

M-S Flame Spread Ratings

M-T High Pressure Requirements

$\mathrm{M}-\mathrm{U}$ Joining of Pipes

$\mathrm{M}-\mathrm{V}$ Tank Mounting and Protection

$M-W$ Roof and Outdoor Installation

$\mathrm{M}-\mathrm{X}$ Water Supply Connections

$\mathrm{M}-\mathrm{Y}$ Controls

$\mathrm{M}-\mathrm{Z}$ Miscellaneous 
(SEE FIG. 1)

of all the model mechanical codes, only ICBO contains a definitive statement of purpose. The purpose stated is to provide minimum standards to safeguard life or limb, health, property, and public welfare by regulating and controlling the design, construction, installation, quality of materials, location, operation, and maintenance and use of heating, ventilating, cooling, refrigeration systems, incinerators and other miscellaneous heat producing appliances within the jurisdictions. Although the other model codes do not contain such definitive statements, the code provisions, in aggregate, are written in a manner which is generally in keeping with the above purpose. Also, as is generally true in most model codes, the efficiency, economy, effectiveness, or durability of systems are not directly addressed although through the control of design, materials, and installation the above attributes are usually influenced in a positive manner.

Since the scope of each of the mechanical codes covers mechanical systems, heating systems, water heaters, cooling systems, hot water systems, pressure vessels, etc., the responsibility for phase-change thermal storage devices would seem to lie with the mechanical official. An exception could be those phase-change thermal storage devices which are free standing along with those which are building integrated. There is also a question of responsibility concerning those systems which utilize water as the heat transport medium and those systems which supply domestic hot water to a building.

Although phase-change thermal devices are not mentioned in the mechanical codes, the nature and function of these devices in heating, cooling, or hot water systems would, in most cases, bring them under the purvue of the mechanical official. As stated above, an exception might be the free standing and building integrated storage devices. However, even for this situation, a building integrated device such as an interior thermal storage wall containing phase-change materials built next to a window might be considered a heating device if a fan were installed to enhance the natural convective heat flow. In other cases, systems using a phase-change thermal storage device located somewhere in the air stream to capture and release heat may be viewed as being beyond the jurisdiction of the mechanical official if there is a structural concern or if the phase-change material is used to heat or preheat domestic hot water. For these cases, the building and plumbing official may also claim jurisdiction.

\section{REFERENCES}

Organization

Code

Section

BOCA

ICBO

SBCC

AInA
The BOCA Basic Mechanical Code

The Uniform Mechanical Code

Standard Mechanical Code

National Building Code
$\mathrm{M}-100.2 ; \mathrm{M}-100.3$

$102 ; 103$

101.3

Appendix E-1.la 


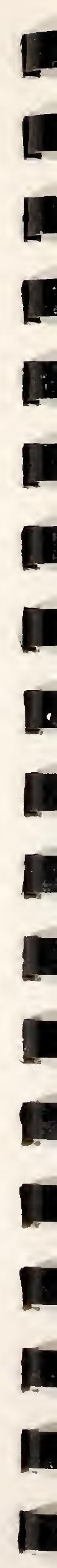




\begin{tabular}{l|l|l|l|l|l|l|l|l|l|l|l}
\hline$M-B$ & DEFINITIONS & Al & Al & A3 & A4 & L1 & L2 & L3 \\
\hline
\end{tabular}

(SEE FIG. 1)

Each of the mechanical codes contains a section on definitions to aid the user in understanding the code. When applying the information in this report, the reader should refer to the specific code of interest, and if there is any doubt about the technical meaning of a word, the definition section of the code should be consulted. It should be noted, that many of the definitions in each of the mechanical codes are identical while other definitions, although worded differently, are similar in intent. Some definitions for the same word in the different mechanical codes, however, contain subtle differences and nuances and should be read carefully for their full meaning and implication.

REFERENCES

Organization

Code

Section

\begin{tabular}{lll}
\hline BOCA & The BOCA Basic Mechanical Code & M-201.0 \\
ICBO & The Uniform Mechanical Code & 403 through 425 \\
SBCC & Standard Mechanical Code & 201 \\
AInA & National Building Code & 200, Appendix E, Sect. 1.7
\end{tabular}




\begin{tabular}{l|l|l|l|l|l|l|l|l|l}
\hline $\mathrm{M}-\mathrm{C}$ & REPAIR AND MAINTENANCE & & A2 & A3 & A4 & L1 & L2 & L3 \\
\hline
\end{tabular}

(SEE FIG. 1)

The mechanical codes generally require that all mechanical systems, both existing and new, and all parts thereof, be maintained in a safe and hazardfree condition. In addition, all devices or safeguards required by the codes are to be maintained in good working order and ICBO also specifies that the devices and safeguards be maintained in conformance with the code edition under which installed. Both ICBO and SBCC state that the owner or his designated agent are responsible for the maintenance of mechanical systems and equipment. BOCA also provides that minor repairs or replacements of any existing system may be made in the same manner and arrangement as in the existing system, provided that such repairs or replacements are made in a safe manner and are approved by the mechanical official.

In the above context, a mechanical official could question the installation of phase-change devices if the supporting infrastructure, including spare parts, skilled technicians, etc. were not available to properly service, maintain, or repair the equipment. This may be particularly true for innovative devices where the longevity of the manufacturer is uncertain or the existance of a supporting framework is in doubt.

\section{REFERENCES}

Organization

Code

Section

\begin{tabular}{lll}
\hline BOCA & The BOCA Basic Mechanical Code & M-105.1; M-105.2 \\
ICBO & The Uniform Mechanical Code & $104(\mathrm{~d})$ \\
SBCC & Standard Mechanical Code & 101.4
\end{tabular}




\begin{tabular}{c|c|c|c|c|c|c|c|}
\hline M-D & ALTERNATE MEASURES & A2 & A3 & A4 & L1 & L2 & L3 \\
\hline
\end{tabular}

(SEE FIG. 1)

Each of the mechanical codes includes provisions giving the mechanical official flexibility in permitting him to approve new materials and equipment. Without these provisions it would be very difficult, if not impossible, to accept new ideas, systems, and concepts. The purpose of these provisions is to allow the mechanical official to live within the spirit and intent of the code in providing public welfare and safety.

These provisions enable the mechanical official to expedite approval in certain cases where the letter of the code is not exactly followed and also allows him to accept non-standard materials and equipment. The burden of proof, however, lies with the individual requesting the permit and he must show that the proposed design is satisfactory and complies with the intent of the code in that the material, method, or work offered is at least equivalent in quality, strength, effectiveness, fire resistance, durability, safety, etc. The proof can be provided by documentation or through testing using methods approved by the mechanical official.

In many instances, the acceptance of phase change thermal storage devices by the mechanical official will probably be through the operational use of the alternate measures provisions. The lack of test procedures and a phase-change equipment infrastructure, along with unfamiliarity by the mechanical official, could make acceptance of innovative systems a costly and time-consuming venture until these innovative systems are generally accepted as reliable and safe.

- REFERENCES

Organization

Code

Section

\begin{tabular}{lll}
\hline BOCA & The BOCA Basic Mechanical Code & M-101.2;M-108.2; M-108.4; \\
& & M-108.4.1;M-108.4.2; M-108.4.3 \\
ICBO & The Uniform Mechanical Code & $105 ; 106 ; 107$ \\
SBCC & Standard Mechanical Code & $103.5 ; 103.6 . \mathrm{a} ; 103.6 . \mathrm{b} ;$ \\
& & $103.6 . \mathrm{c} ; 103.6 . \mathrm{d}$ \\
AInA & National Building Code & $100.7 ; 101.2 ; 101.3 ; 101.4 ;$
\end{tabular}




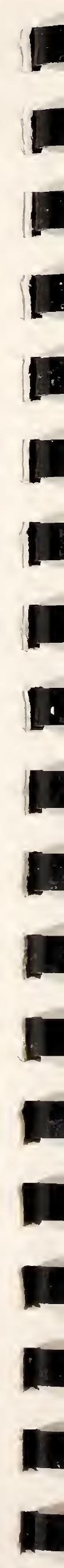




\begin{tabular}{|c|c|c|}
\hline$M-E$ & UNSAFE COṄDITIONS & \begin{tabular}{|l|l|l|l|l|l} 
A2 & A3 & A4 & L1 & L2 & L3 \\
\end{tabular} \\
\hline
\end{tabular}

(SEE FIG. 1)

The mechanical official's authority concerning the approval of the design and installation of equipment under his purvue is detailed throughout the mechanical codes. The provisions in this section extend that authority to installed systems while placing on the user the responsibility to maintain, repair, and take whatever action is required to assure that the installed equipment does not constitute a hazard to safety, health, and public welfare. The mechanical official may require unsafe conditions to be abated by repair, rehabilitation, or removal or he may institute other appropriate actions to prevent, restrain, or correct the violation.

These provisions should not impact phase-change thermal storage devices any differently than they impact commonly used conventional equipment. From a practical point of view, the mechanical official normally does not periodically inspect equipment installed in single family dwellings and other small installations and the user has the prime responsibility to keep his equipment in a safe operating mode. After several years of operation, however, the user may not be able to carry out this responsibility as he may be unable to locate anyone who can inspect or repair the equipment if the original installer is no longer in business. This could conceivably be an influence on the acceptance of this equipment by the mechanical official if the prospects of uncorrected safety defects becomes a chronic reality because of a lack of development of a phasechange storage infrastructure.

\section{REFERENCE}

Organization

Code

Section

\begin{tabular}{lll}
\hline BOCA & The BOCA Basic Mechanical Code & M-120.1 \\
ICBO & The Uniform Mechanical Code & 202 \\
SBCC & Standard Mechanical Code & 103.4
\end{tabular}




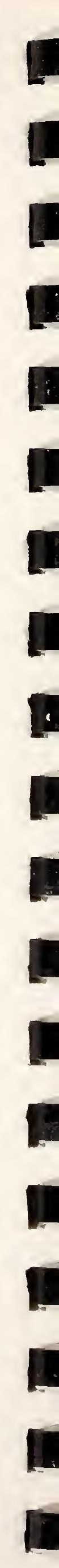




\begin{tabular}{l|l|l|l|l|l|l|l|l|}
\hline M-F & REVIEW OF PLANS AND SPECIFICATIONS & & A2 & A3 & A4 & L1 & L2 & L3 \\
\hline
\end{tabular}

(SEE FIG。 1)

Plans and specifications along with computations are generally required before a permit is issued and work authorized. These submittals are not required in all cases and may be waived at the discretion of the mechanical official. In addition, the certification of a registered engineer or architect is sometimes required. The provisions seem to be written so that the more complex the design, the greater the chance that the mechanical official will require documentation to be prepared and certified.

Specifically, BOCA, ICBO, and AInA require that applications for permits shall be accompanied by drawings of the proposed work, drawn to scale and in sufficient detail and clarity to indicate the location, nature, and extent of work to be performed. BOCA also states that when quality of materials is essential, specific information shall be given to establish such quality and that the mechanical official may require adequate details of mechanical and electrical work, including computations and other essential technical data. BOCA requires all engineering plans and computations to bear the signature of the engineer or architect responsible for the design while both ICBO and SBCC codes state that the building official may require such materials to be certified. BOCA does allow the mechanical official to waive the requirements for filing plans when the work involved is of a minor nature and ICBO allows the building official to waive the submission of plans, calculations or other data if reviewing of the plans is not necessary to assure compliance with the code.

Fina11y, BOCA, ICBO and SBCC Codes require plans for buildings more than two (2) stories in height to indicate how required structural and fireresistance rating integrity will be maintained, and where a penetration will be made for electrical, mechanical, plumbing and conmunication conduits, pipes and systems.

In view of the above, the installer of phase-change thermal storage devices may be required to submit plans, specifications, and calculations to the mechanical official. Because these devices are unconventional and complex, they may be required to be certified by a registered engineer or architect. Because of these requirements, the approval process may be extensive and if the documentation is unclear or unacceptable, tests may have to be run to substantiate specification compliance. 


\begin{tabular}{l|l|l|l|l|l|l|l|l}
\hline M-F & REVIEW OF PLANS AND SPECIFICATIONS (Cont.) & & A2 & A3 & A4 & L1 & L2 & L3 \\
\hline
\end{tabular}

(SEE FIG。1)

Although the approval process may become involved for innovative devices, it seems reasonable for the mechanical official to follow this process in safe-guarding the health and welfare of the community. The installers of solar devices may have to prove the safety of their systems along with others developing new and innovative equipment. An institutionalized testing program implemented early in the development cycle would expedite the acceptance of phase-change thermal storage devices.

\section{REFERENCES}

BOCA

ICBO

SBCC

AInA
The BOCA Basic Mechanical Code

The Uniform Mechanical Code

Standard Mechanical Code

National Building Code
$\mathrm{M}-111.4 ; \mathrm{M}-111.5$

302 (b) ; 302 (c)

104.4

102.6 


\begin{tabular}{l|c|c|c|c|c|c|c|}
\hline$M-G$ & InSPECTIONS & & & & L1 & L2 & L3 \\
\hline
\end{tabular}

(SEE FIG. 1)

The Mechanical Codes generally require that boilers and unfired pressure vessels be inspected before being placed into operation and periodically inspected thereafter. The BOCA Mechanical Code, however, excludes oneand two-family dwellings from annual inspections. The ICBO Mechanical Code specifies that mechanical systems shall not be concealed until inspected and further requires that mechanical systems not be connected to energy fuel-supply lines until authorized by the building official.

It should be expected that phase change thermal storage devices would be subject to inspection by the mechanical official. If these devices are treated as other mechanical devices one would think that jurisdictions excluding periodic inspections for unfired pressure vessels in one- and two-family dwellings would also extend this provision to phase change thermal storage devices. The provision which requires mechanical systems not be concealed until inspected may be irrelevant as applied to systems using liquid as the heat transfer fluid since these systems are generally free standing vessels and are not intended for concealed installation. However, if this provision is applied to systems using air as the working fluid, this inspection provision could require "window" units and other units which also function as a collector to be left unconcealed until inspected.

\section{REFERENCES}

Organization

Code

Section

The BOCA Basic Mechanical Code

$\mathrm{M}-501.1 ; \mathrm{M}-501.2$

ICBO

The Uniform Mechanical Code

305 (a)

SBCC

Standard Mechanical Code

107.1 


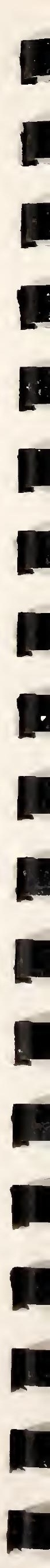




\begin{tabular}{l|l|l|l|l|l|l|l|l|l|l|l|l|l|l}
\hline M-H & USE OF APPROVED MATERIALS AND EQUIPMENT & & A2 & A3 & A4 & L L & L2 & L3 \\
\hline
\end{tabular}

(SEE FIG. 1)

All equipment used directly or indirectly for heating and cooling must be approved by the mechanical official. To obtain this approval the equipment must meet the requirements of the code and generally must be listed by an approved agency and tested using nationally recognized standards. The codes also generally require that accepted equipment be labeled with the seal or mark of the approving agency as certification of that approval. In addition, the BOCA Code requires equipment to be installed in accordance with the manufacturer's installation instructions. It should be noted that unlisted equipment may also be approved under the Alternate Measures provisions (see Reference M-D).

The BOCA Code requires all materials, equipment and devices which are approved for use by the mechanical official to be constructed and installed in accordance with such approval. This code also requires warm air heating, ventilating, air conditioning, evaporative cooling, blower and exhaust equipment and their appurtances to be of an approved type, conforming to this code's requirements, and to be installed in accordance with the manufacturer's installation instructions. The BOCA Code also requires all equipment used for steam or water heating systems and related process piping to be constructed, installed and maintained in accordance with this code's requirements and the ASME Boiler and Pressure Vessel Code, which is listed in Appendix A of the BOCA Mechanical Code. The equipment in question must also be approved by the mechanical official.

The SBCC and ICBO Codes require all equipment to be listed and to be installed in accordance with the listing. The installation is subject to approval by the mechanical official. The equipment is required to be labeled accordingly, including the seal or mark of the approved testing agency which certifies the listing. These codes also state that when the requirements for listed appliances and their accessories are different from each code's requirements, these listed appliances are allowed to be installed in accordance with the conditions specified in their listing. Listed appliances and their accessories which are installed or used not according to the conditions specified in their listing and all appliances not listed are required to conform to code requirements.

The AInA Code prohibits the use of any material or method of construction which fails to conform to the provisions of this code. Whenever there is reason to question the quality of a material or method of construction to be used in a building or structure, the building official is permitted by this code to require tests to be made in order to establish its suitability or to determine whether it conforms to the intent of this code. The AInA Code states that such tests are to be made at the expense of the owner or his agent.

The impact of the approved materials and equipment provisions on any new technology is rather crucial and there is no exception for phase-change thermal storage devices. Since the mechanical official may have little experience with these devices, one may expect difficulty in receiving an ad hoc approval of phase-change storage systems without a great deal of supporting documentation. 


\begin{tabular}{l|lll|l|l|l|l|l|l|l|l|l|l|l}
\hline M-H & USE OF APPROVED MATERIALS AND EQUIPMENT (CONT) & & A2 & A3 & A4 & L1 & L2 & L3 \\
\hline
\end{tabular}

(SEE FIG. 1)

The type of concern is dependent upon the system involved. Free standing phase change thermal storage devices using a liquid as the heat transfer medium could be tested as a unit. As more devices become commercially viable, perhaps consensus test procedures will be developed and the systems tested and approved by recognized testing organizations. The required seals, levels, etc. which demonstrate an institutional acceptance of these devices is an important step in making these phase change thermal storage devices available for use.

The systems using air as the heat transfer fluid may encounter some additional difficulty in acceptance by the mechanical official. These devices would normally be tailored for integration into a specific installation, with perhaps the exception of the individual window units. As such, the testing of these units might be done on a component basis rather than as an integrated device. Any test procedures and specifications developed may result in acceptance of specific increments of the system and not for the system as a whole. One could conceive specifications and test procedures for each type of phase change package with an individual certification for each generic type approving the contents (phase change material) and packaging. For such approvals, the mechanical official may be concerned about the aggregation of these individual devices since there could be a threshold above which the aggregation of individually acceptable devices could be considered unsafe.

In summary, without approval generated through the established infrastructure, phase change thermal storage devices will be judged on an individual basis and acceptance could be a difficult procedure.

\section{REFERENCES}

Organization

Code

Section

\section{BOCA}

SBCC

AInA

ICBO
The BOCA Basic Mechanical Code

Standard Mechanical Code

National Building Code

The Uniform Mechanical Code
$\mathrm{M}-108.1, \mathrm{M}-300.3, \mathrm{M}-400.2$

$301.2,303.1$

101.1

502,507 
The use of a structural member or part of a building intended for another function to also serve as an air plenum is an attractive concept. If the space constructed for another purpose can also be used as an air plenum, such as the attic or crawl space, there is a potential to gain some economic advantage if, in the process, the elimination of separate ducting is accomplished. The provisions discussed in this section generally address the use of such areas as air distribution systems while other provision topics in this report addressed the placement of equipment in crawl spaces (see Reference M-J) and attics (see Reference M-P).

The provisions regarding the use of uninhabited basements, cellars, crawl spaces, cavity walls, areas above ceilings, or attic spaces as air plenums are complex and varied among the mechanical codes.

The BOCA code prohibits the use of these areas as supply, makeup, exhaust air or return air plenums or ducts. However, the code will allow air ceiling plenums to be installed as supply or return air plenums in all occupancies except Use Group R-3, if such air plenums meet the other requirements of this code which are applicable, and those of the building code listed in Appendix A, and if fuel-fired equipment or exposed combustible materials are not located therein. The use of air ceiling plenums must be confined to one fire area. The floor or roof assembly above an unlisted air ceiling plenum cannot depend upon the air ceiling for a portion of its fireresistive rating. The BOCA code allows insulated cold water, hot water, steam, fire protection piping, building, sanitary and storm drains, and vent systems to be installed in air ceiling plenums. Electrical wiring and equipment in air ceiling plenums must conform to the applicable requirements. The BOCA code prohibits the use of air ceiling plenums in evaporative cooling systems. Panning of the joist or stud space for return air is permitted by this code in buildings of Use Group R-3 only. Pipe or duct insulation may also be used in air plenums if in compliance with the applicable requirements contained in the BOCA mechanical code.

The BOCA and ICBO codes allow underfloor space to be used as a supply plenum providing the following requirements are met. The use of this space is allowed only in buildings of Use Group R-3 not more than two stories in height. The BOCA code also allows this in fire areas of buildings exceeding 25,000 cubic feet in volume in any other use group. The BOCA code and ICBO code both allow supply ducts to be extended from the plenum to registers on other floor levels, except for the floor immediately above the underfloor plenum. The SBCC code also prohibits the use of attic, crawl or other concealed spaces as plenums unless constructed of non-combustible materials, or properly protected by means of fire dampers, fan cut-off controls to restrict fire spread, or by arrangement to protect the fire-resistiveness of the assembly. The SBCC code states that public exit halls in hotels, hospitals, institutions, and similar occupancies and in multi-family houses cannot be used as plenums for adjoining areas other than toilet rooms, bathrooms, shower rooms, sink closets and similar auxiliary spaces opening directly on the corridor. This requirement must not prohibit mechanical ventilation of the corridor. For multi-family houses, hotels, and similar occupancies, this requirement must not prohibit the use of the corridor as a source of make-up air through normal leakage around doors. The SBCC code does not allow stairway enclosures connecting two or more stories 
to be used as plenums. Electrical wire and cable insulation is allowed in plenums under the SBCC code provided it meets the applicable U.L. requirements and is classified by U.L. as a low smoke, low flame spread material, meeting applicable requirements of the National Electrical code. Crawl spaces are allowed by the SBCC code to be used as plenums if they have not less than 3 inchès clearance between the bottom of the floor joists and girders and the vapor barrier membrane. The BOCA and SBCC codes state that such crawl spaces cannot be used for storage, and the SBCC, ICBO and BOCA codes require that before use these plenums must be cleaned of all loose scrap material, and be tightly and substantially closed. Also, the BOCA, ICBO, SBCC, and AInA codes state that the enclosing material of the under-floor space, including the side wall insulation, cannot be more flammable than one-inch (nominal) wood boards (flame-spread classification of 200.) The AInA code also requires that combustible vapor barriers be covered with not less than 2 inches of sand or other noncombustible material. Access to the plenums must be through an opening in the floor. The BOCA code requires this opening to be 18 by 24 inches. The ICBO code requires not less than 24 by 24 inches. The SBCC and AInA codes require no greater than 24 by 24 inches. A11 four codes require that the furnace supplying warm air to this plenum space be equipped with an automatic control which will start the air-circulating fan when the air in the furnace bonnet reaches a temperature not higher than $150^{\circ} \mathrm{F}$. The BOCA, ICBC, and AInA codes also state that this control must be one that cannot be set higher than $150^{\circ} \mathrm{F}$. The AInA code also requires that the setting limit of this control be $165^{\circ} \mathrm{F}$. This code also states that units which incorporate heating elements, heated surfaces, or combustion chambers, which develop temperatures higher than $165^{\circ} \mathrm{F}$ must have these components shielded to prevent direct radiation onto combustible material. All four codes require, too, that this furnace be equipped with a control that will limit outlet air temperature to $200^{\circ} \mathrm{F}$. The BOCA, ICBO, SBCC, and AInA codes require a noncombustible receptacle to be placed below each floor opening into the air chamber. This receptacle must be securely suspended from the floor members and cannot be more than 18 inches below the floor opening. The area of the réceptacle must extend 3 inches beyond the opening on all sides. The perimeter of this receptacle must have a vertical lip at least one inch high at the open sides if it is at the level of the bottom of the joist. The BOCA, SBCC, and ICBO codes require this lip to be at least 3 inches high if the receptacle is suspended. The AInA code requires this height to be at least 2 inches. All four codes require that floor registers be designed for easy removal in order to give access for cleaning the receptacles. All four codes require that exterior walls and interior stud partitions adjoining underfloor spaces used as plenums must be firestopped at the floor. Also, the codes require that each wall register be connected to the air chamber by a register box or boot.

The BOCA and ICBO codes require that approved ductwork must extend from the furnace supply outlet at least 6 inches below combustible framing. Also, the BOCA, ICBO and SBCC codes prohibit fuel-gas lines and plumbing waste cleanouts to be located in plenums. The SBCC and AInA codes also state that furnaces, boilers, or other heat-producing appliances cannot be installed within a plenum space. 


\begin{tabular}{l|l|l|l|l|l|l|l|l|}
\hline M-I & PLENUMS (Continued) & & & A4 & & \\
\hline
\end{tabular}

(SEE FIG. 1)

For crawl spaces used as plenums, the BOCA, ICBO, and SBCC codes require a vapor barrier to cover the entire ground surface of the under-floor space, and for this space to have a flame spread rating of 200 or less. The ICBO and SBCC codes require that this vapor barrier have a minimum thickness of 4 mils. The BOCA. code requires that it have a vapor permeability rating of one perm or less.

The SBCC code requires that for crawl spaces used as plenums, the foundation wall raust be insulated along its inner face from the sill vertically to the under-floor plenum grade level and horizontally over the vapor barrier a distance of 2 feet. The plenum system must be insulated to provide a thermal resistance, excluding film resistances, of:

$$
\mathrm{R}=\frac{\Delta \mathrm{t}}{15} \mathrm{~h} \cdot{ }^{\circ} \mathrm{F} \cdot \mathrm{ft} \mathrm{t}^{2} / \mathrm{Btu}
$$

where $\Delta t=$ the design temperature between the air in the plenum floor system and the minimum outdoor design temperature.

The AInA code has additional specific requirements regarding the use of plenums in habitable buildings. The use of under floor space as a supply plenum is restricted to single family dwellings, and to heating or cooling the story immediately above the under floor space. Supply and return ducts to the air chamber or plenum must be in accordance with the codes applicable provisions. Supply ducts must terminate approximately under the center of the room above, at a distance of no less than 6 feet from the plenum chamber. The openings in exterior walls required for ventilation of crawl spaces must be equipped with covers or doors, located on the exterior surface of the walls, which can be opened or removed during the seasons that the heating or cooling system is not being operated.

The AInA code also restricts the use of concealed ceiling spaces as supply or return plenums to dwellings. The concealed ceiling space plenum cannot serve more than one story. Also, these plenums must be separated from any other concealed spaces and completely enclosed in material having a flame spread rating of not more than 200. Ventilating systems cannot discharge into concealed spaces used as plenums.

The AInA code also specifies that return air systems must be constructed of materials permitted for supply ducts, of wood boards not less than $5 / 8$ of an inch actual thickness, of plywood not less than $1 / 4$ of an inch in thickness, or other material that has a flame spread rating of not more than 200 and a potential heat content of not more than 9,000 Btu per pound. The interiors of combustible ducts must be lined with non-combustible materials at points where there might be danger from incandescent particles dropped through the register or heater, for example, directly under floor registers and the bottoms of vertical ducts or directly under heaters having a bottom return. 


\begin{tabular}{l|l|l|l|l|l|l|l|l|}
\hline M-I & PLENUMS (Continued) & & & A4 & & \\
\hline
\end{tabular}

(SEE FIG. 1)

The AInA code also requires that portions of spaces between studs in walls or partitions used as ducts must be separated from all remaining unused portions by tight fitting stops of sheet metal or of wood not less than 2 inches, nominal, in thickness. Vertical ducts are not allowed by this code to have openings to receive return air on more than one story. Under floor spaces may be used as plenums for return air from the story directly above, provided these spaces are not more than 2 feet in depth to the bottom of the floor joists; are void of all combustible materials; and are tightly and substantially enclosed, except for openings required for ventilation of crawl spaces. Openings in exterior walls required for ventilation of crawl spaces shall be equipped with covers or doors, located on the exterior surface of the walls, which can be opened or removed during the seasons that the heating or cooling system is not being operated. In a single story dwelling, the return air is allowed to travel through the first story living space to the return air inlet on the furnace.

Other return air distribution, not included in the above stated circumstances, must be conducted through continuous ducts.

Public halls or public stairways cannot be used as plenums according to the AInA code. Also, this code requires that the return system and circulating fan be arranged so that negative pressure from the circulating fan cannot affect the air supply for combustion or draw products of combustion from joints or openings in the furnace or flue.

The AInA code also permits the space between the ceiling and the floor or roof of floor-ceiling or roof-ceiling assemblies which have been assigned a rating of not less than one hour to be used as a plenum, providing that the following requirements are met. Construction of the assembly must comply with details of the rated assembly. The assembly must be constructed of non-combustible or approvet limited-combustible materials or be approved as a limited combustible assembly. The space can be used for a plenum provided the assembly was rated with the space having air movement as a plenum. The temperature of air in the system cannot exceed $250^{\circ} \mathrm{F}$. When an assembly is used as a plenum, the proportionate area and arrangement of openings in fire resisting ceilings and ducts cannot be larger than those of the rated assembly. Material with "through perforation" cannot be used for fire resisting ceilings except where they have been tested as part of the rated assembly.

All electrical wiring in a concealed space must conform to the provisions of the standards included in this code. 


\begin{tabular}{l|l|l|l|l|l|l|l}
\hline$M-I$ & PLENUMS (Continued) & & & A4 & & & \\
\hline
\end{tabular}

(SEE FIG. 1)

The AInA code also permits the space between a ceiling and the floor or roof, where the floor, or roof, and its supports have been tested or investigated and assigned a fire resistance rating to be used as a plenum provided certain requirements are met. One such requirements states that the floor or roof and its supports must be constructed of noncombustible or approved limited-combustible materials, or be an approved limited-combustible assembly. The ceiling must also be constructed of noncombustible or approved limited-combustible materials and cannot deteriorate or deform when exposed to long exposures of temperatures of $250^{\circ} \mathrm{F}$, high humidity or excessive moisture, or mildew. The support system for the ceiling, including its hangers, must be made of nomcombustible materials and must resist collapse and deformation. Here, too, temperature cannot exceed $250^{\circ} \mathrm{F}$.

The AInA code also allows the space between a ceiling and a floor or roof above where no fire resistance rating is required for the floor or roof to be used as a plenum provided certain requirements are met. Floor finishes of combustible materials cannot be adjacent to floors but can be installed on an insulation material, not less than one inch in thickness, which has a potential heat content of not more than 3,500 Btu per pound. All adhesives and vapor barriers cannot have a flame spread rating of more than 25. Combustible roof coverings are not allowed adjacent to roofs, but may be installed on an insulation material, not less than one inch thickness, which has a potential heat content of not more than 3,500 Btu per pound. Rooms or spaces used as plenums must be constructed with floor, floor-ceiling, roof, roof-ceiling, partition, and wall assemblies constructed of noncombustible material.

The AInA code also addresses portions of buildings such as attics, basements, rooms or concealed spaces which can be used as ducts. Exits, including enclosed stairways and ramps, and exit passageways cannot be used as a plenum or as a portion of a supply, return, or exhaust air duct system. Corridors and hallways in buildings having health care occupancies cannot be used as plenums or as a portion of an air duct system. Such corridors may have mechanical ventilation and can handle incidental infiltration from rooms where pressure differentials are required. Corridors and hallways in buildings with residential occupancies other than dwellings cannot be used as plenums or a portion of an air duct system. Such corridors are allowed to handle limited quantities of make-up air for exhausts from kitchens, bathrooms or toilets. Concealed or reentrant spaces of beam, column, partition, and wall assemblies required to have a fire resistance rating cannot be used as ducts. Shafts constructed of noncombustible materials, and having a fire resistance rating of not less than one hour in buildings less than 4 stories in height and a fire resistance rating of not less than 2 hours in buildings 4 or more stories in height, can be used as ducts, provided openings for distribution ducts are protected with fire approved fire dampers.

Individuals wishing to install a phase-change thermal storage device in a crawl space or wishing to use another passageway as a "natural" plenum must comply with a variety of provisions. The most common system adaptable for use in a central plenum would be one which uses air as the working fluid. 


\begin{tabular}{l|l|l|l|l|l|l|l|l}
\hline $\mathrm{M}-\mathrm{I}$ & PLENUMS (Continued) & & & & A4 & & & \\
\hline
\end{tabular}

(SEE FIG. 1)

The first issue to be addressed might center on the operating temperature of the phase-change thermal storage device. In operation, these devices would be placed in some centralized location within the plenum and heated air passed over the phase change material in the heat storage mode. In the heat retrieval mode, cool air would pass over the phase change material. Because of the isothermal characteristics of these devices, high temperatures are not necessary for effective operation. However, the air entering the plenum would normally be heated air coming from the collectors. This heated air could exceed the temperature limitation of the codes, especially under stagnation conditions. Although highly heated air would improve the efficiency of the thermal storage device, the design must be checked as a system to assure that the temperature limitations are not exceeded even though the storage device itself is acceptable for crawl space installation.

Another concern would be the placement of "potentially hazardous" materials in a crawl space. This includes materials which do not meet the required flame spread ratings of materials that are capable of producing smoke or toxic substances when heated. These requirements might eliminate the use of phase change materials that are encased in plastic but may accept other concepts (as the rotating drum system) since the phase change material is contained in a metal cylinder. This, of course, assumes that the phase change material itself is intrinsically non-hazardous and materials such as the paraffins might not be acceptable regardless of how they are packaged. A solution to the use of those materials that give off smoke or toxic substances when heated is the inclusion, within the crawl space, of a smoke detector which would sound an alarm and perhaps automatically close a damper to prevent the air from circulating.

The final concern would be the insulation of the crawl space itself. Any insulation used must comply with the requirements governing the application of insulations in crawl spaces or ducts and present no potential hazard.

\section{REFERENCES}

Organization

Code

Section

$\begin{array}{lll}\text { BOCA } & \text { The BOCA Basic Mechanical Code } & \text { M-301.1 } \\ \text { ICBO } & \text { The Uniform Mechanical Code } & 1008 \\ \text { SBCC } & \text { Standard Mechanical Code } & 512,509.1,509.2 \\ \text { AInA } & \text { National Building Code } & 22.7,22.8,22.9,\end{array}$




\begin{tabular}{|c|c|c|c|c|c|}
\hline $\mathrm{M}-\mathrm{J}$ & HEATING EQUIPMENT IN CRAWL SPACES & A4 & L1 & $\mathrm{L} 2$ & L3 \\
\hline
\end{tabular}

(SEE FIG. 1)

The placement of heating equipment in craw1 spaces is addressed by the provisions in this section. The provisions are oriented to heating devices that burn fuel using air to support combustion and also to those systems that use electricity as the energy source. The BOCA and ICBO Mechanical Codes require that this type of equipment be placed on raised concrete slabs within the crawl space. Both codes require that this concrete or masonry base extend not less than 3 inches above the adjoining ground level. The BOCA Code permits installation in a depression or excavation if placing the equipment on a raised slab will reduce the desired clearances between the top portion of the equipment and the combustionable portions of the floor structure located above. In this type of installation, a concrete floor and retaining wall must be constructed in the depression, and the wall must extend to a point 4 inches above the surrounding grade. The floor of the depression must extend 6 inches beyond all sides of the equipment and 24 inches on the service side. Depressions which are greater than 36 inches below grade must be provided with a stairway and handrails, and the burner control clearance must be increased to a minimum 48 inches.

The codes also require access openings to enable the equipment to be removed or replaced without disassemb1y. The BOCA code prohibits this access from being through the floor unless specifically approved by the code official. This code requires a vertical access opening with the furnace located no further than 20 feet from it. The BOCA code also prohibits the installation of liquefied petroleum gas-fired heating appliances in any under floor space unless the space is provided with an approved means for removal of unburned gas.

The ICBO code requires that access openings be no smaller than 30 inches by 30 inches and that this area be provided to the working space in front of the furnace. This code permits access to be through an opening in an exterior wall of the building or through a trap door within the building. Passageway access cannot exceed 20 feet to the centerline of the working space in front of the furnace, with this distance measured along the centerline of the passageway.

The ICBO code also provides requirements for suspended furnaces. The lowest portion of a suspended furnace must have a clearance of at least 6 inches from the ground. If excavation is necessary to install the furnace, it must extend to a depth of 6 inches below and 12 inches on all sides of the furnace except the control side, which must have 30 inches. If the depth of the excavation for either furnace or passageway exceeds 12 inches, walls of the excavation must be lined with concrete and masonry extending 4 inches above the adjoining ground level. In flood plain areas, the entire crawl space grade or height must provide a 12-inch clearance between the bottom of the furnace and the ground. 
(SEE FIG. 1)

The BOCA code also has requirements regarding clearances. For other than horizontal type units, bonnets, plenums and fittings for upflow furnaces must be extended full size of the furnace outlet to a minimum of 18 inches above the furnace casing. The BOCA code also requires a minimum height of 30 inches be maintained from the ground level to the bottom of the floor joists in those portions of the crawl space where necessary for the installation and service of equipment.

The ICBO code requires that a permanent electric outlet and lighting fixture controlled by a switch located at the passageway opening be provided at or near the furnace.

The AInA code does not permit furnaces, boilers or other heat producing appliances to be installed in under floor spaces used as supply plenums.

Although the provisions discussed above are intended to be operative for fuel burning or electrically heated equipment, there may be some applicability to phase-change thermal storage devices located in crawl spaces. Since phasechange thermal storage devices (generally those using a liquid as the heat transfer medium) could be designed with electric heating coils to provide backup input heat, these provisions may apply. In addition, the ICBO Mechanical Code states in the introduction to Chapter 7 , that the provisions in that chapter apply to warm-air furnaces and heating systems. The AInA code prohibits heat-producing appliances to be installed at all under floor space used as a supply plenum.

The use of the crawl space for phase change materials might be viewed from two perspectives; (1) systems using a liquid as the working fluid; and (2) systems using air as the working fluid.

Systems using a liquid as the working fluid would normally have the phase change material contained in a vessel with the working fluid piped into and out of the vessel. If installed in a crawl space, that space would not be used as a plenum but rather a convenient area for the heat storage device to be installed. Other sections of this report describe requirements necessary if the device is to be accepted by the mechanical official for installation and use. Some of these requirements include pressure/temperature relief devices, overflow tubes, drains, accessibility for maintenance, etc. In addition, immiscible fluid systems generally include an oil based heat-transfer fluid - an unlikely material to be approved for circulation in a crawl space under a habitable area.

With regard to systems using air as the working fluid, other considerations should be noted. The phase change material may be a salt hydrate contained in individual plastic trays or plastic film, or a paraffin housed in metal containers with the packages stacked or arranged in open racks so that the air may circulate around the packages. The device, however, may be a free standing integrated unit, such as the rotating drum system, which also depends on a salt hydrate for heat storage. Regardless of configuration, these devices would not be placed randomly in the crawl space, but rather in a manner that the air flow can be directed and carefully controlled. 


\begin{tabular}{l|l|l|l|l|l|l|l|l|l|l|l|l|l}
\hline M-J & HEATING EQUIPMENT IN CRAWL SPACES (Continued) & & & & A4 & L1 & L2 & L3 \\
\hline
\end{tabular}

(SEE FIG. 1)

The issue which arises is that of allowing the material to be placed in the crawl space at all, the major concern being fire-related. The presence of a paraffin material under a habitable space may be too great a risk to be accepted by the mechanical official. Also, the plastic encasing the normally inert salt hydrate material may present a large smoke hazard to the occupants in case of fire. Some solution such as the installation of smoke detectors in the crawl space must be provided before this concept will be accepted.

\section{REFERENCES}

Organization

Code

Section

BOCA

ICBO

AInA
The BOCA Basic Mechanical Code

The Uniform Mechanical Code

National Building Code
$\mathrm{M}-306.1, \mathrm{M}-306.2, \mathrm{M}-306.3$, $M-306.5 .1, M-306.5 .2, M-306.5 .3$ 709

22.7 (i) 


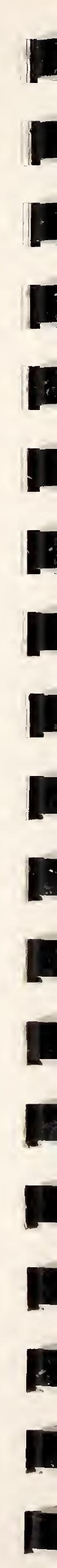




\begin{tabular}{l|l|l|l|l|l|l|l|l}
\hline$M-K$ & AIR FILTERS & A2 & A3 & A4 & & & \\
\hline
\end{tabular}

(SEE FIG. 1)

Systems using air as the heat transport medium would normally employ some device to remove dust and other particles from the air stream. The existing provisions in the mechanical codes cover such concerns as the physical requirements for these filters, their accessibility for servicing, and their construction to minimize fire, smoke, and toxic material spread.

The SBCC Mechanical Code requires that all heating and air conditioning systems of the central type be provided with approved air filters. Further, this code requires that low velocity type filters must have a face area of not less than one square inch for each 2.5 cubic feet per minute of air circulated by the unit. This code requires that filters be installed in the recurn air, upstream from any heat exchanger or coil, in an approved convenient location.

The BOCA, ICBO and SBCC codes state that filters must be easily accessible for cleaning or replacement.

The BOCA, SBCC, and AInA codes also specify that the filters used must be of a type that will not burn freely or emit large volumes of smoke or other objectionable products of combustion when attacked by flames. These codes also state that liquid adhesive coatings used on filters must have a flash point not lower than $325^{\circ} \mathrm{F}$. The ICBO code requires this flash point to be $350^{\circ} \mathrm{F}$ or higher as determined by the Uniform Fire Code Standard No. 9-6.

The BOCA code further requires that duct connections be constructed so as to allow even distribution of air over the entire filter bank. This code also requires that all filters used in assembly occupancies be labeled by an approved testing or inspection agency.

The AInA and ICBO codes require that approval of all air filters used must be based on tests and listings of air filter units by a nationally recognized testing laboratory. The AInA code also states that where filters are of a type that is flushed with liquid adhesives, the system must be designed to prevent flushing of filters when a fan is in operation. Also, approval of electrostatic air cleaners by AInA must be based on tests and listings by a nationally recognized testing laboratory. 


\begin{tabular}{l|l|l|l|l|l|l|l}
\hline $\mathrm{M}-\mathrm{K}$ & AIR FILTERS (Continued) & A2 & A3 & A4 & & & \\
\hline
\end{tabular}

(SEE FIG. 1)

The application of a filter to a phase change thermal storage system would, of course, be generally limited to those thermal storage devices that use air as the heat transport medium, although filters could be used in all categories of phase change thermal storage devices. When applied to storage devices that are centrally located and connected to the building ductwork, the ductwork leading into or exiting the phase change material enclosure could contain an air filter. This filter, if the SBCC requirement for filter location is followed, would have to be located "in the return air, upstream from any heat exchanger or coil." Or the filter may be located in another location in the air-stream away from the thermal storage device. In either case, the system's designer would have to integrate the effects of the filter on the overall air flow.

Filters may also be installed as part of the thermal storage subsystem for devices that also function as collectors. Individual window unit applications also cause concern if the filter impedes the air flow and consequently the thermal storage performance, especially in those devices which depend on natural convection for circulation.

\section{REFERENCES}

Organization

Code

Section

$\begin{array}{lll}\text { BOCA } & \text { The BOCA Basic Mechanical Code } & \text { M-314.2.1, M-314.2.3, } \\ & \text { Standard Mechanical Code } & 513 \\ \text { SBCC } & \text { National Building Code } & 23.11 \mathrm{a}, 23.11 \mathrm{~b}, 23.11 \mathrm{c}, \\ \text { AInA } & & 23.11 \mathrm{~d}, 23.11 \mathrm{e}\end{array}$




\begin{tabular}{l|l|l|l|l|l|l|l|}
\hline $\mathrm{M}-\mathrm{L}$ & INSULATION & A2 & A3 & A4 & & & \\
\hline
\end{tabular}

(SEE FIG. 1)

The Mechanical Codes address ductwork insulation in different ways. Regardless of these differences, the intent of the insulation provisions is to minimize the thermal losses through ductwork especially when the ductwork carries conditioned air through an environment which is not intended to be conditioned or through an environment that could adversely affect the heat loss of the conditioned air flowing through the ductwork. This is especially true of air ducts passing through unheated attics and crawl spaces although some exceptions are made for ducts in crawl spaces that have insulated walls if located in oneand two-family dwellings. In addition, several provisions require the use of vapor barriers to prevent condensation from wetting the insulation.

The BOCA code requires that all duct systems, or portion thereof, exposed to nonconditioned space be insulated to provide a thermal resistance, excluding film resistances, of

$$
R=\frac{t_{i}{ }^{-t} 0}{15}(h r)\left(s q \cdot f t_{0}\right)(F) / B t u,
$$

where $t_{i}-t$ is the design temperature differential between the air in the duct and the ${ }^{\circ}$ surrounding air. However, the BOCA code does not require duct insulation, except when needed to prevent condensation, in several cases. These involve cases where $t_{i}-t_{0}$ is 25 degrees $F$ or less; when the heat gain or loss of the ducts, without insulation, will not increase the energy requirements of the building; for exhaust air ducts; and for supply or return air ducts installed in crawl spaces with insulated walls, basements, or cellars in one and two-family dwellings (Use Group R-3). Insulation, however, must be installed when required to prevent condensation.

The ICBO code requires that every supply and return air duct and plenum of a heating or cooling system be insulated as per the code's specifications, except for ducts and plenums used exclusively for evaporative cooling systems.

The SBCC code requires that all duct work installed in an attic be insulated. Also, all metal supply ductwork installed in a ventilated crawl space or other non-conditioned area must be insulated. Insulation must be a minimum 2 inch thick $3 / 4$ pound density blanket or one-inch thick, $11 / 2$ pound density liner. When ducts are used for cooling and are externally insulated, the insulation must be covered with a vapor barrier having a maximum permeance of 0.05 perms or aluminum foil having a minimum thickness of 2 mils. When nonmetallic ducts or other approved insulating or lining materials are used, this code specifies that the minimum allowable thermal conductance value of the material is 0.23 at 75 degrees F. Also, all exterior ducts that are insulated must be properly protected with an approved weatherproof vapor barrier. Where duct liner is interrupted, it is also required that a duct covering of equal thermal performance be installed. Also, the SBCC code requires that for all ducts which operate at temperatures in excess of 120 degrees $\mathrm{F}$, sufficient thermal insulation must be provided to limit the exposed surface temperature to 120 degrees $F$. In this case a vapor barrier is not required. 


\begin{tabular}{l|l|l|l|l|l|l|l|l|l|l}
\hline M-L & INSULATION (Cóntinued) & A2 & A3 & A4 & & & &
\end{tabular}

(SEE FIG. 1)

Another reason for requiring insulation in ductwork, although a secondary consideration, is for acoustical (sound deadening) purposes. The ICBO provision requires that such material have a mold-, humidity-, and erosion-resistant face and be fastened securely when installed in a high velocity environment so that the swiftly moving air will not disturb or damage the insulating material.

If insulation is installed in or around ductwork, then the mechanical provisions detail a number of specifications to limit flame spread, smoke, and other fire related hazards. The general requirement for externally placed insulation is a flame spread rating of 25 and a smoke-developed rating of not more than 50 .

However, the ICBO code states that insulation having a flame-spread rating of not over 50 and a smoke-developed rating not over 100 may be installed in dwellings or apartment houses where the duct system serves not more than one dwelling unit.

The SBCC code also has specific requirements regarding the fire safety of duct insulation. Duct covering or linings cannot flame, glow, smolder or smoke when tested in accordance with the test for Hot-Surface Performance of High-Temperature Thermal Insulation (ASTM C411) at the temperature to which it is exposed in service. In no case can the test temperature be below 250 degrees $\mathrm{F}$. Further, linings can be interrupted at the area of operation of a fire damper or fire door. Linings can also be interrupted for a minimum of 18 inches upstream and 30 inches downstream from electric resistance and fuel burning heaters in a duct system. Listed equipment that is internally lined are considered in compliance, with the SBCC code requirement for insulation. Duct coverings cannot penetrate a wall or floor required to have a fire resistance rating or required to be firestopped. Service openings cannot be concealed by duct coverings unless the exact location of the opening is properly labeled. Both the SBCC and ICBO codes require insulation to be properly labeled, with information on the manufacturer, nominal thickness and density of the -nsulation, R-values, flame spread and smoke developed ratings.

The provisions specifying insulation requirements may have an important impact on phase change thermal storage devices - especially those devices which use air as the working fluid. These devices would normally be located directly in the duct-work or air stream and, as such, the conditioned air would directly interface with the container encapsulating or packaging the phase change material.

For effective heat transfer, it would be expected that the air duct or plenum containing the phase change package would be insulated. In systems that also use the phase change package as a solar collector, one side would not be insulated but would be glazed to allow the entry of solar radiation. This window could be constructed so that movable insulation covers the opening during the evening to minimize nocturnal heat loss. On the other hand, air systems which serve only as storage units would most likely be insulated on all sides, with the exception of the air entry and exit openings. 


\begin{tabular}{l|l|l|l|l|l|l|l|l|l|l|l}
\hline$M-L$ & INSULATION (Continued) & A2 & A4 & & & & \\
\hline
\end{tabular}

(SEE FIG. 1)

In either case, the extended use of insulation, if placed inside the duct/plenum, would be of concern to the mechanical official as would any material in the conditioned air stream which has a potential for flame or smoke, or the potential for emitting other substances which could contaminate the air stream and be circulated to habitable spaces. In this regard, the flame spread, smoke ratings, and other provisions of the code which provide for uncontaminated conditioned air would most likely be strictly enforced.

This brings up the issue of the phase change packaging and material itself. If items contained within the ductwork/plenum are controlled to mitigate fire and smoke risk to occupied areas, why not control the phase change thermal storage device itself. Although many of the salt hydrates are relatively inert materials themselves, their packaging could cause concern. The flat plastic trays used in certain systems used to encapsulate the phase change material and the plastic encasing of the "chubb" system are two examples of materials which might be prohibited for use in a plenum if their flame spread and smoke ratings present a higher potential danger than that allowed for the insulation material. Also, the mechanical official may be concerned directly with the phase change material such as the paraffins, which are considered by some as an undesirable material for use in a heat storage plenum.

It is unclear how this problem would be resolved if there is concern by the mechanical official. A solution could involve the control of the materials and packaging through certification or another solution may be the installation of a smoke detector suitable for such application in the plenum. This smoke detector, if activated, would sound an alarm and close off the ductwork from the inhabitable areas by closing an appropriate damper.

\section{REFERENCES}

Organization

Code

Section

\begin{tabular}{lll}
\hline BOCA & The BOCA Basic Mechanical Code & M-1302.1 \\
ICBO & The Uniform Mechanical Code & 1005 \\
SBCC & Standard Mechanical Code & $506(\mathrm{a}), 506(\mathrm{~b})$ \\
& & \\
& & \\
& & \\
& &
\end{tabular}




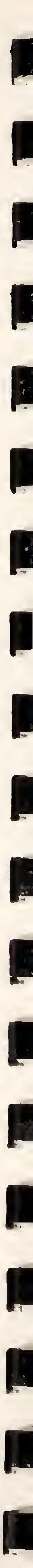




\begin{tabular}{l|l|l|l|l|l|l|l|l|l|l|l|l}
\hline M-M & MANUFACTURER'S INSTRUCTIONS & A2 & A3 & A4 & L1 & L2 & L3 \\
\hline
\end{tabular}

(SEE FIG. 1)

Both the BOCA and the ICBO Mechanical Codes require that operating instructions be attached to the appliance or instructions placed in a conspicuous place in the mechanical equipment room. The BOCA Mechanical Code specifically states that warm air heating, ventilating, air conditioning, evaporative cooling, blower and exhaust equipment and their appurtances must be of an approved type. This code also states that this equipment must conform to all applicable articles of the code, and must be installed in accordance with the manufacturer's installation instructions. The BOCA Mechanical Code also requires that all steam and hot water heating systems and piping conform to the manufacturers instructions in addition to the code's requirements. It also states that the contractor must attach operating instructions of a permanent type to the appliance or system. In addition, the manufacturer's rating data and the name plate must be attached to the appliance or system. The ICBO Mechanical Code requires that operating instructions be attached to the appliance where they can be read easily.

The implementation of these provisions as applied to phase change thermal storage devices is unclear. BOCA defines an appliance (see Reference $\mathrm{M}-\mathrm{B}$ ) as a device which utilizes electricity, natural gas, manufactured gas, mixed gas, liquified petroleum products, solid fuel, oil, or any gas as a fuel; ICBO defines an appliance as a device which utilizes fuel or other forms of energy; while SBCC does not address fuel at all; and AInA defines an appliance as a device which burns a variety of fuels and other heat producing appliances.

Regardless of the above, it might be reasonable for the mechanical official to require operating instructions and other pertinent data to be attached to or mounted near the phase change thermal storage device.

\section{REFERENCES}

Organization

Code

Section

BOCA

The BOCA Basic Mechanical Code

$M-300.3, M-400.4$

ICBO

The Uniform Mechanical Code 


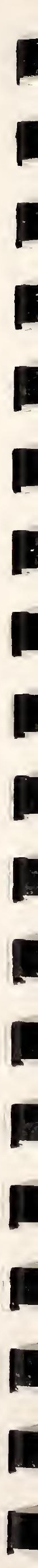




\begin{tabular}{l|c|c|c|c|c|c|c}
\hline $\mathrm{M}-\mathrm{N}$ & $\begin{array}{c}\text { MOTORS, FANS, AND BLOWERS } \\
\text { (ELECTRICAL REOUIREMENTS) }\end{array}$ & A2 & A3 & A4 & & L2 & \\
\hline
\end{tabular}

(SEE FIG. 1)

Each of the Building Codes requires that electrical systems and devices be installed in a manner that satisfies the requirements of the National Electrical Code. In addition, several of the Mechanical Codes list definitive electrical requirements regarding the installation and use of motors, fans, and blower assemblies and for a method of disconnect for electrically operated components.

The BOCA Mechanical Code requires that all blowers and fans bear the label of a nationally recognized testing or inspection agency. Also, this code requires that motors, fans, and blower assemblies and their locations must meet the requirements of the system in which they are installed.

The ICBO Mechanical Code requires that all equipment regulated by it, which requires electrical connections of more than 50 volts, have a positive means of disconnect adjacent to and in sight from the equipment served. A 120-volt receptacle must be located within 25 feet of the equipment for service and maintenance purposes. Low-voltage wiring of 50 volts or less within a structure must be installed in a manner to prevent physical damage. This code requires that such wiring, exposed to weather, be installed in conduit approved for exterior use.

The SBCC Mechanical Code also requires that a disconnecting means and a 115 volt outlet be installed within sight and easy reach in the ungrounded leads of each power circuit to electrically operated components. The disconnecting means must in no case be installed further than 6 feet from the service side of the equipment.

With regard to phase change thermal storage devices, the above provisions would only affect those in systems using a blower or fan to circulate the air past the phase change material or a motor to stir or agitate a phase change liquid.

An air system using a fan integral with the phase change thermal storage material could include the individual window unit configuration. Other air system configurations may also have fans or blowers to move the air, but these fans or blowers would be part of the overall air distribution system and not an integral part of the phase change thermal storage device. For the individual window unit configuration, these provisions may be interpreted as requiring some disconnect means for fans and blowers and a label from a nationally recognized testing or inspection agency.

Liquid systems using motors to stir or agitate the phase change liquid, or to drive a pump which might circulate an immiscible fluid or a phase change "slurry," are also subject to the requirements of the National Electrical Code and the individual electrical provisions of the Mechanical Codes. These systems may be required to contain only labeled equipment with a disconnect provision as specified above.

REFERENCES

Organization

Code

Section 


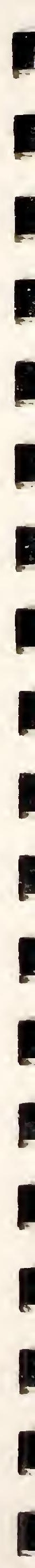




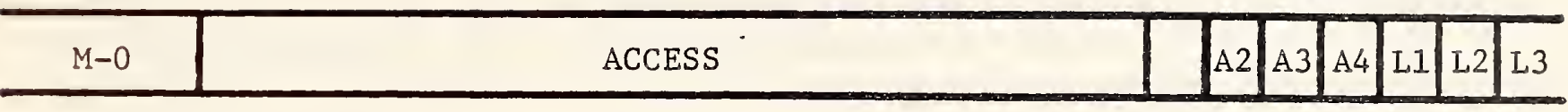

(SEE FIG。1)

The model Mechanical Codes contain provisions regarding accessibility of equipment for inspection, repair, or maintenance. To facilitate these functions, an adequate working space adjacent to the equipment is required. In addition, the SBCC Code contains provisions which would allow removal and replacement of equipment by requiring access doors to be wide enough to accommodate this activity.

The BOCA Code states that clearances must be maintained around all boilers, generators, heaters, tanks and all other equipment to permit inspection, servicing, repair, replacement, and normal visibility of all gauges.

The ICBO Code states that appliances must be accessible for inspection, service, repair and replacement without removing permanent construction. This code also states that not less than 30 inches of working space and platform must be provided to service the appliance.

The SBCC Code states that every appliance must be located with respect to building construction and other equipment so as to permit access to the appliance. It states that sufficient clearance must be maintained to permit cleaning of heating surfaces; the replacement of filters, blowers, motors, burners, controls and vent connections, the lubrication of moving parts where required, and the adjustment and cleaning of burners and pilots. Also, this code states that appliances which are listed for outdoor installation may be installed without protection in accordance with the provisions of their listing and must be accessible for servicing. Also, this code prohibits appliances which are listed "for outdoor installation only" to be installed inside a building. Also, when an appliance is located in an equipment room, this room is required by the SBCC Code to have an opening or door and passageway thereto which is large enough to permit removal of the largest piece of the appliance in such a room, but in no case less than 20 inches in width.

The AInA Code states that the installation of heat-producing appliances must be in all cases accessible for cleaning, maintenance, and operation.

The access provisions stated above as applied to phase change thermal storage devices seem reasonable. Each of the devices using liquid as the working fluid should be located and designed with access for maintenance and repair as a consideration. Those units using air as the working 


\begin{tabular}{|c|c|c|c|c|c|c|c|}
\hline$M-0$ & ACCESS (Continued) & A2 & A3 & A4 & LI & L2 & L3 \\
\hline
\end{tabular}

fluid would most likely be integrated greater into the building structure than the free standing vessels which use a liquid as the working fluid. As such, these air dependent systems, especially, the individual "window" units, may be more difficult to access and particular attention need be given to repair and maintainability by designing these attributes into the system from the start. Of concern would be motor/blower repair, maintenance or replacement; phase change material packaging inspection and replacement; and access to filters, if used.

\section{REFERENCES}

Organization

Code

Section

BOCA

ICBO

SBCC

AInA
The BOCA Basic Mechanical Code

The Uniform Mechanical Code

Standard Mechanical Code

National Building Code
$M-400 \cdot 5$

505

$303.2(a), 303.2(b)$, 303.2 (c)

$1.2(\mathrm{a})$ 


\begin{tabular}{l|l|l|l|l|l|l|l|l|l|l|l|l|}
\hline$M-P$ & ATTIC INSTALLATION & & & A3 & A4 & & & \\
\hline
\end{tabular}

(SEE FIG. 1)

The Mechanical Codes, although not consistent with one another, generally allow some type of attic installation for heating equipment. The Codes require that provision be made for removal of products of combustion, that the ceiling joists and supports be capable of supporting the appliance loads, and that equipment installed is approved for attic installation. In addition, there are requirements for a stairway or ladder access to the attic, the installation of solid flooring from the access point to the equipment, and a twenty-foot limitation with regard to the location of heating equipment and the attic access point. The Codes also require an opening large enough to install or remove the largest major component of the unit without disassembling and a permanent electric outlet and lighting fixture near the furnace controlled by a switch located at the required passageway opening.

The BOCA Mechanical Code also specifically requires that the space in which any attic furnace is installed must be accessible by an opening that is not less than 24 inches by 36 inches. Access openings to the attic must be so located that a clearance of 4 feet exists between the top of the ceiling joists and the bottom of the rafter at the point of entrance. Adequate 1ighting must also be provided at the equipment. Further, the BOCA Code requires that access to the attic opening must be provided by a ladder or stairway which is permanently fastened to the building. Alternative access methods require approval prior to installation. This code also requires an unobstructed catwalk with a nominal width of 24 inches to lead from the access opening to the service side of the furnace. This catwalk must be securely fastened to the ceiling joist. The BOCA Code requires that all attic furnaces must be set on an unobstructed approved platform which must extend at least 12 inches on all sides of the furnace, except that on the control side or other sides where access is necessary for servicing, the platform must extend a distance of 32 inches from the furnace. Also, the BOCA Code does not allow attic furnace platforms to bear on or contact the ceiling joists unless the platforms are protected according to the code's requirements and the joists are designed for such loads. If supported by the roof joists, the design live load and dead load cannot be exceeded. The furnace must be provided with at least one inch ventilated clearance from the bottom of the unit to the noncombustible insulating millboard. The BOCA Code requires that the platform on which the furnace rests must be covered with at least $1 / 4$ inch noncombustible insulating millboard or its equivalent. Attic furnace installations are required by the BOCA Code to comply with the National Electrical Code.

The ICBO Mechanical Code requires that a warm air furnace installed in an attic or a furred space less than 5 feet in height at the furnace location must be listed for installation in such an area and for use on combustible flooring. The ICBO Code also requires that the access panel and passageway to the furnace be no less than 30 inches by 30 inches continuous from the opening to the furnace and its controls. The SBCC requires this opening to be 22 inches by 36 inches. 


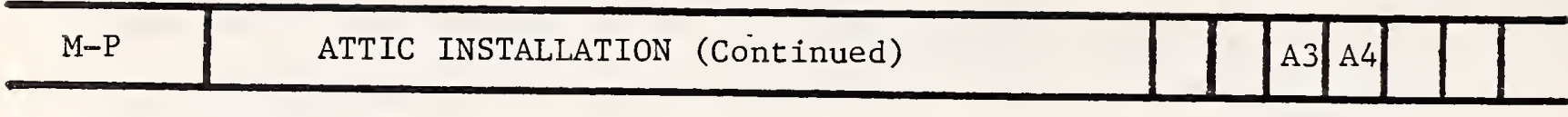

(SEE FIG. 1)

The BOCA, ICBO and SBCC Mechanical Codes require that the entrance to the access passageway be located not more than 20 feet from the furnace. The ICBO and SBCC Codes require that every passageway be unobstructed and have continuous solid flooring not less than 24 inches wide from the entrance opening to the furnace. These codes also require a permanent electric light outlet and lighting fixture, controlled by a switch located at the required passageway opening, to be provided at or near the furnace.

The SBCC Code also requires a level working platform to be located on the control side of the furnace and other sides where access is necessary. This platform must extend a minimum of 30 inches from the edge of the equipment with a 36 inch high clear working space provided. Top or bottom service equipment must have a full clearance above or below the unit for component removal.

The AInA Code status that residential type boilers and central furnaces cannot be installed in attics, except by approval of the Building Official. Appliances must use gas as the fuel. Appliances must be tested and listed by a nationally recognized testing laboratory for installation on floors constructed of combustible materials. A permanent or folding inside stairway must be provided for access to the attic. Attics must be ventilated to provide air for combustion and ventilation of the appliance. Ceiling joists and their supports must be capable of supporting the loads of the appliances.

Although the code provisions addressed in this topic apply directly to attic installations of heating equipment and are oriented toward fuel burning devices, the provisions might give some guidance to the installation of phase-change thermal storage devices. Applicability would generally cover only those thermal storage devices which use air as the heat transfer medium as a device using a liquid would probably be too heavy for practical installation in an attic, although some liquid operated phase-change systems may also fall into this category.

The phase-change material located in the attic could be operated through a skylight, in which case it would also function as a collector; or in a totally enclosed attic while functioning solely in a thermal storage mode. In either case, the access requirements for personnel or equipment including the requirements for an attic ladder, the provision for a 


\begin{tabular}{|c|c|c|}
\hline $\mathrm{M}-\mathrm{P}$ & ATTIC INSTALLATION (Continued) & A3 A4 \\
\hline
\end{tabular}

(SEE FIG。1)

walkway to the equipment, the attic opening to be large enough to accommodate installation or removal of equipment, and perhaps the provision for a light or electric receptacle, should be studied. Also, although not a requirement in the present codes, the issue of smoke or fire actuated dampers may be a concern as well as phase-change material leakage through the ceiling if there is the possibility of the phase-change containers degrading with age.

REFERENCES

Organization Code Section

BOCA

The BOCA Basic Mechanical Code

ICBO

SBCC

AInA
The Uniform Mechanical Code

Standard Mechanical Code

National Building Code
$M-304.1, M-304.2$

$\mathrm{M}-304.2 .1, \mathrm{M}-304.2 .2$, $\mathrm{M}-304.2 .3, \mathrm{M}-304.2 .4$, $\mathrm{M}-304.3, \mathrm{M}-304.3 .1$, $\mathrm{M}-304.3 .2, \mathrm{M}-304 \cdot 3 \cdot 3$, $\mathrm{M}-304.3 .4, \mathrm{M}-304 \cdot 3.5$, $M-304.3 .6, M-304.3 .7$

708

303.3

$2.3 \mathrm{C}$ 


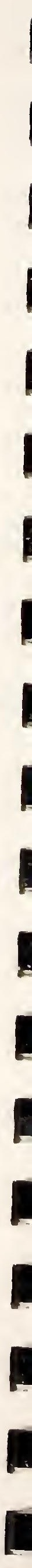




\begin{tabular}{l|l|l|l|l|l|l|l|l|l|l|l|l}
\hline M-Q & CLEARANCES & & & & L2 \\
\hline
\end{tabular}

(SER FIG。1)

The Mechanical Codes address the topic of clearances to combustible material as applicable to the installation of heat producing appliances. Although most of the provisions cover those appliances which provide heat directly through the local combustion of a fuel or the use of electricity, clearances for other heat associated equipment, namely heat exchangers, are also listed.

The Mechanical Codes become rather detailed and complex'in their treatment of clearances and most of the provisions are not included herein as their applicability to phase change thermal storage devices seem rather far fetched. Those provisions that generally apply to heat exchangers, however, are included. From a general inspection of the requirements, it appears that a clearance of one inch between a heat exchanger and any combustible materials is an appropriate clearance for the front, sides, and back of the device. These clearances assume that the hot water in the appliance does not exceed $250^{\circ} \mathrm{F}$. In addition, the clearance shown is for fire protection only and may not be adequate for operation, repair, or maintenance.

In addition, the AInA, SBCC and ICBO Codes state that clearances covered by this code must conform to the one inch requirement. However, when clearances are listed for greater or less than stipulated by these codes, they shall conform to their listings, subject to the approval of the Mechanical official. Also, the SBCC Code states that clearances not covered in this code shall be subject to the approval of the Mechanical Official. If clearances shown in various sections of the SBCC Code differ, they shall take precedence, subject to approval by the Mechanical official.

The AInA Code states that room heaters and their connectors, except as permitted, must be installed with the required clearances. Room heaters that have been tested and listed by a nationally recognized testing laboratory are permitted to be installed with clearances less than the AInA Code specifies, provided they are installed in accordance with the requirements of the listing and conditions of approval.

Further, the AInA, ICBO and SBCC Codes state that room heaters are permitted to be installed in rooms, but not in confined spaces such as alcoves or closets, unless so listed.

The AInA Code also requires that floor-mounted room heaters burning liquid fuel which have a fuel tank attached to the heater be installed with sufficient clearances to provide direct and easy access to the fuel tank.

The applicability of these Mechanical Code provisions to phase-change thermal storage devices is unclear except one could conclude that the minimum one-inch clearance from the storage device to any combustible material might be a reasonable requirement. This puts the phase-change thermal storage device in the heat exchanger category and perhaps excludes these devices from the requirements imposed on devices which use direct fired fuel as energy input. 


$$
\mathrm{M}-\mathrm{Q}
$$

CLEARANCES (Continued)

(SEE FIG。 1)

A particular observation is made regarding the AInA Code. The provision of Section 6.4 requires residential type water heaters to have clearances as required by the provision of Section 4.3. Section 4.3, however, addresses room heater clearances which may have requirements that are irrelevant to residential type.water heaters. This brings out the point that in seeking guidance for new and innovative devices, the mechanical official may not select the most analogous situation in the codes to base the requirements for the new device and, of course, the requirements and interpretations could vary from official to official.

It also should be noted that the clearance requirements stated herein address the clearances from combustibles (a fire prevention measure) which may not provide for clearances required for operation, repair, or maintenance (see $\mathrm{M}-0$; Access).

\section{REFERENCES}

BOCA

ICBO

SBCC

AInA
The BOCA Basic Building Code

The Uniform Mechanical Code

Standard Mechanical Code

National Building Code
M-423.2.1, Table M-423.2

Table 5-A

303.7

$6.4,4.3$ 


\begin{tabular}{l|l|l|l|l|l|l|l}
\hline M-R & NON-COMBUSTIBLE CONSTRUCTION & & A2 & A3 & A4 & & \\
\hline
\end{tabular}

(SEE FIG。1)

The BOCA Mechanical Code contains several provisions regarding non-combustible construction and specifically addresses those concerns related to ducts and plenums. Other fire related provisions are also included in the BOCA and ICBO Codes covering flame spread ratings (see Reference $M-S$ ). The Building Codes, however, should be studied to understand the fire requirements.

Tables M-302.2 and M-303.2 in the BOCA Code provide for construction details for sheet metal ducts and list minimum sheet metal gauges. These tables are not included in the report. Non-metallic ducts also may be used but must be constructed and installed in accordance with applicable standards.

Specifically, the BOCA Code requires that metallic ducts and plenums be constructed in sheet metal which is in accordance with the code's requirements (Tables $M$ 302.2 and M-303.2) or with the SMACNA Low Pressure or High Pressure Duct Construction Standards which are referenced in this code. This requirement also applies to metallic supply ducts in residential construction (use group R-3). Also, nonmetallic ducts in all occupancies except $\mathrm{R}-3$, and nonmetallic supply ducts in R-3 occupancies must be Class 0 or Class 1 duct material as determined by UL 181, which is referenced in this code, constructed and installed in accordance with SMACNA Fibrous Duct Construction Standards, which are also 1isted. Aluminum ducts are not allowed to be used in equipment rooms with fuel fired equipment, encased in or under concrete slabs on grade, for kitchen or fume exhausts, or in systems where air entering the duct is over $250^{\circ} \mathrm{F}$. Flexible air duct material is also permitted if it conforms to UL 181 and is not limited in length.

These requirements are the same in both the SBCC and ICBO codes with the added provision that Class 0 and Class 1 ducts cannot be used in vertical risers serving more than 2 stories. The ICBO and SBCC Codes also state that approved Class 2 air ducts can be installed only in dwellings or apartment houses where the duct system serves not more than one dwelling unit. However, the ICBO Code states that Class 2 ducts cannot be installed within 3 feet of a heat exchanger. The SBCC code states that this distance must separate the duct from the bonnet, plenum or casing of the heating unit.

The BOCA, ICBO and SBCC Codes allow ducts to be used as part of the building structure providing certain requirements regarding the combustibility of duct materials are met. The BOCA Code states that the duct or plenum must be of sheet metal or other approved materials similar in vapor permeability, structural rigidity, air flow friction co-efficient, flexibility and combustibility. The ICBO Code states that materials exposed within ducts or plenums must have a flame-spread rating of not more than 25 and a smoke-developed rating of not more than 50. In a dwelling unit, however, ducts or plenums may be of combustible construction. The ICBO code also states that when gypsum products are exposed in ducts or plenums, the air temperatures are restricted to between $50^{\circ} \mathrm{F}$ and $125^{\circ} \mathrm{F}$, and moisture content is controlled so that the material is not affected. 
The SBCC Code also allows the use of gypsum products in duct construction. For commercial duct systems, $3 / 4$ inch cement or gypsum plaster on metal lath applied to suitable supports is allowed. Properly constructed and lined gypsum wallboard may also be used for duct walls providing no condensation is to be encountered. This code also allows use of duct walls of masonry construction.

The BOCA Code further requires ducts to be installed so as not to impair the effectiveness of the fire protection materials surrounding structural members of the building. The ICBO Code requires ducts to extend from the furnace supply outlet at least 6 inches below combustible framing.

The SBCC Code requires metal ducts to be securely supported, hung, or suspended by metal straps, hangers, lugs or brackets complying with duct construction standards which are referenced in this code. Approved nonmetallic ducts must be installed and supported in accordance with the terms of their listing. When approved by the Mechanical official, heavy gauge galvanized wire can be used for supports. When duct static pressure exceeds two inch water gauge, any piercing of the duct wall to attach the duct to a support structure must be sealed. This code also requires vertical supply ducts in residential buildings which are exposed in closet or rooms to be covered or lined with a minimum of one-quarter inch thick approved fire-resistant material.

The ICBO Code has similar requirements which are outlined in Table 10-A through $10-\mathrm{E}$.

These provisions should need little interpretation when applied to air systems that contain phase change materials that operate in the storage mode only. The interconnecting ductwork should be indistinguishable from conventional ductwork with perhaps tighter seals to reduce air leakage. The chamber, however, which contains the phase change material could be considered either an extension of the duct system or a plenum and, in this regard, may also have to comply with these provisions. This may have the effect of influencing the Mechanical Code official to require the enclosure in which the phase change material is contained to be constructed of sheet metal or some other approved construction. Any unlisted or nonconventional construction could result in the requirement for testing to demonstrate compliance with these provisions.

In addition, the configuration which also uses the phase change material as a collector may present a problem if the entire system is treated as a duct. In this case, the glazing as well as the remainder of the structure surrounding the phase change material may be required to be constructed of noncombustible material so that the effectiveness of the fire protection materials in the rest of the building is not degraded. 


\begin{tabular}{l|l|l|l|l|l|l|l|l|}
\hline M-R & NON-COMBUSTIBLE CONSTRUCTION (Continued) & & A2 & A3 & A4 & & & \\
\hline
\end{tabular}

(SEE FIG. 1)

It is unclear, also, how these provisions would affect structures constructed, within the duct, to hold and expose the phase change material to the airstream for effective thermal transfer. In some designs, the supporting structure would not be free standing but rather attached to the duct itself and the effects of these attachments on the noncombustibility of the ductwork may be uncertain.

\section{REFERENCES}

Organization

Code

Section

BOCA

ICBO

SBCC
The Uniform Mechanical Code

The Standard Mechanical Code
M-302.2.1, M-302.2.2, M-303.2.1, Tables $M-302.2$, and $M-303.2$

$1002,1004(a), 1004(b)$, 1008, Tables 10A-10E

$503,504(d), 504(f)$ 


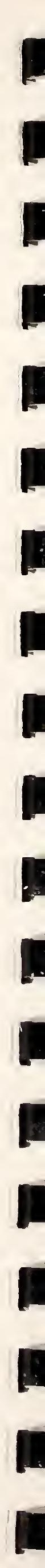




\begin{tabular}{l|l|l|l|l|l|l|l|l|}
\hline M-S & FLAME-SPREAD RATINGS & A2 & A3 & A4 & & & \\
\hline
\end{tabular}

(SEE FIG. 1)

The BOCA and ICBO Codes both contain provisions regarding allowable flame spread and smoke ratings for materials associated with duct construction. These generally are stated as restricting materials used in this application to a flame spread rating of not more than 25 and a smoke developed rating of not more than 50. The BOCA Code allows an exception to duct coverings located entirely outside of a building. The ICBO Code also requires materials within the duct or plenum to meet the flame spread ratings.

Specifically, the BOCA Mechanical Code requires that duct coverings, duct linings, tapes, and core materials in panels used in duct systems have a flame spread rating not over 25 without evidence of continued progressive combustion and a smoke developed rating no higher than 50 or less when tested in accordance with ASTM E84 listed in the BOCA Appendix. If coverings and linings are to be applied with adhesives, the code requires that they be tested as applied with these adhesives, or that the adhesives used have a flame spread rating not over 25 and a smoke developed rating which is less than 50 when in the final dry state. Duct coverings, however, are not required by the BOCA Code to meet these requirements when they are located entirely outside of a building, do not penetrate a wall or roof, and do not create an exposure hazard.

The BOCA Code also requires that duct coverings and linings do not flame, glow, smolder or smoke when tested in accordance with ASTM C411, which is listed in the Appendix of this code, at the temperature to which it is exposed in service. In no case can the test temperature be below $250^{\circ} \mathrm{F}$. Further, this code requires that appliances such as fan coil units, self-contained air conditioning units, furnaces, etc., meet these flame-spread and smoke-developed rating requirements if they are listed. The BOCA Code also requires that duct linings be interrupted at fire dampers and fire doors in order not to interfere with their operation. This code also states that the tape used for sealing joints be an approved material with a maximum flame spread rating of 25 , or less if tested in accordance with ASTM E84. Further, ducts cannot be installed so as to impair the effectiveness of the fire protection materials surrounding structural members of the building. Duct coverings, linings, and panels must conform to all of the above requirements.

The ICBO Code states that circulating air and conditioned-air supply for heating, cooling, absorption or evaporative cooling systems must be conducted through duct systems constructed of metal as defined in Tables 10-A, 10-B, 10-C, in compliance with U.M.C. Standard No. 10-2 with prior approval, or factory made air ducts complying with U.M.C. Standard No. 10-1. Ducts, plenums and fittings can be constructed of asbestos cement, concrete, clay or ceramics when installed in the ground or in a concrete slab, provided all joints are tightly sealed. Concealed building spaces or independent construction within buildings can be used as ducts or plenums. Vents or vent connectors cannot extend into or through ducts or plenums. Materials exposed within ducts or plenums must have 


\begin{tabular}{l|l|l|l|l|l|l|l|l}
\hline M-S & FLAME-SPREAD RATING (Continued) & A2 & A3 & A4 & & & \\
\hline
\end{tabular}

(SEE FIG. 1)

a flame-spread rating of not more than 25 and a smoke-developed rating of not more than 50. However, this code permits circulating air ducts, plenums or concealed spaces which serve a dwelling to be of combustible construction. Further, all wiring in plenums must comply with the Electrical Code. Where gypsum products are exposed in ducts or plenums, the air temperatures are restricted to between $50^{\circ} \mathrm{F}$ and $125^{\circ} \mathrm{F}$. Moisture content must be controlled so that the material is not adversely affected. Gypsum products cannot be exposed in ducts serving evaporative coolers.

The SBCC Code states that return ducts, except those portions directly above the heating surface or closer than 2 feet from the heating unit casing, must be contructed of materials having a flame spread rating no higher than 200 . This code also requires that vibration connectors between ducts and mechanical systems be of an approved flame retardant fabric, such as woven asbestos and cannot exceed 10 inches in length. On commercial systems, a sleeve joint packed with an approved material having a maximum flame-spread rating of 25 and a maximum smoke-developed rating of 50 can be used.

The flame spread and smoke provisions shown above have a direct impact on phase change materials using air as the working medium. These phase change materials are normally located within the ducts or plenums and depend on the circulating air to bring heat to the phase change material for storage and later to circulate the stored heat when needed.

Because of the extensive ductwork normally associated with a heating system, the intent of these provisions is the prevention of rapid flame spread throughout a building in case of a fire. Likewise, these provisions are also meant to prevent any smoke generated locally from quickly permeating the building. In this regard, the phase change materials themselves may not meet these requirements or the packaging or containers associated with the materials may also be unacceptable from a flame spread or smoke generation viewpoint. And in other cases, the supporting structure holding the phase change packages may also be so constructed as not to meet the stated requirements. Storage systems which are configured to operate also as a collector may face additional problems in that at least one face must be opened and exposed to the sun and this open face is usually covered with a glazing. If a plastic material is chosen as the glazing, the above requirements may not be met.

Some have suggested that this problem can be solved by installing an appropriate smoke detector in the duct. This installed smoke detector may sound an alarm and/or automatically close a smoke damper or prevent the wide distribution of the locally generated smoke.

REFERENCES

Organization

Code

Section

BOCA

The BOCA Basic Mechanical Code

$\mathrm{M}-302.4, \mathrm{M}-302.4 .1, \mathrm{M}-302.4 .2$, $\mathrm{M}-302.4 .3, \mathrm{M}-302.4 .4, \mathrm{M}-302.4 .5$, $\mathrm{M}-302.6, \mathrm{M}-302.7$

ICBO

The Uniform Mechanical Code

1002

SBCC

Standard Mechanical Code

503, 504 (b) 


\begin{tabular}{l|l|l|l|l|l|l|l|l|l|l|l}
\hline$M-T$ & HIGH PRESSURE REQUIREMENTS & & & & L1 & L2 & L3 \\
\hline
\end{tabular}

(SEE FIG。1)

Some high pressure requirements are addressed specifically by the BOCA, ICBO, and AInA Codes. These requirements are concerned with approved materials and components for use in high temperature and pressure applications. The codes also.provide for temperature and pressure relief or safety valves.

There are many other high pressure requirements in the codes which relate generally to refrigeration, and these are not included in this report. In addition, the plumbing codes cover additional high pressure requirements which either duplicate or complement the mechanical code requirements.

Specifically, the BOCA Code states that all pipes, fittings, valves, traps, pumps or other equipment that is to be installed on high pressure installations must be fabricated of materials that are approved for the temperatures and pressures indicated. Further, BOCA requires that all approved materials must be designated for the pressure and temperatures at which they will be operated, for the materials they are to handle, and for their intended use. These materials are required to meet established technical standards of quality and strength necessary to produce safe installations and conform to standards listed in Table M-400.8 of the BOCA Code. The BOCA Code further requires that all steam boilers, hot water boilers, any type of pressure vessel used for steam generation, for processing or for building heating systems and tanks, and other equipment used for the purpose of generating or storing hot water under pressure be equipped with a side outlet type approved safety or safety relief valve(s) constructed and marked in accordance with the requirements of the ASME Boiler and Pressure Vessel Code listed in Appendix A, approved for the type of equipment on which it is installed, and for the temperatures, pressures and fluids with which it is to operate (for the purposes of this article ASME means American Society of Mechanical Engineers). Such valves must be sized for the maximum unit capacity or not less than the burner output capacity. Water heaters or hot water supply boilers are also required by the BOCA code to be equipped with temperature valves. This code also requires that all relief valves be installed in openings by the manufacturer of the equipment. If such openings are not provided, the valves must be installed in the piping of the equipment as close to the equipment as possible.

Similar requirements regarding approvals of construction, installation, operation and repair and alteration of all boilers and pressure vessels are contained in the ICBO Code with the following exceptions:

1. Listed or approved pressure vessels (hot-water tanks) with a nominal water containing capacity of 120 gallons or less having a heat input of 200,000 $\mathrm{Btu} / \mathrm{h}$ or less used for hot water supply at pressure of 160 lbs per square inch or less and at temperatures of $200^{\circ} \mathrm{F}$ or less. 
2. Pressure vessels used for unheated water supply, including those containing air which serves only as a cushion and is compressed by the introduction of water and tanks connected to sprinkler systems.

3. Portable unfired pressure vessels and I.C.C. containers.

4. Containers for liquefied petroleum gases, bulk oxygen and medical gas, which are regulated by the Fire Code.

5. Unfired pressure vessels in Groups B, H, R and M Occupancies having a volume of 5 cubic feet or less and operated at pressures not exceeding 250 psi.

6. Pressure vessels used in refrigeration systems which are regulated by Chapter 15 of this code.

7. Pressure tanks used in conjunction with coaxial cables, telephone cables, power cables, and other similar humidity control systems.

8. Any boiler or pressure vessel subject to regular inspection by Federal Inspectors or licensed by Federal authorities.

The ICBO Code requires that all boilers and pressure vessels, and their installation conform to minimum requirements for safety from structural and mechanical failure and excessive pressures, established by the building official in accordance with nationally recognized standards. Also, required electrical, mechanical, safety and operating controls must carry approval from an approved testing agency. Further, electrical controls must be of such design and construction as to be suitable for installation in the environment in which they are located. All steam boilers must be provided with a pressure gage and a water gate gage. All water boilers must be provided with a pressure gage and a temperature indicator. The ICBO Code also requires that every boiler and pressure vessel must be provided with a safety or relief valve to insure positive relief of any pressure over the pressure rating of the system. Each such valve must be placed on the boiler side of all other valve and accessories and must be of sufficient capacity to relieve the heat energy that can be supplied to the boiler, or as otherwise approved by the building official. Valves so employed must be of such nature and so constructed and arranged as to permit their being tested manually to determine their operating condition.

The AInA Code requires that pressure and temperature limit controls, which have been tested and listed by a nationally recognized testing laboratory be installed on all water heaters. Controls which are on water heaters that are tested and listed by a nationally recognized testing laboratory will be considered in compliance with this provision. 


\begin{tabular}{l|l|l|l|l|l|l|l}
\hline M-T & HIGH PRESSURE REQUIREMENTS (continued) & & & & LI & L2 & L3 \\
\hline
\end{tabular}

(SEE FIG。1)

With regard to the applicability of the high pressure requirements to phasechange storage devices, a key ingredient is the word "approved." Certainly these provisions would apply to closed vessels in which the phase-change materials are operated under pressure as in the case of the direct contact liquid (immiscible fluid) systems and the direct contact solid systems. The separated element system could be operated as a closed or open system; however, in either case the vessel could be subjected to pressure if the circuit carrying the heat transfer fluid should fail.

Since there is no present mechanism to approve these devices, these systems could not be directly accepted by the mechanical official but would have to qualify under some other provision (see Reference M-D) or perhaps not accepted at all.

Relief valve provisions would most likely be enforced for closed or pressurized systems and would contain overflow or other provisions to accommodate transport circuit failures for open or nonpressurized systems. The location and settings of these devices would be determined by the specific configuration of the phase-change storage device.

\section{REFERENCES}

Organization

Code

Section

\begin{tabular}{lll}
\hline BOCA & The BOCA Basic Mechanical Code & M-400.7, M-400.8, \\
& & M-405.1, M-405.2 \\
ICBO & The Uniform Mechanical Code & $2102,2106,2112(2)$ \\
AInA & National Building Code & Appendix E, 6.5
\end{tabular}




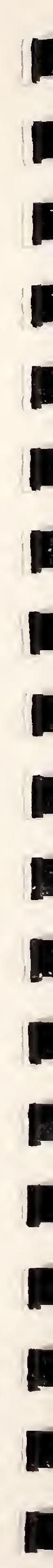




\begin{tabular}{l|l|l|l|l|l|l|l|l|l|l}
\hline$M-U$ & JOINING OF PIPES & & & & L.1 & L2 & L3 \\
\hline
\end{tabular}

(SEE FIG。1)

Each system which depends on a liquid to transport heat must pipe this liquid to those system components where heat is removed or added. The liquid generally used would be water although a rust inhibitor and/or anti-freeze may be added. Those systems, however, which operate using immiscible fluids as the heat transfer medium would normally use an oil circulating through the phase change material.

The Mechanical Codes contain provisions for steam and water piping. Provisions which seem most appropriate for application to phase change material storage systems are described below. It should be noted that the plumbing codes also contain provision for the joining of pipes and these are discussed in the plumbing section (see Reference P-L). The two sets of requirements should be read together for a comprehensive understanding of pipe joining provisions.

\section{A. MATERIALS}

Several of the Mechanical Codes contain requirements for piping materials. The BOCA and SBCC Codes require that all steel and wrought iron pipe be at least Schedule 40 pipe, or pipe or tubing of equivalent working pressure and strength. Both codes allow brass or copper pipe, and copper or steel tubing to be used on steam and water heating installations if the system is designed to operate with such pipe or tubing working pressure rating. The ICBO Mechanical Code requires that piping be at least standard weight brass or copper, Class 150 cast iron, standard weight galvanized or block wrought iron, ASTM Schedule 40 steel, suitable asbestos-cement of adequate pressure rating, or other approved materials. This code also requires all tubing to be copper water tube. Also, plain screwed fittings are required to be brass, bronze, cast iron or galvanized or black malleable iron, or galvanized or black steel. The ICBO Code also states that fittings for copper tubing must be wrought copper, wrought bronze or cast brass. Welded fittings are required by ICBO to be black steel, and fittings for asbestos cement must be cast iron. Fluxes for solder, sweat and brazed joints are required by this code to be a noncorrosive type and suitable for the use intended. The ICBO Code states that all piping, tubing, valves, joints, fittings, devices and materials must be free of defects and comply with nationally recognized standards which are approved by the building official. The ICBO Code also requires that tubing be at least Type $K$ for condensate lines, Type $L$ for steam condenser cooling water lines, underground water lines, and above ground water lines, Type $M$ for above ground water lines not embedded in concrete or masonry.

The BOCA and SBCC Codes require that all pipe fittings and valves that are used on high pressure installations be of the type designed for the pressures and temperatures of the installation. These codes also require that all pipe and piping used on high pressure-high temperature installations be of the required weight and strength suitable for the type service and pressure intended. Also, both codes state that stress relieving might be required by the department for high pressure-high temperature welded installations. 


\section{B. PIPE JOINING AND CONNECTIONS}

The BOCA and SBCC Codes state that steel or wrought iron piping can be joined by welding or by the use of screw or flanged fittings. Copper or tinned steel tubing can be joined by blazing, soldering or approved compression fittings. The ICBO Code states that surfaces that are to be joined by soldering must be cleaned bright by manual or mechanical means. Also, this code requires that joints be properly fluxed and tubing be reamed out to the full size of the bore. Joints in brass and copper piping must be screwed, brazed, welded, flanged, or mechanical type. Joints in cast-iron pipe must be screwed, flanged or mechanical type. Joints in galvanized wrought-iron and galvanized steel piping must be screwed, flanged or mechanical type. Joints in black wroughtiron piping must be screwed, brazed, welded, flanged or mechanical type except that joints built into or embedded in concrete or masonry must be welded. The ICBO code further requires that joints in black steel piping must be screwed, brazed, welded, flanged or mechanical type. Also joints in copper tubing must be soldered, sweated, or brazed; except that joints under a building and in or under any concrete slab resting on the ground must be silver brazed, or equal, and fittings shall be of wrought copper. All solder and seat joints can be made with 95 percent tin - 5 percent antimony solder; however, if the steam pressure does not exceed 15 psig nor the water pressure exceed 30 psig, then 50 percent tin - 50 percent lead can be used.

\section{WELDING}

The BOCA and SBCC Codes state that where welding is used as a means of connecting or joining branch mains to the main steam piping, provisions must be made for the expansion of the pipe at this point so that undue stresses or strains will not be placed on the welds or piping. The BOCA and SBCC Codes prohibit use of the bull-heading or rigid tee on this type of connection.

The ICBO Code requires that welding be performed in accordance with nationally recognized standards approved by the building official.

\section{THREADED JOINTS}

The BOCA and SBCC Codes require all threads on pipe, valves, flanges, and similar fittings conform to the American Standard Taper Pipe Threads. These two codes also require that threaded joints be made up with an approved thread compound or lubricant. The ICBO Code requires that pipe compound be noncorrosive and insoluble in the material being carried in the pipe. Also, the ICBO Code requires the threads on iron pipe size (I.P.S. pipe) be standard taper pipe threads, with all burrs removed, pipe ends reamed or filed out to full size of bore and all chips removed. 


\begin{tabular}{l|l|l|l|l|l|l|l|l|l|l|}
\hline$M-U$ & JOINING OF PIPES (Continued) & & & & LI & L 3 \\
\hline
\end{tabular}

(SEE FIG。1)

\section{E. REAMING}

The BOCA and SBCC Codes require all pipe and tubing to be reamed after cutting to not less than full internal dimensions.

\section{F. FLANGES AND GASKETS}

The BOCA and SBCC Codes require screw-type flanges of cast iron, steel or forged integral type to be used up to their working pressure and temperature ratings. All companion flanges must have matching facing and drilling. These codes also state that required gaskets must be made of material approved for the pressure and temperature to which they are to be subjected. Rubber is not allowed to be used where pressures exceed 15 psig steam and 45 psig water or where temperatures are greater than $250^{\circ} \mathrm{F}$.

The ICBO Code requires flanged joints to be tightened evenly and to be provided with suitable nuts, bolts, and gaskets. This code also requires flange gaskets to be metal or asbestos or other approved materials.

Although the heat transfer fluid piping is not normally considered a part of the phase change thermal storage device, the piping system must interface with the phase change thermal storage component so that the heat transfer fluid may enter and leave. In the separated element systems, this connection may take place at a coupling, flange, or other interface provided by the manufacturer.

Other types of phase change systems may have external piping which is considered part of the storage system. An example could be the immiscible fluid or direct contact liquid system. This type of system could be designed to contain the immiscible fluid totally within the vessel or could depend on an external heat exchanger to interface with other circulating water loops. This may also be true of the direct contact solid which uses water as the carrier of the pellet slurry and the entire piping loop containing the slurry considered a part of the phase change thermal storage device. In either case, the pipe joining provisions of the codes may be considered a requirement or the provisions contained in the codes at least be considered a useful guideline of good commercial practice.

It is unclear whether the mechanical official or the plumbing official, or both would be responsible for piping. Generally, the provisions indicated in both the mechanical codes and the plumbing codes are complementary and should offer little conflict although the plumbing provisions appear to be more comprehensive in scope. 


\begin{tabular}{l|c|c|c|c}
\hline M-U & JOINING OF PIPES (Coninued) & & L1 & L2 \\
\hline \\
$\begin{array}{l}\text { REFERENCES } \\
\text { Organization }\end{array}$ & (SEE FIG. 1) \\
\hline
\end{tabular}

A. MATERIALS

BOCA

SBCC

ICBO
The BOCA Basic Mechanical Code

Standard Mechanical Code

The Uniform Mechanical Code

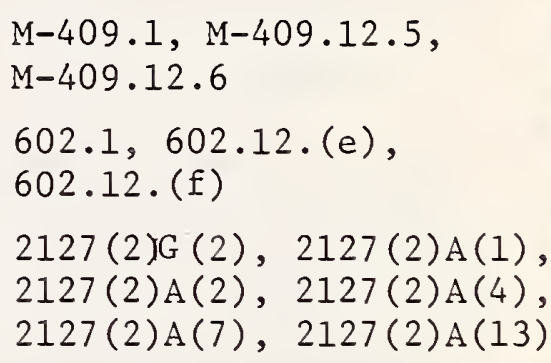

B. PIPE JOINING AND CONNECTIONS

BOCA

The BOCA Basic Mechanical Code

SBCC

Standard Mechanical Code

ICBO

The Uniform Mechanical Code

The BOCA Basic Mechanical Code

$\mathrm{M}-409.9$

602.9

$2127(2) B(3)$

ICBO

The Uniform Mechanical Code

D. THREADED JOINTS

BOCA

The BOCA Basic Mechanical Code

SBCC

Standard Mechanical Code

ICBO

The Uniform Mechanical Code

E. REAMING

BOCA

The BOCA Basic Mechanical Code

SBCC

Standard Mechanical Code

$\mathrm{M}-409.2$

602.2

F. FLANGES AND GASKETS

BOCA The BOCA Basic Mechanical Code

SBCC

Standard Mechanical Code

$\mathrm{M}-409.12 .4, \mathrm{M}-409.12 .2$

$602.12(d), 602.12 .2$

$2127(2) B(4), 2127(2) A(10)$ 


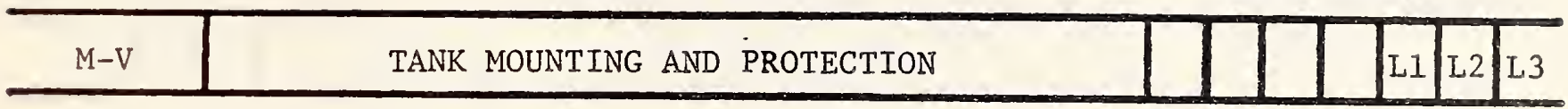

(SEE FIG。1)

The BOCA and ICBO Mechanical Codes contain provisions relative to tank installation and protection. A major concern is the ability of the tank stand and/or supporting floor to carry the weight of the tank and its contents, although the ICBO Code also addresses vibration isolation.

The BOCA Mechanical Code requires all tanks to be installed on a suitable type stand or concrete foundation which is capable of supporting the combined weight of the tank and contents. This code also requires tank stands to be constructed of fabricated steel beams or channels welded or bolted together, or steel pipe and malleable iron fittings welded to form adequate support for the tank and contents. When pipe is used for the cross member on which the tank will rest, the BOCA Code requires that this pipe be double strength or extra heavy pipe or two pipes, one inside the other, the inner pipe to be of the next size smaller than the pipe used as the cross pipe or bearings pipe. Further, BOCA requires that the tank stands must be supported directly from floor to tank foundation and not from a partition or building wall unless such wall is designed to carry the additional load. When tanks are installed in the basement, and the floor under the tank stand is not capable of supporting the weight of the tank and contents, such floors are required by the BOCA Code to be reinforced to be capable of carrying the weight. All stand legs resting on concrete (basement floor) are required to be set on either round or square bearing plates not less than $1 / 2$ inch thick and sized so that stress or load on concrete at its perimeter does not exceed 200 pounds per lineal inch of perimeter.

The ICBO Mechanical Code specifically states that all equipment must be set or mounted on a level base which is capable of supporting and distributing the weight contained thereon. All boilers, tanks and equipment are required by the ICBO Code to be securely anchored to the structure. Further, the ICBO Code states that equipment requiring vibration isolation must be installed as designed by a registered engineer to the satisfaction of the building official. The ICBO Code also states that appliances installed in garages, warehouses or other areas where they may be subjected to mechanical damage must be suitably guarded against such damage by being installed behind protective barriers or by being elevated or located out of the normal path of vehicles.

Phase change material storage systems using liquid as a working fluid must, of course, be designated to be accommodated by an adequate supporting structure. If these provisions did not exist in the codes, good design practice would dictate that floor loadings, slab stresses, and tank supports be checked to assure a structurally safe installation. These provisions might act as a reminder to the designer or installer to review their installation for unsafe supporting structural conditions. 


\begin{tabular}{l|l|l|l|l|l|l|l|l}
\hline M-V & TANK MOUNTING AND PROTECTION (Continued) & & & & & L1 & L2 & L3 \\
\hline
\end{tabular}

(SEE FIG. 1)

Although the above provisions address tanks specifically and imply applicability to all liquid heat transfer devices, phase change installations using air as the working medium should also be checked for proper structural support. This is particularly true if large numbers of modular trays are.aggregated and stacked in a single location.

\section{REFERENCES} $M-420.6 .2$ 
The BOCA, ICBO, and AInA Mechanical Codes provide for the installation of equipment on the roof of a building or other outdoor applications. The provisions are intended for heating equipment; however, the BOCA and AInA Codes refer to the broad scope of "appliances."

The codes cover requirements for outdoor construction or weather protection to assure that the equipment is designed to withstand hostile outdoor climatic conditions and also require the supporting roofs and other structural members to be adequate for supporting the additional loads. Additionally, provisions are made for service receptacles and lighting, drainage and access, and the installation of platforms and catwalks under certain conditions.

\section{A. OUTDOOR CONSTRUCTION OR WEATHER PROTECTION}

The BOCA Mechanical Code requires that appliances must be approved for outdoor installation and must be designed to withstand atmospheric and climatic conditions in the areas in which they are to be installed. This code also requires that all access locks, screws and bolts be of corrosionresistant material. The ICBO Code states that unless listed or designed for outside installation, a furnace on the roof of a building must be enclosed in a penthouse which complies with the requirements of the Building Code for roof structures or must be completely enclosed in weatherproof housing. When constructed of metal, the ICBO Code requires that it be galvanized steel not less than No. 24 U.S. Standard gage or of aluminum not less than No. 22 B\&S gage supported on a substantial metal frame. The housing cannot be larger than necessary to properly cover and provide a minimum 6 inch clearance around the appliance or appliances enclosed therein, including all controls and draft diverters. The AInA Code requires appliances installed on roofs or outside of buildings to be tested and listed by a nationally recognized testing laboratory for outdoor installations. This cude also requires appliances to be installed in accordance with the requirements of the listing and conditions of approval.

Also, the AInA Code requires appliances to be designed to withstand the atmospheric and climatic conditions and be installed in enclosures that will provide adequate protection from the atmospheric and climatic conditions. Enclosures must be designed and constructed to make them accessible for operation and maintenance.

\section{B. ABILITY TO SUPPORT LOAD}

The BOCA Code states that roofs on which appliances are to be installed must be capable of supporting the additional load due to the appliance weight and dynamic action. The AInA Code also requires roofs, including the structural members and the supports, to be capable of supporting the loads of appliances and any enclosures. Where appliances are installed on an elevated structure, the AInA Code requires the structure to be capable of supporting the loads of the appliances and any enclosures and to withstand wind loads. 


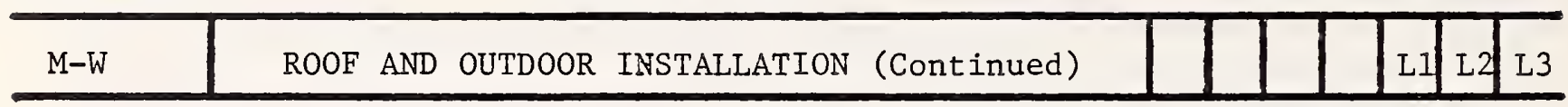

(SEE FIG. 1)

\section{SERVICE RECEPTACLES AND LIGHTING}

The BOCA Code requires that each appliance have an accessible weatherproof disconnect switch and a 110-120 volt AV grounding-type convenience outlet on the roof adjacent to the appliance. The convenience outlet must be on the line side of the disconnect switch. The BOCA Code also requires that proper permanent lighting be provided at the roof access. The switch for such lighting must be located inside the building near the access means leading to the roof. The AInA Code also requires permanent lighting for each access required. The switch must be located inside the building in a location convenient for the maintenance personnel. Also, AInA Code requires that each appliance have an accessible disconnect switch and a 110-120 volt a-c grounding type convenience receptacle on the roof near the appliance. This switch must be on the supply side of the disconnect switch.

\section{DRAINAGE}

The BOCA Code requires appliances to be installed on a well-drained surface. This code also requires at least 6 feet clearance to be maintained between the appliance and the edge of the roof or similar hazard. Otherwise rigidly fixed rails or guards at least 3 feet in height must be provided on the exposed side; parapets at least 3 feet in height may be used in lieu of guards or rails. The AInA Code also requires appliances on roofs to be installed on well drained surfaces, or mounted on bases or platforms and provided with walkways around the appliances, having a height such that the bases or platforms, and walkways will be above the expected level of water. This code also requires that appliances installed outside of buildings be mounted on permanent bases or platforms made of materials that will provide for the expected life of the appliance. Bases or platforms must have supports that extend below the frostline. The height of bases and platforms must be above the expected level of any accumulation of water, or permanent drainage must be provided to keep the appliance from being in the water.

E. ACCESS

The BOCA Code requires that adequate access be provided to appliances located on roofs or other elevated locations. This code also states that permanent or portable outside ladders can be provided on the inside or outside of single story buildings not over twenty feet in height. All other means of access must be a permanent or fold-away inside stairway or ladder with railings, terminating in an enclosure, scuttle or trap door. Such scuttles or trap doors must be at least thirty inches in the smallest dimension and must open easily and safely under all conditions, especially snow, and must be constructed so as to permit access from the roof side, unless deliberately locked on the inside. The BOCA Code also requires that at least six feet clearance must be available between the access opening and the edge of a roof or similar hazard. Otherwise, rigidly fixed rails or guards at least three feet in height must be provided on the exposed side, except that parapets at least three feet in height can be utilized in lieu of guards and rails. 


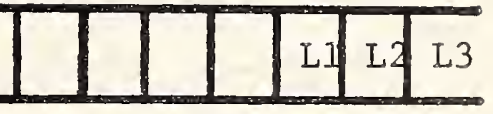

(SEE FIG。1)

With regard to access, the ICBO Mechanical Code states that required working platforms, railings, and catwalks are allowed to be omitted when access to the equipment is through a required roof scuttle and all of the following provisions are met.

1. The required scuttle must be located immediately adjacent to the control side of the equipment unit.

2. Controls, filters, burners, fans and motors must be accessible for service and repair within two feet of the edge of the equipment platform on the scuttle side.

3. The equipment platform cannot be more than twenty inches above the high side of the scuttle opening.

4. A substantial working platform not less than 30 inches by 30 inches must be provided directly below the scuttle at a point not less than 30 inches or more than 32 inches below the high side of the scuttle opening.

5. Scuttles that are located on other than the roof incline side of the equipment unit must have the hatch hinged on the low side of the scuttle. Hatches must be equipped with means to insure an opening radius of not less than 90 nor more than 100 degrees from the closed position. Hatches and hardware, when open, must be capable of withstanding a 300 pound lateral force from the roof of the incline side.

6. Access to scuttles must comply with section 708 of the ICBO Code.

Also, the ICBO Mechanical Code requires that every furnace installed in or on an exterior wall of a building which is designed so that the burners or controls must be serviced from outside the building be readily accessible. This code requires every furnace which is located on the roof of any building to be readily accessible. Exceptions to this requirement are the following. Permanent exterior ladders providing roof access do not need to extend closer than eight feet to the finish grade. A portable ladder can be used for access for furnaces on the single-story portion of a Group $M$ or $R$ occupancy.

The AInA Code requires appliances which are installed on roofs of buildings more than two stories or 20 feet in height, or installed at other elevated locations, to be provided with a permanent means of access to the roof or to appliances. The means of access must be approved by the Building Official and the Chief of the Fire Department. Also, access must be provided in compliance with the requirements of the provisions of section 807.3 of the National Building Code.

\section{F. PLATFORM}

The BOCA Mechanical Code requires every appliance located on a roof to be installed on a substantial level platform. Whenever the roof has a slope greater than three inches measured vertically to twelve inches measured horizontally, a level working platform not less than 30 inches in depth must be provided on each downslope side of the appliance. All sides of any working 


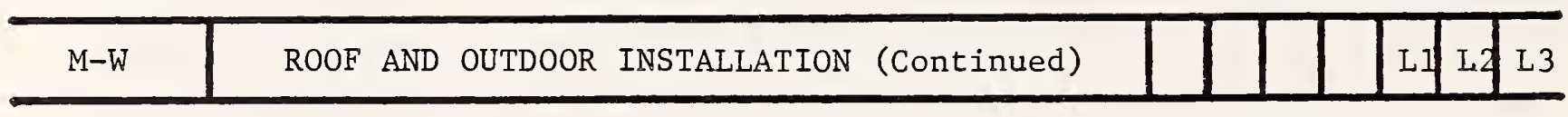

(SEE FIG. 1)

platform must be protected by a substantial railing thirty-six inches in height with vertical rails not more than twenty-one inches apart, except that parapets at least thirty-six inches in height can be utilized in lieu of rails or guards. Scuttles located on other than the roof incline side of the equipment unit must have their lids or trap doors hinged on the low side of the scuttle. Such lids or trap doors must be equipped with means to ensure an opening radius of not less than 90 degrees nor more than one hundred degrees from the closed position. Scuttle lids or trap doors and hardware, when opened, must be capable of withstanding a three hundred pound lateral load from the roof incline side.

The ICBO Mechanical Code also requires a furnace that is located on a roof to be installed on a substantial level platform. When the roof has a slope greater than 4 in 12, this code requires a level working platform at least 30 inches in depth to be provided along the firebox and control sides of the furnace. Sides of a working platform facing the roof edge below must be protected by a substantial railing 42 inches in height with vertical rails not more than twenty-one inches apart, except that parapets at least twenty-four inches in height can be utilized in lieu of rails or guards.

\section{G. CATWALK}

The BOCA Mechanical Code requires level catwalks not less than twenty-four inches wide to be provided from the roof access to every required working platform at the appliance. Catwalks with slope greater than twelve inches to three inches must have substantial cleats which are spaced not more than sixteen inches apart. The downslope side of catwalks on pitched roofs must be provided with a hand rail which is at least thirty-six inches high.

The ICBO Mechanical Code states that a catwalk at least sixteen inches in width with substantial cleats spaced not more than 16 inches apart must be provided from the roof access to the working platform at the appliance, except on roofs having a slope less than 4 in 12.

Although these provisions are oriented toward heating equipment generally mounted on roofs, they may be applicable to phase-change storage devices constructed to operate outdoors. Roof mounted storage devices may not receive widespread application; however, the outdoor placement of phase-change devices is an attractive option since placement does not encroach on valuable living space.

Outdoor installation of phase-change storage devices may present special problems to the manufacturer. Although some of the above provisions may not apply in specific system applications, other requirements may need to be addressed. Specifically, the method of filling, inspecting, and emptying may need study to assure a safe installation. The problem of making the system tamper-proof as well as accessible for servicing and maintenance may be another issue for investigation. 


\begin{tabular}{l|c|c|c|c|c}
\hline M-W & ROOF AND OUTDOOR INSTALLATION (Continued) & & L1 & L2 & L3 \\
\hline & & (SEE FIG。 I) \\
REFERENCES & Code & Section \\
\hline
\end{tabular}

A. OUTDOOR CONSTRUCTION AND WEATHER PROTECTION

BOCA: The BOCA Basic Mechanical Code

ICBO

AInA

$M-305.1 .1, M-305.1 .3$

$710(\mathrm{~b})$

$1.4 \mathrm{a}, 1.4 \mathrm{~b}, 1.4 \mathrm{c}$

B. ABILITY TO SUPPORT LOAD

BOCA The BOCA Basic Mechanical Code

A InA

National Building Code

C. SERVICE RECEPTACLES AND LIGHTING

BOCA

A InA

D。 DRAINAGE

BOCA

AInA

E. ACCESS

BOCA

ICBO

A InA

F。 PLATFORM

BOCA

ICBO

G。 CATWALK

BOCA

ICBO
The BOCA Basic Mechanical Code

National Building Code

The BOCA Basic Mechanical Code

National Building Code

The BOCA Mechanical Code

The Uniform Mechanical Code

National Building Code

The BOCA Basic Mechanical Code

The Uniform Mechanical Code

The BOCA Basic Mechanical Code

The Uniform Mechanical Code
$M-305.1 .2$

$1.4 \mathrm{~h}$

$M-305.2 .3, M-305 \cdot 3 \cdot 2$

$1.4 \mathrm{f}, 1.4 \mathrm{~g}$

$M-305.2 .2$

$1.4 i, 1.4 j$

$M-305.3, M-305.3 .1$

$710(\mathrm{~g}), 710(\mathrm{~h})$

$1.4 \mathrm{~d}, 1.4 \mathrm{e}$

$M-305.3 .3$

$710(\mathrm{e})$

$M-305.3 .4$

$710(f)$ 


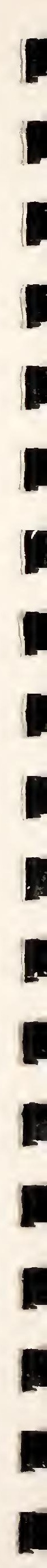




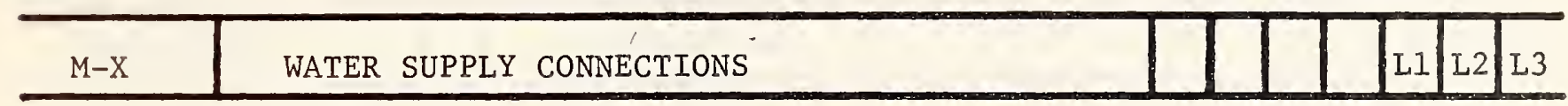

(SEE FIG. 1)

The BOCA and SBCC Mechanical Codes contain provisions for water supply protection so that the possibility of water tank backflow into the potable water supply system is minimized. These provisions are more definitively contained in the various plumbing codes which address protection of the water supply (see Reference $P-I)$ :

However, provisions of the Mechanical Codes address water supply connections. The BOCA Mechanical Code requires that the cold water supply to a hot water tank used for processing be discharged within three inches of the bottom of the tank either by direct connection at this point or by means of a pipe or tube inside of the tank. This code also requires that a hand shut-off valve and a check valve be installed on the cold water line close to the tank. The check valve must be installed in order to prevent hot water flow back from the tank into the cold water supply piping.

The SBCC Code also requires that the cold water supply to a hot water tank be discharged within three inches of the bottom of the tank either by direct connection at this point or by means of a pipe or tube inside the tank. This code also requires a hand shut-off valve and a vacuum relief valve be installed on the cold water line close to the tank. The vacuum relief valve must be installed so that hot water cannot flow back from the tank through the cold water supply piping.

The BOCA Mechanical Code requires all hot water heating systems, boilers, generators or pressure vessels be provided with a permanent make-up or feed water connection to such equipment from the water supply. Such water supply piping is required to be of a size proper for furnishing water to the equipment but cannot be less than one-half inch iron pipe size. Also, the BOCA Code requires that a hand operated compression, globe or gate type valve be installed on this line. This code also requires that water supply connections be connected to the piping of the heating system. Further, this code requires that a check valve of the same size as the water heating supply piping to the boiler be installed in the feed waterline so that water from the heating system cannot flow into the building supply line. Where pressure-reducing feed valves are installed that have check valves incorporated, a separate check valve is not required by this code.

The SBCC Mechanical Code also requires that from an approved back-flow preventer installed as required by the SBCC Plumbing Code to the inlet on a boiler, chiller, or other water-using device covered by this code, the piping must be as specified before in this code for hot and chilled water piping, except on boilers operating above 200 degrees F, or 100 P.S.I.G. pressure. Here the make-up water line must be black iron or wrought-iron pipe which conforms to Schedule Eighty of the American Standard on Wrought-Steel and Wrought-Iron Pipe ANSI B36.10-1959, and extra-heavy malleable iron fittings. Make-up water piping to chillers or water towers must be either galvanized steel or copper pipe. Also, the SBCC Code does not permit a direct cross-connection between the potable water supply and any other circulating water system. On closed type systems an approved backflow preventer must be installed in the water 


\begin{tabular}{l|l|l|l|l|l|l|l|l}
\hline$M-X$ & WATER SUPPLY CONNECTIONS (continued) & & & & L1 & L2 & L3 \\
\hline
\end{tabular}

(SEE FIG. 1)

supply line ahead of the control valve. On open type systems, where the water is supplied to an open tank or vessel, the outlet of the water supply must terminate not less than three inches above the highest possible water level in the tank or vessel. Waste water lines are required by the SBCC Code to terminate not less than three inches above the floor drain or fixture into which they spill.

The technique for protecting the potable water supply and the impact on phasechange storage systems is described in Reference P-I.

\section{REFERENCES}

BOCA

SBCC
The BOCA Basic Mechanical Code

Standard Mechanical Code
$\mathrm{M}-409.11, \mathrm{M}-413.1, \mathrm{M}-413.2$, $M-413.3$

$602.11,606.1,606.2$ 


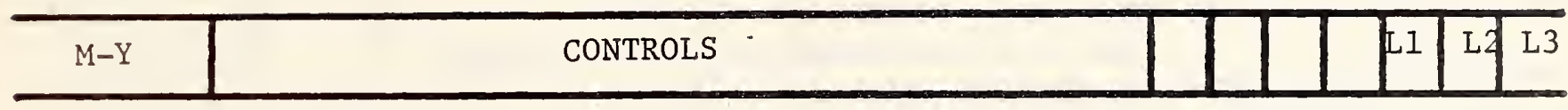

(SEE FIG. 1)

The provisions addressed by this topic are concerned with fire safety and the capability of air moving equipment (fans) to be shut off in case of fire. The fire may be detected by high temperature or smoke detecting devices and may be shut off automatically or manually.

The BOCA Mechanical Code requires that each air handing system be equipped with a high temperature shut-off control and disconnect switch located at a convenient accessible point adjacent to the unit for shutting down of the fan in the event of fire.

The ICBO Code states that each single system providing heating or cooling air in excess of 2000 cubic feet per minute in Group A, Division 1, 2, and 2.1; Group B, Division 2; Group E; Group I and Group R, Division 1 Occupancies are required to be equipped with an automatic shutoff. Automatic shutoffs must shut down the air-moving equipment when smoke is detected in a circulating airstream or as an alternate when smoke is detected in rooms served by the system. Whenever such system serves more than one occupancy, such devices must be provided. Such detectors do not have to be installed when rooms have direct exit to the exterior of the building. Neither do they have to be installed in systems specifically designed for smoke control. Smoke detection required by this code must be by a smoke detector installed in the main circulating-air duct ahead of any fresh-air inlet or installed in each room or space served by the return-air duct. Activation of any detector must cause the air-moving equipment to automatically shut down.

The AInA Code requires all duct systems to be equipped with not less than one manually operated device that will stop the operation of the fans in case of fire. The device must be at a convenient, accessible location approved by the Chief of the Fire Department. Where the height of the building exceeds 75 feet, one of the devices must be located in the fire emergency control station required by the provisions of Section 520.4 of the National Building Code. Also, duct systems having a capacity of $2,000 \mathrm{cfm}$ or more but not more than $15,000 \mathrm{cfm}$, except systems regulated by the provisions of Section 520.9 of the National Building Code must be equipped with automatically operating devices to cause shutdown of the fans when the temperature of the air in the system becomes excessive due to fire. Systems in buildings having health care occupancies and in penal institutions, hotels, dormitories, and lodging and rooming houses must also comply with the provisions of Sections $360.14 \mathrm{~d}$, $361.12 \mathrm{~d}$, and $380.12 \mathrm{~d}$ of the National Building Code. The automatically operating devices and their installation must comply with the provisions of Sections 23.16b (1) through (4). 


\begin{tabular}{l|l|l|l|l|l|l|l|l}
\hline $\mathrm{M}-\mathrm{Y}$ & CONTROLS (continued) & & & & L1 & L2 & L3 \\
\hline
\end{tabular}

(SEE FIG. 1)

The AInA Code requires fixed temperature thermostatic devices with a setting not greater than $136^{\circ} \mathrm{F}$ to be located at a suitable location in the stream of return air prior to the point where air is exhausted from a building prior to the point where air is diluted by air from outside the building. Approved smoke detectors suitable for duct installation are permitted to be used in place of fixed temperaturej thermostatic devices. Also, the AInA Code requires fixed temperature thermostatic devices with a setting not greater than $50^{\circ} \mathrm{F}$ above the maximum operating temperature of the system to be located at a suitable location in the main supply duct on the downstream side of the filters. Approved smoke detectors suitable for duct installation are permitted by this code to be used in place of fixed temperature devices. Thermostatic devices are required to be of a type that is manually reset, or the control system must be arranged so that some manual operation is required in order to restart the fan after a thermostatic device has operated. Approval of smoke detectors for compliance with the AInA Code will be based on tests and listings of smokeautomatic fire detectors by a nationally recognized testing laboratory.

Also, the AInA Code requires that duct systems having a capacity of more than 15,000 CFM must be equipped with approved smoke detectors connected to devices to cause shutdowns of the fans when the amount of smoke in the air in the systems becomes excessive due to fire. Systems in buildings having health care occupancies and in penal institutions, hotels, dormitories, and lodging and rooming houses are required by this code to comply with the provisions of Sections $360.14 d, 361.12 d$, and $380.12 d$ of the National Building Code. The smoke detectors and their installation must comply with the provisions of Sections 23.16c (1) through (4). Approved smoke detectors which are suitable for duct installation are required by the AInA Code to be located at a suitable location in the stream of return air prior to the point where air is diluted by air from outside the building. Approved smoke detectors of this type are also required by this code to be located in a suitable place in the main supply duct on the downstream side of the filters. Smoke detectors are required to be arranged to automatically, upon activation, close the smoke dampers required by the provisions of Sections 23.141. Approval of smoke detectors for compliance with the AInA Code will be based on tests and listings of smoke-automatic fire detectors by a nationally recognized testing laboratory.

With regard to phase-change thermal storage devices, one might argue that these provisions do not apply. However, a new element is introduced in the ductwork/ plenum configurations in systems using phase-change thermal storage devices, in that an unconventional device, the phase-change material, is placed within the air circulating loop. These phase-change thermal storage devices are a potential source of flame and smoke if subjected to high temperatures with the resulting products of combustion being circulated by the fan through the ductwork to the living areas. It would be reasonable for the mechanical official to require manual or automatic fan cutoff devices in case of fire, and this should be considered in the design and installation of these type units (also see Reference $\mathrm{M}-\mathrm{S})$. 


\begin{tabular}{l|c|c|c|c|c|c|}
\hline DESIGNATOR & PROVISION TOPIC & APPLICABILITY \\
\hline$M-Y$ & CONTROLS (Continued) & LI & L2 & L3 \\
\hline
\end{tabular}

\begin{tabular}{lll}
$\begin{array}{l}\text { REFERENCES } \\
\text { Organization }\end{array}$ & \multicolumn{1}{c}{ Code } & \multicolumn{1}{c}{ Section } \\
\hline BOCA & The BOCA Basic Mechanical Code & $1-302.10$ \\
ICBO & The Uniform Mechanical Code & 1009 \\
AInA & National Building Code & $23.16 \mathrm{a}, 23.16 \mathrm{~b}$
\end{tabular}




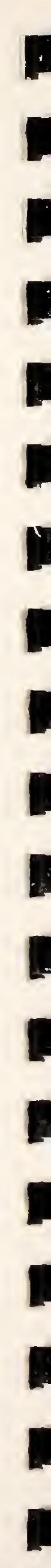




\section{$\mathrm{M}-\mathrm{Z}$}

MICELLANEOUS

(SEE FIG. 1)

Code provisions applicable to phase-change storage devices that do not fall into other categories in this section are discussed here under "Miscellaneous." For liquid systems, they include provisions for tank construction, approval and labeling, which are part of the safeguards to prevent tanks from being subjected to pressures in excess of the rated working pressure (also see Reference $M-T$ ). The requirements for air outlets and inlets for air systems are also addressed in the AInA Code which specifies air outlet and inlet locations and the combustibility attributes of devices located at outlets or inlets of supply and return duct systems.

The other miscellaneous provisions are concerned with outside air entering heat exchangers, thermostat requirements for space temperature regulation, thermometer installation for heat exchangers, cleaning and antifreeze provisions, and relief valve discharge requirements.

\section{A. TANK CONSTRUCTION, APPROVAL, AND LABELING}

The BOCA Mechanical Code requies all hot water storage tanks with a capacity of 120 gallons or more and tankless heaters with a capacity of 200 gallons per hour to be installed in compliance with this code. When these tanks are used for storage of hot water at municipal water pressure, they are required by the BOCA Code to be constructed of metal and have a working pressure rating of at least 160 psig. However, tanks with a working pressure rating of 100 psig may be used, provided an approved type of pressure-reducing valve is installed in the supply piping to the tank in order to maintain the pressure at or below 100 psig, and the tank is equipped with a pressure-relief valve equal in size to either the supply or discharge line, whichever is the larger.

The BOCA Code also states that tanks will be approved for use if labeled by an approved testing or inspection agency, when tested and stamped in accordance with the ASME Boiler and Pressure Vessel Code listed in Appendix A or the BOCA Mechanical Code, or if permanently labeled or stamped by the manufacturer that the tanks have been tested to 235 percent of the maximum working pressure, but not less than 200 psig hydraulic or hydrostatic pressure and the maximum working pressure at which it may be installed.

On indirect heated type water heaters, the BOCA Code requires that the design working pressure be permanently stamped or marked. Direct heated type water heaters are required by this code to have their design working pressure permanently stamped or marked on them, and this pressure must be the maximum permissable working pressure of the tank or heater. If the pressure of the water supply to the heater is greater than the design working pressure, the BOCA Code requires a reducing valve to be installed to lower the pressure to the rated working pressure permitted on the tank or heater, whichever is the lessor. Safeguards are also required to be provided to prevent the water heater from being subjected to pressures in excess of the rated working pressure. 


\begin{tabular}{l|l|l|l|l|l|l|l|l}
\hline $\mathrm{M}-\mathrm{Z}$ & MISCELlANEOUS (Continued) & & A2 & A3 & A4 & L1 & L2 & L3 \\
\hline
\end{tabular}

(SEE FIG. 1)

\section{B. AIR OUTLETS AND INLETS}

The AInA Code requires outlets and inlets of supply and return ducts to be located not less than 3 inches above the floors. This requirement is waived, however, in theaters, where inlets are permitted to be located on the floor under fixed seats, when a system is designed to prevent the accumulation of dust and particles in the system (in which case linear air outlets and air inlets are permitted to be located in floors, as are outlets and inlets for air curtains in doorways).

The AInA Code also requires outlets and inlets of supply and return duct systems located less than 7 feet above a floor to have a grille or screen with openings which will prevent passage of a sphere having a diameter of $1 / 2$ inch. This code also requires devices located at outlets or inlets of supply and return duct systems, except as permitted, to be made of noncombustible materials. However, these devices may be of limited combustible or combustible materials if: the material used and the design is such that the devices will fall from position before the device ignites, if the devices are not installed on outlets or inlets located less than 7 feet above the floor, if the location and design of the devices do not permit propagation of flame from one device to another or to another outlet or inlet.

\section{MISCELlanEOUS}

The BOCA Mechanical Code requires that when more than 50\% of the air entering a heat exchanger is taken directly from the outside at winter design temperature, the heat exchanger through which such air passes must be constructed of an approved noncorrosive material unless provisions are made to assure a mixture temperature of at least 55 degrees $\mathrm{F}$.

This code also requires, in all buildings and structures of use group $\mathrm{R}-3$, at least one thermostat for regulation of space temperature be provided for each separate heating, ventilating, and air conditioning system. In addition, a readily accessible manual or automatic means must be provided to partially restrict or shut off the heating or cooling input to each zone or floor, excluding unheated or uncooled basements and garages.

Buildings and structures in use group R-2 (residential, multi-family) will have each individual unit considered separately. Each unit must meet the above requirements for use group R-3. For all other buildings and structures other than use group R-3 and in spaces other than dwelling units in use group R-2 at least one thermostat is required to be provided for regulation of space temperature for each separate heating, ventilating, and air conditioning system, and for each floor of the building.

The BOCA Code also requires a standard type hot water thermometer be installed on all hot water boilers or heat exchangers and must be so located as to indicate the true temperature of the water. Hot water systems are required by this code to be cleaned according to the recommendations of the manufacturers of the component water carrying parts and as approved by the building official before such a system will be allowed to be placed in service. This code also requires that antifreeze solutions used in radiant heating coils within a building must not contain any liquid with a flash point which is less than 225 degrees $F$. 


\begin{tabular}{l|l|l|l|l|l|l|l|l|l}
\hline $\mathrm{M}-\mathrm{Z}$ & MISCELlanEOUS (Continued) & & A2 & A3 & A4 & L1 & L2 & L33 \\
\hline
\end{tabular}

(SEE FIG。1)

The ICBO Mechanical Code requires the discharge from relief valves to be piped to within 18 inches of the floor or to an open receptacle, and, when the operating temperature is in excess of 212 degrees $F$, these must be equipped with a splash shield or centrifugal separator. When the discharge from safety valves would result in a hazardous discharge of steam inside the boiler room, such discharge must be extended outside the boiler room. No valve of any description will be allowed by the ICBO Code to be placed between the safety or relief valve and the boiler, nor on the discharge pipe between the safety valve and the atmosphere.

The provisions concerned with tank construction, approval, and labeling have direct application to phase-change thermal storage devices. The provision for approval is the most troublesome unless the device has been tested and labeled by a nationally recognized testing or inspection agency. Although specific working pressures are detailed, each pressurized or closed phase-change device would have to be reviewed to determine the appropriate working and test pressures. The requirements for marking design working pressures and other information on the vessel itself also should apply to closed phase-change devices.

The provisions related to air outlets and inlets would apply to the air systems which serve as a collector as well as "storage only" phase-change thermal storage devices. The air outlets and inlets for the "storage only" system might be considered part of the ductwork and too far removed from the phasechange thermal storage components to be a cognizant part of the phase-change system itself.

The remaining miscellaneous items could be applied on a specific system-bysystem basis. If no outside air is used, the noncorrosive material requirement should not apply. The thermostat regulation of space temperature perhaps should be considered for individual window unit systems as some room temperature control may be indicated.

The hot water thermometer for heat exchangers may be an unnecessary requirement; however, the manufacturer's recommended cleaning instructions should be used and the flashpoint requirement followed if the heat transfer medium contains antifreeze or other additives. The relief valve discharge requirements may also be reasonable for phase-change thermal storage vessels if the system's operating characteristics are as specified in the provisions.

\section{REFERENCES}

Organization

Code

Section

A. TANK CONSTRUCTION, APPROVAL, AND LABELING

BOCA The BOCA Basic Mechanical Code

$M-420.1, M-420.2$,

$M-420.2 .1, M-420.2 .2$, $M-420.4, M-420.5$

B. AIR OUTLETS AND INLETS
AInA
National Building Code

$23.10 \mathrm{a}, 23.10 \mathrm{~b}, 23,10 \mathrm{c}$, $23.10 \mathrm{~d}, 23.10 \mathrm{e}$ 


\begin{tabular}{l|l|l|l|l|l|l|l|l}
\hline $\mathrm{M}-\mathrm{Z}$ & MISCELLANEOUS (continued) & & A2 & A3 & A4 & L1 & L2 & L3 \\
\hline
\end{tabular}

(SEE FIG. 1)

\section{MISCELLANEOUS}

BOCA

ICBO
The BOCA Basic Mechanical Code

The Uniform Mechanical Code
$M-612.10, M-1304.4$, $M-414.2, M-422.1$, $M-423.6$

2108 


\section{TOPICS AND PROVISIONS OF THE MODEL PLUMBING CODES RELEVANT TO PHASE CHANGE SYSTEMS}

\subsection{OVERVIEW}

This section addresses those provisions contained in the Model Plumbing Codes that would impact phase change thermal storage systems when they are integrated into the temperature comfort condition systems in buildings. Each of the issues presented is organized into a "provision topic" which aggregates the code information related to that topic by identifying the code and section and then detailing the specific provision language found in that section. Provisions common to more than one code are quickly recognized and the degree of commonality or divergence between codes is easily distinguished. Each provision topic is discussed from a code perspective and the impact of these issues upon system design and installation is provided.

A "reference" designator is also included in the heading of each provision topic which keys to the Appendix. In the Appendix, each of the model plumbing codes are shown. The topics discussed in this report are cross-referenced to the table of contents, or provisional outline, of each of the model plumbing codes. In this format, the user of the Appendix is directed by the code reference to the applicable provision topic and phase change issue found in the report. In addition, the "applicability" boxes shown in the heading of each provision topic found in the report refer to the appropriate phase change material classification, as shown in Figure 1 , and as defined in the text.

The material presented on the following pages, although paraphrased, is based on the model codes referenced under each provision topic. These model codes are copywritten material published periodically by each of the model code organizations (see page 50 for a complete listing of these codes and the names of the parent organizations). The user should refer directly to the source document(s) applicable to the jurisdiction in question if specific provisions are required for design, installation, maintenance, or other needs. 


\subsection{TOPICS AND PROVISIONS}

P-A Purpose and Scope

P-B Basic Principles

$P-C$ Definitions

P-D Repair and Maintenance

P-E Alternate Measures

P-F Unsafe Plumbing

$P-G$ Review of $P l$ ans and Specifications

$\mathrm{P} \rightarrow \mathrm{H}$ Inspections

P-I Connections to the Plumbing System

$\mathrm{P}-\mathrm{J}$ Use of Approved Materials and Equipment

$\mathrm{P}-\mathrm{K}$ Markings and Identification

P-I Joining of Pipes

$\mathrm{P}-\mathrm{M}$ Testing

$\mathrm{P}-\mathrm{N}$ Drains

P-0 Interceptors and Separators

P-P Toxic or Harmful Wastes

$\mathrm{P}-\mathrm{Q}$ Cross Connections and Backflow

P-R Water Shut-Off Valves

P-S Pressure and Temperature Relief

P-T Energy Cut-off Devices

$\mathrm{P}-\mathrm{U}$ Miscellaneous 


$$
\mathrm{P}-\mathrm{A}
$$

PURPOSE AND SCOPE

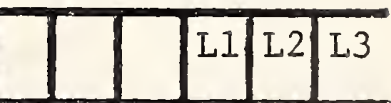

Each of the plumbing codes includes a statement addressing the (SEE FIG. 1) scope of the code. The main reason given is the concern for public welfare, health, and safety, and this is accomplished through the assurance of properly designed and installed potable water systems. As is generally true of most codes, efficiency, economy, effectiveness, and durability are not issues. However, these attributes are indirectly influenced in a positive manner through the control of system design, materials used, and methods of installation.

With regard to the scope of the codes, only BOCA states explicitly that hot water piping in conjunction with building heating is excluded from the scope. The other codes do not address this topic at all. Also, the plumbing official's concern is not limited merely to the design and installation of the plumbing system, but also covers alteration, repair, relocation, replacement, use, and maintenance. Material found in the appendix of the code is generally not considered enforceable but rather included for reference, unless those appendix provisions are specifically adopted by the jurisdiction.

Specifically, the BOCA Plumbing Code states that it must be construed liberally and justly to secure the proper installation of systems for furnishing potable water, for sanitary sewage disposal and storm drainage; and to insure public safety, health and welfare insofar as they are affected by the installation and maintenance of plumbing. This code also states that the design and installation of plumbing systems, including sanitary and storm drainage, sanitary facilities, water supplies, storm water and sewage disposal in buildings must comply with the requirements of this code. The design and installation of gas piping, chilled water piping in connection with refrigeration process and comfort cooling, and hot water piping in connection with building heating is required by the BOCA code to conform to the requirements of its Mechanical Code in Appendix A. The design and installation of piping for fire sprinklers and standpipes is required by BOCA to conform to the provisions of its Building Code, listed in Appendix A. Water and drainage connections to such installations are required by BOCA to be made in accordance with the requirements of its code.

The SBCC Plumbing Code states that it is to be remedial and construed to secure the beneficial interest and purposes thereof, which are health, sanitation, general public safety and welfare, by regulating installation and maintenance of all plumbing, The SBCC Code also states that its provisions apply to every plumbing installation, including alterations, repairs, replacement, equipment, appliances, fixtures, fittings and appurtenances thereto, and when connected to a water or sewerage system.

The IAPMO/ICBO Code states that it is an ordinance which provides minimum requirements and standards for the protection of the public health, safety, and welfare. It also states that its provisions apply to the erection, installation, alteration, addition, repair, relocation, replacement, maintenance or use of any plumbing system, except as otherwise provided for in this code. 


\begin{tabular}{l|l|l|l|l|l|l|l|l|}
\hline $\mathrm{P}-\mathrm{A}$ & PURPOSE AND SCOPE (Continued) & & & & & L1 & L2 & L33 \\
\hline
\end{tabular}

(SEE FIG. 1)

The NAPHCC Code states that it is a recommended code of plumbing practice, design and installation which includes the establishment of performance criteria that is predicted on the need for protection of health and safety through proper design, installation, and maintenance of plumbing systems. Its scope exclüdes the development of specific standards which are related to the composition, dimensions, and/or mechanical and physical properties of materials, fixtures, devices, and equipment used or installed in plumbing systems.

Because the scope of each of the codes does not explicitly cover phase change thermal storage devices, one might question the authority that the plumbing official has in regulating and controlling these devices. One might cite BOCA, wherein hot water piping in connection with building heating is excluded from the scope of that code.

To view this issue in perspective, it must be recognized that all codes, including BOCA, control the design and installation of domestic hot water systems. If the system includes a phase change thermal storage device, then this device must also be considered the purview of the plumbing official. An example of this is the tankless water heater which derives its source of heat through the insertion of a heat exchanger into a boiler whose main function is the supplying of hot water to a hydronic heating system.

Finally, one might ask the function of the plumbing official in approving phase change thermal storage devices if the system does not interfere at all with the domestic hot water supply. In that case, the responsibility may indeed be beyond the scope of the plumbing official but then would fall under the responsibility of the mechanical official. (See Mechanical Code Analysis.) In either case, the plumbing official, the mechanical official, or both would have jurisdiction.

\section{REFERENCES}

Organization Code Section

\begin{tabular}{lll}
\hline BOCA & The BOCA Basic Plumbing Code & $\mathrm{P}-100.2, \mathrm{P}-100.3$ \\
SBCC & Standard Plumbing Code & $101.2,101.3$ \\
IAPMO/ICBO & The Uniform Plumbing Code & $10.2,10.3$ \\
NAPHCC & National Standard Plumbing Code & Scope \\
& \\
& $-194-$
\end{tabular}


(SEE FIG. 1)

Three of the plumbing codes (BOCA, SBCC, and NAPHCC) contain "Basic Principles" of good practices for designing and fabricating plumbing systems. The basic principles of environmental sanitation and safety through properly designed, acceptably installed, and adequately maintained plumbing systems are declared as the foundation of the codes. The codes state further that although some of the details of plumbing construction may vary, the basic sanitary and safety principles are desirable and necessary to protect health and safety. These principles are to be used as interpretations when necessary and also in situations not specifically covered by the plumbing codes.

For example, the codes do not contain provisions concerning any type of thermal storage device while hot water tanks, as such, are mentioned. In addition, phase change thermal storage devices are so new in this application that they certainly were not considered by the plumbing code community. The basic principles, however, can provide guidance to the types of requirements and provisions pertinent to this new family of devices until they are accepted and specifically addressed by the codes. The parts of this section that follow are discussions of the basic plumbing principles which apply to phase change thermal storage devices and how they can affect hardware design, installation, and maintenance. The basic principles which do not affect thermal storage devices directly are not discussed. It should be noted that neither the Mechanical or Building Codes contain such basic principles for guidance.

\section{A. PROTECTION OF POTABLE WATER SUPPLY}

The overriding mission of the plumbing official is the protection of the potable water supply. No other situation commands the level of concern as does that of a poorly designed fixture or plumbing system that would allow "used" water, unsafe liquids, or other contaminents to enter the potable water system. The codes describe these situations in their basic principles.

The NAHPCC Code states that all premises intended for human habitation, occupancy or use shall be provided with a supply of potable water. The BOCA Code expands this statement to also include all premises intended for employment, or the preparation or processing of food, drinks or other materials for human consumption. The BOCA Code also states that not only will an adequate, safe and potable water supply be provided, but it must be done so through a safe system of piping to all fixtures, appliances and appurtances. Both codes also state that such a water supply must not be connected with unsafe water sources, nor be subject to the hazards of backflow or backsiphonage.

The SBCC Code states that there must be no direct or indirect cross connections, either existing or potential, between a safe potable water supply and an unsafe, non-potable supply. This code also requires that adequate protection be provided to prevent possible backflow or back siphonage of an unsafe or potentially hazardous fluid or material into a safe water system. 


\begin{tabular}{l|l|l|l|l|l|l|l|l|}
\hline $\mathrm{P}-\mathrm{B}$ & BASIC PRINCIPLES (Continued) & & & & L1 & L2 & L3 \\
\hline
\end{tabular}

(SEE FIG. 1)

Thermal storage devices using phase change materials and a liquid as the working fluid would normally interface with the potable water supply. Once the potable water is introduced into the heat storage/transport 1oop it is no longer considered potable water and must be prevented from connecting or mixing with the potable water system by cross-connection or backsiphonage. Therefore, it may be concluded that all exchanges of heat to a domestic hot water system must take place through a heat exchanger.

This certainly is true in an immiscible fluid or direct contact liquid system since the heat transfer fluid is commonly a type of oil or some other substance immiscible with the storage medium. On the other hand, the direct contact solid system would contain small particles of phase change substance which, if present in the water system, would make it non-potable.

This leaves the separated element system which in itself contains a heat exchanger. But this may not be the heat exchanger which interfaces with the domestic hot water system since this heat exchanger must supply as well as remove heat from the storage system. One can argue that heat might be piped in on one circuit and removed from another circuit, but these solutions would either result in an impractical system or would unacceptably subject the system to the risks of cross-connection.

\section{B. ADEQUATE WATER REQUIRED}

Another principle requires that all plumbing fixtures, devices, and appurtenances be supplied with sufficient water to function properly.

The BOCA and NAPHCC Codes state that plumbing fixtures, devices, and appurtenances must be supplied with water in sufficient volume and at pressures adequate to enable them to function properly and without undue noise under normal conditions of use.

The SBCC Code requires all plumbing fixtures, devices, appliances, and appurtenances to be adequately supplied with water in sufficient volume and pressure to enable them to function properly.

One can argue that this principle really does not apply to phase change thermal storage systems because if water is not supplied in sufficient volume and at adequate pressures there is no harm to the system. A system, however, could be constructed where insufficient volume and reduced pressures could cause harm, especially at stagnation conditions. In addition, note should be made of the "without undue noise" condition which is rarely considered in the design of the thermal storage devices.

\section{DANGERS OF EXPLOSION OR OVERHEATING}

The danger of explosion or overheating is always present in heat storing devices and this concern is expressed in the basic principles of several codes. 
The BOCA and NAPHCC Codes require that devices for heating and storing water be so designed and installed as to guard against dangers from explosion and overheating. The SBCC Code states this same requirement and extends it to also require the prevention of undue flow of hot water or steam into the cold water supply pipes.

It could be argued that phase change thermal devices generally are designed to operate in the latent mode only (isothermally) and that the chance of overheating is remote. If indeed this is the case, it should be demonstrated beyond doubt to the code official. On the other hand, under stagnation conditions, some phase change thermal storage devices could be driven into the sensible mode of operation and exceed design limits. In the future, perhaps, some type of certification could be given to these devices attesting to their capability for withstanding stagnation conditions or perhaps safety features could be provided to prevent explosion or overheating. In either case, the plumbing official must be satisfied that the device is safe.

\section{TESTING}

Plumbing systems are usually tested before they are committed to operation. This is manifest in the BOCA and NAPHCC principles although it should be noted that it is omitted from the SBCC list of principles.

The BOCA and NAPHCC Codes require that the plumbing system be subjected to such tests as will effectively disclose all leaks and defects in the work or material.

It might be concluded that the only way to effectively test the phase change thermal storage device is through a certifying procedure that indicates that the unit is in compliance with established standards. This, of course, could be done in conjunction with any necessary thermal performance testing. The installed unit, however, would likely be subjected to an overall system's leak test once the entire system is in place.

\section{E. EXCLUSION OF SUBSTANCES FROM THE DRAINAGE SYSTEM}

The preceding principles were all generally concerned with the supply or potable water side of the plumbing system. This principle concerns itself with the waste or drainage portion of the system.

The BOCA Code states that a storm, surface or ground water, or any substance which will clog or accentuate clogging of pipes, produce explosive mixtures, destroy the pipes or their joints or interfere unduly with the sewage-disposal process will not be allowed to enter the building drainage system.

Iikewise the SBCC Code states that it will not allow any substance which will clog the pipes, produce explosive mixtures, destroy the pipes or their joints or interfere unduly with the sewage-disposal process to enter the building drainage system. 


\begin{tabular}{l|l|l|l|l|l|l|l|}
\hline $\mathrm{P}-\mathrm{B}$ & BASIC PRINCIPLES (Continued) & & & & L1 & L2 & L3 \\
\hline
\end{tabular}

(SEE FIG. 1)

Similarly, the NAPHCC Code will not allow any substance which will clog or accentuate clogging of pipes, produce explosive mixtures, destroy the pipes or their joints, or interfere unduly with the sewage-disposal process to enter the building drainage system.

Each of the three classes of thermal storage devices that use liquid as the transport and/or storage media is basically a container filled with phase change material. The transport/storage media enters this vessel and transfers its heat to or from the confined phase change material either through direct contact or by means of an internal heat exchanger. In either case, the system could develop a leak through normal usage, corrosion, or accident. In installing such a phase change thermal storage device, it would be reasonable for the building official to require a drain. After all, drains are generally required with conventional water heaters although they may corrode and fail through leakage, perhaps after ten years.

With the assumption that each storage device may require a drain, the next issue might address toxicity, corrosiveness, or other factors relative to the composition of the phase change materials or the heat transfer fluid. Upon failure, the direct contact solid systems could introduce a "slurry" of phase change material into the drainage system; the direct contact liquid system could cause immiscible fluid to flow into the drainage system along with the phase change material itself; and the separated element system could also introduce the phase change material into the drainage system. The quantity of materials may be slight and of no consequence; however, the plumbing official may want some assurance that this principle is not being violated.

\section{F. PROPER MAINTENANCE}

The principle concerns itself with the maintenance of the system. As such, it implies that the thermal storage device must also be maintained properly.

The BOCA and NAPHCC Codes state that plumbing systems must be maintained in a safe and serviceable condition from the standpoint of both mechanics and health. The SBCC Code requires that plumbing systems, including fixtures must be maintained in sanitary condition and proper working order.

When considering maintenance of the phase change thermal storage device, the issue of accessibility (covered in the next principle) must also be included along with the ability to remove and replace the entire unit if necessary. As guidance, the practices used to maintain commonly used equipment such as boilers, water storage tanks, and water heaters should be followed.

\section{G. ACCESSIBILITY}

One might consider this principle as being included as a part of the "proper maintenance" principle; however, BOCA and NAPHCC list accessibility as a separate issue. These codes state that all plumbing fixtures must be so installed with regard to spacing as to be accessible for their intended use and cleansing. 


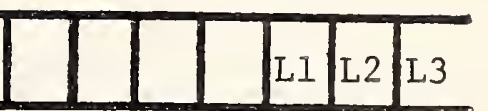

(SEE FIG。 I)

Although this principle addresses spacing with regard to use and cleansing, the principle might be broadened by the plumbing official to include accessibility for maintenance and repair. Maintenance might include such activities as the periodic replacement of the phase change material or the immiscible fluid in direct contact liquid systems.

\section{H. STRUCTURAL SAFETY}

The last principle relating directly to phase change thermal storage devices addresses structural safety. The BOCA, SBCC, and NAPHCC Codes all state that plumbing must be installed with due regard to preservation of the strength of structural members, and preservation of damage to walls and other surfaces through fixture usage.

A major structural concern could be the load-bearing characteristics of these densely packed containers. However, this should present no problems to the plumbing official since he probably has had much experience with similar tanks and vessels used for water storage or heating. Some extra review and evaluation is probably in order for containers installed in retrofit systems or in unusual locations which could require reinforcement to carry the required load.

\section{REFERENCES}

Organization

Code

Principal No.

\section{A. PROTECTION OF POTABLE WATER SUPPLY}

BOCA

The BOCA Basic Plumbing Code

NAPHCC

National Standard Plumbing Code

1

SBCC

Standard Plumbing Code

15,16

B. ADEQUATE WATER REQUIRED

BOCA

The BOCA Basic Plumbing Code

NAPHCC

National Standard Plumbing Code

SBCC

$$
\text { Standard Plumbing Code }
$$

C. DANGERS OF EXPLOSION OR OVERHEATING

BOCA

NAPHCC

SBCC

D. TESTING

BOCA

NAPHCC
The BOCA Basic Plumbing Code

National Standard Plumbing Code

Standard Plumbing Code

The BOCA Basic Plumbing Code

National Standard Plumbing Code 


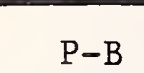

BASIC PRINCIPLES (Continued)

E. EXCLUSION OF SUBSTANCES FROM THE DRAINAGE SYSTEM

BOCA

The BOCA Basic Plumbing Code

NAPHCC

National Standard Plumbing Code

$\mathrm{SBCC}$

Standard Plumbing Code

F. PROPER MAINTENANCE

BOCA

The BOCA Basic Plumbing Code

NAPHCC

National Standard Plumbing Code

SBCC

Standard Plumbing Code

G. ACCESSIBILITY

BOCA

The BOCA Basic Plumbing Code

NAPHCC

National Standard Plumbing Code

H. STRUCTURAL SAFETY

BOCA

NAPHCC

SBCC
The BOCA Basic Plumbing Code

National Standard Plumbing Code

Standard Plumbing Code 


\begin{tabular}{l|l|l|l|l|l|l|l|l|l|l|l}
\hline P-C & DEFINITIONS & & & & L1 \\
\hline
\end{tabular}

(SEE FIG。1)

Each of the plumbing codes contains a section on definitions to aid the user in understanding the codes.

Because the definitions included in each code may vary slightly and these variations may have a major impact on the interpretation of each provision, the definitions deemed pertinent to the understanding of provisions related to phase change thermal storage devices are referenced below. When reading the code provisions described in this report, the definitions should be used as references if there is any doubt about the technical meaning of a word. The referenced tables are of interest in themselves in comparing the subtle differences and nuances between definitions of the same terms as defined in the different plumbing codes.

REFERENCES

Organization

Code

Section

BOCA

The BOCA Basic Plumbing Code

P-201.0

IAPMO / ICBO

The Uniform Plumbing Code

102-126

$\mathrm{SBCC}$

Standard Plumbing Code

302

NAPHCC

National Standard Plumbing Code

1.2 


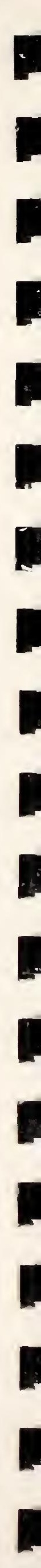




\begin{tabular}{l|l|l|l|l|l|l|l|l|l|l|l}
\hline$P-D$ & REPAIR AND MAINTENANCE & & & Li1 & L2 & L3 \\
\hline
\end{tabular}

(SEE FIG。1)

The plumbing codes generally require that all systems be maintained in a safe and sanitary condition. The BOCA code further states that minor repairs or replacements of any existing system may be made in the same manner and arrangement as in the existing system. Only the SBCC code directly addresses the issue of the homeowner's function in installing and maintaining equipment.

The BOCA Code states that minor repairs or replacement to any existing system can be made in the same manner and arrangement as in the existing system, provided such repairs or replacements are made in a safe and sanitary manner, and are approved by the plumbing official. The BOCA Code also requires that all plumbing systems, both existing and new, be maintained in a safe and sanitary condition. Also, all service equipment, devices and safeguards which the BOCA Code requires or which were required by a previous statute in a building or structure, when erected, altered, or repaired, must be maintained in good working order.

The SBCC Code states that all plumbing, both existing and new and all parts thereof, must be maintained in a safe and sanitary condition. This code also requires that all devices or safeguards which it requires must be maintained in good working order. The SBCC Code requires that the owner, or his designated agent, must be responsible for the maintenance of plumbing. This code also states that nothing in it should prevent a homeowner from installing or maintaining plumbing within his own property boundaries, providing such plumbing work is done by him or his family. Such privilege does not convey the right to violate any of the provisions of the SBCC Code, nor can this statement be construed as exempting any such property owner from obtaining a permit and paying the required fees.

Regarding water heaters and storage tanks, the SBCC Code requires that they be so located and connected that they will be readily accessible for observation, maintenance, servicing, and replacement.

The IAPMO/ICBO Code requires any plumbing and drainage system of any premises under the jurisdiction of the Administrative Authority to be maintained in a sanitary and safe operating condition by the owner or his agent.

The NAPHCC Code requires the plumbing system of every building to be maintained in such a manner as to be at all times in compliance with the provisions of the code, except that existing plumbing installed under prior regulations or lack thereof, may remain unchanged unless immediate hazards to health, life or property are evident. 


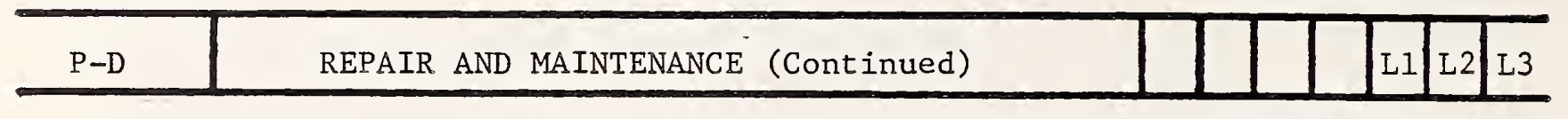

(SEE FIG。 1)

These provisions would also apply to any phase change thermal storage devices installed. Because of these provisions, the plumbing official might be concerned about the qualifications of individuals repairing and maintaining unfamiliar devices. Certain qualifications could be imposed if the concern is great enough. On the other hand, the plumbing official may require that the thermal storage device be designed in a manner that does not present greater danger than that normally encountered in maintaining or repairing conventional water heating or storage equipment.

\section{REFERENCES}

Organization

Code

Section

$\begin{array}{cll}\text { BOCA } & \text { The BOCA Basic Plumbing Code } & \text { P-105.1, P-105.2 } \\ \text { SBCC } & \text { Standard Plumbing Code } & 101.4,101.5, \\ & & 921.2(\mathrm{~b}) \\ \text { IAPMO/ICBO } & \text { The Uniform Plumbing Code } & 319 \\ \text { NAPHCC } & \text { National Standard Plumbing Code } & 15.8\end{array}$


In each code, there is a recognition that there may be times when it is impractical for a designer or installer to follow the letter of each provision. To allow for innovation, there is within each code an alternate materials and methods provision which, in summary, states that the provisions of the code are not intended to prevent the use of any material, device, method, etc. provided any such alternate has been approved and its use authorized by the plumbing official. Further, the plumbing official may approve such alternate materials and methods if he finds them to be in compliance with, and at least the equivalent of, the materials and methods prescribed in the code. In order to substantiate the proposed use of any material or method, the plumbing official may require technical data to be submitted or tests to be made to demonstrate compliance. The tests may be required to be performed in accordance with generally recognized standards or a test procedure specified by the plumbing official.

\section{A. ENABLING PROVISION}

The BOCA Code states that any plumbing requirements which are essential for the sanitary safety of an existing or proposed building or structure or essential for the occupants thereof and which is not specifically covered by this code will be determined by the plumbing official. The BOCA Code also states that when there are practical difficulties involved in carrying out the provisions of this code or of an approved rule, the plumbing official can vary or modify such provision upon application of the owner or his representative, provided that the spirit and intent of the law can be observed and public health, safety, and welfare be assured. This code also states that its provisions are not intended to prevent the use of any material or equipment not specifically prescribed by it, provided any such alternative has been approved. The BOCA Code also allows the plumbing official to approve any suc.a alternate provided he finds the proposed design to be satisfactory and in compliance with the intent of the provisions of this code, and that the material, method or work offered is, for the purpose intended, at least the equivalent of that prescribed in this code in quality, strength, effectiveness, fire resistance, durability, and safety.

The SBCC Code states that any requirement necessary for the safety, strength or stability of an existing or proposed plumbing installation, or for the safety of the occupants of a building or structure, not specifically covered by this code must be determined by the Plumbing official. This code also states that in existing buildings or premises in which plumbing installations are to be altered, repaired or renovated, the Plumbing official has discretionary power to permit deviation from the proposals of this code, provided that such proposal to deviate is first submitted for proper determination in order that health and safety requirements, as they pertain to plumbing, are observed. The SBCC Code also states that its provisions are not intended to prevent the use of any material, device, method of assemblage or installation, fixture or appurtenance not specifically authorized by this code, provided that any 


\begin{tabular}{l|l|l|l|l|l|l|l|l|}
\hline $\mathrm{P}-\mathrm{E}$ & ALTERNATIVE MEASURES (Continued) & & & & & L1 & L2 & L3 \\
\hline
\end{tabular}

(SEE FIG. 1)

such alternate has been approved and its use authorized by the Plumbing official. The Plumbing official is allowed by this code to approve any such alternate materials and methods, provided he finds them to be in compliance with and at least the equivalent of the materials and methods prescribed in this code. This code also states that the Plumbing official will require sufficient evidence to enable him to judge whether proposed alternates meet the requirements of this code for health and safety.

The IAPMO/ICBO Code states that its provisions are not intended to prevent the use of any alternate material or method of construction, provided any such alternate has first been approved and its use authorized by the Administrative Authority. This code also states that the Administrative Authority can approve any such alternate provided he finds that the proposed design is satisfactory and complies with the intent of this code and the material offered is for the purpose intended, at least the equivalent of that prescribed in this code, in quality, strength, effectiveness, durability and safety or that the methods of installation proposed conform to other acceptable recognized plumbing standards. This code also requires that sufficient evidence or proof be submitted to substantiate any claims that may be made regarding the sufficiency of any proposed material or type of construction.

The NAPHCC Code states that plumbing work performed in existing buildings must conform to its requirements, unless the Administrative Authority finds that this conformance would result in an undue hardship. In this case, this code allows the Administrative Authority to grant a deviation to the extent necessary to ameliorate the undue hardship. This code requires that a record which is open to the public be kept of each and every deviation granted under this allowance provision. This code allows the Administrative Authority to approve the use of any material or method not expressly conforming to its requirements provided all of the conditions described here are met. These conditions are: the material or method is not expressly prohibited by this code; the material or method is determined to be of such design or quality as to appear suitable for the proposed use; a record of this approval is kept and must be available to the public.

\section{B. EVIDENCE OF COMPLIANCE}

The BOCA Code states that the plumbing official must require sufficient technical data be submitted to substantiate the proposed use of any material or assembly, and if it is determined that the evidence submitted is satisfactory proof of performance for the use intended, the plumbing official is allowed by this code to approve its use subject to the requirements of this code. This code also states that the costs of all tests, reports and investigations required under these provisions must be paid by the applicant. This code also allows the plumbing official to accept as supporting data to assist him in his determination duly authenticated Research Reports from the Building Officials and Code Administrators International or from other approved authoritative sources for all materials or assemblies proposed for use which are not specifically provided for in this code. 
The SBCC, IAPMO/ICBO, and NAPHCC Codes state that when there is insufficient evidence to substantiate claims for alternatives, the plumbing official can require tests of compliance as proof which must be made by an approved agency at the expense of the applicant. These codes also require that these tests be made in accordance with generally recognized standards; but in the absence of such standards however, the plumbing official must specify the test procedure. The SBCC, IAPMO/ICBO, and NAPHCC Codes also state that the plumbing official is allowed to require tests to be repeated if, at any time, there is reason to believe that an alternate no longer conforms to the requirements upon which its approval was based.

Because of the innovative character relative to commonly used and accepted heat producing and heat storage devices, phase change thermal devices would most likely have to qualify under the alternate measures provision to be accepted by the plumbing official. There is little guidance in the current plumbing codes for acceptance of these devices and, because of the variety of provisions related to commonly used equipment, a plumbing official trying to match the current requirements against phase change thermal storage devices may prohibit the use of these devices. In addition, the general principles included in several of the codes (see P-B) would offer little guidance for detailed acceptance since they are so broad in nature.

The plumbing official may have little alternative than to insist that the designer or manufacturer of phase change thermal devices prove, through test or otherwise, that the intent of the code has been met. This may be a costly and time-consuming procedure and in itself may be impossible without an accepted test method. Although the codes allow tests to be made in the absence of generally recognized standards, the burden is on the plumbing official to specify the test procedure to be used - a rather formidable task for the individual plumbing official since even simple test procedures developed by a committee of experts is a complex undertaking.

\section{REFERENCES}

Organization

Code

Section

A. ENABLING PROVISION

BOCA

SBCC

IAPMO/ICBO

NAPHCC
The BOCA Basic Plumbing Code

Standard Plumbing Code

The Uniform Plumbing Code

National Standard Plumbing Code

$$
\begin{aligned}
& P-101.2, P-108.2, P-108.4 \\
& 103.5,103.6(a), 103.6(b) 103.6(c) \\
& 201(e), 201(f), 201(g) \\
& 3.12 .1,3.12 .2
\end{aligned}
$$

B. EVIDENCE OF COMPLIANCE

BOCA

SBCC

IAPMO/ICBO

NAPHCC
The BOCA Basic Plumbing Code

Standard Plumbing Code

The Uniform Plumbing Code

National Standard Plumbing Code

$$
\begin{aligned}
& P-108.4 .1, P-108.4 .2 \\
& 103.6(d), 103.6(e), 103.6(f) \\
& 201(h), 201(i), 201(j) \\
& 3.12 .3,3.12 .4,3.12 .5
\end{aligned}
$$


;

,

.

,

,

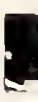

,

,

,

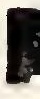

,

.

,

,

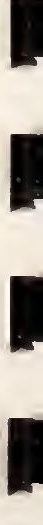




$$
\mathrm{P}-\mathrm{F}
$$

UNSAFE PLUMBING

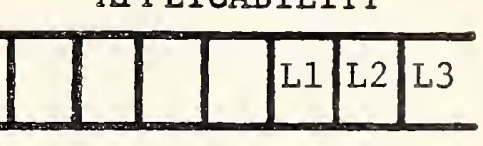

(SEE FIG。1)

The codes require that all plumbing systems which constitute a hazard to human life, health, or welfare be abated by repair, rehabilitation, or removal. The intent of these provisions is to provide the plumbing code official the authority to remove unsafe conditions even if the system was initially installed correctly under the code and subsequently deteriorated to a point where the system became a nuisance or dangerous.

Specifically, the BOCA Plumbing Code states that all plumbing installations, regardless of type, which are unsanitary or which constitute a hazard to human life, health or welfare are declared to be illegal and must be abated by repair and rehabilitation or removal.

The SBCC Code states also that all plumbing installations, regardless of type, which are unsanitary or which constitute a hazard to human life, health or welfare are declared illegal and must be abated by repair and rehabilitation or by demolition in accordance with the provisions of the Standard Code for the Elimination or Repair of Unsafe Buildings.

The IAPMO/ICBO Code requires the owner or his agent, whenever compliance with all the provisions of this code fails to eliminate or alleviate a nuisance, or any other dangerous or unsanitary condition which may involve health or safety hazards, to install such additional plumbing and draining facilities or to make such repairs and alterations as may be ordered by the Administrative Authority.

The NAPHCC Code states that where a health or safety hazard exists on a premise by reason of an existing plumbing installation or lack thereof, the owner or his agent must install additional plumbing or make corrections as are necessary to abate the nuisance and bring the plumbing installation within the provisions of this code. The NAPHCC Code also requires that any part of a building or premise which is changed, altered or required to be replaced as a result of the installation, alteration, renovation, or replacement of a plumbing system, or any part thereof, be left in a safe, non-hazardous condition.

The provisions above imply that phase change thermal storage devices be built of durable material and of a design that is inherently long lasting to that the plumbing system which interfaces with the device is not jeopardized. Should the device deteriorate, the plumbing official will require abatement in the same manner as required of other equipment controlled by the code.

\section{REFERENCES}

Organization Code Section

\begin{tabular}{cll}
\hline BOCA & The BOCA Basic Plumbing Code & P-120.1 \\
SBCC & Standard Plumbing Code & 103.4 \\
IAPMO/ICBO & The Uniform Plumbing Code & 321 \\
NAPHCC & National Standard Plumbing Code & $2.5,2.7$
\end{tabular}




\begin{tabular}{c|l|l|l|l|l|l|l|l|}
\hline$P-G$ & REVIEW OF PLANS AND SPECIFICATIONS & & & & L1 & L2 & L3 \\
\hline
\end{tabular}

(SEE FIG。1)

The submittal of plans and specifications is required, in varying degrees, by the plumbing codes. Most of the codes state that the plumbing official may require submission of plans and specifications, although BOCA specifically requires the submittal of plans and specifications for engineered plumbing systems with one and two family dwellings generally excluded from this requirement. No such submittal is included in the NAPHCC plumbing code. In most cases the level of detail of plans and specifications is not defined although adequate details, including computations and other technical data, are called for in some cases. Both ICBO and SBCC give the plumbing official the option of requiring plans and specifications to be signed by a licensed or registered professional engineer or architect.

Specifically, the BOCA Code states that the plumbing official can require the submission and approval of plans and specifications in duplicate showing the nature and extent of the proposed work before a permit is issued. If, in the course of the work, it is found necessary to make any change from the approved plans and specifications on which a permit has been issued, amended plans and specifications are required to be submitted and, if approved, a supplementary permit will be issued to cover the change after the same conditions required to secure the original permit have been satisfied. This code also states that the plumbing official can require adequate details of plumbing work, including computations and other technical data, to be filed. The BOCA Code also requires plans and specifications for all engineered plumbing systems to be submitted in duplicate, showing the nature and extent of the proposed system, including all pertinent data, before a permit is issued. If, in the course of the work, it is found necessary to make any change from the approved plans, specifications or data on which the permit has been issued, amended plans, specifications, or data is required to be submitted. If approved, a supplementary permit or approval will be issued to cover the change after the same conditions required to secure the original permit have been satisfied. The BOCA Code also requires that plans, specifications or data required by the plumbing official include complete plans indicating the fixture arrangements and the locations of drainage stacks, vertical waste pipes and horizontal drains. Drawings are required to show the complete DWV system, showing all piping in proper sequence, identifying the load value of each in drainage fixture units (dfu), the direction of flow, pipe size, grade of horizontal piping, support, and the supply fixture unit load for the water system and any branch supplies which serve more than one (1) plumbing fixture, appliance or hose outlet. Symbols used on these drawings are required to be in accordance with accepted engineering practice. The BOCA Code also states that the plumbing official can require additional details of the engineered plumbing system, including computations, isometric details, and other technical data to be filed when deemed necessary.

The SBCC Code requires that application for a permit to install plumbing be accompanied by drawings and specifications and other necessary information as required by the Plumbing official in order that he can accurately determine the character of the work and compliance with this code. This code also states that all plans and specifications, when they are required by the Plumbing official, must be signed by a registereü professional engineer or architect 
provided however that drawings and specifications are not required for one and two family dwellings, or for one story buildings, unless, in the opinion of the Plumbing Official, the complexity of the installation necessitates the filing of plans and/or specifications to ascertain code compliance. The SBCC Code also requires that drawings and specifications be drawn to scale and submitted in duplicate. If approved, one set must be returned to the applicant marked approved, and one set is required by this code to be retained and filed as a permanent record by the Plumbing official. It is required that the applicant's approved set remain on the job at all times. Such information or drawings and specifications must be specific and this code cannot be cited as a whole or in part, nor can the term "legal" or its equivalent be issued as a substitute for specific information.

The IAPMO/ICBO Code states that the Administrative Authority can require the submission of plans, specifications, drawings, and other such information that he may deem necessary, prior to the commencement of, and any time during the progress of any work regulated by this code. This code also states that the issuance of a permit upon plans and specifications does not prevent the Administrative Authority from thereafter requiring the correction of errors in the plans and specifications, or from preventing construction operations being carried on when in violation of this code or any other pertinent ordinance, or from revoking any certificate of approval when issued in error.

It is unclear as to what extent the designer or installer of phase change thermal storage devices will be required to comply with these requirements. One might expect that until these devices are proven, become commonly accepted devices, and are familiar to the plumbing code official, this requirement may be imposed and might require the professional seal of a registered or licensed architect or engineer. If plans, specifications, and data are indeed required, it is also unclear as to the degree of detail of the required documentation. The detail could range from a functional block diagram of the system to perhaps an accurate assembly drawing showing the dimensions, materials, etc. of the device.

\section{REFERENCES}

Organization

Code

Section

\begin{tabular}{|c|c|c|}
\hline $\mathrm{BOCA}$ & The BOCA Basic Plumbing Code & $\begin{array}{l}\mathrm{P}-111.5, \quad \mathrm{P}-111.7, \\
\mathrm{P}-1801.1, \mathrm{P}-1801.2, \\
\mathrm{P}-1801.3\end{array}$ \\
\hline $\mathrm{SBCC}$ & Standard Plumbing Code & $104.3(a), 104.3(b)$ \\
\hline IAPMO/ICBO & The Uniform Plumbing Code & 306 \\
\hline
\end{tabular}




\begin{tabular}{|c|c|c|}
\hline $\mathrm{P}-\mathrm{H}$ & INSPECTIONS & \begin{tabular}{ll|l}
$\mathrm{L} 1$ & $\mathrm{~L} 2$ & $\mathrm{~L} 3$
\end{tabular} \\
\hline
\end{tabular}

(SEE FIG. 1)

The codes generally require inspections to be performed by the plumbing official to assure compliance with the codes. The codes also prohibit the plumbing system to be concealed until the work is inspected and approved. These provisions are usually combined with and complement the requirements for testing of the plumbing system (see Reference $\mathrm{P}-\mathrm{M}$ )。

The IAPMO/ICBO Code states that all new plumbing work and those portions of existing systems as can be affected by new work or any changes, are required to be inspected to insure compliance with all the requirements of the code, and to assure that the installation and construction of the plumbing system is in accordance with approved plans. The SBCC Code has the same requirement regarding inspections except it also states that the permit holder or his representative can be required by the Plumbing official to be present at all inspections.

The IAPMO/ICBO Code also specifically addresses final inspection of the water heater. This inspection must be made after all work that is authorized by the permit has been installed. This code states that the Administrative Authority will make such inspection as he deems necessary to assure himself that the work has been installed in accordance with the intent of this code. No equipment or part thereof can be covered or concealed until it has been inspected and approved by the Administrative Authority.

The BOCA Code states that a plumbing system or a part of it cannot be enclosed, covered up or put into operation until it has been inspected and approved by the plumbing official. During the progress of the plumbing work, it is stated that inspection by the plumbing official will be made as required and that it will be the responsibility of the holder of the permit to arrange for these inspections with the plumbing official at least 24 hours before the inspection is to be made. Tests required by the BOCA Code are to be made by the permit holder and observed by the plumbing official. Installation of plumbing work, whether new or existing, that is found to be defective or unsafe will revoke all permits and certificates in effect and the use of such a defective system must be discontinued until such time as it is brought into compliance with the BOCA Code.

It is reasonable to assume that the plumbing official will wish to inspect phase change thermal storage devices that are authorized for installation. The nature of the inspection and the ability of the plumbing official to properly inspect such devices will be a function of the plumbing official's familiarity with these devices. If the plumbing 


\begin{tabular}{|l|l|l|l|l|l|l|l|}
\hline $\mathrm{P}-\mathrm{H}$ & INSPECTIONS (Continued) & & & & L1 & L2 & L3 \\
\hline
\end{tabular}

(SEE FIG。 1)

system approval process reaches the stage that a thermal storage device is approved for installation, the supporting documentation which allowed initial approval may contain the needed elements to allow the plumbing official to make a meaningful inspection.

\section{REFERENCES}

Organization Code Section

BOCA

$\mathrm{SBCC}$

IAPMO/ICBO

Code
The BOCA Basic Plumbing Code
Standard Plumbing Code
The Uniform Plumbing Code

The Uniform Plumbing Code $\mathrm{P}-1701.1$

107.1

$318(1)(a), 1304(b)$ 


\begin{tabular}{l|l|l|l|l|l|l|l|l|l|l|}
\hline P-I & CONNECTIONS TO THE PLUMBING SYSTEM & & & L1 & L3 \\
\hline
\end{tabular}

(SEE FIG。1)

These provisions relate to several other provisions in the Plumbing Codes -specifically the provisions concerned with cross connections and backflow prevention (Reference $P-Q$ ); the provisions related to unsafe plumbing (Reference $\mathrm{P}-\mathrm{F}$ ); and toxic or harmful wastes (Reference P-P)。 In effect, the provisions described below redefine the breadth of the plumbing codes, although they may perhaps be redundant with the provisiontopics referenced above.

The BOCA Code states that every plumbing fixture, drain, appliance, or appurtenance thereto which is to receive water or waste or discharge any liquid wastes or sewage must discharge to the sanitary drainage system of the building in accordance with the requirements of this code.

The SBCC Code states that every plumbing fixture or device or appliance that requires or uses water for its proper operation must be directly or indirectly connected to the water supply system in accordance with the provisions of the code.

The IAPMO/ICBO Code states that all plumbing fixtures, drains, appurtenances and appliances which are used to receive or discharge liquid wastes or sewage, shall be connected properly to the drainage system of the building or premises, in accordance with the requirements of this code. This code also requires that no installation of potable water supply piping or part thereof can be made in such a manner that will make it possible for used, unclean, polluted or contaminated water, mixtures or substances to enter any portion of such pipe from any tank, receptacle, equipment or plumbing fixture by reason of back siphonage, by suction or any other cause, either during its normal use and operation or when any such tank, receptacle, equipment or plumbing fixture is flooded or subject to pressure in excess of the operating pressure in the hot or cold water piping. The IAPMO/ICBO jode also prohibits anyone from making or allowing to exist a connection between pipes and conduits carrying domestic water supplied by any public or private water service system, and any pipes, conduits or fixtures containing or carrying water from any other source or containing or carrying water which has been used for any purpose whatsoever, or any piping carrying chemicals, liquids, gases, or any substances whatsoever, unless there is provided an approved backflow prevention device. This code also prohibits the installation, maintenance or connection of any plumbing fixture, device or construction to any domestic water supply, when such an installation or connection can provide a possibility of polluting the water supply or provide a cross-connection between a distributing system of water for drinking and domestic purposes and water which may become contaminated by such plumbing fixture device or construction unless there is provided an approved backflow prevention device. 


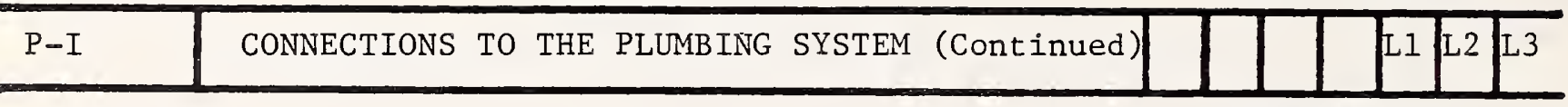

(SEE FIG. 1)

The NAPHCC Code requires every plumbing fixture, drain, appliance, or appurtenance which is to receive or discharge any liquid waste or sewage to discharge to the sanitary drainage system of the building in accordance with the requirements of the code.

With regard to the effect of these provisions on phase change thermal storage devices, see the individually referenced provision topics described above and referenced below.

\section{REFERENCES}

Organization

Code

Section

\begin{tabular}{cll}
\hline BOCA & The BOCA Basic Plumbing Code & P-302.1 \\
SBCC & Standard Plumbing Code & 413.2 \\
IAPMO/ICBO & The Uniform Plumbing Code & $302,1002(\mathrm{a})$ \\
& & $1002(\mathrm{~b}), 1002(\mathrm{c})$ \\
NAPHCC & National Standard Plumbing Code & 2.18
\end{tabular}


The codes are very specific regarding the use of approved materials and equipment. By documenting those types of materials that are suitable for certain applications and requiring equipment to be constructed and perhaps installed in accordance with prescribed standards, the resulting installation should be predictable in performance and safety. In essence, the listing of approved materials and equipment has the effect of reducing risk and uncertainties and provides all concerned with a vehicle for gaining confidence in the installed system.

The listing of equipment may be a lengthy process and there is an underlayment of extensive evaluation and testing that supports the project. In addition, the institutional mechanisms involved generally insure a reasonably serviceable and safe product. The code provisions requiring approval of materials, equipment, and devices are described below along with the specific standards applicable to water heating equipment. Of course, only commonly used devices are referenced in the codes.

The BOCA Code requires that all materials, equipment and devices which are approved for use by the plumbing official be constructed and installed in accordance with this approval. Also, this code requires that all materials, fixtures or equipment that is used in the installation, repair or alteration of any plumbing system conform to the standards, listed in this code's Appendix A, except as otherwise approved by the Plumbing official when permitted by the code. The BOCA Code references the following standards which relate to water heaters: ANSI C72.1-72, Z21.10.1-75, Z21.10.3-75 and FS-W-H-196J-73, FS-W-H$196 \mathrm{~J}-1-76$.

The SBCC Code states that each material listed in its Table 500 of materials for plumbing installations must conform to at least one of the standards cited opposite it. Its use will be further governed by the requirements imposed in other chapters of the code. Materials which are not included in Table 500 must be used only as provided for in the code. Materials must be free of manufacturing defects or damage, however occasioned, which would render the materials defective, unsanitary, or otherwise improper to accomplish the purpose of this Code. The code specifically indicates the type of materials permitted for the various parts of the plumbing system. This code also requires that all water heaters and accessories comply with the applicable standards listed. Further, all water heaters must be tested and listed by an approved agency. The SBCC code references the following standards relating to water heating: FS-W-H-1961.11971, and ANSI Z21.10.1-74, Z21.10.3-74.

The IAPMO/ICBO Code states that unless otherwise provided for in this code, all materials, fixtures or devices used or entering into the construction of plumbing and drainage systems, or parts of these systems, must be submitted to the Administrative Authority for his approval and must conform to approved applicable standards or to other equivalent standards acceptable to the Administrative Authority and must be free of defects. All pipe, pipe fittings, and fixtures must be listed or labeled by a listing agency or be approved by the Administrative Authority when listing or labeling by a listing agency is not available. Water heaters which derive heat from sources other than gas are required by this code to be constructed and installed in accordance with approved standards in a satisfactory manner. Vents or chimneys for these appliances must be approved or listed types and must be made for an adequate supply of air for combustion 
and for adequate ventilation of heater rooms or compartments. Each appliance must be installed in a location approved by the Administrative Authority and local and state fire prevention agencies. This code references the ANSI Z21.10.1-74, Z21.10.3-74 and UL 174-1956 standards with regard to water heaters.

In the NAPHCC Code, the standards which are cited within it control all materials, systems and equipment used in the construction, installation, alteration, repair or replacement of any plumbing or drainage system or part thereof. There are exceptions, however, which this code will allow. For instance, the Administrative Authority will allow the extension, addition to, or relocation of existing water, soil, waste vent pipes with materials of like grade or quality as permitted by this code. Also, materials not covered by the standards referenced by this code can be used with the approval of the Administrative Authority as permitted by this code. This code requires that all materials, fixtures or equipment used in the installation, repair or alteration of any plumbing system must at least conform to the standards cited. All materials installed in plumbing systems are required by this code to be handled and installed as to avoid damage so that the quality of the material will not be impaired. This code prohibits the installation and maintenance of defective or damaged materials, apparatus or equipment. All materials must be installed in strict accordance with the approved and accepted standards, including all appendices of the standards and in strict accordance with the manufacturer's instructions. This code will consider a material approved if it meets one or more of the standards cited, and in the case of plastic pipe also the listed standard of the National Sanitation Foundation. Materials not listed can be used only as provided for in this code. The standards which are cited by the NAPHCC Code are the ANSI Standards, Z21.10.1-74, Z21.10.3-74, FS Standards W-H-196h-1971 and W-H-191b-1970 and UL Standard 174-1972.

Although it is possible to achieve recognition regarding the safety of a device through the Alternate Measures Provisions in the Codes (see P-E), this could be a lengthy process. The building official might require extensive testing and evaluation and in the end decide that the safety of the device has not been proved. It is obvious that if phase change thermal storage devices are to be viable components of solar energy (and other energy) systems, they must be identified as devices that have a potential for success and use. The normal infrastructure that develops standards for new products must monitor the development progress of these devices and develop the required standards in a timely fashion.

\section{REFERENCES}

Organization

Code

Section

BOCA The BOCA Basic Plumbing Code

SBCC Standard Plumbing Code

IAPMO/ICBO The Uniform Plumbing Code

NAPHCC
National Standard Plumbing Code
P-108.1, P-400.1, Appendix A

$501.2,503.1$, $921.1 \mathrm{c}$, Table 500

201 (a), 1306 (a)

Table A

3.1 .1 , Table 3.1 .3 


\begin{tabular}{c|c|c|c|c|c|c|c|}
\hline P-K & MARKINGS AND IDENTIFICATION & & & LI & L2 & L3 \\
\hline
\end{tabular}

(SEE FIG。1)

Numerous sections of the codes specify that certain identification and marking be made on certain plumbing related equipment. Specifically, the codes call for the identification of materials and devices; the marking of pressure information on storage tanks; and the distinction of potable from non-potable water through a number of methods.

With regard to the identification of materials, the codes generally require that each component be marked for identification as provided by the applicable standard to which it conforms. Identification is also required for devices such as water heaters and the markings made in a manner satisfactory to the plumbing official. Pressure markings showing the maximum allowable working pressure are required for hot water storage tanks. In addition, systems carrying non-potable water are required to be identified by color markings, metal tags, or other appropriate means as approved by the plumbing official.

\section{A. IDENTIFICATION OF MATERIALS}

The BOCA Plumbing Code states that each length of pipe and each pipe fitting, trap, fixture material and device used in a plumbing system is required to have cast, embossed, stamped or indelibly marked on it the manufacturer's mark or name as well as the quality of the product or identification in accordance with the applicable approved standard.

Similarly, the SBCC Code requires each length of pipe and each pipe fitting trap, fixture material and device used in a plumbing system to be marked in accordance with the approved applicable standard to which it is manufactured.

The IAMPO/ICBO Code requires also that each length of pipe and each pipe fitting, trap, fixture material and device used in a plumbing system have cast, stamped, or indelibly marked on it, the maker's mark or name, the weight and the quality of the product, when this kind of marking is required by the approved standard that applies. All materials and devices used or entering into the construction of plumbing and drainage systems, or parts thereof, are required to be marked and identified in a manner satisfactory to the Administrative Authority. All such markings are required by the IAMPO/ICBO Code to be done by the manufacturer. Field marking is not acceptable.

The NAPHCC Code requires materials to be identified as provided in the standard to which they conform.

\section{B. PRESSURE MARKINGS}

The BOCA Code requires water heaters to be permanently marked in an accessible place on the water heater with the maximum allowable working pressure.

The NAPHCC Code requires hot-water storage tanks to be permanently marked in an accessible place with the maximum working pressure that is in accordance with the applicable standards. 


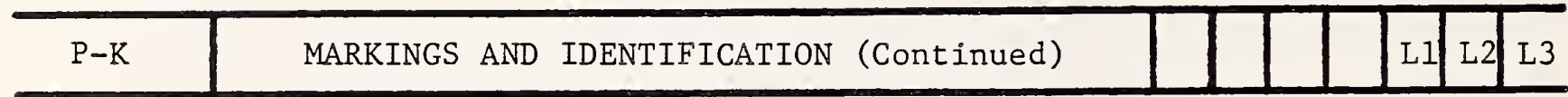

(SEE FIG. 1)

The SBCC Code requires all storage tanks and water heaters to be clearly and indelibly marked showing the allowable safe working pressure. This code also states that any storage tank installed for domestic hot water must have clearly and indelibly stamped in the metal, or so marked upon a place welded to the metal, the maximum allowable working pressure. These markings are required to be in an accessible position outside of the tank so that inspection and reinspection is readily possible. All unlisted storage tanks for domestic hot water are required to meet the applicable ASME standards. This code also requires all water heaters to bear wording on a visible decal that is in conformance with that stated in the ANSI Standard Z21.22

\section{IDENTIFICATION OF POTABLE AND NON-POTABLE WATER}

The NAPHCC Code requires in all buildings where dual water distribution systems are installed, one potable water and the other non-potable water, each system to be identified either by color marking or metal tags or other appropriate method as approved by the Administrative Authority. Each outlet on the nonpotable water line which could be used for drinking or domestic purposes is required to be posted: DANGER - UNSAFE WATER.

The SBCC Code requires all piping and outlets which convey non-potable water to be adequately and durably identified by a distinctive yellow-colored paint so that they are readily distinguishable from piping carrying potable water. The code refers then to ANSI Standard 253-1-1953, Safety Color Code for Marking Physical Hazards. Where non-potable water is used, all valves, branch fittings and branch terminals are required to be identified by the words "non-potable water." This identification can be signs or brass tags which are permanently affixed to the pipes, valves, etc. This identification is prohibited by this code from being concealed by pipe insulation. When insulated, the insulation must be painted the same color as is required for the pipe. Maintenance of all identification is the responsibility of the owner.

The IAMPO/ICBO Code states that whenever possible, all portions of the nonpotable water line are required to be exposed and all exposed portions must be properly identified in a manner satisfactory to the Administrative Authority. Each outlet on a non-potable water line which could be used for drinking or domestic use is required by this code to be posted: DANGER - UNSAFE WATER.

It is not clear how these requirements will be implemented for phase change thermal storage devices by the plumbing official. It would be reasonable to expect the thermal storage device to have affixed to it a tag or plate indicating pertinent information as required by a standard for this device. Included could be pressure markings indicating allowable safe working pressures and other technical data, such as the phase change material used, temperature ranges, capacities, etc. The identification of the potable or non-potable water also may be required. The more complex and unique the device, the more information which may be required on the identification plate. 


\begin{tabular}{c|cc|c|c|c|c|c} 
DESIGNATOR & PROVISION TOPIC & \multicolumn{2}{c|}{ APPLICABILITY } \\
\hline P-K & MARKINGS AND IDENTIFICATION (Continued) & & & L1 & L2 & L3 \\
\hline & & (SEE FIG。 1) \\
REFERENCES \\
Organization
\end{tabular}

A. IDENTIFICATION OF MATERIALS

$\begin{array}{lll}\text { BOCA } & \text { The BOCA Basic Plumbing Code } & \text { P-403.1 } \\ \text { SBCC } & \text { Standard Plumbing Code } & 501.4 \\ \text { IAMPO/ICBO } & \text { The Uniform Plumbing Code } & 201(\mathrm{~b}) \\ \text { NAPHCC } & \text { National Standard Plumbing Code } & 3.1 .4 \\ \text { B. PRESSURE MARKINGS } & \\ \text { BOCA } & \text { The BOCA Basic Plumbing Code } \\ \text { NAPHCC } & \text { National Standard Plumbing Code } & \text { P-1506.3.3 } \\ \text { SBCC } & \text { Standard Plumbing Code . } & 10.15 .5 \\ \text { C. IDENTIFICATION } & \text { OF POTABLE AND NON-POTABLE WATER } & 921.1(\mathrm{~b}), 1213.5,921.5 \\ \text { NAPHCC } & \text { National Standard Plumbing Code } \\ \text { SBCC } & \text { Standard Plumbing Code } & 10.2 \\ \text { IAMPO/ICBO } & \text { The Uniform Plumbing Code } & 1202\end{array}$


; 


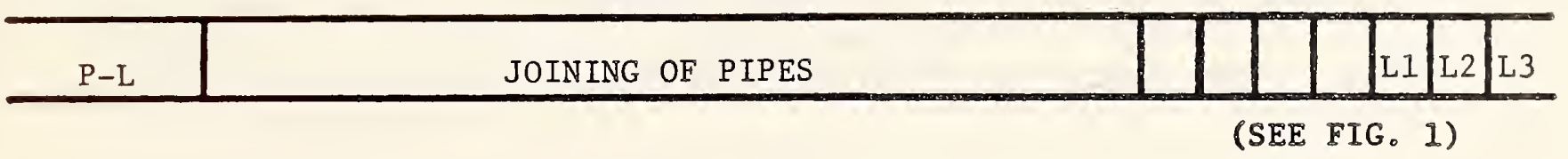

Each of the codes studied has some provisions for the joining of pipes. These provisions appear directly applicable to those systems that use liquid as the working fluid since the working fluid must ultimately be piped from some part of the system into and out of the thermal storage device. The heat transfer fluid would probably be water for those devices classified as separated element systems; probably some type of oil for the systems using immiscible liquids; and perhaps water as the "carrier" of the pellet slurry for direct contact solid systems.

In addition to the variety of substances carried through the pipes, these substances will normally be transported at elevated temperatures and pressures and the building official would be concerned about proper containment of these fluids within the pipes. Certainly, this concern exists even when water alone is flowing through the pipes and would be of greater concern if the liquids were unknown or perhaps perceived as being hazardous.

The provisions that are described below would most likely be applied to the interface connections between the device itself and the piping entering and leaving the device. It is uncertain whether these provisions would be applied to connections internal to the device, but some pipe joining standards would be enforced; either those shown below or some other standards expressly written for the specific thermal storage device. In reviewing the plumbing codes, only those provisions which seem directly applicable to the thermal storage devices addressed in this study have been described. It is conceivable however that a developer of an innovative thermal storage device might use piping and joining methods included in the code, but not listed herein.

\section{A. TIGHTNESS OF JOINTS}

Each of the plumbing codes contains provisions addressing joint tightness.

The BOCA, SBCC, and NAPHCC Codes require joints and connections in the plumbing system to be gastight and watertight for the pressure required for the test, with the exceptions of those portions of perforated or open joint piping which are installed for the purpose of collecting and conveying ground or seepage water to the underground storm drains.

The IAPMO/ICBO Code requires joints and connections in the plumbing system to also be gastight and watertight for the pressures required by test.

\section{B. BRAZED OR WELDED JOINTS}

The BOCA and NAPHCC Codes require that brazed joints be made by first cleaning the surfaces to be joined down to the base metal, applying flux approved for these joints and for the filler metal to be used, and making the joint by heating to a temperature sufficient to melt the approved brazing filler metal on contact. 


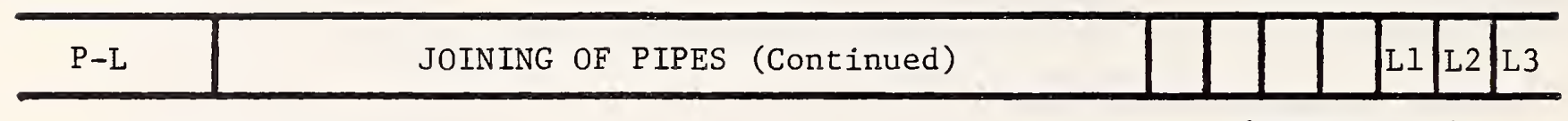

(SEE FIG. 1)

The SBCC Code requires brazed joints to be made in accordance with the provisions of Section 6, of the Code for Pressure Piping, ANSI B31.1-1955.

WELDED JOINTS

The BOCA Code requires joints that are to be welded to be prepared by approved procedure, cleaned free from paint, oil, rust, scale or other objectionable material. The NAPHCC Code requires joints that are to be welded to be prepared by approved procedure, cleaned free from paint, oil, rust, scale, or other objectionable material and welded by welders who qualify according to Section 5 of the code for pressure piping, ANSI B31.1-1955, with addenda B31.1a-1955.

\section{BRAZING OR WELDING}

The SBCC Code requires brazing or welding to be performed in accordance with requirements of recognized published standards of practice and by licensed or otherwise qualified mechanics.

The IAPMO/ICBO Code states that brazing or welding must conform to the appropriate standards in Table A of that code.

\section{FLARED JOINTS}

If used to connect thermal storage devices, flared joints would be subject to the code provisions described below.

The NAPHCC Code requires every flared joint for annealed-temper copper water tubing to be made with fittings which meet approved standards. The tubing is required by this code to be reamed and then expanded with a proper flaring tool.

The BOCA Code requires every flared joint to be made with approved fittings. The SBCC Code and the IAPMO/ICBO Code require flared joints for soft tempered copper water tubing to be made with fittings meeting approved standards. The tubing must be expanded with a proper flaring tool.

\section{SOLDERED JOINTS}

The provisions for soldered joints are virtually identical although each code spells out the requirements in a slightly different way. The differences are not substantive and may be regarded as clarifications. 


\begin{tabular}{l|l|l|l|l|l|l|l|}
\hline P-L & JOINING OF PIPES (Continued) & & & & LI & L2 & L3 \\
\hline
\end{tabular}

(SEE FIG。1)

The BOCA Code requires every soldered joint for tubing to be made with approved fittings. Surfaces that are to be soldered must be cleaned bright by other than chemical means. The joints must be properly fluxed and made with solder conforming to ASTM Standard B32 listed in Appendix A of this code. Joints made in copper water tubing are required to be made by the appropriate use of approved cast bronze or wrought copper fittings, properly soldered together.

The SBCC Code requires soldered joints for tubing to be made with approved fittings. Surfaces to be soldered are required to be cleaned bright, all burrs removed, and tubing returned to full bore. The joints must be properly fluxed and made with approved solder.

The NAPHCC Code also requires every soldered joint for tubing to be made with approved fittings. Surfaces to be soldered are required to be cleaned bright and the joints must be properly fluxed and made with approved solder. Joints in copper water tubing are required to be made by the appropriate use of approved cast brass or wrought copper fittings, properly soldered together.

The IAPMO/ICBO Code requires joints in copper tubing to be made by the appropriate use of approved brass or copper fittings. Surfaces to be joined by soldering are required to be cleaned bright by manual or mechanical means. The joints must be properly fluxed with an approved non-corrosive type flux and made up with approved solder. All solder and fluxes must be manufactured to approved standards.

\section{E. THREADED JOINTS}

The BOCA Code requires every threaded joint to conform to American National Taper Pipe Thread, ANSI B2.1 which is listed in Appendix A of this code. A11 burrs are required to be removed. Pipe ends must be reamed or filed out to size of bore, and all chips must be removed. Pipe joint compound is allowed to be used only on male threads.

The SBCC Code also requires threaded joints to conform to American National Taper Pipe Thread ANSI B2.1. Also, all burrs are required to be removed and pipe-joint cement and paint are to be used only on male threads.

The NAPHCC Code states that thread joints must conform to all approved standards that are listed in Table 3.1.3 of that code.

The IAPMO/ICBO Code states that threads on iron pipe size (I.P.S.) pipe must be standard taper pipe threads. Threads on tubing are required to be approved types. Threads on plastic pipe must be factory cut or molded. Threaded plastic pipe must be Schedule 80 minimum wall thickness. Tubing threads must conform to fine tubing thread standards. When a pipe joint material is used, it must be applied only on male threads and this material must be an approved type, insoluable in water and non-toxic. Cleanout plugs and caps are required to be lubricated with water-insoluable, non-hardening material or tape. 


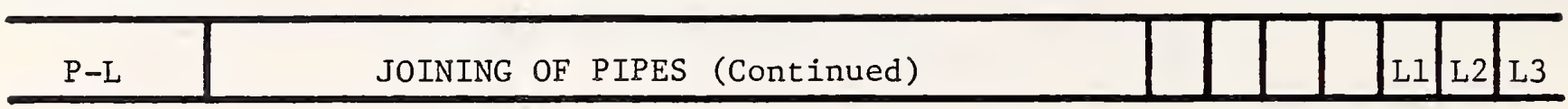

(SEE FIG. 1)

\section{F. PLASTIC FITTINGS}

The use of plastic pipe is relatively new to the construction community and the provisions specified in each code vary considerably, some in greater detail than others. The codes, however, do not specify the intended in-service applications and the characteristics specified are the same or at least very similar for all applications.

The BOCA Code requires flexible joints between plastic pressure pipe to be made with an elastomeric seal conforming to ASTM D3139 which is listed in this code's Appendix A. Flexible joints between plastic drainage pipe are required to be made with an elastomeric seal conforming to ASTM D3212 which is also listed in this code's Appendix A. Flexible joints between plastic pipe are only allowed by this code to be installed in underground systems. With regard to plastic pipe that is joined to other materials, the joints are subject to special requirements. Joints between different grades of plastic pipe must be made by use of an approved adapter fitting. Joints between the hub of cast iron pipe and plastic pipe must be made by caulking with lead and oakum or by use of an approved compression gasket. Joints between cast iron pipe, steel pipe, copper tube, or other piping materials and plastic pipe are required by the BOCA Code to be made by use of an approved adapter fitting.

The SBCC Code states that ABS and PVC pipe and fittings can be solvent cemented using the proper cement recommended for the particular materials. All pipe cuts must be square, and both pipe and fittings must be cleaned of all soil, dirt, oil and grease. Solvent joints must be made according to the recommendations of the manufacturer and/or the Plastics Pipe Institute. Joints must be allowed to dry before testing. If any leak occurs during water test, the defective joint is required to be replaced. Further, the SBCC Code requires all solvent cements used to bear the NSF Seal of Approval for the particular cement being used. Plastic pi,e and fittings for sewer and water pressure lines are allowed by this code to be joined by use of elastomeric joints when the respective standards for the materials so specify. Joints must comply with standards for elastomeric joints which are listed in Table 500 of this code. The SBCC Code also allows plastic pipe and fittings for water service piping to be of the insert type, solvent cemented, or hot and cold flared as recommended by the manufacturer and/or the Plastics Pipe Institute for the particular materials being used. This code also requires the joints between plastic pipe and other materials to be formed with proper adaption fittings as furnished by the manufacturer.

The NAPHCC Code requires every joint in plastic piping to be made with approved fittings by either solvent welded or fusion welded connections, approved elastomeric gaskets and metal clamps and screws of corrosion resistant material, or threaded joints according to approved standards. 


\begin{tabular}{l|l|l|l|l|l|l|l}
\hline P-L & JOINING OF PIPES (Continued) & & & & LI & L2 & L3 \\
\hline
\end{tabular}

(SEE FIG。1)

The IAPMO/ICBO Code requires plastic pipe and fittings designed to be joined by solvent cementing to comply with appropriate IAPMO installation standards.

These provisions certainly apply to any interface between a thermal storage device terminating with plastic pipe "stubs" intended for connection to a plastic pipe system. It is not clear, however, if the provision applies to plastic joints made internally to the thermal storage device. Since some thermal storage devices use plastic pipe internally, the proper joining of these internal pipes may be addressed by the plumbing official. In some applications it may not be desirable to use all the methods indicated in the provisions. In addition, only SBCC addresses the joining of plastic pipe to other materials and that provision is not very definitive.

\section{G. COPPER TUBE TO THREADED PIPE}

The interface between the thermal storage device and the piping system may not be neatly accomplished through the hook-up of similar pipes. One type of dissimilar interface, plastic pipe to other materials, is addressed by SBCC (see $\mathrm{F}$ above). Although many other possibilities exist, the most common could be copper tube to threaded pipe joints. This combination is addressed below, along with stainless steel which is also included by SBCC.

The BOCA Code requires every joint from copper tube to threaded pipe to be made by the use of brass converter fittings or dielectric fittings. The joint between the copper pipe and the fitting is required to be properly soldered, and the connection between the threaded pipe and fitting must be made with a standard pipe size screw joint.

The NAPHCC Code requires every joint from copper tube to threaded pipe to be made by the use of brass or copper converter fittings. The joint between the copper pipe and the fitting must be properly soldered, and the connection between the threaded pipe and the fitting must be made with a standard pipe size screw joint.

The SBCC Code states that joints for copper water tubing or stainless steel water tubing must be formed either by the appropriate use of approved brass, bronze or wrought copper water fittings, properly soldered or brazed together or by means of approved flare fittings as provided in this code. This code also requires joints from copper water tubing or stainless steel tubing to threaded pipe to be formed by the use of bronze or copper adapter fittings. The joint between the copper tube or stainless steel tube and fittings must be properly soldered and brazed and the connection between the threaded pipe and the fitting must be made with a standard pipe size threaded joint.

The IAPMO/ICBO Code requires joints from copper tubing to threaded pipe to be made by the use of brass adapter fittings. The joint between the copper tubing and the fitting is required to be properly sweated or soldered, and the connection between the threaded pipe and the fitting must be made with a standard size screw joint. 


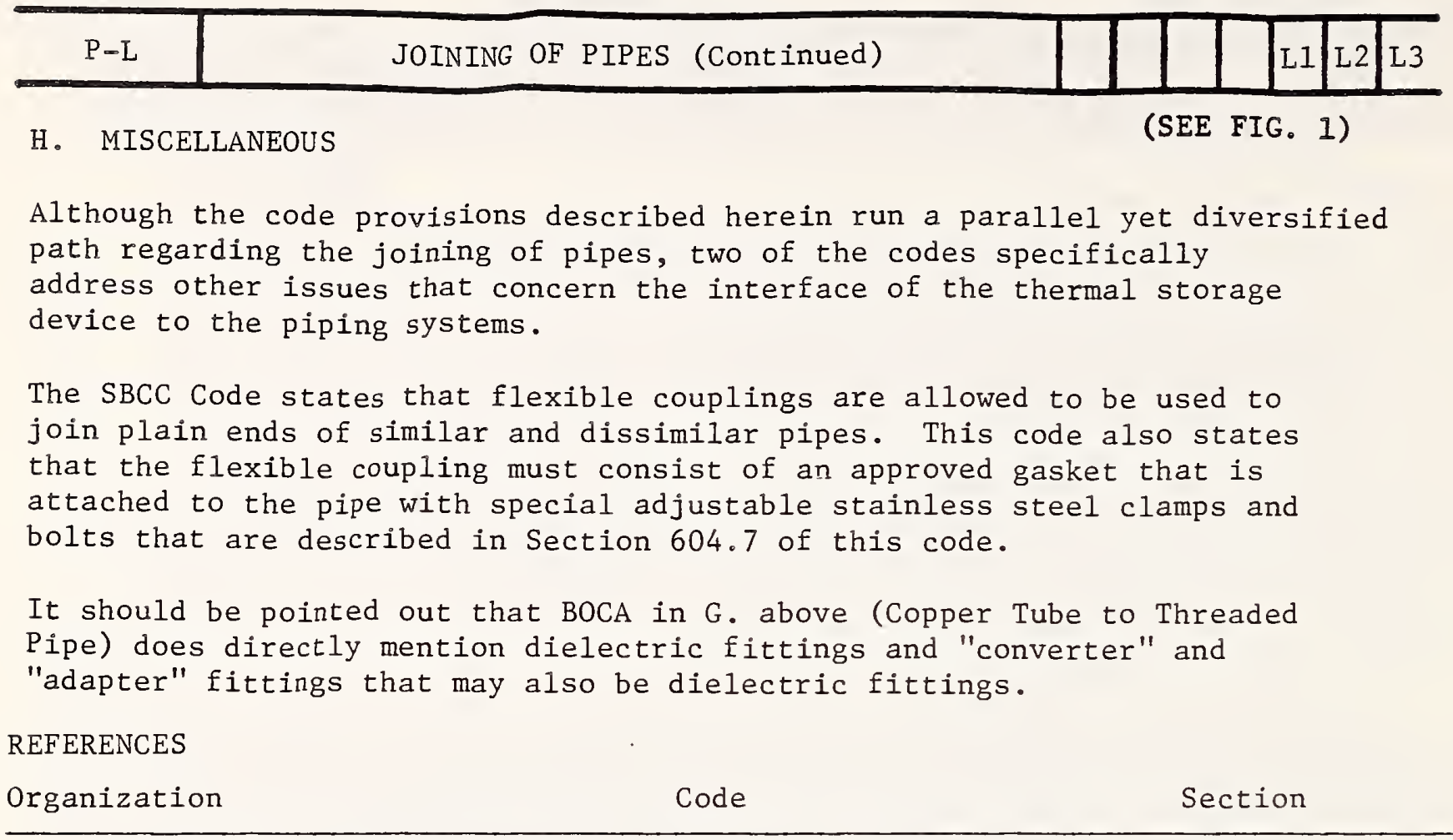

A. TIGHTNESS OF JOINTS

BOCA

The BOCA Basic Plumbing Code

$P-504.1$

SBCC

Standard Plumbing Code

601

NAPHCC

National Standard Plumbing Code

4.1 .1

IAPMO/ICBO

The Uniform Plumbing Code

801

B. BRAZED OR WELDED JOINTS

BOCA

NAPHCC

SBCC

IAPMO / ICBO

The BOCA Basic Plumbing Code

National Standard Plumbinc Code

Standard Plumbing Code

The Uniform Plumbing Code

C. FLARED JOINTS

BOCA

The BOCA Basic Plumbing Code

NAPHCC

National Standard Plumbing Code

SBCC

IAPMO / ICBO

Standard Plumbing Code

The Uniform Plumbing Code

D. SOLDERED JOINTS

BOCA

The BOCA Basic Plumbing Code

SBCC

NAPHCC

IAPMO/ICBO
Standard Plumbing Code

National Standard Plumbing Code

The Uniform Plumbing Code
$\mathrm{P}-501.2, \mathrm{P}-501.3$

$4.2 .8 .1,4.2 .13$

$602.8,604.2$

802 (p)

P-501. 8

4.2 .5

602.5

802 (e)

$\mathrm{P}-501.10$

602.4

4.2 .4

802 (d) 


\begin{tabular}{l|l|l|l|l|l}
\hline P-L & JOINING OF PIPES (Continued) & & L1 & L2 & L3 \\
\hline
\end{tabular}

E. THREADED JOINTS
BOCA
The BOCA Basic Plumbing Code
$\mathrm{P}-501.13 .9$
$\mathrm{SBCC}$
Standard Plumbing Code
602.2
NAPHCC
National Standard Plumbing Code
4.2 .2
IAPMO/ICBO
The Uniform Plumbing Code
802 (b)
F. PLASTIC FITTINGS

$\begin{array}{ll}\text { BOCA } & \text { The BOCA Basic Plumbing Code } \\ \text { SBCC } & \text { Standard Plumbing Code } \\ \text { NAPHCC } & \text { National Standard Plumbing Code } \\ \text { IAPMO/ICBO } & \text { The Uniform Plumbing Code }\end{array}$
$\mathrm{P}-501.13 .5, \mathrm{P}-502.8$
$602.14,602.15,604.6$
4.2 .14
$802(1)$
G. COPPER TUBE TO THREADED PIPE

$\begin{array}{ll}\text { BOCA } & \text { The BOCA Basic Plumbing Code } \\ \text { SBCC } & \text { Standard Plumbing Code } \\ \text { NAPHCC } & \text { National Standard Plumbing Code } \\ \text { IAPMO/ICBO } & \text { The Uniform Plumbing Code }\end{array}$
$\mathrm{P}-502.3$
$603.6,604.1$
4.3 .7
804 (a)
H. MISCELLANEOUS
SBCC Standard Plumbing Code
$602.6(a), 602.6(b)$ 


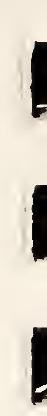

,

,

,

'

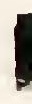

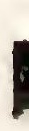

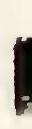

,

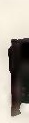

,

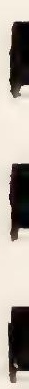

I 


\begin{tabular}{l|l|l|l|l|l|l|l|l|l|l|l|l|l}
\hline$P-M$ & TESTING & & & & L1 & L2 \\
\hline
\end{tabular}

(SEE FIG。1)

The model codes generally require plumbing systems to be tested after they are installed and most codes also require the plumbing work to remain uncovered until the required tests are passed. Some of the tests specified refer to the drainage system and this type of test does not normally apply to phase change thermal storage devices. The other tests specified refer implicitly or explicitly to the water supply system which could involve the phase change thermal storage device.

The BOCA and NAPHCC Codes state that new plumbing systems and parts of existing systems which have been altered, extended, or repaired are required to be tested as prescribed by these codes in order to disclose leaks and defects, except that testing may be waived in the following cases: in any case which does not include addition to, replacement, alteration or relocation of any water supply, drainage, or vent piping, and in any case where plumbing equipment may be set up only temporarily for exhibition purposes.

The IAPMO/ICBO code requires the holder of the permit to make sure that the work will stand the test prescribed before giving notification calling for the particular test and inspection. This code also states that if the Administrative Authority finds that the work will not pass the test, necessary corrections must be made and then the work resubmitted for test and inspection. The tests are required by this code to be conducted in the presence of the Administrative Authority or his duly appointed representative. The piping of the plumbing, drainage and venting systems are required by this code to be tested with water or air. The Administrative Authority might require the removal of any cleanouts, etc. in order to ascertain if the pressure has reached all parts of the system. After the plumbing fixtures have been set and their traps filled with water, they must be submitted to final test. The water used in the test must be applied to the drainage and vent systems either in its entirety or in sections. If applied to the entire system, all openings in the piping must be tightly closed, except the highest opening, and the system then filled with water to the point of overflow. If the system is tested in sections, each opening must be tightly plugged except the highest opening of the section under test, and each section must be filled with water, but no section is allowed by the IAPMO/ICBO Code to be tested with less than a ten foot head of water. In testing successive sections, at least the upper ten feet of the next preceding section must be tested, so that no joint or pipe in the building (except the uppermost ten feet of the system) will have been submitted to a test of less than ten feet head of water. The water must be kept in the system, or in the portion under test, for at least fifteen minutes before inspection starts. The system must then be tight at all points. The air test is required by this code to be made by attaching an air compressor testing apparatus to any suitable opening, and, after closing all other inlets and outlets to the system, forcing air into the system until there is a uniform gage pressure of five pounds per square inch or sufficient to balance a column of mercury ten inches in height. The pressure must be held without introduction of additional air for a period of at least fifteen minutes. 


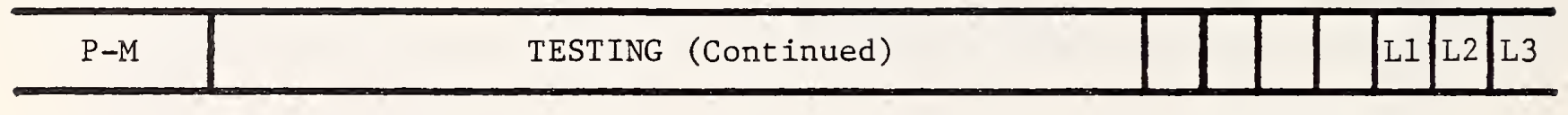

(SEE FIG. 1)

It is unclear how the testing requirements would be applied by the plumbing official. The application could range from strict enforcement to an interpretation that no testing be required for these devices. Nevertheless, one can assume that if a system using liquid as the working fluid is installed, some test to detect leakage will be required. The tests, however, may differ depending on the type of storage system, the pressures involved, and the type of working fluid.

A separated element phase change thermal storage device would interface with the piping carrying the working fluid into and out of the thermal storage device. The design of the thermal storage device would have to be compatible with the maximum working pressure in the heat transfer loop and not be the weakest element of that loop. The same would be true of the direct contact solid device; however the container itself may be a pressure vessel and a leak test of the entire assembly might be warranted. In systems using immiscible fluids (direct contact liquid systems) a separate pressure test may be required in the immiscible fluid loop along with a pressure test in the water loop that interfaces with the immiscible fluid loop. These two loops would normally interface in a heat exchanger and this heat exchanger could be external to or internal to the thermal storage device.

\section{REFERENCES}

Organization

Code

Section

\begin{tabular}{cll}
\hline BOCA & The BOCA Basic Plumbing Code & P-1702.1 \\
NAPHCC & National Standard Plumbing Code & 15.3 \\
IAPMO/ICBO & The Uniform Plumbing Code & $318(\mathrm{a})(3), 318(\mathrm{a})(4)$, \\
& & $318(\mathrm{a})(5), 318(\mathrm{~b})(2)$, \\
& $318(\mathrm{~b})(3), 318(\mathrm{~b})(4)$
\end{tabular}




\begin{tabular}{l|l|l|l|l|l|l|l|l|l|l|l}
\hline $\mathrm{P}-\mathrm{N}$ & DRAINS & & & & L1 & L2 \\
\hline
\end{tabular}

(SEE FIG。1)

A separate issue, independent of the concern relative to the toxicity of any liquid discharged accidently or intentionally from a phase change thermal storage device is the need to supply a drain. The various plumbing codes generally do not specify that a drain need be provided, but this need may be read as being implicit in the codes. Regardless of the legal need for such drains, good design practice or custom may dictate that drains be installed. The code provisions concerning drains are described below.

\section{A. PRESSURE TANKS, BOILERS, AND RELIEF VALVES}

The BOCA, NAPHCC and SBCC Plumbing Codes require that the drains from pressure tanks, relief valves, and similar equipment do not discharge directly into the drainage system. The BOCA and NAPHCC Codes allow this discharge to be through an indirect waste by means of an air gap. The NAPHCC Code also requires that there be no traps or vents on this indirect piping. The SBCC Code states that the outlet of a pressure, temperature, or other relief valve cannot be connected to the drainage system as a direct waste.

\section{B. WASTE WATER TEMPERATURE}

The BOCA and NAPHCC Codes state that no steam pipe is allowed to connect to any part of a drainage or plumbing system, nor can any water above $140^{\circ} \mathrm{F}$ be discharged into any part of a drainage system. Such pipes must be connected by discharging into an indirect waste receptor connected to the drainage system.

\section{DRAIN COCKS}

The SBCC Code requires all storage tanks to be equipped with adequate drain cocks. The BOCA and NAPHCC Codes require drain cocks or valves for emptying to be installed at the lowest point of each hot water storage tank.

\section{MISCELLANEOUS}

The SBCC Code states that no floor drain or other plumbing fixture except electric water heaters are allowed to be installed in a room containing air handling machinery when such a room is also used as a plenum. When rooms are used as plenums, this code requires that equipment drains be conveyed through an indirect waste receptor which is located outside these rooms or at other approved points of disposal. This code also states that when water heaters or hot water storage tanks are installed in areas where leakage could cause water damage to the building or injury to the building occupants, the tank or water heater is required to rest in a high impact plastic pan of at least $60 \mathrm{mil}$ thickness, or in a galvanized steel or other metal pan of equal corrosive resistance having a thickness at least equal to twenty-four gauge galvanized sheet steel. This code also requires safety pans to be no less than one and one-half inches deep and of sufficient size and shape to receive all drippings and condensate from the tank or heater and the discharge from the relief valve or valves. The pan is also required to be drained by an indirect waste pipe 


\begin{tabular}{l|l|l|l|l|l|l|l|l|}
\hline $\mathrm{P}-\mathrm{N}$ & DRAINS (Continued) & & & & L1 & L2 & L3 \\
\hline
\end{tabular}

(SEE FIG. 1)

no less than one inch in diameter or the diameter of the outlets of the required relief valve(s) whichever is larger. The SBCC code further requires the pan drain to extend full size and terminate over a suitably located indirect waste receptor or floor drain or to extend to the exterior of the building and terminate no less than six inches or more than twenty-four inches above grade. This code also states that when the discharge from the relief valve(s) is to be discharged into the safety pan it is required to be piped full-size of the valve outlet pipe size to a point not more than two inches or no less than one inch above the pan flood level rim. Also, the discharge from the relief valve is required to be piped full-size separately to the outside of the building or to another approved terminal as provided for safety pan drain terminals but in no case can the discharge from a relief valve be trapped.

The NAPHCC Code states that appliances, devices, or apparatus not regularly classed as plumbing fixtures but which have drips or drainage outlets are allowed to be drained by indirect waste pipes discharging into an open receptàcle through either an air gap or air break as determined by the Administrative Authority.

One concern of the plumbing official is the dumping of waste material directly into the drainage system without an air gap. In the event of a negative pressure condition in the main water supply system due to a water main break or other causes, this air gap is necessary to prevent back-siphonage of material from the drainage system into the thermal storage device and possibly into the potable water supply. In addition, a $140^{\circ} \mathrm{F}$ limit for material discharge into the drainage system is imposed by three of the codes.

The requirement for drain cocks at the lowest point of each hot water storage tank seems reasonable for conventional tanks but a different configuration might be desirable for certain thermal storage systems and some systems might not require a drain cock at all. The SBCC requirement for installing a pan under water heaters or hot water storage tanks in such areas where leakage could cause water damage to the building can be reasonably applied to phase change thermal storage devices. These pans, however, must have the ability to dump their contents through an air gap into the building drainage system or outside the building. (Also see Reference P-S for a discussion of pressure and temperature relief.)

\section{REFERENCES}

Organization

Code

Section

A. PRESSURE TANKS, BOILERS, AND RELIEF VALVES

BOCA

The BOCA Basic Plumbing Code

P-701.1.7

NAPHCC

National Standard Plumbing Code

9.1 .7

SBCC

Standard Plumbing Code

$1206.2,1213.4$ 


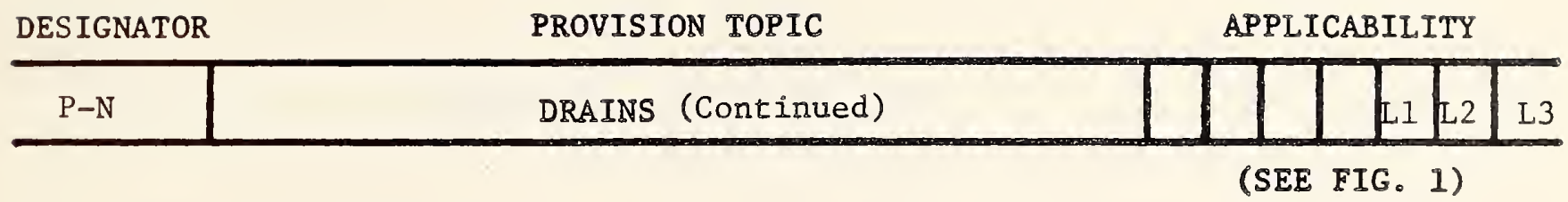

B. WASTE WATER TEMPERATURE

BOCA

NAPHCC

C. DRAIN COCKS

SBCC

BOCA

NAPHCC

D. MISCELLANEOUS

$\mathrm{SBCC}$

NAPHCC
The BOCA Basic Plumbing Code

National Standard Plumbing Code

Standard Plumbing Code

The BOCA Basic Plumbing Code

National Standard Plumbing Code

Standard Plumbing Code

National Standard Plumbing Code
$P-701.4$

9.6

1214.1

1506.3 .4

10.15 .4

$914.4,1213.7$

9.1 .6 
1

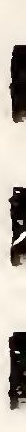

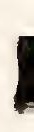

,

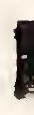

,

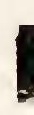

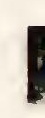

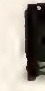

,

,

,

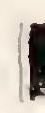

,

1 
As discussed in Reference $\mathrm{P}-\mathrm{P}$, it is prohibited to discharge into the building drainage system any material which will damage, overload, or otherwise have a detrimental effect on the system. Although certain phase change thermal storage devices present no hazard if their contents are deliberately or accidentally discharged into the drainage system, other devices could present a hazard, or at least could be perceived as presenting such a hazard. Until a consensus is reached that specific phase change materials and heat transport fluids do not adversely affect the building drainage system, the plumbing official may require interceptors or separators to be installed.

\section{A. INTERCEPTORS}

The BOCA Code requires interceptors for oil, grease, sand and other substances harmful or hazardous to the building drainage system, the public sewer, or sewage treatment plant or processes to be provided as required by the Plumbing Official and as stated elsewhere in the BOCA Code.

The IAPMO/ICBO and NAPHCC Codes require interceptors (including grease, oil, and sand interceptors, etc.) to be provided when, in the opinion of the building official, they are necessary for the proper handling of liquid wastes containing grease, flammable wastes, sand, soils or other ingredients which are harmful to the drainage system, the public sewer, or sewage-treatment plant or processes.

In a more general manner, the SBCC Code also requires interceptors or separators to be provided when in the opinion of the Plumbing Official, they are necessary for the proper handling of wastes containing ingredients potentially harmful to the public sewer, or sewage-treatment plant or processes.

\section{B. SEPARATORS}

In the BOCA Code separators for oil and flammable liquids are subject to compliance with provisions regarding treatment of liquids before separation, and the design of separators.

The SBCC Code requires an oil separator to be installed in the drainage system or section of the system where, in the opinion of the Plumbing Official, a hazard exists or where oils or other flammables can be introduced or admitted into the drainage system by accident or otherwise.

\section{APPROVAL}

The BOCA Code states that approval of interceptors and separators is subject to compliance, as required, with provisions of this code which address size, type and location of separators and interceptors, and grease interceptors.

The SBCC Code requires the size, location, and type of each interceptor or separator to be approved by the Plumbing Official. 


\section{$\mathrm{P}-\mathrm{O}$}

INTERCEPTORS AND SEPARATORS (Continued)

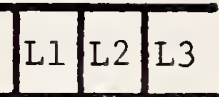

(SEE FIG. 1)

Similarly, the NAPHCC Code states that no interceptor is allowed to be installed if it does not comply in all respects with the type or model of each size which has been approved by the Building Official.

The IAMPO/ICBO Code requires also that the size, type and location of each interceptor or separator be approved by the Administrative Authority, in accordance with appropriate standards. Except where otherwise specifically permitted, this code does not allow any wastes other than those requiring treatment or separation to be discharged into any separator. Wastes in excess. of $140^{\circ} \mathrm{F}$ are not allowed to be discharged into a grease interceptor.

The codes are also detailed and specific regarding design, venting, maintenance, etc. of interceptors and separators. These detailed provisions are not included in this report.

\section{REFERENCES}

Organization

Code

Section

\section{A. INTERCEPTORS}

BOCA

IAPMO/ICBO

NAPHCC

SBCC

\section{B. SEPARATORS}

BOCA

SBCC

C. APPROVAL

BOCA

SBCC

NAPHCC

IAPMO / ICBO
The BOCA Basic Plumbing Code

The Uniform Plumbing Code

National Standard Plumbing Code

Standard Plumbing Code

The BOCA Basic Plumbing Code

Standard Plumbing Code

The BOCA Basic Plumbing Code

Standard Plumbing Code

National Standard Plumbing Code

The Uniform Plumbing Code
$\mathrm{P}-1002.1$

708 (a)

6.1 .1

801 (a)

$\mathrm{P}-1002.5, \mathrm{P}-1002.5 .1$, $\mathrm{P}-1002.5 .2$

803

P-1002.3, P-1002.3.1, P-1002.3.5, Appendix A

801 (b)

6.1 .3

$708(\mathrm{~b})$ 


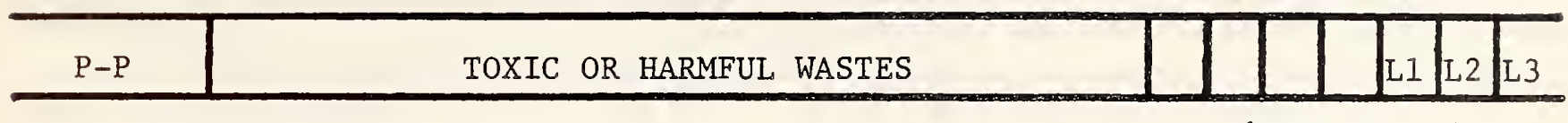

(SEE FIG。1)

The need to protect the water supply and the building drainage system is articulated in the general principles included in three of the plumbing codes (see Reference $\mathrm{P}-\mathrm{B}$ ). These principles are included as definitive provisions covering toxic materials and other harmful wastes.

\section{A. POTABLE WATER SYSTEM PROTECTION}

The requirement to protect the potable water supply (the pressured supply side of: the system) is contained in the provisions below. Although the SBCC Code does not have a definitive provision referenced, protection of the supply water is implied throughout the code. (The methods to be followed for protection against connections, backflow, and siphonage are covered in Reference $P-Q$ ).

The BOCA Code states that toxic materials must be kept out of the potable water system as required in provisions of this code which address the painting of water tanks and chemicals and other substances. With regard to chemicals and other substances that could produce either toxic conditions, taste, odor or discoloration in a potable water system, the BOCA Code prohibits their introduction or use in potable water systems.

The BOCA and NAPHCC Codes require that a potable water supply system be designed, installed and maintained in such a manner as to prevent contamination from nonpotable liquids, solids, or gases being introduced into the potable water supply through cross connections or any other piping connections to the system.

The IAPMO/ICBO Code prohibits the installation of any water operated equipment or mechanism or use of any water treating chemical or substance, if it is found that such equipment, mechanism, chemical, or substance may cause pollution of the domestic water supply. Such equipment or mechanism may be permitted only when equipped with an approved backflow prevention device.

of particular concern to the plumbing official would be the possibility of the phase change material entering the potable water supply. Although some of the codes explicitly say "toxic material" or "chemicals or other substances which can produce toxic conditions," the argument that a particular phase change material is not toxic or harmful may not be valid. One could interpret the general principles and the definitive provisions to mean that the water supply must be protected from "any foreign substance." In addition, immiscible systems (direct contact liquid systems) would present a particular hazard because the immiscible heat transfer fluid usually used is flammable.

To maintain its integrity, the potable water supply must be protected at the interface between the heat transport loop and the piping that allows make-up water to enter the system. This would also be true of the domestic hot water interface - the tank that feeds the building "potable" hot water supply. The greater the number of heat exchangers (or more precisely heat exchanger walls) between the phase change material and the potable water/heat transport loop, the more confidence the building official would have regarding the contained integrity of the water supply. This being the case, the review of most configurations should be on an overall system basis and not limited solely to the phase change heat storage device. 


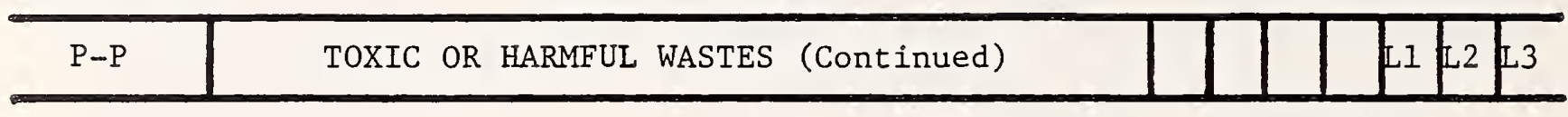

(SEE FIG. 1)

\section{B. BUILDING DRAINAGE SYSTEM PROTECTION}

One of the basic principles discussed previously includes the principle to "Exclude Certain Substances from the Plumbing System." The definitive provisions identified in the plumbing codes relative to this principle as applied to phase change thermal storage devices are described below.

The BOCA Code prohibits any person from depositing by any means into the building drainage system or sewer any ashes, cinders, rags, inflammable, poisonous or explosive liquids, gases, oils, grease, or any other insoluable material which would or could either obstruct, damage or overload the system or which could interfere with the normal operation of the sewage treatment processes. Corrosive liquids, spent acids, or other harmful chemicals which might destroy or injure a drain, sewer, soil or waste pipe, or create noxious or toxic fumes, or interfere with sewage treatment processes are prohibited by the BOCA Code from being discharged into the plumbing system without being thoroughly diluted, neutralized, or treated by passing through a properly constructed and acceptable dilution or neutralizing device. The BOCA Code further requires that these devices be provided automatically with a sufficient supply of diluting water or neutralizing medium, so as to make its contents non-injurious before discharge into the drainage system. This code also requires that the nature of the corrosive or harmful waste and method of its treatment or dilution be submitted to, and be accepted by the Plumbing official prior to installation.

Similarly, the SBCC Code prohibits corrosive liquids, spent acids, or other harmful chemicals which might destroy or injure a drain, sewer, soil or waste pipe, or which might create noxious or toxic fumes from being discharged into the plumbing system without being thoroughly diluted or neutralized by passing through a properly constructed and acceptable dilution or neutralizing device. This device is also required by the SBCC Code to be automatically provided with a sufficient intake of diluting water or neutralizing medium, so as to make its contents noninjurious before being discharged into the soil or sewage system.

These provisions might give the plumbing official more latitude in implementation than the provisions regulating the potable water supply. While a code official would be very reluctant to allow even a small amount of "foreign material" to enter the potable water supply, he might allow small quantities of questionable material into the waste system if a hazard to the system is very unlikely. 
As discussed under General Principles (see Reference P-B), each phase change thermal storage device has the potential of spilling or leaking its contents along with the heat transfer medium, as a result of corrosion, vibration, accident, etc. One might conclude then, that a drain should be provided. In fact, other portions of the plumbing codes explicitly call for floor drains for pressure tanks and boilers or devices containing relief valves (this is discussed in detail under Reference $\mathrm{P}-\mathrm{N}$ ). The issue of dumping the contents of a particular thermal storage device with its phase change material and heat transfer liquid must be addressed. "Reasonable" amounts of relatively inert materials may be acceptable while small amounts of active material may not. With unfamiliar materials, the acceptability would be a function of the information available to the Plumbing official and the risk he is willing to accept. This may be an unfair burden to place on the Plumbing official and it would be more desirable if the material was certified as being safe for disposal into the waste system. Those materials that would react adversely with the drainage system could still be drained if special precautions are taken. (This is discussed under Reference P-O)。

\section{REFERENCES}

Organization

Code

Section

A. POTABLE WATER SYSTEM PROTECTION

BOCA

The BOCA Basic Plumbing Code

$\mathrm{P}-1505.5, \mathrm{P}-1505.5 .1$

$\mathrm{P}-1505.1$

NAPHCC

National Standard Plumbing Code

10.4 .1

IAPMO/ICBO

The Uniform Plumbing Code

1003

B. BUILDING DRAINAGE SYSTEM PROTECTION

BOCA The BOCA Basic Plumbing Code

$\mathrm{P}-304.1, \mathrm{P}-702.1$

SBCC

Standard Plumbing Code

815.2 
I

,

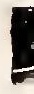

,

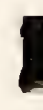

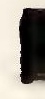

,

,

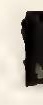

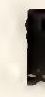

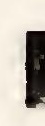

,

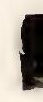

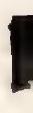

,

,

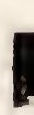

,

1 


\begin{tabular}{c|c|c|c|c|c|c|c|c|}
\hline $\mathrm{P}-\mathrm{Q}$ & CROSS CONNECTIONS AND BACKFLOW & & & L1 & L2 & L3 \\
\hline
\end{tabular}

(SEE FIG。1)

An important principle articulated in those codes that include basic principles (see Reference $\mathrm{P}-\mathrm{B}$ ) is that adequate protection shall be provided to prevent the possibility of backflow or back-siphonage from a non-potable water supply into a safe potable water system. The provisions shown in this section include definitive requirements for such protection. Such words as crossconnection, backflow, back-siponage, etc. all relate to this topic and the definitions of these words, as used in each specific code, can be found in Reference $\mathrm{P}-\mathrm{C}$.

Basically, a cross-connection is any connection or arrangement between two otherwise separate piping systems, one of which contains potable water and the other water of unknown or questionable safety. A cross-connection allows water to flow from one system to the other, the direction of flow depending on the pressure differential between the systems. Backflow is the actual flow of water or other liquids into the potable water supply from unintended sources. If this backflow is due to a negative pressure in the water supply, it is commonly called back-siponage. Backflow preventers are devices which prevent the reverse flow of water due to atmospheric or higher pressure by means of positive check members in addition to atmospheric parts which provide backsiphonage protection. Air gaps in plumbing systems also provide this protection.

The provisions which are described below, discuss the requirements necessary to prevent backflow, the devices used, and the mechanisms for code approval.

\section{A. REQUIREMENT TO PREVENT BACKFLOW}

The BOCA and NAPHCC Codes require a potable water supply system to be designed, installed, and maintained in such a manner as to prevent contamination from nonpotable liquids, solids or gases being introduced into the potable water supply through cross connections or any other piping connections to the system. The BOCA Code also requires that protection against backflow be provided according to the following means: air gap, reduced pressure principle backflow preventer, atmospheric type vacuum breakers, barametric loops. This code provides a provision regarding the application of each of these means of protection. Alternative devices for the prevention of backflow are also allowed by the BOCA Code. Alternatives must be listed by an approved agency and be installed in accordance with their approval. The BOCA Code requires that backflow preventers are installed in an accessible location, preferably in the same room as the fixture or connection they protect. Devices are also allowed by this code to be installed in utility or service spaces. The BOCA Code also specifically requires protection of all potable water openings and outlets against backflow. Means for such protection are described. Protection by air gap is specified with minimum gaps for each type of plumbing fixture. Protection by vacuum breaker is specified with critical level settings for atmospheric type backflow preventers which define levels for each type of fixture or equipment. Protection by reduced pressure principle backflow preventers is also included. Regarding connections to the potable water system, the BOCA Code requires the potable water supply to the boiler to be equipped with a check valve. The code further states that when boilers have conditioning chemicals introduced into the system, the potable water connection must be protected by an air gap or reduced pressure principle backflow preventer. 


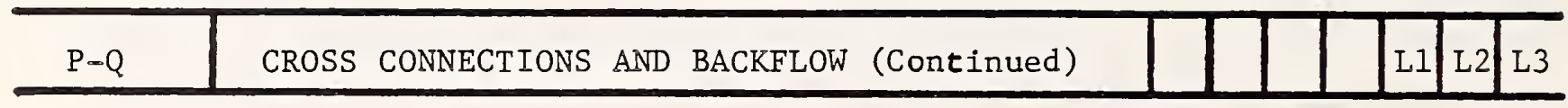

(SEE FIG. 1)

For heat exchangers used to condition potable water, the BOCA code requires that they be constructed with two separate thicknesses separating the potable water from the non-potable transfer fluid. This code requires the potable water supply to automatic fire sprinkler systems and standpipes to be equipped with a check valve. When a potable water connection is made to a nonpotable line, fixture, tank, vat, pump, or other equipment subject to back pressure, the BOCA Code requires the potable water connection to be protected by a reduced pressure principle backflow preventer.

The SBCC Code requires supply lines or fittings for every plumbing fixture to be so installed as to prevent backflow. The SBCC Code also requires that the water distribution system be protected against backflow. In so doing, every water outlet must be protected from backflow, preferably by having the outlet end from which the water flows spaced a distance above the flood-level rim of the receptacle into which the water flows sufficient to provide a "minimum required air gap" as defined by approved ANSI standards. Where it is not possible to provide a minimum air gap, the water outlet is required to be equipped with an accessibly located backflow preventer. This backflow preventer must automatically vent to the atmosphere and be installed in the water supply line to all steam and hot water space heating boilers, heat exchangers and similar devices being supplied from the potable water system. These devices must prevent backsiphonage and backflow from the heating system into the potable supply lines if the supply pressure should fall below the pressure of the heating system. These devices must meet the requirements of ASSE 1012 or 1013 and are required by the SBCC Code to bear identification that is required by the applicable standard. This device is required by the SBCC Code to be maintained in good working condition by the person or persons having control of such devices. Also, the SBCC Code states that the plumbing official having jurisdiction can inspect these devices, and, if he finds them to be defective or inoperative, can require them to be replaced.

The IAPMO/ICBO Code states that no person can install any water operated equipment or mechanism, or use any water treated chemical or substance, if it is found that such equipment, mechanism, chemical or substance may cause pollution of the domestic water supply. The IAPMO/ICBO Code permits this kind of equipment or mechanism only when it is equipped with an approved backflow prevention device.

\section{B. DEVICES AND APPROVAL OF DEVICES}

The SBCC Code requires that means acceptable to the administrative authority be provided to prevent syphoning of any water heater or tank to which any water heater or tank is connected. This code states that a cold water "dip" tube with a hole at the top or a vacuum relief valve installed in the cold water supply line above the top of the heater or tank may be accepted for this purpose. This code also requires bottom fed heaters or bottom fed tanks connected to water heaters to have a vacuum relief valve installed. The vacuum relief valve must be in compliance with the appropriate requirements 


\begin{tabular}{l|l|l|l|l|l|l|l|l|}
\hline P-Q & CROSS CONNECTIONS AND BACKFLOW (Continued) & & & & & L1 & L2 & L3 \\
\hline
\end{tabular}

(SEE FIG。1)

of standard ANSI 221.22. Further, this code requires all devices for the prevention of backflow or backsiphonage to meet the code's requirements regarding materials for plumbing installations, found in Table 500 of this code. The SBCC Code also requires all devices which are installed in a potable water supply for protection against backflow to be maintained in good working condition by the person or persons having control of these devices. The code states that the plumbing official having jurisdiction can inspect these devices, and, if they are found to be defective or inoperative, can require their replacement.

The IAPMO/ICBO Code requires that any device to be installed for the prevention of backflow or back siphonage be approved by the Administrative Authority before it is installed. Devices are required by this code to be tested in conformity with recognized standards or other standards acceptable to the Administrative Authority which are consistent with the intent of this code. This code also states that all devices installed in a potable water supply system for protection against backflow must be maintained in good working condition by the person or persons having control of such devices. The Administrative Authority or other department having jurisdiction can inspect the devices, and, if found to be defective or inoperative, can require the repair or replacement of these devices. No device is allowed by this code to be removed from use or relocated or other device substituted, without approval of the Administrative Authority.

With regard to phase change thermal storage equipment, the need for backflow protection must be made on a system basis and not limited to viewing the thermal storage device separately. Definitive provisions in the codes relative to the use of backflow preventers address steam and hot water space heating boilers, heat exchangers, and similar devices and are based on conventional piping with known and predictable components and systems. Any attempt to directly apply these provisions to thermal storage devices used in solar systems without the systems analysis identified above, could result in solutions that do not afford the protection intended by the codes.

\section{REFERENCES}

Organization

Code

Section

\section{A. REQUIREMENT TO PREVENT BACKFLOW}

BOCA The BOCA Basic Plumbing Code

$$
\begin{aligned}
& \mathrm{P}-1505.1, \mathrm{P}-1505.8, \mathrm{P}-1505.8 .1 \\
& \mathrm{P}-1505.8 .2, \mathrm{P}-1505.8 .3, \\
& \mathrm{P}-1505.8 .4, \mathrm{P}-1505.8 .5, \\
& \mathrm{P}-1505.9, \mathrm{P}-1505.11, \\
& \mathrm{P}-1505.11 .1, \mathrm{P}-1505.11 .2, \\
& \mathrm{P}-1505.11 .3, \mathrm{P}-1505.12, \\
& \mathrm{P}-1505.12 .1, \mathrm{P}-1505.12 .2, \\
& \mathrm{P}-1505.12 .3, \mathrm{P}-1505.12 .4, \\
& \text { Table P-1505.11.1, } \\
& \text { Table } \mathrm{P}-1505.11 .2
\end{aligned}
$$




\begin{tabular}{l|l|l|l|l|l|}
\hline P-Q & CROSS CONNECTIONS AND BACKFLOW (Continued) & & LJ & L3 \\
\hline & & (SEE FIG。 1) \\
REFERENCES (Continued) \\
Organization
\end{tabular}

A. REQUIREMENT TO PREVENT BACKFLOW (Continued)

$\begin{array}{lll}\text { NAPHCC } & \text { National Standard Plumbing Code } & 10.4 .1 \\ \text { SBCC } & \text { Standard Plumbing Code } & 904.1,1204.1,1204.3(\mathrm{e}) \\ \text { IAPMO/ICBO } & \text { The Uniform Plumbing Code } & 1003 \\ \text { B. DEVICES AND APPROVAL OF DEVICES } & \\ \text { IAPMO/ICBO } & \text { The Uniform Plumbing Code } & 1003 \\ \text { SBCC } & \text { Standard Plumbing Code } & 921.7,1204.2\end{array}$




\begin{tabular}{l|c|c|c|c|c|c|c|}
\hline $\mathrm{P}-\mathrm{R}$ & WATER SHUT-OFF VALVES & & & & L1 & L2 & L3 \\
\hline
\end{tabular}

(SEE FIG。1)

The requirement for a cold water shut-off valve appears in most of the codes. This requirement is oriented to conventional water heaters and is included to facilitate repair or replacement. The shut-off valve provides the ability to turn off a leaking water heater without the necessity for incapacitating the water supply for the entire household. Three of the codes require the water supply control valve to be accessible for service and maintenance while SBCC requires this valve to be on the same floor and within three feet of the heater or tank.

\section{A. REQUIREMENTS FOR SHUT-OFF VALVE}

The BOCA Code states that the water supply branch to each hot water storage tank or water heater must be provided with a valve located near the equipment. Similarly, the NAPHCC Code also requires a valve be provided on the cold water branch of each hot-water storage tank or water heater which is located near the equipment and only serving this equipment. This code also requires that each tank or heater be equipped with an approved automatic relief valve as specified by this code (section 10.16.1). The SBCC Code also requires a shut-off valve be provided in the cold water branch line to each water storage tank or each water heater.

\section{B. ACCESS}

The BOCA Code requires all water supply control valves to be placed so as to be accessible for service and maintenance. The SBCC Code requires a shut-off valve to be provided in the cold water supply to each water heater or storage tank and to be accessible on the same floor and within three feet of the heater or tank.

These provisions may be undesirable for phase change thermal storage devices. The specific need for shut-off valves and their location must be determined on a system-by-system basis. The direct contact liquid (immiscible fluid) systems may circulate an oil external to the thermal storage device, and this is not addressed by these provisions. In addition, because of heat flow reversibility to or from the heat transfer fluid, it may be difficult to determine which is the cold water branch line at all. Finally, the provisions could be interpreted as not applying at all since the fluid entering the phase change thermal storage device does not directly interface with the building water supply. 


\begin{tabular}{l|c|c|c|c|c|c|c|}
\hline P-R & WATER SHUT-OFF VALVES (Continued) & & L1 & L2 & L3 \\
\hline
\end{tabular}

A. REQUIREMENTS FOR SHUT-OFF VALVE

BOCA

The BOCA Basic Plumbing Code

NAPHCC

National Standard Plumbing Code

SBCC

B. ACCESS

BOCA

NAPHCC

SBCC
The BOCA Basic Plumbing Code

National Standard Plumbing Code

Standard Plumbing Code
$P-1504 \cdot 1 \cdot 9$

$10.12 .7,10.16 .1$

1209.5

$P-1504.1 .10$

10.12 .9

$921.4(a)$ 


\begin{tabular}{c|c|c|c|c|c|c|c|}
\hline P-S & PRESSURE AND TEMPERATURE RELIEF & & & & L3 & L2 & L3 \\
\hline
\end{tabular}

(SEE FIG。1)

The requirements for pressure and temperature relief are uneven and scattered throughout the plumbing codes. These requirements are mainly oriented to conventional water heating and storage devices. The provisions generally require pressure relief devices and temperature relief devices although combination pressure/temperature relief is permitted. BOCA also allows a separate pressure relief valve and an energy cut-off device, while NAPHCC requires an energy cut-off device (see Reference P-T).

Most of the code requirements related to pressure and temperature relief are oriented toward water heating devices that add energy through the process of burning oil or gas, or by electric resistance heating. Many of the tanks (particularly the domestic water heating tanks) are not designed to be steam pressure vessels, but rather are pressurized by the normal domestic potable water supply entering the system.

The provisions described below address the code requirements for pressure and temperature relief valves, and device approval; separate requirements for pressure and temperature relief valves; requirements for combination pressure/temperature relief valves; along with some guidance regarding installation. In addition, NAPHCC also details the conditions requiring the installation of vacuum-relief valves .

\section{A. PRESSURE AND TEMPERATURE RELIEF VALVES REQUIRED}

The BOCA Code requires all water heaters to be protected with a temperature relief valve and pressure relief valve or a combination temperature and pressure relief valve. The SBCC Code requires that at the time of heater installation, a combination temperature and pressure relief valve be selected and located in conformance with the requirements of ANSI 221.22. The NAPHCC Code requires all storage tanks to be protected against excessive temperatures and pressure conditions.

The SBCC Code also requires all water heaters to be provided with an approved self-closing (levered) water pressure relief valve and temperature relief valve or combination thereof. These valves must be installed in the shell of the water heater tank or in the hot water outlet, provided the thermobulb extends into the shell of the tank. Temperature relief valves must be so located in the tank as to be actuated by the water in the top one-eighth $(1 / 8)$ of the tank served. For installations with a separate storage tank, the valves must be installed on the tank and there cannot be any type of valve installed between the water heater and the storage tank. Also, this code prohibits the use of a check valve or shut-off valve between a relief valve and the heater or tank which it serves. 


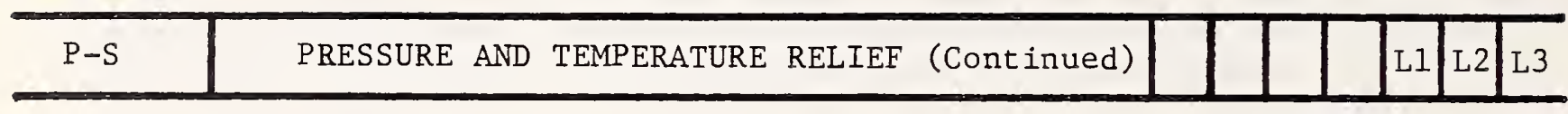

(SEE FIG. 1)

The IAPMO/ICBO Code requires all storage-type water heaters and hot water boilers deriving heat from fuels or types of energy other than gas to be provided with, in addition to the primary temperature controls, an over-temperature safety protection device constructed, listed and installed in accordance with nationally recognized applicable standards for such devices.

The NAPHCC Code requires equipment used for heating water or storing hot water to be protected by approved safety devices in accordance with one of the following methods: a separate pressure relief valve and a separate temperature relief valve, a combination pressure and temperature relief valve, or either of the preceeding methods and an energy cut-off device.

The BOCA Code also requires a separate switch be provided to terminate the energy supplied to electric hot water supply systems. A separate valve must be provided to turn off the energy supplied to the main burner of all other types of hot water supply systems.

\section{B. APPROVAL OF PRESSURE/TEMPERATURE RELIEF DEVICES}

The SBCC Code requires temperature and pressure relief valves, combinations thereof, or energy shut-off devices to bear the label of the AGA, or ASME, with thermosetting of not more than $210^{\circ} \mathrm{F}$, and pressure setting not to exceed the tank or heater manufacturer's rated working pressure. The relieving capacity of these two devices each must equal or exceed the heat input to the water heater or storage tank.

The NAPHCC Code requires safety devices to meet the requirements of the American National Standards Institute, American Society of Mechanical Engineers or the Underwriters Laboratories.

\section{PRESSURE RELIEF VALVES}

The BOCA Code requires that all relief valves conform to ANSI 221.22 which is listed in Appendix A of that code. This code also requires that all relief valves must have a minimum rated capacity for the equipment served. The BOCA Code also requires that pressure relief valves be set at a maximum of the pressure rating of the water heater and cannot exceed 150 psi.

The NAPHCC Gode also requires all pressure relief valves to meet the ANSI Standards and the ASME Standards when required by the building official. The valves are required by this code to have a relief rating which is adequate to meet the pressure conditions in the equipment served. These valves must either be installed directly in a top tank tapping, or in the hot or cold outlet line close to the tank. This code prohibits the use of a shut off valve between the pressure-relief valve and the tank. The pressure-relief valve is required by this code to be set to open at not less than 25 psi above the street main pressure or not less than 25 psi above the setting of any house water pressureregulating valve. The setting is not allowed by this code to exceed the tank rated working pressure. The NAPHCC Code also requires that all water pressure tanks be provided with approved pressure relief valves set at a pressure not in excess of the tank working pressure. 
The IAPMO/ICBO Code states that any water system provided with a pressure regulating device or check valve at its source or any water system containing water heating equipment must be provided with an approved, listed, adequately sized pressure relief valve. This code also requires that any water heating device connected to a separate storage tank and having valves between said heater and tank must be provided with an approved water pressure relief valve.

\section{TEMPERATURE RELIEF VALVES}

The BOCA Code states that all relief valves, including temperature relief valves must have a minimum rated capacity for the equipment served. This code requires that temperature relief valves be set at a maximum of $210^{\circ} \mathrm{F}$.

The NAPHCC Code requires temperature-relief valves be of adequate relief rating, expressed in $B T U / h$, for the equipment served. This code states that the valves must be installed so that the temperature sensing element is immersed in the hottest water within the top six inches of the tank. The valve is required to be set to open when the stored water temperature is $210^{\circ} \mathrm{F}$ or less. The NAPHCC Code also requires that temperature-relief valves conform to an approved standard and must be sized so that when the valve opens, the water temperature cannot exceed $210^{\circ} \mathrm{F}$ with the water-heating equipment operating at maximum input.

\section{E. COMBINATION PRESSURE/TEMPERATURE RELIEF VALVES}

The NAPHCC Code requires combination pressure-temperature relief valves to comply with all the requirements of the separate pressure and temperaturerelief valves.

The IAPMO/ICBO states that nothing in the code must prevent the use of an approved combination temperature and pressure relief valve. The code also states that each approved combination temperature and pressure relief valve must be installed on the water heating device in an approved location based on its listing requirements and the manufacturer's instructions. Each such combination temperature and pressure relief valve is required by this code to be provided with a drain as required.

\section{F. VACUUM-RELIEF VALVES}

The NAPHCC Code states that where a hot water storage tank or an indirect water heater is located at an elevation above the fixture outlets in the hot-water system, a vacuum relief valve must be installed on the storage tank or heater. This code also requires that all water pressure tanks be provided with a vacuum relief valve at the top of the tank which will operate up to a maximum water pressure of 200 psi and to maximum water temperatures of $200^{\circ} \mathrm{F}$. This code also requires that the minimum size of these vacuum relief valves is $1 / 2$ inch. 


\section{P-S

$$
\text { P-S }
$$

PRESSURE AND TEMPERATURE RELIEF (Continued)

\section{G. INSTALLATION OF RELIEF VALVES (ALSO SEE DESIGNATOR P-N)}

(SEE FIG. 1)

The BOCA Code requires the relief valve discharge pipe to be rigid pipe approved for water distribution with a temperature rating of $210^{\circ} \mathrm{F}$. This code also requires that the discharge piping be the same diameter as the relief valve outlet. Valves cannot be connected in the relief valve discharge pipe. This code also states that relief valves cannot discharge so as to be a hazard, a potential cause of damage or otherwise a nuisance. When a relief valve discharges to the drainage system, the BOCA Code requires that it be by indirect connection in accordance with applicable provisions of this code.

The IAPMO/ICBO Code states that relief valves located inside a building must be provided with a full size drain of galvanized steel or hard drawn copper piping and fittings and must extend from the valve to the outside of the building with the end of the pipe not more than two feet nor less than six inches above the ground and pointing downward. Such drain is allowed by this code to terminate at other approved locations. No part of this drain pipe can be trapped and the terminal end of the drain pipe cannot be threaded.

The NAPHCC Code prohibits a check valve or shut-off valve from being installed between any safety device and the hot water equipment used, as well as the use of any shut-off valves or traps or dips in the discharge pipe from the relief valve. The discharge pipe is not allowed to be smaller than the relief valve outlet and it must be in indirect connection into a plumbing fixture, floor drain, sump pit or other approved point of discharge. Relief outlets, when connected to the building drainage system, must be indirectly connected. This code also prohibits the terminal end of a discharge pipe from being threaded. In addition to all other requirements, this code also states that if the relief outlet discharge piping is installed so that it leaves the room or enclosure in which the water heater and relief valve are located, there must be an air gap installed before or at this point of leaving the room or enclosure. This air gap is allowed to be the same one which is used to comply with other provisions in this section of the NAPHCC Code. All piping after the air gap, or indirect connection must be sized as a gravity drain using section 11.4 .2 of this code to determine equivalent fixture unit load and Table 11.5.1 of this code to determine drain sizes and other tables and regulations as may be applicable. The provisions of this code regarding air gap and drain sizing apply to single and multiple relief valve piping installations.

The NAPHCC Code also allows Acrylonitrile-Butadiene-Styrene (ABS) and Polyvinyl Chloride (PVC) DWH plastic pipe and fittings conforming to Table 3.1 .3 of this code to be used to extend relief valve discharge piping and also to serve for the air-conditioning condensate waste. This code also requires an air gap to be installed at the point to discharge into non-metallic material. 


\begin{tabular}{l|l|l|l|l|l|l|l|l|l|l}
\hline P-S & PRESSURE AND TEMPERATURE RELIEF (Continued) & & & L1 L2 L 3 \\
\hline
\end{tabular}

(SEE FIG。1)

With regard to phase change thermal storage devices, the need for pressure/ temperature or vacuum relief valves must be analyzed quite carefully. An argument can be presented that in many cases, the separated element type of system will not require a relief valve since the vessel containing the phase change material is an "open" or unpressurized condition, although it does house a pressurized heat exchanger carrying the heat transport liquid. It can also be argued that, in most cases, the direct contact liquid (immiscible fluid) system and the direct contact solid system, although pressurized, operate only in the latent heat (isothermal) mode and need no over-pressure/overtemperature protection. If direct contact devices are designed with these criteria in mind, the designer/ manufacturer/installer should demonstrate that pressure/temperature relief devices are not needed even when the system is driven to extreme operating and stagnation conditions.

\section{REFERENCES}

Organization

Code

Section

A. PRESSURE AND TEMPERATURE RELIEF VALVES REQUIRED

BOCA The BOCA Basic Plumbing Code

SBCC

NAPHCC

IAPMO/ICBO
Standard Plumbing Code

National Standard Plumbing Code

The Uniform Plumbing Code
$\mathrm{P}-1506.5 .1, \mathrm{P}-1506.4$, $\mathrm{P}-1506.5 .2$

$921.5,1213.1$

$10.16 .1,10.15 .3$

$1306(\mathrm{~b})$

B. APPROVAL OF PRESSURE/TEMPERATURE RELIEF DEVICES

SBCC

Standard Plumbing Code

1213.3

NAPHCC

National Standard Plumbing Code

10.16 .1

C. PRESSURE RELIEF VALVES

BOCA

The BOCA Basic Plumbing Code

NAPHCC

National Standard Plumbing Code

IAPMO/ICBO

The Uniform Plumbing Code

$\mathrm{P}-1506.4$

$10.16 .2,10.8 .9$

1007 (c), 1007 (E)

D. TEMPERATURE RELIEF VALVES

BOCA

The BOCA Basic Plumbing Code

NAPHCC

National Standard Plumbing Code

$\mathrm{P}-1506.4, \mathrm{P}-1506.4 .1$

$10 \cdot 16.3$

E. COMBINATION PRESSURE/TEMPERATURE RELIEF VALVES

NAPHCC

National Standard Plumbing Code

10.16 .4

IAPMO/ICBO

The Uniform Plumbing Code

$1007(\mathrm{~g})$ 


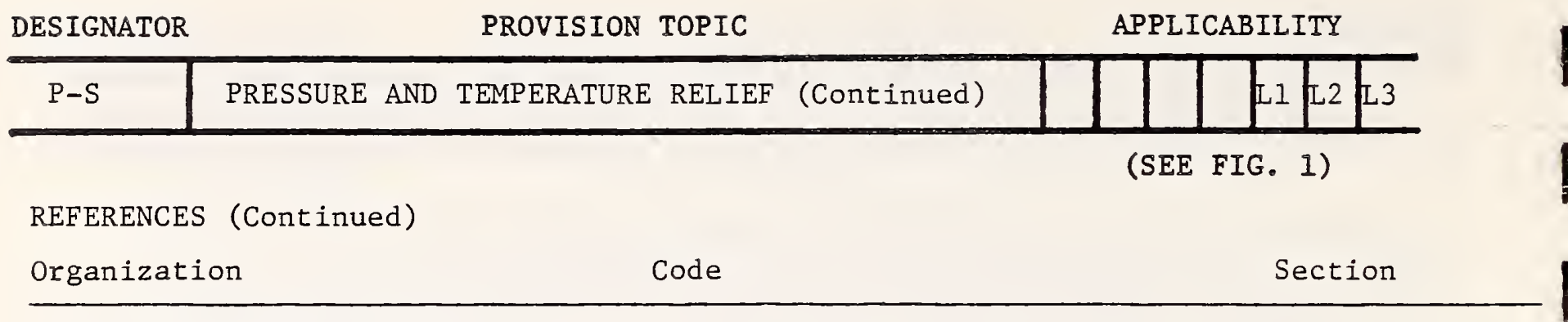

F. VACUUM-RELIEF VALVES

NAPHCC National Standard Plumbing Code $\quad 10.16 .7,10.8 .8$

G. INSTALLATiON OF RELIEF VALVES

BOCA The BOCA Basic Plumbing Code P-1506.4.2

IAPMO/ICBO The Uniform Plumbing Code 1007 (e)

NAPHCC National Standard Plumbing Code $\quad 10.16 .6$ 


\begin{tabular}{c|c|c|c|l|l|l|l|l|l|l}
\hline P-T & ENERGY CUT-OFF DEVICES & & & & L1 & L2 & L3 \\
\hline
\end{tabular}

(SEE FIG。1)

Two plumbing codes, BOCA and $\mathrm{SBCC}$, discuss the requirements for energy cutoff devices. A third, NAPHCC, seems to have had some requirement for this type device, but the requirement is deleted in the current code.

The BOCA Code requires a separate switch to be provided which will terminate the energy supplied to electric hot water supply systems. A separate valve must be provided to turn off the energy supplied to the main burner of all other types of hot water supply systems.

The SBCC Code requires all automatically controlled water heaters to be equipped with an energy cut-off device which will cut off the supply of heat energy to the water tank before the temperature of the water in the tank exceeds two hundred ten degrees $F$. This cut-off device is in addition to the temperature and pressure relief valves.

The requirements for energy cut-off devices are derived from heating equipment using oil, gas, electricity, or other fuels that can be controlled by turning off the fuel source if the device approaches a thermal or pressure condition that has been preprogrammed as being unsafe. Without new energy being added, the system should be self-correcting. An energy cut-off device for a phase change thermal storage package, however, may compound the problem if the system stagnates since continued circulation and not "cut-off" may be the desirable mode to prevent damage or unsafe conditions. The requirements for an energy cut-off device must be carefully evaluated and understood by both the designer/installer and the plumbing official.

\section{REFERENCES}

Organization

Code

Section

BOCA

The BOCA Basic Plumbing Code

$\mathrm{P}-1506.5 .2$

SBCC

Standard Plumbing Code

1213.2 


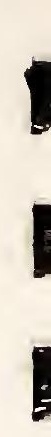

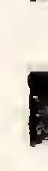

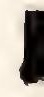

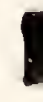

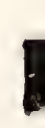

,

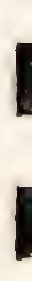

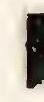

,

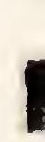

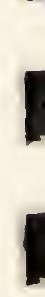

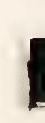

,

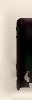

1 


\begin{tabular}{l|l|l|l|l|l|l|l}
\hline $\mathrm{P}-\mathrm{U}$ & MISCELlanEOUS & & & & $\mathrm{L} 1$ & $\mathrm{~L} 2$ & $\mathrm{~L} 3$ \\
\hline
\end{tabular}

(SEE FIG。1)

The model plumbing codes contain additional requirements for storage tanks and associated equipment not addressed in other portions of this report. Several of these provisions relate to the minimum requirements for water heaters and hot water storage tanks. This requirement is in performance language and, in effect, states that sufficient hot water be provided for both the daily requirements and the hourly peak loads for the occupants of the building and that the hot water storage tanks be adequate to provide the necessary rise in temperature.

Another requirement specifies certain conditions based on volume, BTU input and temperature which, if exceeded, obligates the hot water storage tank to meet the construction specification of ASME, ANSI, or other professional organizations. These conditions, in effect, are oriented toward assuring that vessels operating at high temperature, pressure and BTU input are treated as pressure vessels and subject to the construction, testing, and installation provisions of a recognized pressure vessel standard. Storage tanks that contain smaller volumes, and therefore do not fall under the ASME umbrella, are required to be constructed of durable materials and withstand a pressure of one hundred twenty-five (125) psi.

Also, there are some miscellaneous requirements for water heaters to be protected from mechanical damage by moving vehicles if installed in a garage or other location accessible to vehicles. In addition, the BOCA code requires the circulating pump for hot water systems to be capable of being turned-off automatically or manually when the hot water system is not in operation. BOCA also requires storage tanks to be insulated and definitively prescribes that all automatic electric storage water heaters have a standby loss not exceeding four (4) watts per square foot of tank surface area while unfired hot water storage tanks shall be insulated so that the heat loss is limited to a maximum of fifteen (15) BTU/hr per square foot of external tank surface area. Another miscellaneous provision requires that automatic temperature controls capable of adjustments from the lowest to the highest acceptable temperature settings be installed on all hot water supply systems.

\section{A. MINIMUM REQUIREMENTS FOR STORAGE TANKS}

The NAPHCC Code requires hot water storage tanks to be adequate in size when combined with the BTU input of the water heating equipment in order to provide the rise in temperature necessary.

The NAPHCC Code, along with the BOCA Code, also requires the hot water heater and storage tank to be sized to provide sufficient hot water to provide both daily requirements and hourly peak loads of the occupants of the building.

\section{B. ASME CONSTRUCTION REQUIREMENTS}

The SBCC Code requires valves to have a minimum AG temperature steam rating of two hundred thousand BTU; to comply with all construction, testing and installation requirements of ANSI Std. Z21.22 and to have minimum one inch inlet and outlet pipe size connections. In addition, the temperature relieving element of the valve is required by this code to have a water discharge capacity based on one thousand two hundred fifty BTU's for each gallon per 


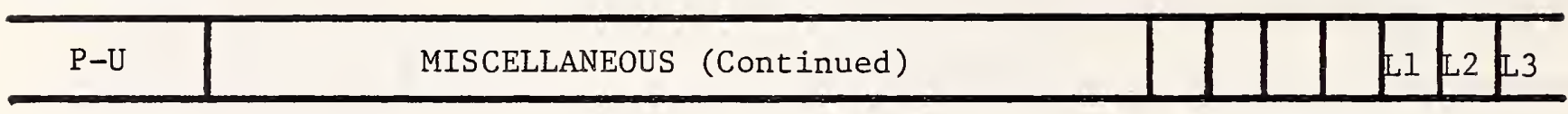

(SEE FIG. 1)

hour of water discharged at 30 1bs. working pressure and a maximum temperature of two hundred ten degrees $F$. This rating must be certified by the valve manufacturer. Also, the pressure relieving element of the valve must be ASME pressure steam rated. Both the temperature water rating and the ASME pressure steam rating of the combination temperature and pressure relief valve must be equal to or in excess of the input to the hot water storage tank or storage water heater.

\section{STORAGE TANK SAFETY FACTOR}

The BOCA Code requires water heaters to be rated for a minimum working pressure of 125 psi, with the allowable working pressure permanently marked in an accessible place on the water heater.

\section{MISCELLANEOUS}

The IAPMO/ICBO Code requires all water heaters installed in areas where they may be subjected to mechanical damage to be suitably guarded against such damage by being installed behind adequate barriers or by being elevated or located out of the normal path of a vehicle.

The BOCA Code states that when a circulating pump is installed on a return circulation hot water system, it must be so arranged to have either an automatic or manual shut off switch for when the hot water system is not in operation.

The BOCA Code also states that unfired hot water storage tanks must be insulated so that heat loss is limited to a maximum of fifteen (15) BTU/hr per square foot of external tank surface area. For purposes of determining this heat loss, the design ambient temperature cannot be higher than sixty-five (65) degrees $\mathrm{F}$.

The BOCA Code also requires all hot water supply systems to be equipped with automatic temperature controls capable of adjustments from the lowest to the highest acceptable temperature settings for the intended use.

With regard to the applicability of these code provisions to phase change thermal storage devices, it is unclear how the minimum requirements for storage tanks would be applied. Certainly, a total system must provide adequate hot water; however, a complex system containing a thermal storage device may operate in many modes with each section providing hot water or storage in different or changing proportions, depending on design conditions. Careful attention, therefore, must be placed on the system rather than each component by itself.

The requirement for certain types of vessels to meet ASME requirements is certainly valid at higher temperatures and pressures (usually above 15 psi) and one could expect the Plumbing official to impose such requirements on highly pressurized phase change thermal storage devices. A problem can be anticipated if a thermal storage device normally operates at low pressures and temperatures and there is uncertainty as to its operating characteristics 


\section{$\mathrm{P}-\mathrm{U}$}

MISCELLANEOUS

(Continued)

\begin{tabular}{l|l|l|l|l}
\hline L1 & L2 & L 3
\end{tabular}

(SEE FIG. 1)

during stagnation conditions. The safety of the device under those conditions would have to be demonstrated. The requirement for smaller storage tanks, which are exempt from meeting the ASME provisions, but which are required to be constructed of durable materials and also constructed to withstand one hundred twenty-five (125) psi also seems like a reasonable requirement for lower temperature, volume and pressure phase change thermal storage devices.

The other miscellaneous provisions must be studied carefully to determine their specific application to phase change thermal storage devices. The provision to protect these devices from mechanical damage by moving vehicles is reasonable if these devices are installed in an environment such as a garage. However, the requirement to automatically turn off the circulating pump when the hot water system is not in operation may not be desirable during stagnation conditions although this provision is certainly valid when applied to conventionally circulating hot water systems. The requirement for insulated storage tanks is not a health and safety issue and it could be argued that this requirement does not belong in the code, although insulating of thermal storage devices probably makes good economic sense. And finally, it is unclear how the provision to provide automatic temperature controls capable of adjustments from the lowest to the highest acceptable temperature settings will impact on thermal storage devices.

\section{REFERENCES}

Organization

Code

Section

A. MINIMUM REQUIREMENTS FOR STORAGE TANKS

NAPHCC

National Standard Plumbing Code

10.15 .3

BOCA

The BOCA Basic Plumbing Code

$\mathrm{P}-1506.3 .2$

B. ASME REQUIREMENTS

SBCC

Standard Plumbing Code

1213.6

C. STORAGE TANK SAFETY FACTOR

BOCA

The BOCA Basic Plumbing Code

1506.3 .3

D. MISCELLANEOUS

IAPMO/ICBO

BOCA
The Uniform Plumbing Code

The BOCA Basic Plumbing Code $1310(c)$

$\mathrm{P}-1506.2 .2, \mathrm{P}-1506.3 .6$

$\mathrm{P}-1506.5 .1$ 
1

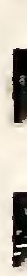

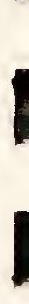

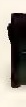

,

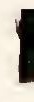

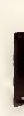

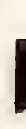

,

,

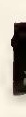

,

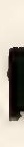

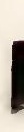

,

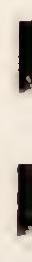




\section{REFERENCES}

[1] Low Temperature Thermal Energy Storage: A State-of-the-Art Survey; F. Baylin; SERI/RR-54-164; July 1979; Solar Energy Research Institute; 1536 Cole Boulevard, Golden, CO, p. 8

[2] Poly Alcohol Solid Phase Change Materials Studied, In Review-A SERI Research Update; D.K. Benson, Vol.V No. 3; March 1983; Solar Energy Research Institute; 1536 Cole Boulevard, Golden, CO 80401

[3] Physical Properties Data Compilations Relevant to Energy Storage 1. Mortar Salts: Eutectic Data, George J. Janz, et al; NSRDS-NBS 61 , Part 1, March 1978; National Bureau of Standards, Washington, D.C.

[4] Technical and Economic Feasibility of Thermal Storage - Final Report; B. Shelpuk, et al; C00/2591-76/1 - June 1976; RCA Advanced Technology Laboratories for Energy Research and Development Administration; Division of Solar Energy

[5] Conservation and Better Utilization of Electric Power by Means of Thermal Energy Storage and Solar Heating - Final Summary Report; NSF/RANN/SE/FI 27976/PR75/5; July 31, 1973; University of Pennsylvania

[6] Phase Change Materials Handbook; D.W. Hale, et al; NASA CR-61363: September 1971; Lockheed Missiles and Space Company for NASA George C. Marshall Space Flight Center; Huntsville, AL

[7] Isotherma1 Solar Heat Storage Materials - Final Project Report; G.A. Lane, et al; NSF-C906; March 1976; Dow Chemical Company, Midland, Michigan

[8] Thermal Energy Storage; M. Telkes; Institute of Energy Conservation, University of Delaware, Newark, Delaware, 19711 as reported in IECEC '75 Record

[9] Form-Stable, Crystalline Polymer Pellets for Thermal Energy Storage; I.0. Salyer, et al; 789154; Society of Automotive Engineers, Warrendale, Pennsylvania

[10] Two Component Thermal Storage Material Study Phase II; E.M. Mehalick and A.T. Tweedie; C0O-2845-78/2; May 1979; General Electric Company: Advanced Energy Programs; Philadelphia, Pennsylvania

[11] 1979 Solar Energy Options Workshop - March 19-20, 1979; San Antonio, TX. Final Report H-CO-199-79-753F; Hittman Associates, Inc.; Columbia, MD 21045

[12] Low Temperature Thermal Energy Storage: A State-of-the-Art Survey: Frank Baylin; SERI/RR-54-164; July 1979; Solar Energy Research Institute; 1536 Cole Boulevard; Golden, CO 80401

[13] Project Summaries - Thermal Energy Storage Program; Dec. 3-4, 1979; Organized by NASA-Lewis Research Center; Thermal Storage Project Office; Tysons Corner, VA 
[14] Design and Installation Manual for Thermal Energy Storage: Solar Energy Group ANL-79-15; Argonne National Laboratories, Argonne, IL

[15] Sol-ar-tile; A Thermal Storage Ceiling Tile developed by Architectural Research Corporation

[16] An Application of Phase Change Materials in Passive Solar Systems; Final Report for DOE under Contract Number EG-77-6-04-4085; January 1979; by Joseph Sliwkowski and Stuart Faunce; University of Delaware, Newark, DE 19711

[17] Valmont Thermal Storage Unit; developed by Valmont Industries

[18] Residential Temperature and Humidity Control Using Storage Assisted Air Conditioning; September 1978; University of Delaware, Newark, DE 19711

[19] Heat Storage Capability of a Rolling Cylinder; paper by C.S. Herrick and K.B. Zarnoch; General Electric Company, Schenectady, NY 12301

[20] Salt Hydrate Thermal Energy Storage System for Space Heating and Air Conditioning; Calmac Manufacturing Corp.; EM-78-C-0Z-4698; Calvin D. MacCraken; Dec. 1, 1977 to June 30, 1980; Annual DOE Active Solar Heating and Cooling Contractor's Review Meeting March 1980

[21] Immiscible Fluid-Heat of Fusion, Heat Storage System; D.D. Edie et a1; Clemson University, Clemson, SC 29631

[22] Heat Storage Battery; developed by International Thermal Instrument Co.

[23] Heat Battery; developed by Solarmatic, a division of O.E.M. Products, 2701 Adamo Drive; Tampa, FL 33605

[24] Development of Optimum Process for Electron Beam Crosslinking of High Density Polyethylene Thermal Energy Storage Pellets, Process Scale-up and Production of Application Quantities of Material;

Fourth Annual Thermal Energy Storage Program Review Meeting; Ival

O. Salyer; University of Dayton; 300 College Park; Dayton, OH 45469

[25] Two Component Thermal Storage Material Study; E.H. Mahalick and A.T. Tweedie; Contract EY-76-C-02-2845, March 1977; General Electric Co.; Advanced Energy Programs, Philadelphia, PA 19101 
APPENDIX A - PROVISION LISTING OF MODEL BUILDING CODES AND THEIR CROSS REFERENCE TO TOPICS DISCUSSED IN THIS REPORT 


$$
\text { A-b }
$$


Building officials and Code Administrators International, Inc. (BOCA)

BASIC BUILDING CODE - 1981

PROVISION TOPIC

ARTICLE 1 - ADMINISTRATION AND ENFORCEMENT

\begin{tabular}{|c|c|c|c|}
\hline Section & 100.0 & Scope & \\
\hline & 100.1 & Title & $N / A$ \\
\hline & 100.2 & Scope & $B-A$ \\
\hline & 100.3 & Application of References & $N \mathrm{~A}$ \\
\hline & 100.4 & Code Remedial & NA \\
\hline Section & 101.0 & Applicability & \\
\hline & 101.1 & General & $N A$ \\
\hline & 101.2 & Exemptions & $N A$ \\
\hline & 101.3 & Matters Not Provided for & $B=D$ \\
\hline & 101.4 & Continuation of Unlawful Use & $N A$ \\
\hline & 101.5 & Other Regulations & NA \\
\hline Section & 102.0 & Validity & $\mathrm{NA}$ \\
\hline Section & 103.0 & Existing Structures & NA \\
\hline Section & 104.0 & Repairs and Maintenance & \\
\hline & 104.1 & Repairs & $\mathrm{B}-\mathrm{C}$ \\
\hline & 104.2 & Maintenance & $\mathrm{B}-\mathrm{C}$ \\
\hline & 104.3 & Owner Responsibility & $N A$ \\
\hline Section & 105.0 & Demolition of Structures & NA \\
\hline Section & 106.0 & Moved Structures & $N / A$ \\
\hline Section & 107.0 & Approval & \\
\hline & 107.1 & Approved Materials and Equipment & $B-E$ \\
\hline & 107.2 & Modifications & $B-D$ \\
\hline & 107.3 & Used Materials and Equipment & N/A \\
\hline & 107.4 & Alternate Materials and Equipment & $B-D$ \\
\hline Section & 108.0 & $\begin{array}{l}\text { Professional Architectural and Engineering } \\
\text { Services }\end{array}$ & $N A$ \\
\hline Section & 109.0 & Department of Building Inspection & N/A \\
\hline Section & 110.0 & Duties and Powers of the Building Official & $\mathrm{N} / \mathrm{A}$ \\
\hline Section & 111.0 & Application for Permit & \\
\hline & 111.1 & When Permit is Required & $N / A$ \\
\hline & 111.2 & Form of Application & $\mathrm{N} / \mathrm{A}$ \\
\hline & 111.3 & By Whom Application is Made & NA \\
\hline & 111.4 & Description of Work & NA \\
\hline & 111.5 & Plans and Specifications & $B-F$ \\
\hline & 111.6 & Site Plan & $N A$ \\
\hline & 111.7 & Engineering Details & $B-F$ \\
\hline & 111.8 & Amendments to Application & $N A$ \\
\hline & 111.9 & Time Limitation of Application & $N A$ \\
\hline Section & 112.0 & Permits & $N A$ \\
\hline Section & 113.0 & Conditions of Permit & $N A$ \\
\hline Section & 114.0 & Fees & NA \\
\hline Section & 115.0 & Inspection & $N / A$ \\
\hline Section & 116.0 & Workmanship & $N A$ \\
\hline Section & 117.0 & Violations & $N / A$ \\
\hline Section & 118.0 & Stop Work Order & $N A$ \\
\hline Section & 119.0 & Certificate of Use and Occupancy & $N A$ \\
\hline
\end{tabular}


Section 120.0 Unsafe Structures

$N A$

Section 121.0 Emergency Measures

$N / A$

Section 122.0 Posting Structures

$N / A$

Section 123.0

Board of Survey

Section 124.0 Board of Appeals

NA

NA

ARTICLE 2 - DEFINITIONS

Accepted Engineering Practice B-B

Approved

Approved Material, Equipment and Methods B-B

Automatic

Building Service Equipment

Combustible (Material)

Fire Resistance

Fire Resistance Rating

Flame Resistance

Flame Spread

Flame Spread Rating

Flammable

$B-B$

$B-B$

$B-B$

$B-B$

$B-B$

$B-B$

$B-B$

$B-B$

Masonry

$B-B$

Noncombustible

$B-B$

Plenum

$B-B$

$B-B$

ARTICLE 3 - USE GROUP CLASSIFICATION

Section 300.0

Section 301.0

Section 302.0

Section 303.0

Section 304.0

Section 305.0 305.1

305.2

305.3

Section 306.0

Section 307.0

Section 308.0

Section 309.0

Section 310.0

Section 311.0

Section 312.0
General

Classification

Use Group A, Assembly Buildings

Use Group B, Business Buildings

Use Group F, Factory and Industrial Buildings

Use Group H, High Hazard Buildings

General

List of High Hazard Uses

Regulations Guide

Use Group I, Institutional Buildings

Use Group M, Mercantile Buildings

Use Group R, Residential Buildings

Use Group S, Storage Buildings

Use Group T, Temporary and Miscellaneous Users

Doubtful Use Classification

Mixed Use Occupancy
$\mathrm{N} / \mathrm{A}$

$N / A$

$N / A$

$N A$

NA

B-P

B-P

$N A$

$N A$

$N A$

$N A$

$N A$

NA

$N / A$

NA

NA

NA

ARTICTE 6 - SPECIAL USE AND OCAUPANCY REQUIREMENTS NA

ARTICTE 7 - LIGHT, VENTILATION AND SOUND TRANSMISSION CONTROL

Section 700.0 General

Section 701.0 Plans and Specifications
NA

NA 
Section 702.0

Section 703.0

Section 704.0

Section 705.0

Section 706.0

706.1

706.2

706.3

706.4

706.5

706.6

706.7

Section 707.0

section 708.0

Section 709.0

section 710.0

section 711.0

section 712.0

section 713.0

Section 714.0

section 715.0

section 716.0

section 717.0

section 718.0
Standards of Natural Light

Standards of Natural Ventilation

Artificial Light and Ventilation

Existing Buildings

Natural Lighting and Ventilation of Rooms

Window and Skylights

Window Size

Openings on Yards and Courts

Alternate Devices

Ceiling Heights

Floor Area

Width

Lighting and Venting Of Special Spaces

Business and Work Rooms

Assembly Rooms

Rocms of Institutional Buildings

Bath and Toilet Rooms

Stainways and Exits

Courts

Rear Yards

Obstruction of Courts and Yards

Fire Emergency Ventilating System

Window Cleaning Safeguards

Sound Transmission Control in Residential Buildings
$B-M$

$B-M$

$B-M$

$N / A$

$B-M$

$B-M$

$B-M$

$\mathrm{B}-\mathrm{M}$

$N / A$

$N / A$

$N / A$

$N / A$

$N / A$

$N A$

$N / A$

$N A$

$N A$

$N / A$

$N / A$

$N / A$

$N / A$

$N A$

$N A$

NA

800.0 through 808.

Section 809.0 Number of Exits

809.2 Minimum Number
809.1 General

809.3 Buildings With One Exit

809.4 Emergency Escape

809.5 Open Parking Structures

Open Parking
hrough 826.0

section 810.0 through 826.0

$N / A$

$N / A$

$N A$

$\mathrm{B}-\mathrm{L}$

$\mathrm{N} / \mathrm{A}$

$N A$

NA

General

Design Safe Load

Safe Support Required

Progressive Collapse

Load Tests

Test Safe Load

When Required

Test Load

902.2

Section 903.0

Section 919.0

919.1

919.2

919.3

Design Strengths of Materials

Controlled Materials

Ordinary Materials

New Materials
$\mathrm{B}-\mathrm{N}$

$\mathrm{B}-\mathrm{N}$

$\mathrm{B}-\mathrm{N}$

$\mathrm{B}-\mathrm{N}$

$\mathrm{B}-\mathrm{N}$

NA

$\mathrm{B}-\mathrm{N}$

$\mathrm{B}-\mathrm{N}$

$\mathrm{B}-\mathrm{N}$ 
ARTICLE 11 - MATERIALS AND TESTS

Section 1100.0 General

1100.1 scope

$\mathrm{N} / \mathrm{A}$

1100.2 New Materials

$B-R$

1100.3 Used Materials

NA

1100.4

Alternate Test Procedures

$B-R$

Section 1101.0

Section 1102.0

Basic Classification of Construction Materials

N/A

1102.1 Test Standards

1102.2 Strength Tests

1102.3 Durability and Endurance Tests

1102.4 Maintenance Test

1102.5 Performance Test

1102.6 Tests of Service Equipment and Devices

1102.7 Fire Tests

1102.8 Prefabricated construction Tests

1102.9 Test Specimens

Section 1103.0 Conditions of Acceptance

1103.1 General

1103.2 Test Load Factor

1103.3 Working Load Deflection

1103.4 Wall and Partition Assemblies

1103.5 Comparative Tests

1103.6 Concentrated Load Tests

B-N

$\mathrm{B}-\mathrm{J}, \mathrm{B}-\mathrm{N}$

$\mathrm{B}-\mathrm{N}$

$\mathrm{B}-\mathrm{N}$

$\mathrm{B}-\mathrm{N}$

$\mathrm{N} / \mathrm{A}$

$\mathrm{B}-\mathrm{N}$

$\mathrm{N} / \mathrm{A}$

$\mathrm{B}-\mathrm{N}$

I103.7 Puncture Penetration Tests

$\mathrm{B}-\mathrm{N}$

$\mathrm{B}-\mathrm{N}$

$\mathrm{B}-\mathrm{N}$

$\mathrm{B}-\mathrm{N}$

$\mathrm{B}-\mathrm{N}$

$\mathrm{B}-\mathrm{N}$

1104.0 Approvals

Section 1104.0

Written Approval

B-

Approval Record

$B-E$

1104.3 Identification of Product:

1104.3 Heretofore Approved Materials

$B-E$

$B-E$

N/A

Section 1105.0 through 1125.0

ARTICLE 12 - STEEL, MASONRY, CONCRETE, GYPSUM AND LUMBER CONSTRUCTION

N/A

ARTICLE 13 - BUILDING ENCLOSURES, WALLS AND WALL THICKNESS

Section 1300.0 General

Section 1301.0 Enclosure Walls

1301.1 General

1301.2 Projections

1301.3 Exterior Wall Pockets

1301.4

1301.5

Exceptions

Glass in Walls

Section 1302.0

Protection of wall Openings

Section 1303.0 Structural Glass Block Walls

Section 1304.0 through 1317.0

Section 1318.0 Thermal and Sound Insulating Materials

1318.1 General

$N A$

$N / A$

$N / A$

$\mathrm{B}-\mathrm{J}$

$N / A$

$N / A$

$N / A$

1318.2 Installation in Type 1 and Type 2 construction

B-I

$B-I$ 
1318.3 Installation in Type 3 and Type 4 Construction B-I

1318.4 Facings and Coverings

1318.5 Cellulosic Insulation

$B=I$

$B-I$

section 1319.0 Foam Plastics

$\mathrm{B}-\mathrm{H}$

ARTICIE 14 - FIRE RESISTIVE CONSTRUCTION REQUIREMENTS

Section 1400.0 through 1402.0

N/A

Section 1403.0 Fire Resistive Tests

1403.1 Structural Building Assemblies

1403.2 through 1403.6

Section 1404.0 Flame Spread and Flame Resistance Tests

Section 1405.0 Special Fire Resistive Requirements

1405.1 through 1405.9

1405.10 Plenums

Section 1406.0 through 1425.0

Section 1426.0 Roof Structures

1426.1 General

1426.2 Scuttles

1426.3 Skylight

1426.4 through 1427.0

$B=0$

N/A

$\mathbb{N} \mathrm{A}$

N/A

$B-Q$

$N \mathbf{A}$

NA

NA

$\mathrm{B}-\mathrm{J}$

NA

ARTICIE 15 - CHIMNEYS, FLUES AND VENT PIPES

$N A$

ARTICIE 16 - MECHANICAL EQUIPMENT AND SYSTEMS

$N A$

ARIICLE 17 - FIRE PROTECTION SYSTEMS

$N A$

ARTICIE 18 - PRECAUTIONS DURING BUIIDING OPERATIONS N/A

ARTICLE 19 - SIGNS

NA

ARIICIE 20 - ELECIRIC WIRING AND EQUIPMENT

NA

ARTICLE 21 - ELEVATOR, DUMBWAITER AND CONEYOR EQUIPMENT, INSTALIATION AND MAINITENANCE

NA

ARTICLE 22 - PLUMBING SYSTEMS

NA

ARIICIE 23 - PREFABRICATED CONSTIRUCTION

NA

ARTICIE 24 - LIGHI-TRANSMITITING PLASTIC CONSTRUCTION

Section 2400.0 General

2400.1 scope

2400.2 Approved Materials

2400.3 Identification

Section 2401.0 Design and Installation

2401.1 Structural Requirements

2401.2 Connections and supports

Section 2402.0 Glazing of Unprotected Openings

$B-G$

$B-G$

$B-G$

$B-G$

$B-G$

2402.1 Use in Type 4B Construction

$B-G$

2402.2 Use Group F

$B-G$ 
PROVISION TOPIC

2402.3 Other Classes of Construction and Use Group B-G

2402.4 Autanatic Fire Suppression B-G

Section 2403.0 Exterior Panel Walls

2403.1 General

2403.2 Automatic Fire Suppression

$B=G$

2403.3 Combinations of Glazing and Wall Panels

$B-G$

$B-G$

Section 2404.0 Roof Panels

2404.1 General

2404.2 Separations

2404.3 Location

2404.4 Area Limitations

2404.5 Exceptions

Section 2405.0 Skylight Assemblies

Section 2406.0 through 2410.0

$B-G$

$B-G$

$B-G$

$B-G$

$B-G$

$B-G$

$N / A$

ARIICLE 25 - ENERGY CONSERVATION

$N A$ 
PART 1 - ADMINISTRATTVE

CHAPTER 1 - TITLE, SCOPE AND GENERAL

$\begin{array}{llr}\text { Sec. } 101 & \text { Title } & \text { NA } \\ \text { Sec. 102 } & \text { Purpose } & \text { B-A } \\ \text { Sec. 103 } & \text { Scope } & \text { B-A } \\ \text { Sec. 104 } & \text { Application to Existing Buildings and Structures } & \text { NA } \\ & \text { (a) General } & \text { NA } \\ & \text { (b) Additions, Alterations or Repairs } & \text { NA } \\ & \text { (c) Existing Occupancy } & \text { B-C } \\ & \text { (d) Maintenance } & \text { NA } \\ & \text { (e) Moved Buildings and Temporary Buildings } & \text { B-D } \\ \text { Sec. } 105 & \text { (f) Historic Buildings Mltemate Materials and Methods of Construction } & \text { B-D } \\ \text { Sec. } 106 & \text { Modifications } & \text { B-K } \\ \text { Sec. } 107 & \text { Tests }\end{array}$

CHAPIER 2 - ORGANIZATION AND ENFORCEMENT N NA

CHAPTER 3 - PERMITS AND INSPECTION

Sec. 301 Permits Required

Sec. 302 Application for Permit

(a) Application N/A

(b) Plans and Specifications B-F

(c) Information on Plans and Specifications B-F

Sec. 303 Permits Issuance

N/A

$\begin{array}{ll}\text { Sec. } 304 & \text { Fees } \\ \text { Sec. } 305 & \text { Inspections }\end{array}$

Sec. 306 Special Inspections

Sec. 307 Certificate of Occupancy

PART II - DEFINITIONS AND ABBREVIATIONS

CHAPTER 4 - DEFINITIONS AND ABBREVIATIONS

\begin{tabular}{|c|c|c|}
\hline \multirow{4}{*}{\multicolumn{2}{|c|}{$\begin{array}{l}\text { Sec. } 401 \\
\text { Sec. } 402\end{array}$}} & General \\
\hline & & Approved \\
\hline & & Approved Agency \\
\hline & & Approved Fabricator \\
\hline \multirow{2}{*}{\multicolumn{2}{|c|}{ Sec. 403}} & Boiler, High Pressure \\
\hline & & $\begin{array}{l}\text { Boiler, Low Pressure Hot Water and Low Pressure } \\
\text { Pressure Steam }\end{array}$ \\
\hline Sec. & 407 & Fire Resistance or Fire Resistive Construction \\
\hline Sec. & 415 & Noncombustible \\
\hline Sec. & 420 & Smoke Detector \\
\hline Sec. & 424 & Water Heater \\
\hline
\end{tabular}


PART III - REQUIREMENTS BASED ON OCCUPANCY

CHAPTER 5 - CLASSIFICATION OF ALL BUILDINGS BY USE OR OCAPANCY AND GENERAL REQUIREMENTS FOR ALL OCCUPANCIES

N/A

CHAPTER 6 - REQUIREMENTS FOR GROUP A OCOUPANCIES N/A

CHAPTER 7 - REQUIREMENIS FOR GROUP B OCCUPANCIES N/A

CHAPTER 8 - REQUIREMENTS FOR GROUP E OCOTANCIES N/A

CHAPTER 9 - REQUIREMENIS FOR GROUP H OCCUPANCIES NVA

Sec. 901 Group H Occupancies Defined B-P

Table 9-A Exempt Amounts of Hazardous Materials, Liquids and Chemicals

$B-P$

CHAPTER 10 - REQUIREMENTS FOR GROUP I OCCUPANCIES N/A

CHAPTER II - REQUIREMENTS FOR GROUP M OCOUPANCIES N/A

CHAPIER 12 - REQUIREMENTS FOR GROUP R $\propto$ CCUPANCIES

Sec. 1201 Group Occupancies Defined

Sec. 1202 Construction Height and Allowable Area N/A

Sec. 1203 Location on Property

Sec. 1204 Exit Facilities

Sec. 1205 Light, Ventilation and Sanitation

Sec. 1206 through Sec. 1215

$N / A$

N/A

$B-I$

$\mathrm{B}-\mathrm{M}$

N/A

CHAPTER 13 through CHAPTER 16

N/A

PART IV - REQUIREMENTS BASED ON TYPES OF CONSTRUCTION

CHAPTER 17 - CLASSIFICATION OF ALL BUILDINGS BY TYPES OF CONSTRUCTION AND GENERAL REQUIREMENTS

Sec. 1701 through Sec. 1711

Sec. 1712 Foam Plastic Insulation

Sec. 1713 through Sec. 1716

NA

$\mathrm{B}-\mathrm{H}$

NA

CHAPIER 18 - TYPE I FIRE-RESISTIVE BUILDINGS N/A

CHAPTER 19 - TYPE II BUILDINGS NVA

CHAPTER 20 - TYPE III BUIIDINGS N/A

CHAPTER 21 - TYPE IV BUILDINGS N/A

CHAPTER 22 - TYPE V BUILDINGS N/A

PART V - ENGINEERTNG REGULATIONS - QUALITY AND DESIGN OF THE MATERIALS OF CONSTRUUCTION 
CHAPTER 23 - GENERAL DESIGN REQUIREMENTS

$$
\begin{aligned}
& \text { Sec. } 2301 \text { Scope } \\
& \text { Sec. } 2302 \text { Definitions } \\
& \text { Sec. } 2303 \text { Design Methods } \\
& \text { Sec. } 2304 \text { through Sec. } 2312
\end{aligned}
$$

CHAPTER 24 - MASONRY

CHAPTER 25 - WOOD

CHAPTER 26 - CONCRETE

CHAPTER 27 - SIEEL

CHAPTER 28 - ALUMINUM

PART VI - DETAILED REGULATIONS

CHAPTER 29 - EXCAVATIONS, FOUNDATIONS AND RETAINING WALIS

CHAPTER 30 - VENEER

CHAPTER 31 - NO REQUIREMENTS

CHAPIER 32 - ROOF CONSTRUCTION AND COVERING

CHAPTER 33 - EXITS

CHAPTER 34 - SKYLIGHTS

CHAPTER 35 - SOUND TRANSMISSION CONIRCL

CHAPTER 36 - PENIHOUSES AND ROOF SIRUCIURES

CHAPTER 37 - MASONRY OR CONCRETE CHIMNEYS, FIREPLACES AND BARBECUES

CHAPTER 38 - FIRE-EXTINGUISHING SYSTEMS

CHAPTER 39 - STAGES AND PLATFORMS

CHAPTER 40 - MOTION PICIURE PROJECTION ROOMS

CHAPTER 41 - NO REQUIREMENTS

PART VII - FIRE-RESISTIVE STANDARDS FOR FIRE PROTECTION

CHAPTER 42 - INTERTOR WALL AND CEIIING FINISH

CHAPIER 43 - FIRE-RESISTIVE STANDARDS

Sec. 4301 General

Sec. 4302 Fire-Resistive Materials
NA

$N A$

$N A$

$\mathrm{B}-\mathrm{N}$

NA

NA

$N A$

NA

NA

NA

$N A$

NA

NA

$N A$

NA

$B-J$

$N A$

NA

NA

NA

NA

NA

NA

N/A

$B-O$ 
Sec. 4303 Protection of Structural Members

N/A

Sec. 4304 Walls and Partitions

Sec. 4305 Floor-Ceilings or Roof-Ceilings

Sec. 4306 Fire-Resistive Assemblies for Protection of Openings

Sec. 4307 Roof Coverings

PART VIII - REGULATIONS FOR USE OF PUBLIC STREETS AND PROTECTIONS OVER PUBLIC PROPERTY

CHAPTER 44 - PROTECTION OF PEDESTRIANS DURING CONSTRUCTION OR DEMOLITION

NA

CHAPTER 45 - PERMANENT OCCUPANCY OF PUBLIC PROPERTY

$N / A$

CHAPTER 46 - NO REQUIREMENTS

NA

PART IX - WALL AND CEILING COVERINGS

CHAPTER 47 - INSTALLATION OF WALL AND CEILING COVERINGS

$\mathrm{N} / \mathrm{A}$

PART X - SPECIAL SUBJECTS

CHAPTER 48 - CELLULOSE NITRATE

N/A

CHAPTER 49 - NO REQUIREMENTS

N/A

CHAPTER 50 - PREFABRICATED CONSTRUCTION

N/A

CHAPTER 51 - ELEVATORS, DUMBWAITERS, ESCALATORS AND MOVING WALKS

NA

CHAPTER 52 - LIGHT TRANSMITTING PLASTICS

Sec. 5201
Sec. 5202
Sec. 5203
Sec. 5204
Sec. 5205
Sec. 5206
Sec. 5207
Sec. 5208
Sec. 5209
Sec. 5210
Sec. 5211
Sec. 5212
Sec. 5213
Sec. 5214

Scope

Definitions

Design and Installation

Glazing of Unprotected Openings

Light-Transmitting Exterior Wall Panels

Roof Panels

Skylights

Light-Diffusing Systens

Diffusers in Electrical Fixtures

Partitions

Awnings and Patio Covers

Greenhouses

Canopies

Solar Collectors

$B-G$

$B-G$

$B-G$

$B-G$

$B-G$

$B-G$

$B-G$

$N / A$

$N A$

$N / A$

$N A$

NA

$N A$

$N A$

CHAPTER 53 - NO REQUIREMENTS

$N A$

CHAPTER 54 - GLASS AND GLAZING

$B-J$

CHAPTER 55 through CHAPTER 59 
PROVISION TOPIC

PART XI - UNIFORM BUILDING CODE STANDARDS

NA

APPENDIX

$\mathrm{N} / \mathrm{A}$

CHAPTER 1 - LIFE SAFETY REQUIREMENTS FOR EXISTING BUILDINGS

$B-D$

CHAPTERS 7, 11, 12, 23, 32, 35, 38, 49, 51, 53, 55, 57, 70

N/A 
Southern Building Code Congress International

STANDARD BUILDING CODE - 1982

PROVISION TOPIC

CHAPTER I - ADMINISTRATION

Section 101 Title and Scope

101.2 Code Remedial

101.3 Scope

101.4 Existing Buildings

101.5 Special Historic Building and Districts

101.6

Section 102

Maintenance

Organization

Section 103

103.1

Powers and Duties of Building Official

103.2 Stop Work Orders

103.3 Revocation of Permits

103.4 Unsafe Buildings

103.5 Requirements Not Covered by Code

103.6 Alternate Materials and Alternate Methods of Construction

103.7 Liability

103.8 Reports

Section 104

Tests

Section 105

Application for Permit

105.1 When Required

105.2 Form

105.3 Drawings and Specifications

105.4 Plot Diagram

105.5 Limitation

105.6 Examination of Drawings

105.7 Street Lines

Section 106

Section 107

Section 108

Section 109

Section 110

Section 111

Section 112

Section 113

Section 114

Section 115

Permits

Fees

Inspections

Certificate of Occupancy

Posting Floor Loads

Board of Adjustment and Appeals

Appeals

Decisions of the Board of Adjustments and Appeals

Violations and Penalties

Validity

$N / A$

N/A

$\mathrm{B}-\mathrm{A}$

N/A

N/A

$B-C$

N/A

N/A

N/A

N/A

N/A

$B-D$

$B-D$

N/A

N/A

$\mathrm{B}-\mathrm{K}$

N/A

N/A

$\mathrm{B}-\mathrm{F}$

N/A

$N / A$

N/A

N/A

$N / A$

N/A

N/A

N/A

N A

N/A

N/A

N/A

N/A

N/A

CHAPTER II - DEFINITIONS

Section 201

Definitions

201.1 General

201.2 Tense, Gender, and Number

N/A

Approved

$\mathrm{B}-\mathrm{B}$

Automatic

B-B 
Boiler

Combustible Material

Fire Resistance Rating

Flame Spread

Flame Spread Rating

Listed

Masonry

Solid Masonry

Noncombustible Building Material

Plenum

Smoke Detector
B-B

$B-B$

$B-B$

$B-B$

$B-B$

$B-B$

$B-B$

$B-B$

$B-B$

$B-B$

$B-B$

$N / A$

NA

NA

$N A$

B-P

N/A

$N A$

N/A

CHAPTER VI - CLASSIFICATION OF BUILDING BY CONSTRUCTION NA

CHAPTER VII - FIRE PROTECTION REQUIREMENIS

Section $701 \quad$ Protection of Vertical Openings, Stairs and Elevators

NA

Section 702 Interior Wall and Partition Fire Separation Requi rements

Section 703

Protection of Wall Openings

Section 704

Restriction on Interior Use of Combustible Materials

Section 705

Section 706

Section 707

Section 708

Section 709

Section 710

Section 711

Section 712

Section 713

Section 714

Section 715

Section 716

Section 717

Section 718

Section 719

Firestopping and Draft Stopping

Foof Coverings

Skylights

Dormer Windows

Architectural Trim, Balconies, Bay Windows

Canopies on Exterior Walls

Gutters and Leaders

Towers, Spires, Cupolas, Aerial supports, Poles Domes

Tanks

Cooling Towers

Drying Rooms

Penthouses and Roof Structures

Foam Plastics

$N A$

$N A$

$N A$

$N A$

NA

$B-J$

$N A$

$N / A$

$N / A$

NA

$N A$

$B-Q$

$N / A$

$N A$

NA

$\mathrm{B}-\mathrm{H}$

Fireman's Access Panels in Windowless Walls N/A

Thermal Insulating Materials

General

$B-I$ 
719.2 Concealed Installation B-I

719.3 Exposed Installation N/A

719.4 Roof Insulation N/A

719.5 Duct Insulation N/A

719.6 Foam Plastics N/A

719.7 Cellulose Fiber Thermal Insulation B-I

CHAPTER VIII - APPURIENANCE REQUIREMENTS NVA

CHAPTER IX - SPRINKLERS AND STANDPIPES NVA

CHAPTER X - FIRE RESISTANCE STANDARDS FOR MATERIALS AND CONSTRUCTION

Section 1001 General

Section 1001.1 through $1002 \quad$ N/A

CHAPTER XI - MEANS OF EGRESS REQUIREMENTS

Section 1101 through Section $1103 \quad$ N/A

$\begin{array}{cll}\text { Section } 1104 & \text { Special Exit Requirements } & \\ 1104.1 & \text { Boiler, Incinerator, Furnace Rooms } & \text { N/A }\end{array}$

1104.2 Dead End Pockets or Hallways N/A

1104.3 Exit Access Corridors N/A

1104.4 Emergency Egress Genings B-L

1104.5 Smoke Proof Enclosures N/A

Section 1105 through Section 1127 N/A

CHAPTER XII - MINIMUM DESIGN LOADS

Section 1201 General B-N

Section 1202 Dead Loads N/A

$\begin{array}{lll}\text { Section } 1203 \quad \text { Live Loads } & \text { N/A } \\ 1203.1 \text { through } 1203.9 & \text { N }\end{array}$

$\begin{array}{ll}1203.1 \text { through } 1203.9 & \text { N/A } \\ 1203.10 \text { Load Tests } & \text { B-N }\end{array}$

Section 1204 through $1208 \quad$ N/A

CHAPTER XIII - FOUNDATIONS-EXCAVATIONS, FOOTINGS AND FOUNDATIONS NVA

CHAPTER XIV - MASONRY CONSTRUCTION NVA

CHAPTER XV - STEEU CONSTRUCTION N/A

CHAPTER XVI - CONCRETE CONSTRUCTION N NA

CHAPTER XVII - WOOD CONSTRUCTION

Sections 1700 through $1702 \quad$ N/A

Section 1703 Fire Protection

1703.1 Firestopping N/A

1703.2 Draftstopping N/A

1703.3 Fire Resistance Ratings B-O

1703.4 Fire Cuts N/A

Sections 1704 through $1708 \quad$ N/A 
CHAPTER XVIII - LATHING, PLASTERING AND GYPSUM WALIBOARD

$N \mathrm{~A}$

CHAPTER XIX - RATLPROOF CONSITRUCTION

$N \mathrm{~A}$

CHAPTER XX -LIGHT, VENIILATION AND SANITATION

Section 2001 Light and Ventilation

2001.1 Minimum Requirements

2001.2 Alcoves

2001.3 Toilets

2001.4 Mechanical Ventilation

Section 2002 Sanitation

$B \rightarrow M$

$N A$

$N A$

$\mathbb{N} \mathrm{A}$

$N A$

CHAPTER XXI - SAFEGUARDS DURING CONSTRUCIION

NA

CHAPTER XXII -USE OF PUBLIC PROPERIY

$N A$

CHAPTER XXIII - SIGNS AND OUTDOOR DISPLAYS

$N A$

CHAPTER XXIV - ELEVATORS, DUMBWAITERS, ESCALATORS, MOVING WALKS NA

CHAPTER XXV - PREFABRICATED CONSIRUICTION

$N A$

CHAPTER XXVI - LIGHT-TRANSMITIING PLASTICS

Section 2601 General

2601.1 Scope

2601.2 Definitions

2601.3 Design and Installation

Section 2602

Glazing of Unprotected Openings

2602.1 General

2602.2 Exceptions

Section 2603 Exterior Wall Panels

2603.1 General

2603.2 Exceptions

Section 2604 Roof Panels

2604.1 General

2604.2 Limitations

2604.3 Exceptions

$B-G$

$B-G$

$B-G$

$B-G$

$B-G$

$B-G$

$B-G$

$B-G$

$B-G$

$B-G$

Section 2605

Skylights

2605.1 General

$B-G$

2605.2 Exceptions

$B-G$

2605.3 Combination of Roof Panels and Skylights

$B-G$

Section 2606

Light Diffusers in Ceilings

NA

Partitions

$N A$

Section 2608

Exterior Veneer

Section 2609

Awnings and Simular Shelters

$N / A$

Greenhouses

NA

Section 2610

Section 2611

Section 2612

Signs and Outdoor Displays

$N A$

$N A$

Bathroom Accessories

NA 
CHAPTER XXVII - GLASS

Section 2701 Labeling

Section 2702 Louvered Windows or Jalousies

$\mathrm{B}-\mathrm{J}$

Section 2703

Human Impact Loads

$B-J$

Section 2704

Glass Supports

Table 2707

Relative Resistance to Wind Load

B-J

$B-J$

B-J

CHAPTER XXVIII - ALUMINUM CONSTRUCTION

N/A

CHAPTER XVIX - ACOUSTICAL CEILING SYSTEMS

Section 2901 General

$B-Q$

Section 2902 Acoustical Materials

$B-Q$

CHAPTER XXX - LISTING OF REFERENCED STANDARDS

N/A 
ARIICLE I - ADMINISTRATION

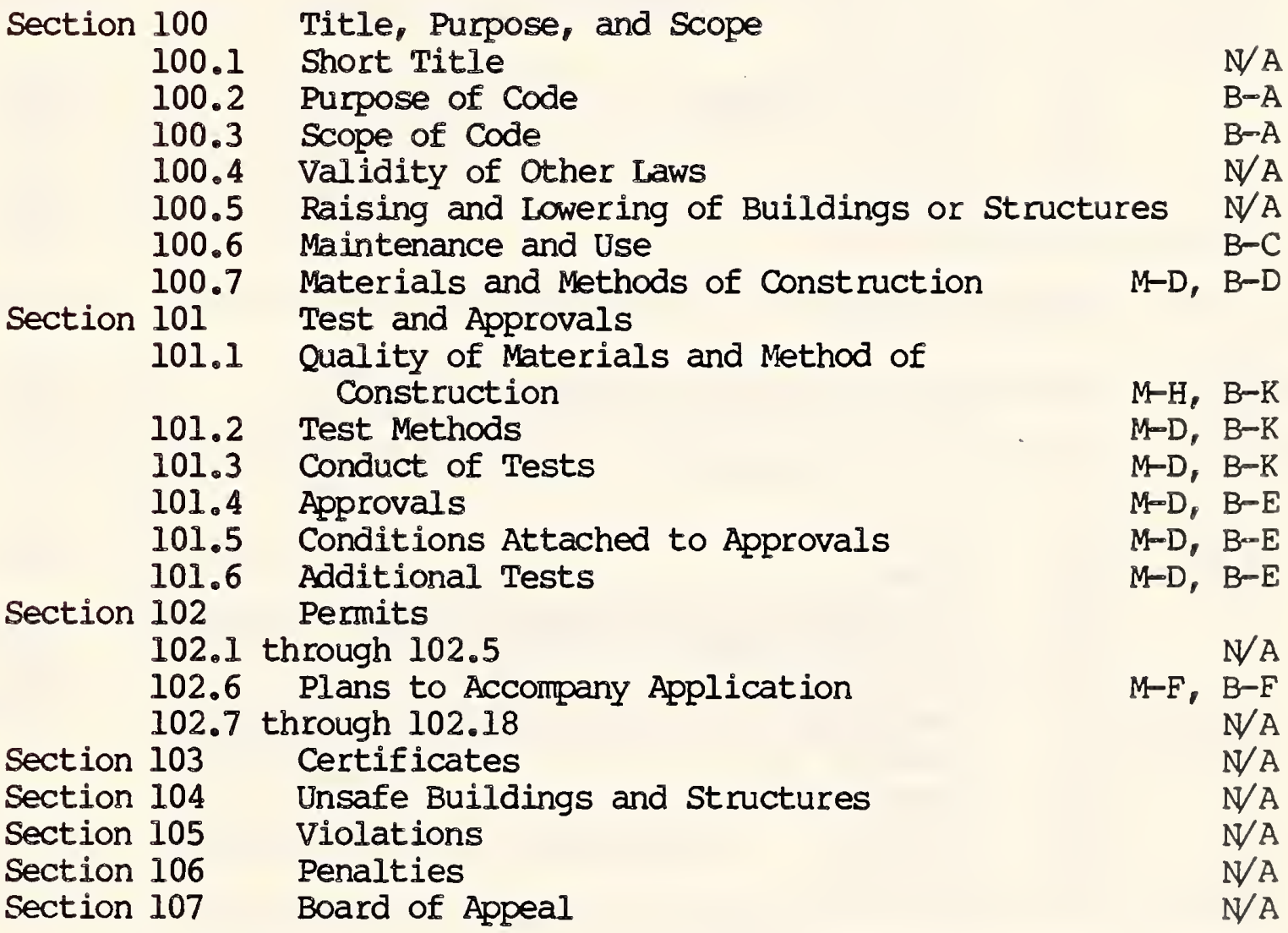

ARTICLE II - DEFINITIONS

Appliance, High Heat Industrial Type

Appliance, Low Heat Industrial Type

Appliance, Medium Heat Industrial Type

Appliance, Residential Type

Approved

Automatic

$B-B, M-B$

Fire Resistance Rating

Flame Spread Rating

Limited-Combustible Material

Masonry

Noncombustible Material

Smoke Detection System

ARTICLE III - OCCUPANCY REQUIREMENTS

Section $300 \quad$ General

300.1 Application 
300.2 Classification of Occupancies

300.3 Mixed Occupancy

e. High Hazard Occupancy

300.4 Doubtful Classification

Section 310 through section 334

Exception - 320.8 - Hazardous Areas

$B-P$

$B-P$

$B-P$

N $\mathrm{A}$

Section 340 High Hazard Occupancies

Section 350 through 381

Section 382 Dwellings

382.1 Means of Egress

382.2 Doors

382.3 Windows

382.4 through 382.8

Section 390 through 392

$B-P$

NA

$\mathrm{N} / \mathrm{A}$

$\mathrm{N} / \mathrm{A}$

$B-L, B-M$

$\mathrm{N} / \mathrm{A}$

$N / A$

N/A

N/A

ARTICLE V - RESTRICTIONS ON BUILDING AND STRUCTURES

ARIICLE VI -ENVIRONMENTAL REQUIREMENTS

Section 600

General

N/A

Section 601

Rooms

601.1 Maximum Number of Occupants for Dwelling Units

N/A

$B-M$

N/A

Section 602

601.3 through 601.9

Section 603 Windows

603.1 Glazed Area

603.2 Glazing

603.3 Openings

Section 604 through 608

N/A

$B-M$

$B-M$

$\mathrm{B}-\mathrm{M}$

$\mathrm{N} / \mathrm{A}$

ARTICLE VII - REQUIREMENTS FOR TYPES OF CONSTRUCTION

Section $700 \quad$ Classification of Construction

Section 701 Extent of Compliance Required

Section 702

702.1 through 702.8

702.9 Insulation

Section 703 Fire-Resistive Construction - Type B

703.1 through 703.8

703.9 Insulation

Section 704 Protected Limited - Combustible Construction

704.1 through 704.8

704.9 Insulation

Section 705 Unprotected Limited-Combustible Construction

705.1 through 705.7

705.8 Insulation

Section 706 Heavy Timber Construction

706.1 through 706.8

706.9 Insulation

N/A

$N / A$

$B-I$

N/A

$B-I$

$\mathrm{N} / \mathrm{A}$

B-I

$\mathrm{N} / \mathrm{A}$

B-I

N/A

B-I 
Section $707 \quad$ Ordinary Construction

707.1 through 707.9

NA

707.10 Insulation

Section 708 Wood Frame Construction

$B-I$

708.1 through 708.8

$N A$

708.9 Insulation

$\mathrm{B}-\mathrm{I}$

ARIICLE VIII - FIRE PROTIECTION REQUIREMENIS

Section 800 through section 806

Section $807 \quad$ Penthouses and Roof Structures

807.1 through 807.6

807.7 Skylights

Section 808 through 815

$$
B \sim G, \begin{aligned}
& N / A \\
& N / A \\
& B / A
\end{aligned}
$$

ARTICLE IX - STRUCIURAL DESIGN REOUIREMENIS OF BUILDINGS AND STRUCIURES

Section $900 \quad$ General

Section $901 \quad$ Workmanship and Structural Safety Tests

Section 902 through section 929

Section $930 \quad$ Glass

930.1 General

Section 931 through 933

ARTICTE X - CHIMNEYS, FIREPLACES, AND VENTING SYSTEMS N/A

ARIICLE XI - HEAT PRODUCING APPLIANCES: AND HEATING, VENIIIATING, AIR CONDITIONING, AND BLONER EXHAUST SYSTEMS

$N A$

ARTICTE XII - SAFEGUARDS DURING CONSTRUCTION N/A

ARIICLE XIII - ELEVATORS AND MECHANICAL EQUIPMENT N N

ARTICLE XIV - GAS PIPING N NA

ARTICLE XV - ELECTRICAL WIRING SYSTEMS N NA

ARTICLE XVI - SIGNS AND OUIDOOR DISPLAY STRUCIURES N/A

ARIICLE XVII - REQUIREMENTS FOR EXISTING BUIIDINGS NA

ARTICIE XVIII - LIST OF STANDARDS AND PUBLICATIONS

APPENDIX A - SUPPLEMENTARY PROVISIONS FOR WOOD FRAME CONSTRUCTION N/A

APPENDIX B - INSPECTED APPLIANCES AND MATERIALS

APPENDIX C - SHEATHING

APPENDIX D - DESIGN DEAD LOADS

APPENDIX E - HEAT PRODUCING APPLIANCES AND HEATING, VENTILATING

$N / A$

NA AIR CONDITIONING, AND BLOWER AND EXHAUST SYSTEMS

Section 1 General Requirements and Definitions

1.1 scope

$M-A$ 
1.2 Accessibility

1.3 Air for Combustion, Ventilation and Flue Dilution

1.4 Appliances Installed on Roofs or Outside of Buildings

1.5 Clearances

1.6 Approval and Installation of Fire Dampers and Fire Doors

1.7 Definitions

Approved

$M-0$

Boiler

Central Warm Air Heating System

Combustible Material

Damper, Fire

Fire Resistance Rating

Heat Exchanger, Direct

Noncombustible Material

Plenum

Residential Type Appliance

Section 2

1.8

Construction of Chimneys and Venting Systems

Residential Type Boilers and Furnaces

2.1

Definitions

2.2 Placement

2.3 Location and Clearances

2.4 Controls

Section 3

Floor Furnaces

Section 4

4.1

Room Heaters

Definitions

Roam Heaters

Circulating Room Heater

Radiant Room Heater

4.2 Placement

4.3 Clearances

4.4

4.5

Section 5

Section 6

6.1

Heaters on Walls

Controls

Residential Type Ranges and Open Top Broilers

Residential Type Water Heaters

Definition

6.2

6.3

Prohibited Installations

Placement

6.4

6.5

Section 7

Clearances

Controls

Section 8

Section 9

Section 10

Section 11

Section 12

Section 13

Residential Type Clothes Dryers

Residential Type Incinerators

Wall Furnaces

Factory-Built Fireplaces, Fireplace Stoves, and Decorative Appliances

Air Conditioning Appliances and Heat Pumps

Low Heat Industrial Type Appliances

Definitions

Unit Heaters

Restaurant Type Cooling Equipment

Medium Heat Industrial Type Appliances

N/A

$M-W$

$M-Q$

N/A

$M-B$

$M-B$

$M-B$

$M-B$

$M-B$

$M-B$

$M-B$

$M-B$

$M-B$

$M-B$

N/A

N/A

N A

$M-P$

N A

N/A

N/A

NA

NA

$M-Q$

$\mathrm{M}-\mathrm{Q}$

N A

N/A

NA

N/A

N/A

$M-Q$

$M-Q$

$M-T$

N $\mathrm{A}$

N A

N/A

N/A

N A

NA

NA

N/A

N/A

NVA 
Section 16

Section 17

Section 18

Section 19

Section 20

Section 21

21.1

21.2

21.3

Section 22

22.1

22.2

22.3

22.4

22.5

22.6

22.7

22.8

22.9

22.10

Section 23

23.1

23.2

23.3

23.4

23.5

23.6

23.7

23.8

23.9

23.10

23.11

23.12

23.13

23.14

23.15

23.16

23.17

Section 24

Section 25

Section 26

Section 27 through Section 30

Supplementary Information (pgs. 670-673) Systems

Clearances

Protection

Antifreeze Solutions Conditioning Systems

Application

Heating Panels or Return Plenums

Return Systems

Registers for Ducts Than Residential Type

General

Installation of Ducts

Shafts

Plenums

Portions of Buildings

Air Filters

Air Handling Equipment

Cooling Equipment

Controls Computer Systems and Vapors Hazardous Occupancies Burners
$N A$

$N A$

NA

Appliance Connections to Chimeys or Venting

Special Venting Arrangements N/A

Steam and Hot Water Pipes

Residential Type Wasm Air Heating and Air

Supply System - Construction

Clearances from Horizontal Supply Ducts

Clearances from Vertical Ducts, Risers, Boots and Register Boxes

Pipeless Furnace Registers

Use of Under Floor Space as a Supply Plenum $\mathbb{M}-\mathrm{J}, \mathrm{M}-\mathrm{I}$

Use of Concealed Ceiling Space as Supply

Warm Air Heating, Air Conditioning, Air Cooling and Ventilating Systems other

Materials for Ducts and Connectors

Installation of Duct Connectors

Cells of Floors for Ducts

Installation of Linings and Coverings

Air outlets, Air Inlets, and Fresh Air Intakes

Fire Dampers, Fire Doors and Smoke Dampers

Inspection, Maintenance, and Service Openings

Air Conditioning and Coolant Systems for

Blower and Exhaust Systems for Dust, Stock

Heating and Ventilating Equipment in

$M-I$

M-I

$N A$

$N / A$

$N A$

$N A$

$N A$

$N A$

$N A$

$N A$

$M-I$

$M-I$

M-Z

$M-K$

$N A$

$N A$

$N A$

$N A$

$M-Y$

NA

NA

$N A$

$N A$

$N A$

$M-Z$ 
APPENDIX B - PROVISION LISTING OF MODEL MECHANICAL CODES AND THEIR CROSS REFERENCE TO TOPICS DISCUSSED IN THIS REPORT

B-a 
B-b

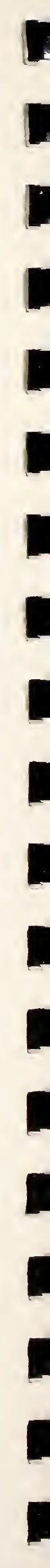


Building Officials and code Administrators Intemational (BOCA)

BASIC MECHANICAL CODE - 1981

ARTICTE 1 - ADMINISTRATIVE AND ENFORCEMENT

PROVISION TOPIC

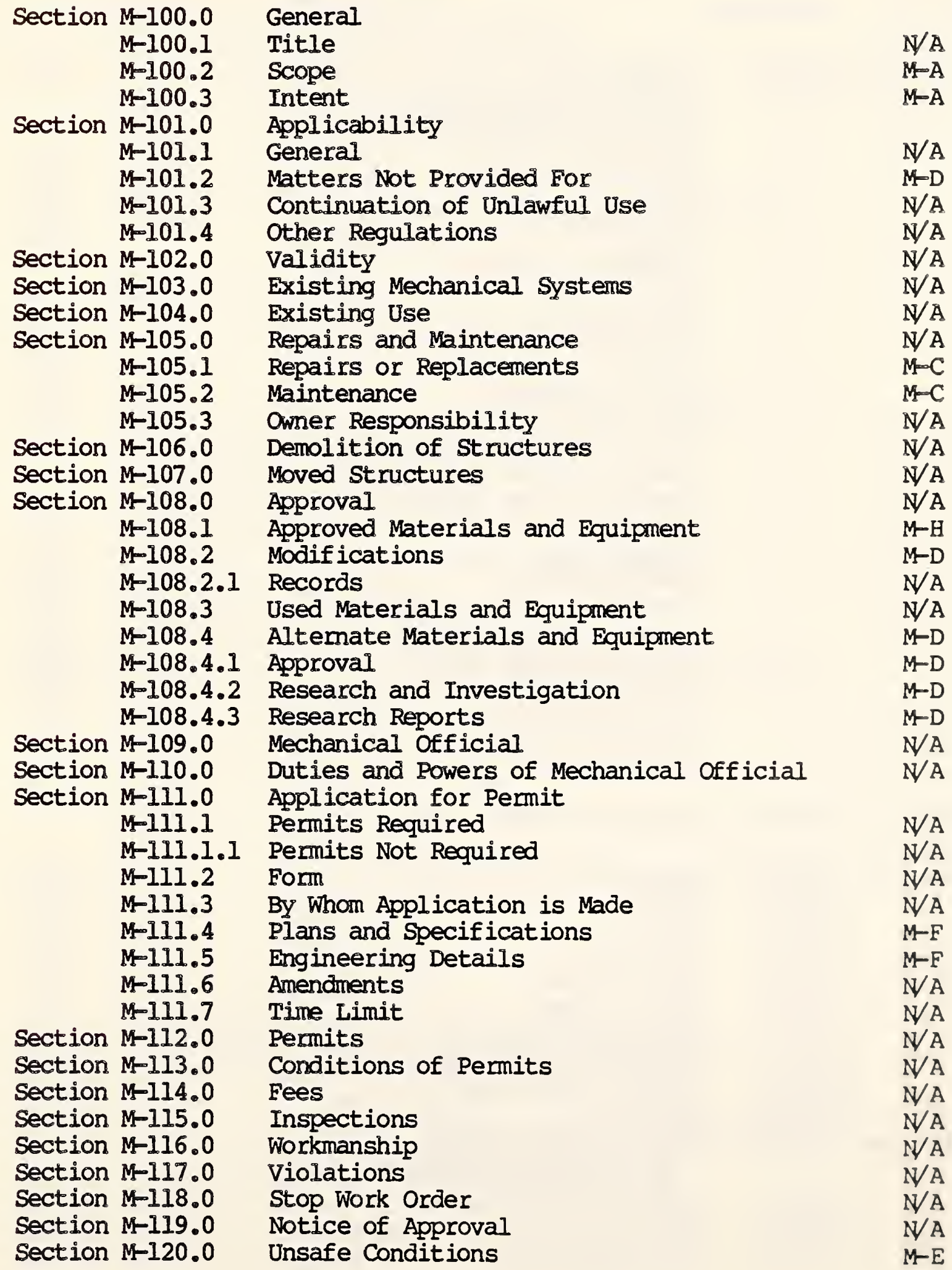


Section M-121.0 Energency Measures

$N / A$

Section $M-122.0$

Means of Appeal

section M-123.0

Accidents

$N A$

NA

ARTICLE 2 - DEFINITIONS

Section M-200.0

section M-201.0
General

General Definitions

Appliance (Mechanical) M-B

Appliance, Approved

Approved

Boiler

Combustible Material

Damper

Duct

Filter, Air

Fire Damper

Fumace

Fumace, General

Heat Exchnager

Heating System, Central Warm Air

Heating System, Forced Air

Heating System, Gravity

Listed

Manufacturer

Noncombustible

Plenum

Pressure-Relief Device

Pressure-Relief Valve

Return Air System

Standard, Generally Accepted

Supply Air System

Water Heater

N/A

$M-B$
$M-B$

$M-B$

$M-B$

$M-B$

$M-B$

$M-B$

$M-B$

$M-B$

$M-B$

$M-B$

$M-B$

$M-B$

$M-B$

$M-B$

$M-B$

$M-B$

$M-B$

$M-B$

$M-B$

$M-B$

$M-B$

$M-B$

$M-B$

$M-B$
ARTICLE 3 - HEATING, COOLING, AND VENTILATING
General

Scope

Plans

Equipment

Type of Fuel

Installation

Negative Pressure Fram Ventilation Systems

Mechanical Refrigeration

Energy Conservation

Plenums

Distribution, Exhaust, and Retum Systems (All Occupancies Except Use Group R-3)

$M-302.1$

$M-302.2$
Scope

Duct Construction
$N / A$

$N / A$

$N / A$

$\mathrm{M}-\mathrm{H}$

N/A

$M-M$

$N / A$

N/A

NA

$M-I$

N A 
M-302.2.1 Duct Material

M-302.2.2 Ducts Formed By Parts of the Building

$M-R$ Structure

M-302.2.3 Flexible Duct

M-302.2.4 Flexible Duct Connectors

M-302.2.5 Flexible Duct Provisions

$M-302.3$

$M-302.4$

$M-302.5$

M-302.6

$M-302.7$

M-302.8

Vibration Isolation Connections

Duct Coverings, Lining and Panels

Prohibited Duct Openings

Joint Tape

Installation of Ducts

Clearance from Warm Air Ducts, Plenums, or Bonnets

M-302.9

$M-302.10$

Section $M-303.0$

M-303.1

M-303.2

$M-303.2 .1$

M-303.2.2

$M-303.2 .3$

M-303.2.4

$M-303.2 .5$

$M-303.2 .6$

$\mathrm{M}-303.2 .7$

$M-303.2 .8$

$M-303.2 .9$

Section $M-304.0$

$M-304.1$

$M-304.2$

$M-304.3$

Section $M-305.0$

M-305.1

$M-305.2$

M-305.3

Air Intake and Exhaust Openings

Controls

Distribution, Exhaust, and Return Systems in Use Group $R-3$

scope

Supply and Return Ducts and Fittings

Supply Ducts

Ducts in Floor Slabs

Duct Connections

Supports and Hangers

Panning

Protection of Combustible Ducts

Firestopping

Duct Coverings

Flexible Duct Material

Heating Equipment Located in Attic Spaces

Installation

M-R

$N / A$

NA

$\mathrm{N}$ A

$\mathbb{N A}$

$M-S$

NA

$\mathrm{N} / \mathrm{A}$

$M-R$

N/A

$N / A$

$M-Y$

Access

Furnace Setting

Equipment on Roofs

General

Installation

Access to Appliances

Section M-306.0

$M-306.1$

$M-306.2$

M-306.3

$M-306.4$

$M-306.5$

Section M-307.0

Section $M-308.0$

Section $M-309.0$

Section $M-310.0$

Section $M-311.0$

Section $M-312.0$

Section $M-313.0$

Section $M-314.0$

Heating Equipment Located in Crawl Spaces

Crawl Space

Clearance

Installation

Illumination

Access

Equipment in Hazardous Occupancies

Equipment in Service Stations

Fans and Blowers

Blower and Exhaust Systems for Removing

Dust, Stock and Vapors

Domestic Hoods and Fans

Commercial Hoods and Fans

$M-R$

N/A

$N A$

$N / A$

$N / A$

$N / A$

$\mathrm{N} / \mathrm{A}$

$M-S$

N/A

$M-P$

$M-P$

N/A

$M-W$

$M-W$

$M-W$

Clothes Dryers

Filters

$M-J$

$M-J$

$M-J$

N A

$M-J$

NA

$N$ A

$M-N$

$N / A$

$N$ A

N $\mathrm{A}$

$N A$

NA 


\section{M-314.1 \\ $M-314.2$ \\ $M-314.3$ \\ $M-314.4$ \\ $\mathrm{M}-314.5$}

Section $M-315.0$

Section M-3I6.0

Section $M-317.0$
Scope

General

Filters in Commercial Range Hoods

Filters for Sprying or Dipping

Other Filters

Fire Dampers

Underground Duct Systems

Evaporative Coolers
PROVISION TOPIC

N/A

$M-R$

$N / A$

$N A$

$N A$

$N A$

$N A$

$N A$

ARTICTE 4 - STEAM AND BOT WATER HEATING SYSTEMS AND PROCESS PIPING

Section $M-400.0$
$M-400.1$
$M-400.2$
$M-400.3$
$M-400.4$
$M-400.5$
$M-400.6$
$M-400.7$
$M-400.8$
$M-400.9$
$M-400.10$
$M-400.11$
$M-400.12$
$M-400.13$
Section $M-401.0$
Section $M-402.0$
Section $M-403.0$
Section $M-404.0$

Section $M-405.0$

$M-405.1$

$M-405.2$

$M-405.3$

$M-405.4$

$M-405.5$

$M-405.6$

$M-405.7$

$M-405.8$

Section $M-406.0$

Section M-407.0

Section M-408.0

Section $M-409.0$

$M-409.1$

$M-409.2$

$M-409.3$

$M-409.4$

$M-409.5$

$M-409.6$

$M-409.7$

$M-409.8$
General

Scope

Equipment

Fuel Conversion

Installation

Access

Boiler Room

High Pressure Steam and Hot Water Heating Systems

Materials

Valves on Boilers

Generators and Pressure Vessels

Installation or Repairs Affecting Building Structure

Temporary Heating During Construction

Prohibited Installations

Boilers or Generators (Steam and Hot Water)

Headers and Connections on Steam Boilers

Boilers in Parallel Batteries

Return Loop Connection and Equalizing Pipe Requirements

Safety or Relief Valves and Reducing Valves

General

Tanks and Heaters

Test Lever

Valve Setting

Valve Seals

Discharge

Pressure Reducing Valve

Pressure Relief Valve

Water Level and Steam Pressure Gauges

Blow-off valves

Low water Cut-Off Controls, water Feeders

Piping for Steam and Hot Water Heating Systems

General

Reaming

Piping Joining

Pipe Support

Piping Through Portions of the Structure

Vertical Piping Secured

Branch Main Stress

Bull-Heading Tee
NA

$M-\mathrm{H}$

NA

$M-M$

$M-0$

N/A

$M-T$

$M-T$

$N / A$

N/A

N/A

$N A$

$N / A$

$N / A$

$N / A$

$N A$

N/A

$M-T$

$M-T$

N/A

$N A$

$N / A$

$N / A$

$N$ A

$N / A$

$N / A$

$N A$

$N A$

M-U

$M-U$

M-U

N/A

$N A$

$N A$

N/A

$N A$ 
M-409.9 Welding

M-409.10 Connections from Mains, Branch Mains or Return Piping

$M-409.11$

M-409.12

$M-409.13$

Section $M-410.0$

Section $M-411.0$

Section M-412.0

Section $M-413.0$

Section $M-414.0$ $M-414.1$

Section $M-415.0$

Section $M-416.0$

Section $M-417.0$

Section $M-418.0$

Section $M-419.0$

Section $M-420.0$

$M-420.1$

$M-420.2$

$M-420.3$

$M-420.4$

$M-420.5$

$M-420.6$

Section $M-421.0$

Section $M-422.0$

$M-422.1$

Section $M-423.0$

$M-423.1$

$M-423.2$

$M-423.3$

M-423.4

$M-423.5$

$M-423.6$

$M-423.7$

Cold Water Supply to Hot Water Tank

Approved Materials

Piping Insulation

Pitch of Piping

Expansion Tanks

Low-Ater Cut-Off, Hot Water Heating Boilers

Water Supply Connections

Gauges and Thermometers

General

Heating With Steam From Utility Central

Steam Heating System or Other Types

of Steam Distributing Systems

Gas, Oil and Solid Fuel Bumers

Radiant Heating Systems

Chimneys, Flues, Vents and Combustion Air

Blow-Off Tanks

Hot Water Storage Tanks, Hot Water

Heaters, Tankless Type Water Heaters

and Equipment: Construction and Moving

General

Approved Tanks

Tankless Water Heaters

Indirect Heated Type Water Heaters

$M=U$

$N / A$

$M=X$

$M-U$

$\mathbb{N} \mathrm{A}$

$\mathbb{N A}$

$\mathbb{N A}$

$\mathbb{N A}$

$M-X$

$M=Z$

Direct Heated Type Water Heaters

Tank Stands

Boiling-out Procedure for Steam Boilers and Generators

N

$N / A$

$N / A$

$N / A$

$\mathbb{N} \mathrm{A}$

Cleaning Procedure, Hot-Water System

General

Boiler and Generator Mountains and Clearances

Fire Resistive Mounting

Clearance to Combustible Material

Separation of Equipment

Boiler Room

Steam and Hot Water Pipes

Pipes Through Shelving

Anti-freeze Solution for Radiant Heating Coils

M-423.8 Air Cooling Equipment

M-423.9 Flue Exhausters

Section M-424.0 Welding of Pipe Joints

$M-Z$

$M-Z$

NA

$M-Z$

$M-2$

$M-V$

N/A

M-Z

N A

$M-O$

$N A$

$N / A$

$N A$

$N A$

M-Z

$N \mathrm{~A}$

$N A$

NA

ARTICLE 5 - BOILERS AND PRESSURE VESSELS, MAINIENANCE AND INSPECTION

Section $M-500.0$

Section $M-501.0$

$M-501.1$

M-501.2

M-501.3

M-501.4
General

Inspections

Periodic Inspection

Certificate of Inspections

Boiler Record

Major Repairs
N/A

$M-G$

$M-G$

$N / A$

N A 
PROVISION TOPIC

M-501.5 Owners to Provide Facilities

M-501.6 Equipment Testing and Additional Fee

$N / A$

M-501.7 Hydrostatic Pressure

$N / A$

M-501.8 Test Formulae

$N / A$

M-501.9 Inspection to Determine Remaining Thickness

$N / A$

M-501.10 Seller's Inspection

M-501.11 Welding

M-501.12 Electrical

M-501.13 Boiler settings

$N / A$

$N / A$

$N / A$

$N / A$

$\mathrm{N} / \mathrm{A}$

Annual Inspection Fees N/A

ARTICIE 6 - GAS, LIQUID AND SOLID FUEI PIPING AND EQUIPMENT N/A

ARTICLE 7 - CHIMNEYS AND VENTS N NA

ARTICLE 8 - MECHANICAL REFRIGERATION N/A

ARTICLE 9 - INCINERATORS, CREMATORIES, FIREPLACES AND BARBECUES N/A.

ARIICLE 10 - VENTIIATION AIR N N/A

ARTICLE 11 - AIR POILUTION CONIROL N NA

ARTICLE 12 - SOLAR HEATTNG AND COOLING SYSTEMS

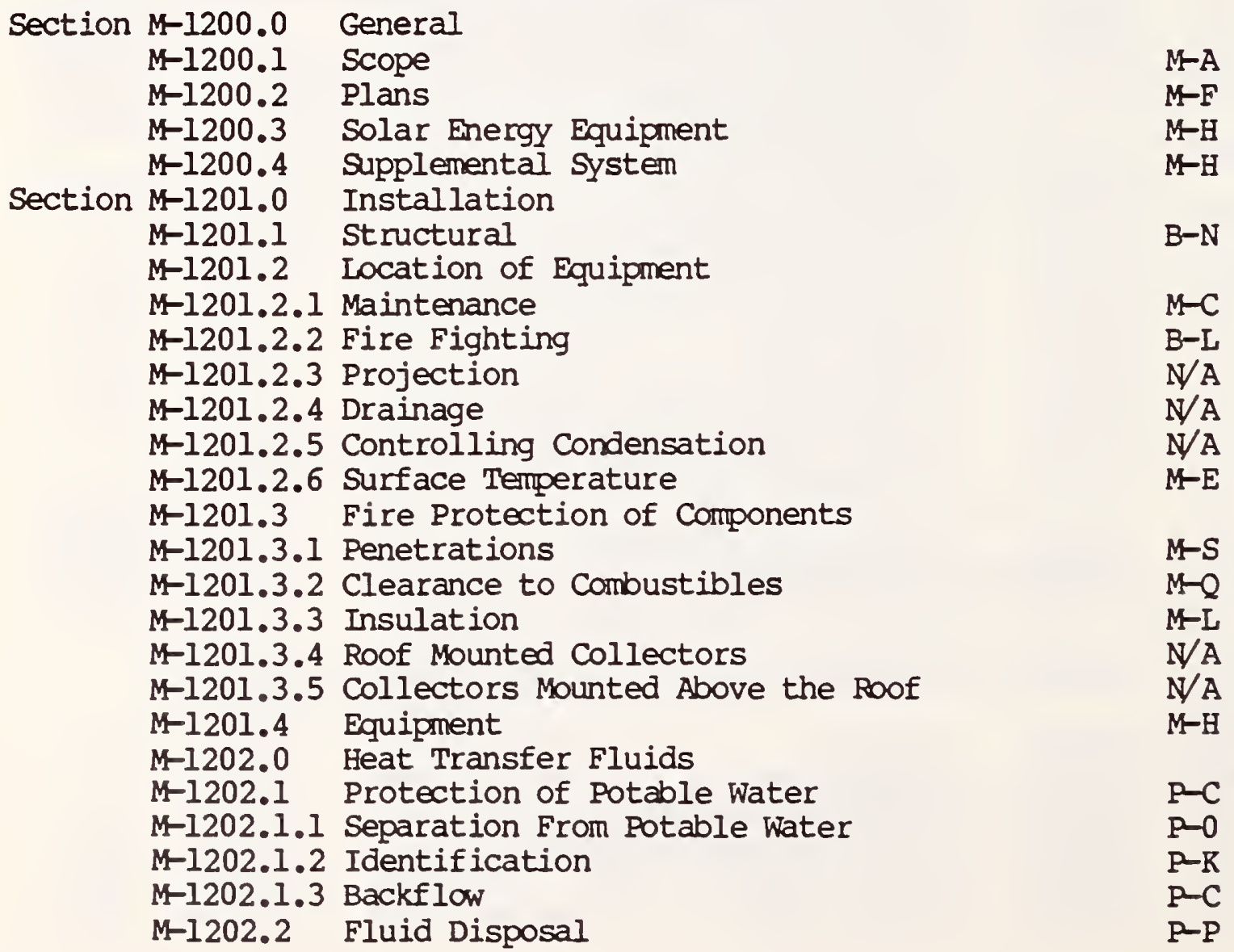


$M-1202.3 \quad$ Piping

M-1202.4 Leakage Waming

M-1202.5 Emergency Procedure

M-1202.6 Flash Point

M-1203.0 Materials

ARTICLE 13 - ENERGY CONSERVATION

Section M-1300.0 General

M-1300.1 Scope

M-1301.0 Design Conditions

M-1302.0 Duct Installation

M-1303.0 Equipment Performance Requirements

M-1304.0 Controls

APPENDIX A - REFERENCE STANDARDS AGENCIES

APPENDIX B - ACCEPTED ENGINEERTNG PRACTICE STANDARDS

APPENDIX C - MATERIAL AND TEST STANDARDS

APPENDIX D - WATER SPRINRIER SYSTEMS WITH BASIC COMPONENTS

APPENDIX E - MEIRIC INIERNATIONAL UNIT EQUIVALENTS
$M-S$

$P-P$

$P-R$

$\mathrm{P}-\mathrm{P}$

$P \sim J$

NA

NA

$M-L$

$N / A$

$M-Y$

$N / A$

N/A

NA

N A

NA 
PART I - ADMINISTRATIVE

CHAPTER 1 - TITLE, SCOPE, AND GENERAL

$\begin{array}{ll}\text { Sec. } 101 \text { - Title } & \text { N/A } \\ \text { Sec. } 102 \text { - Purpose } & \text { M-A } \\ \text { Sec. } 103 \text { - Scope } & \text { M-A } \\ \text { Sec. } 104 \text { - Application to Existing Mechanical Systems } & \text { M-C } \\ \text { Sec. } 105 \text { - Altemate Materials and Methods of Construction } & \text { M-D } \\ \text { Sec. } 106 \text { - Modifications } & \text { M-D } \\ \text { Sec. } 107 \text { - Tests } & \text { M-D }\end{array}$

CHAPTER 2 - ORGANIZATION AND ENFORCEMENT

Sec. 201 - Powers and Duties of Building Official N/A

Sec. 202 - Unsafe Equipment M-E

Sec. 203 - Board of Appeals N/A

Sec. 204 - Violations NA

CHAPTER 3 - PERMITS AND INSPECTIONS

Sec. 301 - Permits

Sec. 302 - Application for Permit

NA

Sec. 303 - Permit Issurance

$M-F$

Sec. 304 - Fees

Sec. 305 - Inspections

Sec. 306 - Connection Approval

PART II - DEFINITIONS AND ABBREVIATIONS

CHAPTER 4 - DEFINITIONS AND ABBREVIATIONS

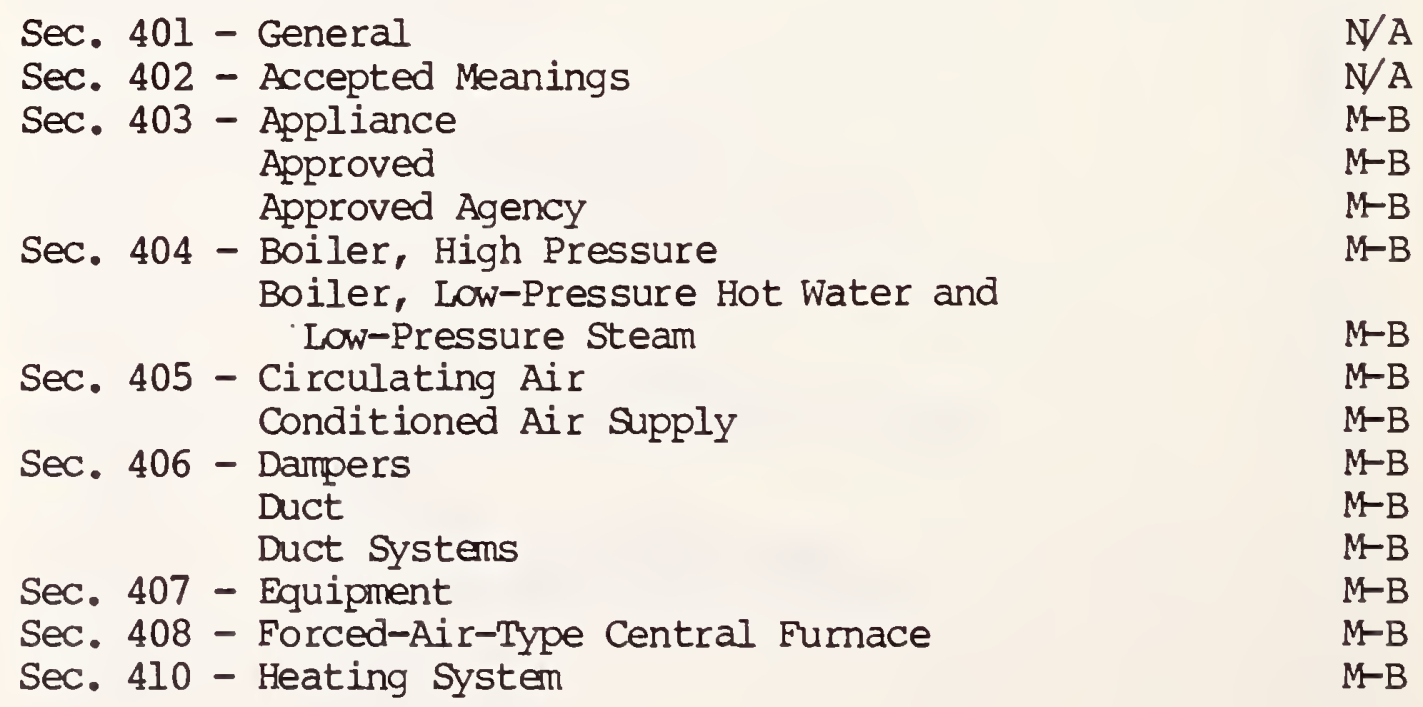




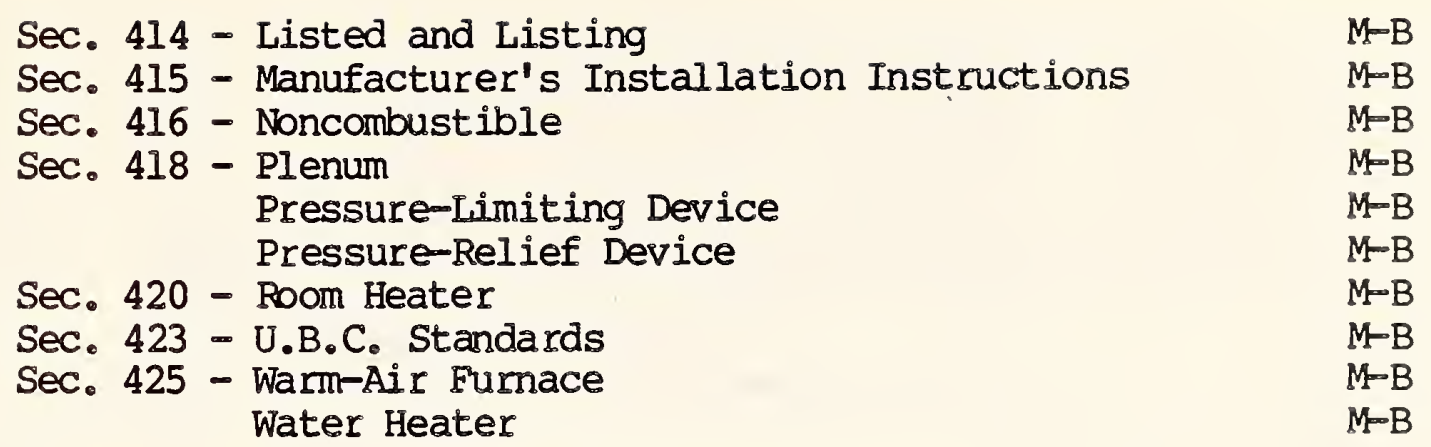

PART III - HEATING, VENTILATING AND COOLING

CHAPTER 5 - EQUIPMENT - GENERAL

Sec. 501 - Scope

$N A$

Sec. 502 - Approval

Sec. 503 - Type of Fuel and Fuel Connections

$\mathrm{M}-\mathrm{H}, \mathrm{M}-\mathrm{Q}$

Sec. 504 - Installation

Sec. 505 - Access

Sec. 506 - Automatic Control Devices

Sec. 507 - Labeling

Sec. 508 - Location

Sec. 509 - Electrical Connections

Sec. 510 - Indirect Waste Connections

$N A$

NA

$M-M, M-0$

$N A$

$N A$

$M-V$

$M-N$

Sec. 511 - Personnel Protection

$N A$

$N A$

CHAPTER 6 - COMBUSTION AIR

NA

CHAPTER 7 - HEATING SYSTEMS

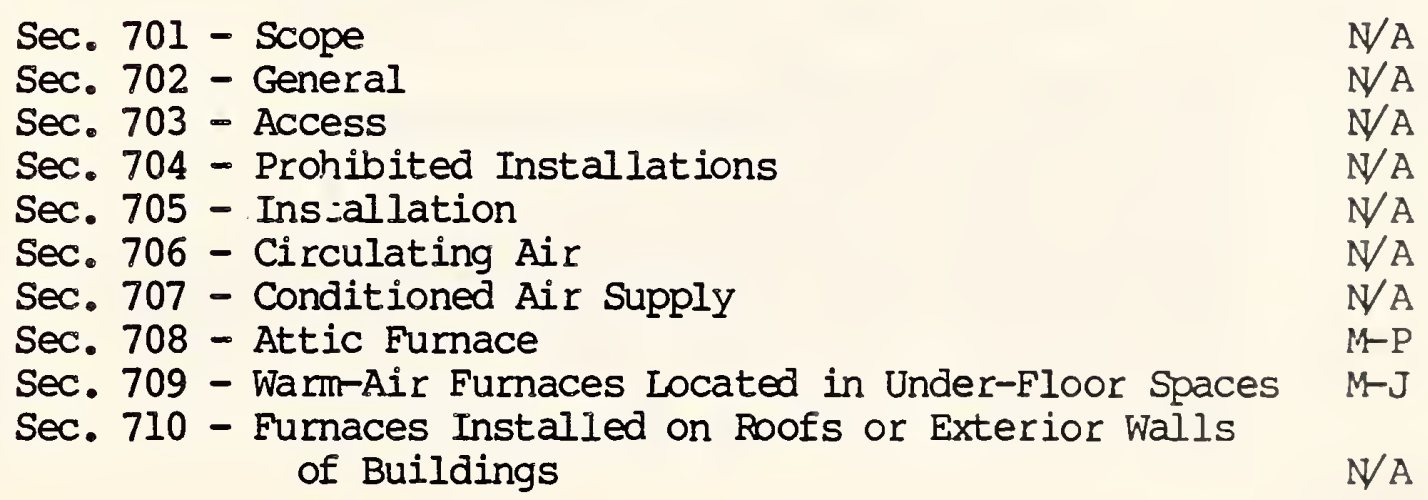

CHAPTER 8 - VENTED DECORATTVE APPLIANCES, FLOOR FURNACES, VENTED WALL FURNACES, UNIT HEATERS AND ROOM HEATERS

NA

CHAPTER 9 - VENTING OF APPLIANCES

NA

CHAPTER 10 - DUCTS

Sec. 1001 - Scope

Sec. 1002 - Material 
Sec. 1003 - Quality of Material

$N A$

Sec. 1004 - Installation of Ducts

NA

Sec. 1005 - Insulation of Ducts

Sec. 1006 - Fire Dampers

Sec. 1007 - Ventilating Ceilings

Sec. 1008 - Use of Under-Floor Space as Supply Plenum

Sec. 1009 - Automatic Shutoffs

M-L

$N / A$

NA

$M-J$

$M-Y$

CHAPTER 11 - VENTIIATION SYSTEMS AND PRODUCT CONVEYING SYSTEMS NA

CHAPTER 12 - COOLING

NA

CHAPTER 13 - EVAPORATIVE COOLING SYSTEMS

NA

PART IV - REFRIGERATION

CHAPTER 14 - ABSORPTION REFRIGERATING EQUIPMENT $\quad$ NA

CHAPTER 15 - MECHANICAL REFRIGERATING EQUIPMENT N NA

CHAPTER 16 - STORAGE OF REFRIGERANTS N/A

CHAPIER 17 - COOLING TOWERS N/A

PART V - MISCELIANEOUS

CHAPTER 18 - INCINERATORS N/A

CHAPTER 19 - MISCELLANEOUS HEAT-PRODUCING APPLIANCES NA

CHAPTER 20 - COMMERCIAL HOODS AND KITCHEN VENTILATION N/A

APPENDIX A - GALVANIZED SHEET METALS N/A

FACTOR-MADE AIR-DUCT MATERIALS AND SYSTEMS N/A

STANDARD FOR METAL DUCTS N/A

WROUGHT-STEEL AND WROUGHT-IRON PIPE N/A

SEAMLESS COPPER TUBE, COPPER PIPE AND RED BRASS PIPE N/A

SMOKE DETECTORS FOR FIRE-PROTECTIVE SIGNALING SYSTEM

AND SINGLE - AND MULTIPLE-STATION SMOKE DETECIORS N/A

FIRE DAMPERS

FLASH POINT BY PENSKY-MARTENS CLOSED TESTER

N/A

NA

APPENDIX B

CHAPTER 21 - STEAM AND HOT-WATER BOILERS STEAM AND HOT-WATER PIPING (HYDRONICS)

Sec. 2101 - Purpose

NA

Sec. 2102 - Scope

$M-T$

Sec. 2103 - Workmanship

$\mathrm{N} / \mathrm{A}$

Sec. 2104 - Definitions

$N A$

Sec. 2105 - Permit Required

$N A$

Sec. 2106 - Detailed Requirements

$M-T$ 
Sec. 2107 - Expansion Tanks

Sec. 2108 - Safety or Relief Valve Discharge

NA

Sec. 2109 - Shut-off Valves

$M-Z$

Sec. 2110 - Gas Pressure Regulators

N/A

Sec. 2111 - Low-Water Cut off

$N / A$

Sec. 2112 - Combustion Regulators: Safety Valves

$N A$

M-T

Sec. 2113 - Automatic Boilers

$N \mathrm{~A}$

Sec. 2114 - Clearance for Access

$N \mathrm{~A}$

Sec. 2115 - Boiler Rooms and Enclosures

NA

Sec. 2116 - Mounting

Sec. 2117 - Floors

Sec. 2118 - Chimeys or Vents

Sec. 2119 - Drainage

Sec. 2120 - Fuel piping

Sec. 2121 - Air for Combustion and Ventilation

Sec. 2122 - Operating Adjustments and Instructions

Sec. 2123 - Inspections and Tests

Sec. 2124 - Operating Permit

Sec. 2125 - Maintenance Inspection

Sec. 2126 - Operation and Maintenance of Boilers and Pressure Vessels

$M-V$

$\mathrm{N} / \mathrm{A}$

$N \bar{A}$

$N / A$

$N / A$

$N A$

$N A$

$N A$

$N A$

N A

Sec. 2127 - Steam and Water Piping

NA

$M-U$

CHAPTER 22 - FUET - GAS PIPING

NA

APPENDIX $C$ - SIZING OF VENTING SYSTEMS SERVING APPLIANCES EQUIPPED WITH DRAFT HOODS AND APPLIANCES LISTED FOR USE WITH TYPE B VENTS EQUIPMENT STANDARDS 
CHAPTER I - ADMINISTRATION

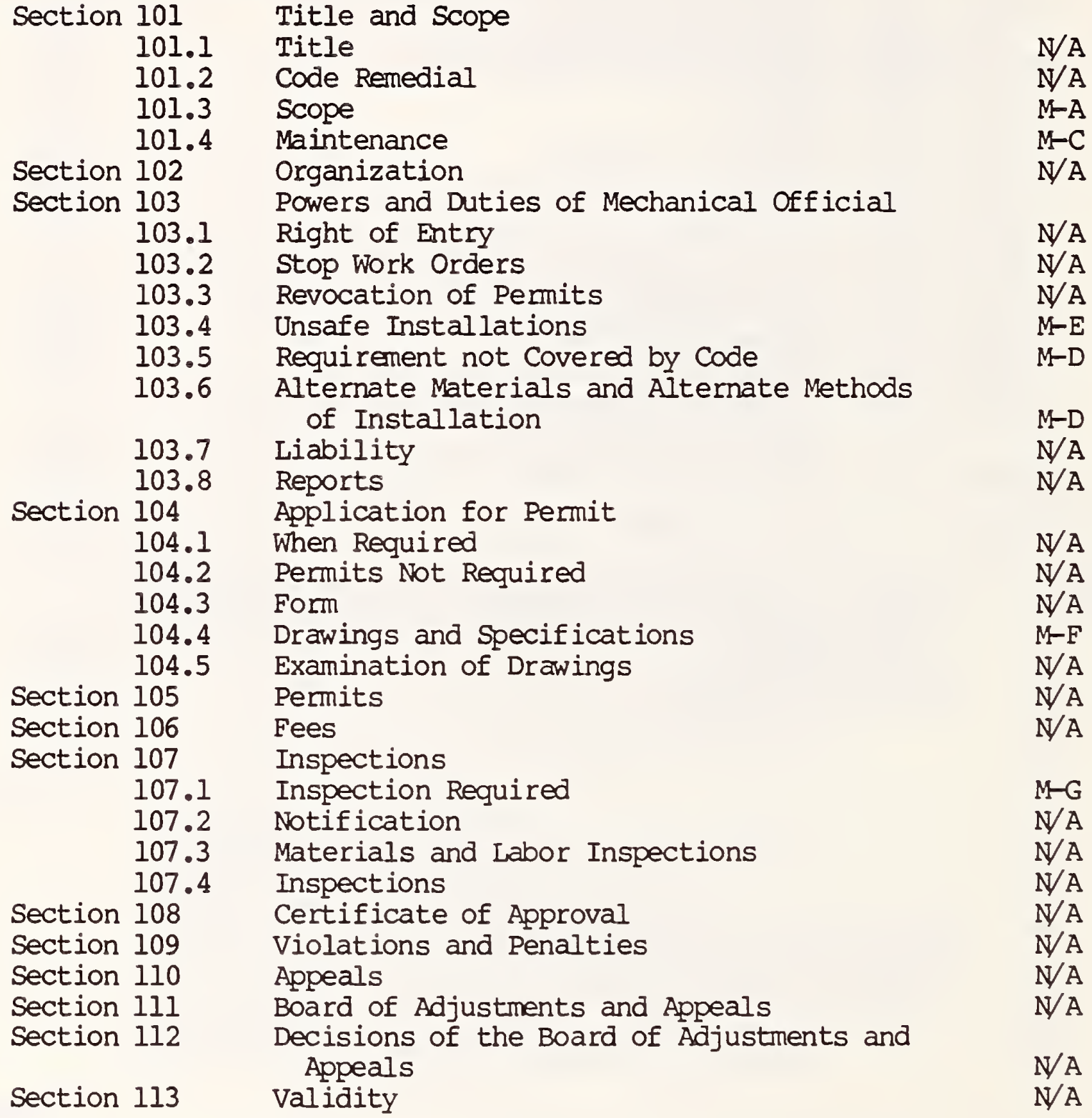

CHAPTER II - DEFINITIONS

Section 201

Appliances

Approved

Boiler, Heating (Low Pressure)

Combustible Material

Duct System

Filter, Air

Fire Damper
$M-B$

$M-B$

$M-B$

$M-B$

$M-B$

$M-B$

$M-B$ 
Furnace

$M-B$

Furnace, Central

$M-B$

Heat Exchangers

Heating System, Central Warm Air

$M-B$

High Pressure (and Temperature)

$M-B$

Listed

$M-B$

Low Pressure (and Temperature)

$M-B$

Non-Combustible Material

$M-B$

Plenum

$M-B$

Return Air System

$M-B$

Smoke Damper

$M-B$

Supply Air System

$M-B$

$M-B$

CHAPTER III - AIR CONDITIONING, HEATING AND VENIILATION EOUIPMENT

$\begin{array}{ll}\text { Section } 301 & \text { General } \\ 301.1 & \text { Scope } \\ 301.2 & \text { Approval } \\ 302 & \text { Air Conditioning Equipment } \\ 303 & \text { Heating Equipment Other Than Boilers } \\ 303.1 & \text { General } \\ 303.2 & \text { Accessibility for Service } \\ 303.3 & \text { Attic Installation } \\ 303.4 & \text { Under Floor Installations } \\ 303.5 & \text { Roof or Exterior Wall Installation } \\ 303.6 & \text { Mounting } \\ 303.7 & \text { Clearances for Heat Producing Appliances } \\ 303.8 & \text { and Their Accessories } \\ 303.9 & \text { Flearances with Protection } \\ 303.10 & \text { Electric Heating Equipment } \\ 303.11 & \text { Solar Equipment }\end{array}$

304

Boilers

305

Combustion and Ventilation Air

306

Chimneys and Vents

307

Ventilation Systems

308

Exhaust Systems

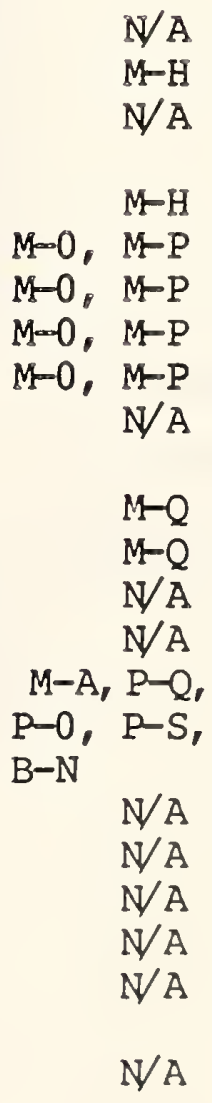

CHAPTER V - DUCTS AND DUCT SYSTEMS

$\begin{array}{ll}\text { Section } 501 & \text { General } \\ 502 & \text { Standards } \\ 503 & \text { Duct Materials } \\ 504 & \text { Duct Construction and Installation } \\ 505 & \text { Flexible Air Duct Connectors } \\ 506 & \text { Insulation } \\ 507 & \text { Ducts in Concrete Slabs } \\ 508 & \text { Duct Clearances } \\ 509 & \text { Plenum Floor Systens }\end{array}$

$N A$

$N A$

$M-R, M-S$

$M-R, M-S$

$N A$

$M-L$

$N A$

$N A$

$M-I$ 
Section 601

602

602.1

602.2

602.3

602.9

602.11

602.12

603

604

605

606

606.1

606.2
General

Steam and Hot Water Piping

General

Reaming

Pipe Joining

welding

Cold Water Supply to Hot Water Tank

Materials

Condensate Drain Piping

Chilled Water Piping

Condenser Water Piping

Make-Up Water Piping

General

Cross Connections

$N A$

M-U

H-U

$M-U$

$M-U$

$M-X$

$M-U$

$N / A$

$N / A$

NA

$M-X$

$M-X$

$\mathrm{N} / \mathrm{A}$

CHAPTER VII - INCINERATORS

CHAPTER VIII - ELECTRICAL REQUIREMENTS

Section 801

802

803

804

805
Electrical connections

Electrical Ignition and Control Devices

Electrical Ground

Electrical Circuit

Continuous Power
M-N

N/A

$\mathrm{N} / \mathrm{A}$

N/A

$N / A$ 
APPENDIX C - PROVISION LISTING OF MODEL PLUMBING CODES AND THEIR CROSS REFERENCE TO TOPICS DISCUSSED IN THIS REPORT

C-a 


$$
\text { C-b }
$$


Building officials and Code Administrators International. Inc. (BOCA)

BASIC PLUMBING CODE - 1981

PROVISION TOPIC

BASIC PRINCIPLES

No. 1
No. 2
No. 3
No. 4
No. 5
No. 6
No. 7
No. 8
No. 9
No. 10
No. 11
No. 12
No. 13
No. 14
No. 15
No. 16
No. 17
No. 18
No. 19
No. 20
No. 21
No. 22
No. 23

All Occupied Premises Shall Have Potable Water

$P=B$

Adequate Water Required

Hot Water Required

Water Conservation

Dangers of Explosion or Overheating

Use Public Water and Sewer Where Available

Required Plumbing Fixtures

Smooth Surfaces Required

Drainage System of Adequate Size

Durable Materials and Good Workmanship

Liquid Sealed Traps Required

Trap Seals Shall be Protected

Exhaust Foul Air to Outside

Test the Plumbing System

Exclude Certain Substances from the Plumbing System

Prevent Contamination

Light, Heat and Ventilation

Individual Sewage Disposal Systems

Prevent Sewer Flooding

$P-B$

$N / A$

$N A$

$P-B$

$N / A$

$N A$

$N A$

N/A

$N A$

$N / A$

$N / A$

$N / A$

$P-B$

Proper Maintenance

Fixtures Shall be Accessible

P-B

N/A

$N A$

$N A$

$N A$

$P-B$

Structural Safety

$P-B$

Protect Ground and Surface Water

$\mathrm{P}-\mathrm{B}$

N/A

ARTICLE I - Administration and Enforcement

Sec. P-100.0 General

P-100.1 Title

NA

P $=100.2$ Scope

$P-A$

p -100.3 Intent

$\mathrm{P}-\mathrm{A}$

Sec. P-101.0

$\mathrm{P}=101.1$

Applicability

P-101.2 Matters Not Provided For

P-101.3 Continuation of Unlawful Use

N/A

P-E

$\mathrm{N}$ A

Validity

Sec. P-102.0

Existing Plumbing Systems

NA

$N A$

Existing Use

Sec. P-104.0

Repairs and Maintenance

Ordinary Repairs

NA

P-105.1

Maintenance

$P-105.2$

Owner Responsibility

Sec. $P-106.0$

Demolition of Structures

Sec. $P-107.0$

Moved Structures

P-D

$P-D$

$N A$

NA 
Sec. P-108.0 Approval

P-108.1 Approved Materials and Equipment

$\mathrm{P}-\mathrm{J}$

P-108.2

Modifications

P-108.3

Used Materials and Equipment

P-108.4

Alternate Materials and Equipment

Sec. P-109.I

Plumbing Official

Duties and Powers of the Plumbing official

P-E

$N / A$

$P-E$

Sec. P-110.0

Application for Permit

Sec. P-111.0

$\mathrm{P}-111.1$

$\mathrm{P}-111.2$

Permit Required

Form

P-111.3

By Whom Application is Made

P-111.4

Description of Work

N/A

P-111.5

Plans and Specifications

P- 111.6

Site Plan

Pol11.7

Engineering Details

P-111.8

Amendments

P-111.9

Time Limit

Sec. P-112.0

Permits

Sec. P-113.0

Conditions of Permits

Sec. P-114.0

Fees

Sec. P-115.0

Inspection

Sec. P-116.0

Workmanship

Sec. P-117.0

Violations

Sec. P-118.0

Stop Work Order

Sec. P-119.0

Notice of Approval

Sec. P-120.0

Unsafe Conditions

Sec. P-121.0

Emergency Measures

Sec. P-122.0 Means of Appeal

$N / A$

N/A

$N / A$

$N A$

$N A$

$P-G$

$N A$

$P-G$

$N / A$

$N / A$

$N / A$

$N A$

NA

NA

$N / A$

$N A$

$N / A$

NA

$\mathrm{P}-\mathrm{F}$

$N / A$

N/A

ARTICLE 2- Definitions

Sec. P-200.0 General

Sec. P-201.0 Definitions of Plumbing Terms

N/A

Accessible

Anti-Siphon

Backflow

Backflow Connection

Backflow Preventer

Cross Connection

Hot Water

Interceptor

Non-Potable Water

Nuisance

Plumbing Appliance

Plumbing Appurtenance

Plumbing Fixture

Plumbing System

Potable Water

$\mathrm{P}-\mathrm{C}$

P-C

$\mathrm{P}-\mathrm{C}$

$P-C$

$P-C$

$P-C$

$P-C$

$P-C$

$P-C$

$P-C$

$P-C$

$P-C$

$P-C$

$\mathrm{P}-\mathrm{C}$

$\mathrm{P}-\mathrm{C}$

ARTICLE 3 - General Regulations

Sec. P-300.0 General

NA

Sec. P-301.0 Health and Safety

NA 
Sec. P-302.0

Sec. P-303.0

Sec. P-304.0

Sec. P-304.1 $\mathrm{P}-304.2$

Sec. P-305.0

Sec. P-306.0

Sec. P-307.0

Sec. P-308.0

Sec. P-309.0

Sec. P-310.0

Sec. P-311.0

Sec. P-312.0
Connections to Plumbing Systems Required Connection to Public Water and Sewer System Exclusion of Materials Detrimental to the Sewerage System

Detrimental or Dangerous Materials

Industrial wastes

Piping Measurements

Washroom and Toilet Room Requirements

Strain and Stresses in Pipe

Protection of Pipes

Sleeves

Ratproofing

Toilet Facilities for Workmen

Elevator Machinery Rooms
$P=I$

$N / A$

P-P

$N / A$

N/A

$N / A$

$\mathrm{N} / \mathrm{A}$

$\mathrm{N} / \mathrm{A}$

$N / A$

$N / A$

N A

N/A

N/A

$\mathrm{P}-\mathrm{J}$

$\mathrm{N} / \mathrm{A}$

P-R

$N A$

N

NA

Sec. P-405.0

General

Performance Requirements

Approved Materials Required

Sec. P-402.0

Minimum Standards

Identification of Materials

Piping System Materials

Special Materials

Sec. P-406.0

Fixture Materials

NA

Sec. P-501.0

P-501.1

P-501.2

P-501.3

P-501.4

P-501.5

P-501.6

P-501.7

P-501.8

P-501.9

P-501.10

P-501.11

P-501.12

P-501.13

Sec. P-502.0

General

Types of Joints for Piping Materials

General

Brazed Joints

Welded Joints

Burned Lead (Welded)

Caulked

Cement

Expansion

Flared

Hot Poured

Soldered

Wiped

Solvent Cementing

Mechanical (Flexible or Slip Joint)

Types of Joints Between Different Piping Materials

P-502.1 Cast Iron to Copper Tube

NA

P-502.2

Cast Iron to Vitrified Clay

P-502.3

Copper Tube to Threaded Pipe Joints

N/A

P-L

NA

P-502.5

P-502.6

P -502.7

Lead to Cast Iron or Steel

Threaded Pipe to Cast Iron

Abestos Cement Pipe to Metal Pipe

NA

Special Joints for Drainage Piping

NA

$N / A$

P-502.8 Plastic Pipe to Other Materials 
Sec. P-503.0 Connections Between Drainage Piping

Sec. P-504.0 Tightness

Sec. P-505.0 Waterproofing of Openings

$N / A$

P-L

N/A

N/A

ARTICLE 6 - Drainage Systems

ARIICLE 7 - Indirect Waste Piping and Special Waste

Sec. P-700.0 General

N/A

Sec. P-701.0 Indirect Wastes

P-701.1 Indirect Wastes Required

P-701.2 Air Gap or Air Break Required

p-701.3 Receptors or Sumps

P-701.4 Wastewater Temperature

Sec. P-702.0 Special Wastes

ARTICLE 8 - Storm Drains

ARTICLE 9 - Vents and Venting

P-N

$\mathrm{N} / \mathrm{A}$

N/A

$\mathrm{P}-\mathrm{N}$

$P-P$

NA

$\mathrm{N} / \mathrm{A}$

ARTICLE 10 - Traps, Interceptors, Separators, and Backwater Valves

Sec. P-1000.0 General

Sec. P-1001.0 Fixture Traps

Sec. P-1002.0 Interceptors and Separators

P-1002.1 Interceptors Required

P-1002.2 Separators Required

P-1002.3

P-1002.4

Approval of Interceptors and Separators

Grease Interceptor Requirements

Oil and Flammable Liquids Separator

P-1002.5

P-1002.6

Interceptors and Separators for Specific Installations

P-1002.7 Venting of Interceptors and Separators

P-1002.8 Accessibility and Maintenance of Interceptors and separators

P-1002.9

Water cooled Grease Interceptors

Sec. P-1003.0 Backwater Valves

ARTICLE 11 - Drainage Pipe Cleanouts

N/A

$\mathrm{N} / \mathrm{A}$

P-0

N/A

P-O

$N / A$

P-O

$N A$

$N / A$

N/A

N/A

$N / A$

$N / A$

ARTICLE 12 - Plumbing Fixtures

$N A$

ARTICLE 13 - Hangers and Supports

NA

ARTICLE 14 - Health Care Plumbing

NA

ARTICLE 15 - Water Supply and Distribution

Sec. P-1500.0

General

Water Required

N A

$N A$

NA

Sec. P-1502.0

Water Service

Design of Building Water Distribution System

N/A 
Sec. P-1504.0 Installing the Building Water Distribution System

P-1504.1

P-1504.2

Water Supply Control Valves

Water Pressure Booster Systems

Sec. P-1505.0

P-1505.1

P-1505.2

P-1505.3

P-1505.4

P-1505.5

P-1505.6

P-1505.7

P-1505.8

P-1505.9

Protection of Potable Water Supply

General

Identification of Potable and Non-Potable Water

Cross Connection Control

Interconnections

Toxic Materials

Used Piping

Used Water Retum

Backflow protection

P-1505.10

Location of Backflow Preventers

P-1505.11

Inspection of Devices

P-1505.12

Protection of Potable Water outlets

connections to the Potable water System

Hot Water Supply System

Sec. P-1506.0

P-1506.1

P-1506.2

P-1506.3

P-1506.4

P-1506.5

Where Required

Retum Circulation

Water Heaters

Safety Devices

Controls

Sec. $P-1507.0$

Disinfection of Potable Water System

$P-R$

N $A$

$P Q$

NA

$N / A$

NA

P-P

N A

NA

$N A$

$P-Q$

N A

NA

$P-Q$

NA

P-U

$P-R, P-U$

P-S, P-T

P-T, P-U

NA

NA

ARTICLE 16 - Individual Water Supply

ARTICLE 17 - Inspection, Tests and Maintenance

Sec. P-1700.0

Sec. P-1701.0

P-1701.1

P -1701.2

P-1701.3

P-1701.4

Sec. P-1702.0

P-1702.1

P-1702.2

P-1702.3

P -1702.4

P-1702.5

Sec. P-1703.0
General

Inspections

Required

Rough-in Inspection

Final Inspection

Reinspections

Testing of Plumbing Systems

New, Altered, Extendesd or Repaired Systems

Defective Plumbing

Exposure of Work

Equipment, Material, and Labor for Tests

Test Methods

Maintenance
NA

$\mathrm{P}-\mathrm{H}$

$N A$

$N A$

NA

$P-M$

$N A$

$\mathbb{N A}$

$N A$

$N A$

NA

ARTICLE 18 - Engineered Plumbing Systems

Sec. P-1800.0

Sec. P-1801.0 P-1801.1 P-1801.2 P-1801.3

Sec. P-1802.0 P-1802.1 P-1802.2
General

Plans and Specifications

Required

Details

Computations and Data

Engineering Inspection

Required

Optional Inspections
NA

$P-G$

$P-G$

$P-G$

$N \mathrm{~A}$

NA 
PROVISION TOPIC

Sec. P-1803.0 Design Criteria

APPENDIX A - Referenced Standards

APPENDIX B - Typical Symbols and Drawings

APPENDIX C - Sizing the Building Water Supply Distribution System

APPENDIX D - Recommended Sewage Disposal Treatment Systems

APPENDIX E - Gas Water Heater Venting

APPENDIX F - Maximum Rates of Rainfall for Various Cities in instr. N/A

APPENDIX G - Tables, Rules and Conversion Calculations
$\mathrm{N} / \mathrm{A}$

$P$ J

NA

$\mathrm{N} / \mathrm{A}$

NA

NA

NA

CD 
International Association of Plumbing and Mechanical officials (IAPMO)

International Conference of Building Officials

UNIFORM PLIMBING CODE - 1982

PART I - ADMINISTRATION

PROVISION TOPIC

10.1

Title

NA

10.3

Purpose

$P-A$

Scope

$P-A$

10.4

Existing Installations

NA

Authority to Abate

NA

20.1

Administrative Authority

20.2

Duties and Powers of the Adrninistrative Authority

20.3

Violation and Penalties

NA

20.4

Permit Required

Work Not Requiring a Permit

NA

$\mathrm{N} A$

NA

$N A$

Application for Permit

$N A$ Cost of Permit

20.7

20.8

All Work to be Inspected

NA

$\mathrm{P}-\mathrm{H}$

Notification

NA

20.10

Stop Orders

20.11

20.12

20.13

20.14

Suspension on Revocation

NA

NA

Liability

Unconstitutionability

NA

NA

Board of Appeals

NA

INSTAIJATION REQUIREMENTS

CHAPTER 1 - Definitions

Sec. 101 General

Sec. 102 Definition of Terms

NA

Accessible

Airbreak

Airgap

Approved

Approved Testing Agency

Backflow

Backflow Connection

Backflow Preventer

Back-Siphonage

Cross Connection

Interceptor

Iabeled

Listed

Listing Agency

Nuisance

Plumbing Fixtures

Plumbing System

$\mathrm{P}-\mathrm{C}$

$P-C$

$\mathrm{P}-\mathrm{C}$

$\mathrm{P}-\mathrm{C}$

P-C

$\mathrm{P}-\mathrm{C}$

P-C

$\mathrm{P}-\mathrm{C}$

$\mathrm{P}-\mathrm{C}$

P-C

$\mathrm{P}-\mathrm{C}$

P-C

$\mathrm{P}-\mathrm{C}$

P-C

$P-C$

$\mathrm{P}-\mathrm{C}$

Potable Water

$\mathrm{P}-\mathrm{C}$

$\mathrm{P}-\mathrm{C}$ 
CHAPTER 2 - Quality and Weights of Materials; Alternate Materials; Altemate Methods of Construction

Sec. 201 Minimum Standards

a) Use of Approved Materials and Equipment P-J

b) Identification of Materials

c) Use of Standards

d) Alteration of Existing Buildings

e) Alternate Materials or Method of Construction

f) Approval of Altemate Materials

g) Proof of Acceptability

h) Testing of Altemate Material

i) Test Standards

j) Repetition of Tests

Sec. 202

Sec. 203

Sec. 204

Sec. 205

Sec. 206

Sec. 207

Sec. 208

Iron Pipe Size (I.P.S.) Pipe

Use of Copper Tubing

Lead

Ferrules and Bushings

Floor Flanges

Clearout Fittings

Sec. 209

Thread or Solder aup Type Fittings

Back Water Valves

Sec. 210

Valves and Fittings

Sec. 211

zinc Alloy Die Cast Components

P-R

NA

NA

P-E

P-E

P-E

P-E

P-E

P-E

NA

NA

NA

$N A$

NA

NA

NA

NA

NA

NA

CHAPTER 3 - General Regulations: General Instructions and Requirements

Sec. 301 Disposal of Liquid Waste

Sec. 302

Sec. 303

Connection to Plumbing System Required

Sewer Required

Sec. 304

Damage to Drainage System or Public Sewer

NA

P-I

NA

Sec. 305

Industrial Wastes

NA

NA

Plans Required

$P-G$

Sec. 307

Location

NA

Improper Location

NA

Workmanship

Sec. 309

Prohibited

NA

Sec. 310

Sec. 313

Ind Practices

NA

NA

Sec. 314

Repair and Alterations

NA

Sec. 315

Protection of Piping, Materials, and Structures

NA

Hangers and Supports

NA

Trenching, Excavation and Backfill

Sec. 317

Inspection and Testing

Sec. 318

Maintenance

Sec. 319

Existing Conditions

$\mathrm{NA}$

Sec. 320

Health and Safety

Sec. 322

Validity

$\mathrm{P}-\mathrm{H}, \mathrm{P}-\mathrm{M}$

P-D

NA

P-F

P-F 
CHAPTER 6 - Indirect Waste Piping, wet Vented Systems, and Special Wastes

CHAPTER 7 - Traps and Interceptors

Sec. 701 Traps Required

Sec. 702 Traps Protected by Vent Pipes

$N A$

Sec. 703

Traps Described

NA

Sec. 704

Traps Prohibited

$N A$

Sec. 705

Trap Seals

Sec. 706

Floor Drain Traps

Sec. 707

Trap Seal Protection

Sec. 708

Industrial Interceptors and Separators

Sec. 709

Slaughter Houses, Packing Establishments, etc.

$N A$

$N A$

NA

$N A$

$P-0$

Sec. 710

Minimum Requirements for Auto Wash Rack

Sec. 711

Grease Traps

NA

$N A$

NA

CHAPTER 9 - Joints and Connections

Sec. 801

Tightness

$\mathrm{P}-\mathrm{L}$

Sec. 802

Types of Joints

a) Caulked Joints

NA

b) Threaded Joints

P-L

c) Wiped Joints

NA

d) Solder and Sweat Joints

P-L

e) Flared Joints

$\mathrm{P}-\mathrm{L}$

f) Cement Mortar Joints

$\mathrm{NA}$

g) Burned Lead Joints

$N A$

h) Asbestos Cement Sewer Pipe Joints

$N A$

i) Bituminized Fiber Pipe Joints

j) Packing Additives Prohibited

k) Flexible Compression Factory - Fabricated Joints

NA

NA

1) Solvent Cement Plastic Pipe Joints

NA

m) Mechanical Joints

P-L

NA

n) Molded Rubber Complying Joints

o) Elastomeric Gasketed and Rubber-Ring

NA

Sec. 803

p) Brazing and Welding

NA

P-L Use of Joints

Sec. 804

Special Joints

a) Copper Tubing to Screw Pipe Joints P-L

b) Slip Joints

c) Expansion Joints

d) Unions

e) Ground Joint, Flared or Ferrule Connection

f) ABS, PE, and PVC to Other Materials

Sec. 805

Sec. 806 Flanged Fixture Connection

Prohibited Joints and Connections

Sec. 807

Water Proofing of Openings

$N A$

$N A$

$N A$

$N A$

NA

$N A$

$N A$

NA 
Sec. 808 Increasers and Reducers

CHAPTER 10 - Water Distribution

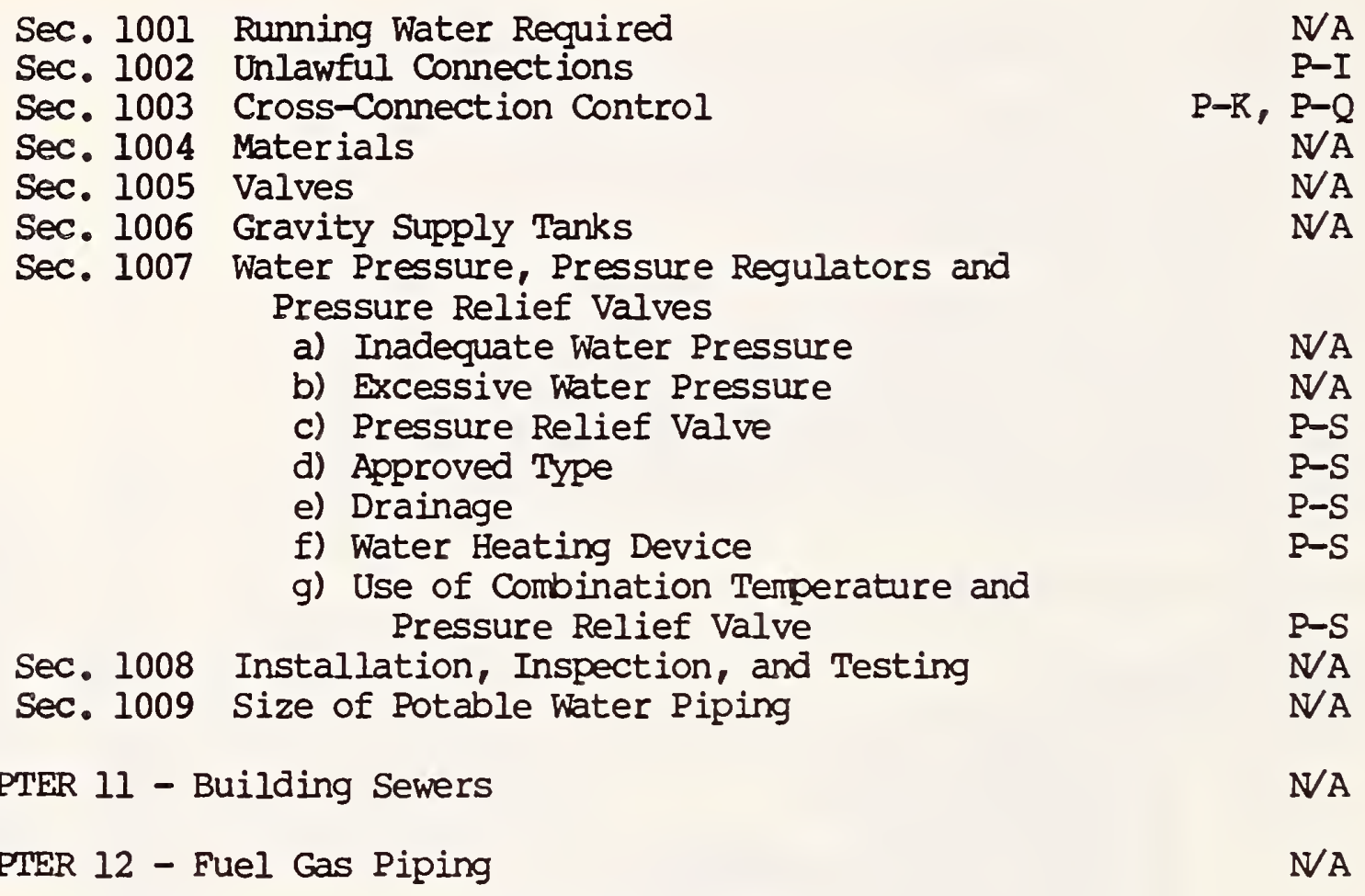

CHAPTER 13 - Water Heaters and Vents

Sec. 1301 General

Sec. 1302 Definitions

NA

Sec. 1303

Permits

NA

Sec. 1304 Inspection

$\mathrm{P}-\mathrm{H}$

Sec. 1305 Gas-Fired Water Heater Approval Requirements
Sec. 1306 Oil Burning and Other Water Heaters

NA

a) Approvals

$\mathrm{P}-\mathrm{J}$

b) Storage-Type hater Heaters

Sec. 1307 Enclosures and Combustion Air

$\mathrm{P}-\mathrm{T}$

Sec. 1308

Clearances

Sec. 1309

Prohibited Locations

$\mathrm{NA}$

NA

Sec. 1310 Protection from Damage

a) Flammable Vapors

b) Access

c) Mechanical Damage

d) Dielectric Insulator

NA

Sec. 1311 Access and Working Space

NA

$\mathrm{NA}$

$P-U$

$\mathrm{NA}$

P-D

Sec. 1312 through Sec. 1325

NA

APPENDIX A - Recommended Rules for Sizing the Water Supply System NA APPENDIX B - Explanatory Notes on Combination Waste and Vent System NA 


\section{PROVISION TOPIC}

APPENDIX C - Minimum Plumbing Facilities

$\mathbb{N} \bar{A}$

APPENDIX D - Rain Water Systems

NA

APPENDIX E - Mobile Home Parks and Recreational Vehicle Parks NA

APPENDIX G - Swimming Pools

NA

APPENDIX H - Recommended Procedures for Sizing Commerical Kitchen Grease Interceptors

NA

APPENDIX I - Private Sewage Disposal Systems

NA 
CHAPTER I - Administration

Sec. 101 Title and Scope N/A

101.1 Title

101.2 Code Remedial

$N / A$

101.3 Scope

$P-A$

101.4 Maintenance

P-A

101.5 Plumbing Installation or Maintenance by Home

P-D

Sec. 102 Owner

$P-D$

Organization

Sec. 103

Powers and Duties of Plumbing Official

103.1 Right of Entry

103.2 Stop Work Orders

103.3 Revocation of Permits

103.4 Unsafe Installations

103.5 Requirements not Covered by Code

103.6 Altemate Materials and Altemate Methods of Installations

103.7 Liability

103.8 Reports

Sec. 104 Application for Permit

104.1 When Required

104.2 Form

104.3 Drawings and Specifications

104.4 Examination of Drawings

Sec. 105

Permits

Sec. 106 Fees

Sec. 107 Inspections

107.1 Inspection Required

107.2 Notification

107.3

Material and Labor for Tests

107.4 Test of Drainage and Vent Systems

107.5 Methods of Testing Drainage and Vent Systems

107.6

107.7

Test of Water Supply System

Test of Building Sewer

107.8 Test of Interior Leaders or Downspouts

107.9 Covering the Work

107.10 Test of Defective Plumbing

Sec. 108

Certificate of Approval

Sec. 109

Excavations and Public Protection Requirements

Sec. 110

Violations and Penalties

Sec. 111

Validity

N/A

N/A

N/A

N/A

P-F

P-E

P-E

N/A

N/A

N/A

N/A

$P-G$

$\mathrm{N} / \mathrm{A}$

$N / A$

N/A

P-H

$\mathrm{N} / \mathrm{A}$

$\mathrm{N} / \mathrm{A}$

$N / A$

$N \mathrm{~A}$

$N / A$

$N / A$

$N / A$

$\mathrm{N} / \mathrm{A}$

$\mathrm{N} / \mathrm{A}$

$\mathrm{N} / \mathrm{A}$

$\mathrm{N} / \mathrm{A}$

$\mathrm{N} / \mathrm{A}$

NA

CHAPTER II - Basic Principles

Sec. 201 Basic Principles

Principle No. 1 through $5 \quad$ N/A

Principle No. 6 
Principle No. 7 through 10

N/A

Principle No. 11

$P-B$

Principle No. 12

$N / A$

Principle No. 13

$P-B$

Principle No. 14

$N A$

Principle No. 15

$P-B$

Principle No. 16

$P-B$

Principle No. 17

$N / A$

Principle No. 18

$P-B$

Principle No. 19 and 20

$N / A$

Principle No. 21

$\mathrm{P}-\mathrm{B}$

Principle No. 22

$N / A$

CHAPIER III - Definitions

Sec. 301 General

Sec. 302 Definition of Terms

$\mathrm{N} / \mathrm{A}$

The following definitions apply directly to Thermal Storage Devices
Approved
Backflow
Backflow Connection
Backflow Preventer
Back-Siphonage
Cross-Connection
Interceptor
Non-Potable Water
Nuisance
Plumbing Fixtures
Plumbing System
Potable Water

$\mathrm{P}-\mathrm{C}$
$\mathrm{P}-\mathrm{C}$
$\mathrm{P}-\mathrm{C}$
$\mathrm{p}-\mathrm{C}$
$\mathrm{P}-\mathrm{C}$
$\mathrm{p}-\mathrm{C}$
$\mathrm{P}-\mathrm{C}$
$\mathrm{p}-\mathrm{C}$
$\mathrm{p}-\mathrm{C}$
$\mathrm{p}-\mathrm{C}$
$\mathrm{p}-\mathrm{C}$
$\mathrm{P}-\mathrm{C}$

CHAPIER IV - General Regulations

Sec. 401 Fittings

Sec. 402 Repairs and Alterations

402.1 Existing Buildings

402.2 Health and Safety

Sec. 403

Sewer and Water Pipes

Sec. 404

Trenching, Excavation, and Backfill

$N A$

Sec. 405

Sec. 406

Sec. 407

Structural Safety

Workmanship

Sec. 408

Sec. 409

Protection of Pipes

Sec. 410

Damage to Drainage System or Public Sewer

Ratproofing

Sec. 411

Used Equipment

Sec. 412

Condemned Equipment

Sec. 413

413.1

Drainage Below Sewer Level

Connections to Plumbing System Required

$N A$

$N A$

$N A$

$N A$

$N A$

$N A$

NA

$N A$

$N A$

$N A$

$N A$

$N A$

413.2 Connections to Water Supply

NA

P-I 
Sec. 414 Individual or Private Sewage - Disposal System

$\mathrm{N} / \mathrm{A}$

Sec. 415 Location of Fixtures

$N / A$

Sec. 416

Toilet Facilities for Workmen

$\mathrm{N} / \mathrm{A}$

CHAPTER V - Materials, Quality and Weight

Sec. 501 Materials

501.1 Minimum Standards

$N / A$

501.2 Use of Materials

501.3 Specifications for Materials

P-J

501.4 Identification of Materials

$N / A$

$P-K$

Sec. 502

Special Materials

Sec. 503 Approved Materials

503.1 Specific Usage

Table 500 Materials for Plumbing Installations

$N / A$

P-J

Water Heater, Electrical, Residential

Water Heater, Gas, Volume I, Automatic Storage Type Water Heaters with Inputs of 75,000 Btu Per Hour of Less

Water Heaters, Gas, Volume II, Circulating

Tank, Instantaneous and Large Automatic

Storage Type Water Heaters

Sec. 504 Limitations of Use of Materials Listed in Table 500

P-J

$\mathrm{P}-\mathrm{J}$

P-J

NA

CHAPTER VI - Joints and Connections

Sec. 601

Tightness

Sec. 602

Types of Joints

602.1 Caulked Joints

P-I

602.2

602.3

Threaded Joints

$N A$

Wiped Joints

P-L

602.4

soldered Joints

N/A

602.5

Flared Joints

P-L

602.6

602.7

Flexible Couplings

P-L

Precast Joints

602.8

602.9

Brazed Joints

602.10

Cement Mortar Joints and Connections

P-L

$N A$

P-L

Burned Lead Joints

602.11

Asbestos Cement-Sewer Pipe Joints

602.12

Elastomeric Compression Gasket Joints for Cast Iron Soil Pipe

602.13 Hubless Cast Iron Soil Pipe System

$\mathrm{N} / \mathrm{A}$

$N A$

NA

602.14 Joints for Plastic Pipes and Fittings

602.15 Joints for Plastic Water Service Pipe and Fittings

602.16 Borosilicate Glass Joints

Sec. 603

Use of Joints

603.1

Clay Sewer Pipe

603.2

Concrete Sewer Pipe

603.3 Cast Iron Soil Pipe

$\mathrm{N} / \mathrm{A}$

NA

P-L

P-L

$\mathrm{N} / \mathrm{A}$

603.4

Threaded Pipe to Cast Iron

NA

N/A

N/A

N/A

603.5

Lead to Cast-Iron or Steel

$N / A$

603.6

Copper Water Tube and Stainless Steel Water Tube

P-L 
Sec. 604 Special Joints

604.1 Copper Water Tubing or Stainless Steel Tubing to Threaded Pipe Joints

604.2 Welding or Brazing

604.3 Slip Joints

604.4 Expansion Joints

604.5 Ground Joint Brass Connections

604.6 Plastic Pipe to Other Materials

604.7 PVC Transition Fittings for Dissimilas Pipe in Building Sewers

Sec. 605 Unions (Threaded)

Sec. 606 Water Closet, Pedestal Urinal, and Trap Standard Service

Sec. 607

Prohibited Joints and Connections

Sec. 608

Increasers and Reducers

$\mathrm{P}-\mathrm{L}$

$P=L$

$N / A$

$N A$

$N A$

$\mathrm{P}=\mathrm{L}$

$N / A$

NA

$N / A$

$N A$

$N A$

NA

CHAPTER VIII - Interceptors - Separators and Backwater Valves

Sec. 801

Sec. 802

Sec。 803

Sec. 804

Sec. 805

Sec. 806

Sec. 807

Sec. 808

Sec. 809

Sec. 810

Sec. 811

Sec. 812

Sec. 813

Sec. 814

Sec. 815

815.1

815.2
Interceptors and Separators

Grease Interceptors

Oil Separators

Sand Interceptors

Venting Interceptors

Accessibility of Interceptors

Water Connection

Laundries

Bottling Plants

Slaughter House-Separators

Food Grinders

Maintenance

Special Type Separators

Backwater Valves

Special Wastes

Acid Waste

Neutralizing Device
P-O

NA

$P-O$

$\mathrm{N} / \mathrm{A}$

$N / A$

NA

$N A$

$N A$

$N A$

$N A$

$N A$

$N A$

$N A$

$N A$

$N A$

$P-P$

CHAPTER IX - Plumbing Fixtures

Sec. 901

Sec. 902

Sec. 903

Sec. 904 904.1

Sec. 905

Sec. 906

Sec. 907

Sec. 908

Sec. 909

Sec. 910

Sec. 911

Sec. 912
General Requirements - Materials

Overflows

Installation

Water Supply Protection

Supply Fittings

Prohibited Fixtures and connections

Water Closets

Urinals

Strainers and Fixtures Outlets

Lavatories

Shower Receptors and Compartments

Sinks - Waste Outlets

Food Waste Grinder Units
$N A$

$N A$

$N A$

$P-Q$

$N A$

$N / A$

$N / A$

$N A$

$N A$

$N A$

$N / A$

$N / A$ 
Sec. 913

Drinking Fountains

N $\mathrm{A}$

Sec. 914 Floor Drains

914.1 Installation

$N / A$

914.2 Strainers

914.3 Acid Resisting Floor Drains

$N / A$

914.4 Prohibited Location

$N / A$

$\mathrm{P}-\mathrm{N}$

Sec. 915

Dishwashing Machines

$N / A$

Sec. 916

Multiple Wash Sinks

$N / A$

Sec. 917

Garbage Can Washers

$N / A$

Sec. 918

Laundry Trays

Sec. 919

Washing Machines for Residences

$N / A$

Sec. 920

Sec. 921

921.1

Special Fixtures and Specialties

Water Heaters and Hot Water Storage Tanks

921.2

General

921.3

Location

Prohibited Installations

921.4

Connections

921.5

Safety Devices

921.6

Sediment Drains

921.7

Anti-Syphon Devices

Sec. 922

Required Minimum Facilities

$N / A$

$N A$

P-J

$P-D$

$N / A$

$\mathrm{P}-\mathrm{R}$

$P-K, P-S$

$\mathrm{N} / \mathrm{A}$

$P-Q$

$N A$

CHAPTER X - Hangers and Supports

$N A$

CHAPTER XI - Indirect Waste Piping and Special Wastes

NA

CHAPTER XII - Water Supply and Distribution

Sec. 1201 Quality of Water Supply

Sec. 1202 Color Code Identification of Piping

Sec. 1203

Water Supply Mandatory

1204

Protection of Potable Water Supply

1204.1 Backflow

1204.2 Approval of Devices

1204.3 Where Required

1204.4 Backflow Preventer Installation

1204.5 Gate Valves and Test Cocks Required

1204.6 Additional Information

Sec. 1205

Water Supply System and Water Service Pipe

N/A

$\mathrm{P}-\mathrm{K}$

$\mathrm{N} / \mathrm{A}$

Sec. 1206

Water Pumping and Storage Equipment

1206.1 Pumps and Other Appliances

1206.2 Pressure Tanks, Boilers, and Relief Valves

1206.3 Cleaning, Painting, Repairing Water Tanks

1206.4 When Required

1206.5 Support

1206.6 Overplan Pipes

1206.7 Drains

1206.8 Gravity and Suction Tanks

1206.9 Pressure Tanks

Sec. 1207

Disinfection of Potable Water System Piping

$P-Q$

$P-Q$

$P-Q$

$\mathrm{N} / \mathrm{A}$

$N / A$

$N / A$

$\mathrm{N} A$

NA

$\mathrm{P}-\mathrm{N}$

$N / A$

$\mathrm{N} / \mathrm{A}$

$\mathrm{N} / \mathrm{A}$

$N / A$

$N / A$

$N / A$

$\mathrm{N} / \mathrm{A}$

$\mathrm{N} / \mathrm{A}$

Sec. 1208

Allowance for Character of Water

$\mathrm{N} / \mathrm{A}$

Sec. 1209

Water Supply Control

1209.1 Water Supply Control

N/A 


\begin{tabular}{ll} 
1209.2 & Tank Controls \\
1209.3 & Controls for Fixtures Within Dwellings \\
1209.4 & Buildings Other Than Dwellings \\
1209.5 & Water Heating Equipment \\
Sec. 1210 & Water Distribution Pipe, Tubing and Fittings \\
Sec. 1211 & Procedure in Sizing the Water Distribution \\
& \multicolumn{1}{c}{ System of a Building } \\
Sec. 1212 & Hot Water Distribution \\
Sec. 1213 & Safety Devices \\
1213.1 & Water Pressure Relief Valves and Temperature \\
& $\quad$ Relief Valves Required \\
1213.2 & Energy Shut-Off Devices \\
1213.3 & Approvals \\
1213.4 & Relief Outlet Wastes \\
1213.5 & Pressure Marketing of Storage Tank \\
1213.6 & Heater Over 200,000 Btu/hr Input \\
1213.7 & Safety Plans and Relief Valve Waste \\
Sec. & Miscellaneous \\
1214 & Drain Cock \\
1214.2 & Line Valves \\
1214.3 & Water Used for Processing \\
1214.4 & Trap Primers
\end{tabular}

$N A$

$N / A$

$N / A$

P-R

$N / A$

N/A

$N / A$

P-S

P-T

P-S

$P-N$

P-K

P-U

$\mathrm{P}-\mathrm{N}$

$\mathrm{P}-\mathrm{N}$

$N A$

$N / A$

$N A$

NA

$N A$

$N A$

$N A$

NA Building Sewers

APPENDIX B - Plumbing Installation Standards for Travel Trailers and Travel Trailer Parks

$N A$

APPENDIX C - Plumbing Installation Standards for Mobile Homes and Mobile Home Parks

NA

$N A$

NA

NA

$N A$

APPENDIX G - Hospital Plumbing Systems

APPENDIX H - Recommended Schedule of Permit Fees NA 
National Association of Plumbing-Heating-Cooling (NAPHCC)

NATIONAL STANDARD PLUMBING CODE - 1983

PROVISION TOPIC

TITLE

N A

SCOPE

P-A

PURPOSE

P-A

EXCEPTIONS

$P-E$

BASIC PRINCIPLES

No. 1

No. 2

No. 3

No. 4

No. 5

№. 6

№. 7

№. 8

NNo. 9

No. 10

No. 11

№. 12

No. 13

No. 14

№. 15

No. 16

No. 17

№. 18

No. 19

No. 20

No. 21

No. 22

All Occupied Premises Shall Have Potable Water

P-B

Adequate Water Required

Hot Water Required

$P-B$

NA

Water Conservation

N/A

Safety Devices

$\mathrm{P}-\mathrm{B}$

Use Public Sewer Where Available

$N / A$

Required Plumbing Fixtures

$\mathrm{N} / \mathrm{A}$

Drainage System

$N / A$

Durable Materials and Good Workmanship

$N / A$

Fixture Traps

$N A$

Trap Seals Shall be Protected

$N / A$

Exhaust Foul Air to outside

$N A$

Test the Plumbing System

$P-B$

Exclude Certain Substances from the Plumbing System P-B

Prevent Contamination

$\mathrm{N} / \mathrm{A}$

Light and Ventilation

$N / A$

Individual Sewage Disposal Systems

$N / A$

Prevent Sewer Flooding

$N / A$

Proper Maintenance

$\mathrm{P}-\mathrm{B}$

Fixtures Shall be Accessible

$\mathrm{P}-\mathrm{B}$

Structural Safety

$P-B$

Protect Ground and Surface Water

P-B

CHAPTER 1 - Definitions

\begin{tabular}{|c|c|}
\hline \multirow{12}{*}{$\begin{array}{l}\text { Sec. } 1.1 \\
\text { Sec. } 1.2\end{array}$} & General \\
\hline & Definition of Tems \\
\hline & Accessible \\
\hline & Approved \\
\hline & Backflow Connection \\
\hline & Backflow Preventer \\
\hline & Back Siphonage \\
\hline & Cross Connection \\
\hline & Hot Water \\
\hline & $\begin{array}{l}\text { Interceptor } \\
\text { Non-Potable Water }\end{array}$ \\
\hline & Nuisance \\
\hline & Plumbing Appliance \\
\hline
\end{tabular}

$\mathrm{P}-\mathrm{C}$

$\mathrm{P}-\mathrm{C}$

$\mathrm{P}-\mathrm{C}$

$\mathrm{P}-\mathrm{C}$

$\mathrm{P}-\mathrm{C}$

$\mathrm{P}-\mathrm{C}$

$\mathrm{P}-\mathrm{C}$

$\mathrm{P}-\mathrm{C}$

$\mathrm{P}-\mathrm{C}$

$\mathrm{P}-\mathrm{C}$

$\mathrm{P}-\mathrm{C}$ 
Plumbing Appurtenance

Plumbing Fixture

Plumbing System

potable Water
$\mathrm{P}-\mathrm{C}$

$\mathrm{P}-\mathrm{C}$

$\mathrm{P}-\mathrm{C}$

$\mathrm{P}-\mathrm{C}$

CHAPTER 2 - General Regulations

\begin{tabular}{|c|c|c|}
\hline Sec. 2.1 & Deleted & $N / A$ \\
\hline Sec. 2.2 & Deleted & $\mathrm{N} / \mathrm{A}$ \\
\hline Sec. 2.3 & Change in Direction of Drainage Piping & $N A$ \\
\hline Sec. 2.4 & Fittings and Connections in Drainage Systems & $\mathrm{N} / \mathrm{A}$ \\
\hline Sec. 2.5 & Health and Safety & $\mathrm{P}-\mathrm{F}$ \\
\hline Sec. 2.6 & Trenching, Bedding, Tunneling, and Backfilling & $N / A$ \\
\hline Sec. 2.7 & Safety & P-D \\
\hline Sec. 2.8 & Installation Practices & $N / A$ \\
\hline Sec. 2.9 & Protection of Pipes & $N / A$ \\
\hline Sec. 2.10 & $\begin{array}{l}\text { Exclusion of Materials Detrimental to the } \\
\text { Sewerage System }\end{array}$ & $\mathrm{P}-\mathrm{P}$ \\
\hline Sec. 2.11 & Deleted & $N A$ \\
\hline Sec. 2.12 & Sleeves & $N / A$ \\
\hline Sec. 2.13 & Ratproofing & $N / A$ \\
\hline Sec. 2.14 & Used Material or Equipment & $N / A$ \\
\hline Sec. 2.15 & Condemned Equipment & $\mathrm{N} / \mathrm{A}$ \\
\hline Sec. 2.16 & Freezing or Overheating & $N A$ \\
\hline Sec. 2.17 & Protection of Footings & $N / A$ \\
\hline Sec. 2.18 & Connections to Plumbing Systems Required & P-I \\
\hline Sec. 2.19 & Connection to Water and Sewer System & $N / A$ \\
\hline Sec. 2.20 & Washroom and Toilet Room Requirements & $N / A$ \\
\hline Sec. 2.21 & Piping Measurements & $N / A$ \\
\hline 2.22 & Water Closest Connections & $N / A$ \\
\hline 2.23 & Dead Ends & $N / A$ \\
\hline Sec. 2.24 & Toilet Facilities for Workers & $N A$ \\
\hline Sec. 2.25 & Food Handling Establishments & $N A$ \\
\hline
\end{tabular}

CHAPTER 3 - Materials

Sec. 3.1 Materials

3.1.1 Minimum Standards P-J

3.1.2 General Requirements P-J

3.1.3 Standard Applicable to Plumbing Materials P-J

3.1.4 Identification of Materials $\mathrm{P}$-K

Sec. 3.2

Sec. 3.3

Special Materials

NA

3.3.2 Cleanout Plugs and Caps P-J

3.3.3 Fixtures P-J

3.3.4 Floor Flanges and Mounting Bolts P-J

3.3.5 Flush Pipes and Fittings P-J

3.3.6 Hangers and Supports P-J

3.3.7 Interceptors p-0

3.3.8 Pressure Tanks and Vessels P-J

3.3.9 Roof Drains N NA

3.3.10 Safety Devices for Pressure Tanks P-S

3.3.11 Septic Tank NA 
Sec. 3.4

Sec. 3.5

Sec. 3.6

Sec. 3.7

Sec. 3.8

Sec. 3.9

Sec. 3.10

Sec. 3.11

Sec. 3.12
Central Vacuum and/or Disposal Systems

Chemical and Special Waste Systems

Sanitary Drainage and Indirect Waste Systems

Local Vent Systems

Potable Water Supply Systems

Storm Drainage Systems

Venting Systems

Air Conditioning and Relief Valve Discharge

Piping

Altemate Materials and Methods
$N / A$

P-P

$\mathrm{P}-\mathrm{N}$

N/A

$P-Q$

N/A

NA

P-S

P-E

CHAPTER 4 - Joints and Connections

Sec. 4.1

Sec. 4.2

4.2 .1

4.2 .2

4.2 .3

4.2 .4

4.2 .5

4.2 .6

4.2 .7

4.2 .8

4.2 .9

4.2.10

4.2 .11

4.2 .12

4.2 .13

4.2 .14

4.2 .15

4.2.16

4.2 .17

Sec. 4.3

4.3 .1

4.3 .2

4.3 .3

4.3 .4

4.3 .5

4.3 .6

4.3 .7

4.3 .8

4.3 .9

Sec. 4.4

Sec. 4.5

Sec. 4.6
General Requirements

Types of Joints for Piping Materials

$$
\text { Caulked }
$$

Threaded

Wiped

Soldered

Flared

Hot Poured

Deleted

Brazed Joints

Cement

Burned Lead (Welded)

Mechanical (Flexible or Slip Joint)

Tapered Couplings

Welded Joints

Plastic

Slip

Expansion

Split Couplings

Types of Joints Between Different Piping Materials

Vitrified Clay to Other Material

Asbestos Cement Pipe to Other Materials

Deleted

Threaded Pipe to cast Iron

Lead to Cast Iron, Wrought Iron, or Steel

Cast Iron to Copper Tube

Copper Tube to Threaded Pipe Joints

Special Joints for Drainage Piping

ABS or PVC Plastic DWV to Other Material

Connection Between Drainage Piping and certain Fixtures

Waterproofing of Openings

Deleted
P-L

NA

P-I

N $A$

P-I

P-I

$N A$

N A

P-L

N/A

N/A

N/A

N/A

P-L

P-L

N/A

N A

N/A

N $\mathrm{A}$

N/A

N/A

$N / A$

N A

$N A$

P-L

$N / A$

$N A$

$N / A$

$N A$

N A

N A

CHAPTER 5 - Traps and Cleanouts

CHAPTER 6 - Interceptors

Sec. 6.1

Interceptors - General

Grease Interceptors
$P-O$

NA 
Sec. 6.3 Oil and Flammable Liquids Interceptor

$N / A$

Sec. 6.4 Sand Interceptors

Sec. 6.5 Special Use Installations

$N A$

NA

$N A$

CHAPTER 7 - Plumbing Fixtures

NA

CHAPTER 8 - Hangers and supports

CHAPTER 9 - Indirect Waste Piping and Special Waste

Sec. 9.1 Indirect Wastes

9.1.1 Air Gap or Air Break Required NA

9.1.2 Food Handling Establishments N/A

9.1.3 Bar and Fountain Sink Traps NA

9.1.4 Connections from Water Distribution System NA

9.1 .5 Sterilizers N/A

9.1.6 Drips or Drasinage Outlets P-N

9.1.7 Pressure Tanks, Boilers and Relief Valves P-N

9.1.8 Air Conditioning Equipment N/A

9.1.9 Drinking Fountain Wastes N/A

Sec. 9.2 Installation of Indirect Waste Piping N/A

Sec. 9.3 Air Gap and Air Break N A

Sec. 9.4 Receptors or Sumps N/A

Sec. 9.5 Clear Water Wastes N/A

Sec. 9.6 Waste Water Temperature P-N

Sec. 9.7 Special Wastes N/A

Sec. 9.8 Swimming Pools N/A

Sec.9.9 Air Conditioning Condensate N/A

CAAPIER 10- Water Supply and Distribution

Sec. 10.1 quality of Water Supply N/A

Sec. 10.2 Identification of Potable and Non-Potable Water P-K

Sec. 10.3 Water Required NA

Sec. 10.4 Protection of Potable Water Supply

10.4 .1 General

10.4.2 Interconnections

$P-P, P-Q$

10.4.3 Deleted

10.4.4 Private Water Supplies N/A

10.4.5 Toxic Materials P-P

10.4.6 Deleted N/A

10.4.7 Deleted NA

10.4.8 Used Materials NA

10.4.9 Water as a Heat Transfer Fluid NA

10.4.10 Deleted N/A

10.4.11 Deleted N/A

10.4.12 Deleted N/A

Sec. 10.5

Protection Against Backflow and Backsiphonage N/A

Water Service

Sec. 10.6

Water Pumping and Storage Equipment

Sec. 10.8 Water Pressure Booster Systems 
10.8.1 through 10.8 .7

$\begin{array}{ll}\text { 10.8.8 } & \text { Pressure Tanks - Vacuum Relief } \\ \text { Sec. 10.8.9 Pressure Tanks - Pressure Relief }\end{array}$

$N / A$

P-S

Sec. 10.9

Disinfection of Potable Water System

P-S

Sec. 10.10

Water Supply System Materials

$N / A$

Sec. 10.11

Allowance for Character of Soil and water

$N / A$

Sec. 10.12 Water Supply Control Valves

10.12.1 through 10.12 .6

$N / A$

10.12.7 Water Heating Equipment Valve

$N / A$

10.12.8 Meter Valve

P-R

10.12.9 Valves to be Accessible

N/A

10.12.10 Deleted

P-R

$N / A$

Sec. 10.13 Water Service

Sec. 10.14 Minimum Requirements for Water Distribution Systems

Sec. 10.15 Hot Water

10.15.1 Hot Water Supply System

10.15 .2

Temperature Maintenance - Where Required

$N A$

10.15 .3

10.15 .4

10.15 .5

Minimum Requirements for Hot Water Storage Tanks

Drain Cocks or Valves for Hot Water Storage Tanks

Pressure Marking of Hot Water Storage Tanks

10.15 .6

Sec. 10.16

Mixed Water Temperature control

Safety Devices

10.16.1 Pressure Relief Valves and Temperature Relief Valves Required

10.16.2 Pressure Relief Valves

10.16 .3

Temperature Relief Valves

10.16 .4

10.16 .5

Combination Pressure - Temperature Relief valves

Deleted

10.16 .6

Installation of Relief Valves

10.16 .7

Vacuum Relief Valves

10.16.8 Deleted

N/A

NA

NA

P-U

$\mathrm{P}-\mathrm{N}$

$P-R$

N/A

P-S

P-S

P-S

P-S

P-S

$\mathrm{P}-\mathrm{S}$

CHAPTER 11 - Sanitary Drainage Systems N/A

CHAPTER 12 - Vents and Venting N/A

CHAPTER 13 - Storm Drains N/A

CHAPTER 14 - Medical Care Facility Plumbing Equipment NVA

CHAPTER 15 - Tests and Maintenance

Sec. 15.1 Exposure of Work

Sec. 15.2 Equipment, Material, and Labor for Tests

NA

Sec. 15.3 Testing of Plumbing Systems

Sec. 15.4

Methods of Testing Drainage and Vent Systems

Sec. 15.5

Methods of Testing Building Sewers

Methods of Testing Water Supply Systems

N/A

$P-M$

$\mathrm{N} / \mathrm{A}$

$N / A$

$N / A$

Sec. 15.7

Defective Plumbing

N/A

Sec. 15.8

Maintenance

P-D 
PROVISION TOPIC

CHAPTER 16 - Regulations Governing Individual Sewage Disposal Systems for Homes and Other Establishments where Public Sewage Systems are not Available

CHAPTER 17 - Potable Water Supply System Pumps

NA

$N A$

NA

NA

$N A$

NA

NA

NA

C-23 

NBS-114A (REV. 2-8C)

U.S. DEPT. OF COMM.

BIBLIOGRAPHIC DATA

SHEET (See in struction s)

1. PUBLICATION OR
REPORT NO.
NBSIR 84-2909

2. Performing Organ. Report Nof 3. Publication Date

August 1984

4. TITLE AND SUBTITLE

PHASE CHANGE THERMAL ENERGY STORAGE AND THE MODEL BUILDING CODES

5. AUTHOR(S)

Joseph Greenberg; Belinda C. Reeder

6. PERFORMING ORGANIZATION (If joint or other thon NBS, see instructions)

MATIONAL BUREAU OF STANDARDS

DEPARTMENT OF COMMERCE

WASHINGTON, D.C. 20234

7. Contract Grant No.

DE-AIO1-76PR06010

\begin{tabular}{l|l} 
Final & Fina
\end{tabular}

9. SPONSORING ORGANIZATION NAME AND COMPLETE ADDRESS (Street. City. Stote, ZIP)

Active Heating and Cooling Division

Office of Solar Heat Technologies

Department of Energy

Washington, D.C. 20585

10. SUPPLEMENTARY NOTES

[D Document describes a computer program; SF-185, FIPS Software Summary, is attached.

11. ABSTRACT (A 200-word or less foctual summory of most significont informotion. If document includes a significant bibliography or literoture survey. mention it here)

Thermal energy systems using phase change materials are currently being developed and used for storing energy collected by solar and other means. This report is intended to bridge the gap between those who design and install phase change thermal storage devices and the building code official who evaluates these devices for code compliance. The initial pages of this report describe the more commonly accepted phase change materials and systems, present a taxonomy which is applicable to building construction, and describe the interface between the various model codes and the more advanced phase change system configurations. The report continues with an analysis of the model codes with a specific orientation to phase change thermal energy storage systems. The analysis is structured a cording to building, mechanical, and plumbing issues with topics relevant to phase change systems identified and specific code provisions applicable to each topic listed. To facilitate use by code officials in evaluating a system for compliance with a specific document, the appendix cross references relevant topics according to individual model code requirements.

12. KEY WORDS (Six to twelve entries: alphobetical order: copitalize only proper names; and separate key words by semicolon s) Building Code Official; Latent Heat; Paraffin Wax; Phase Change Storage; Salt Hydrates; Solar Energy; Thermal Storage

13. AVAILABILITY

[X] Unlimited

For Official Distribution. Do Not Release to NTIS

Order From Superintendent of Documents, U.S. Government Printing Office. Washington, D.C. 20402.

X] Order From National Technical Information Service (NTIS), Springfield, VA, 2216I

\begin{tabular}{|} 
14. NO. OF \\
PRINTED PAGES \\
297 \\
\hline $\begin{array}{l}\text { 15. Price } \\
\$ 22.00\end{array}$
\end{tabular}




